\title{
SÍNTESE RACIONAL AUTOMATIZADA DE
}

\section{CAVERNAS DE EMBARCAÇÕES}

Dissertação apresentada à Escola Politécnica da Universidade de São Paulo para obtenção do título de Mestre em Engenharia. 


\section{SÍNTESE RACIONAL AUTOMATIZADA DE}

\section{CAVERNAS DE EMBARCAÇÕES}

Dissertação apresentada à Escola Politécnica da Universidade de São Paulo para obtenção do título de Mestre em Engenharia.

Área de Concentração:

Engenharia Naval.

Orientador:

Oscar Brito Augusto.

São Paulo

1994 
Cardoso, Ademar de Azevedo

Síntese Racional Automatizada de

Cavernas de Embarcações,São Paulo, 1994.

102p. + apêndices.

Dissertação (Mestrado) — Escola Politécnica da Universidade de São Paulo. Departamento de Engenharia Naval.

1. Estrutura Transversal 2. Síntese I.Universidade de São Paulo. Escola Politécnica. Departamento de Engenharia Naval I I. t 
Aos meus pais

Adauto e Maria. 
"Quando algum profeta vier lhe contar

Que o nosso sol está prestes a se apagar

Mesmo que pareça que não há mais lugar

Você ainda tem a velocidade da luz pra alcançar."

Raul Seixas. 


\section{AGRADECIMENTOS}

Quero agradecer às seguintes pessoas e entidades:

- ao Professor Oscar Brito Augusto, pela orientação do trabalho.

- ao CNPq, pelo auxílio financeiro.

- ao CENO/USP, pela cessão dos relatórios citados no trabalho.

- à Irene Rzezak, pela ajuda e paciência.

- a todos que, direta ou indiretamente, contribuiram para a realização deste trabalho. 


\section{SUMÁRIO}

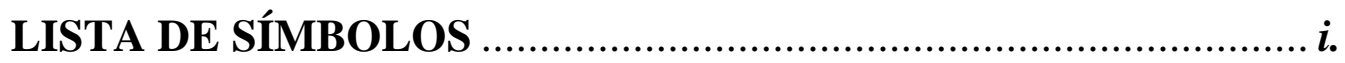

LISTA DE FIGURAS ........................................................ iii.

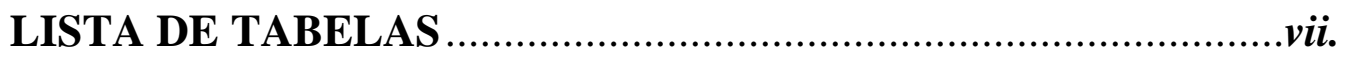

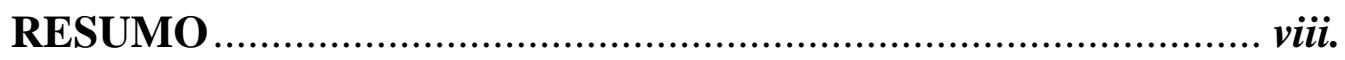

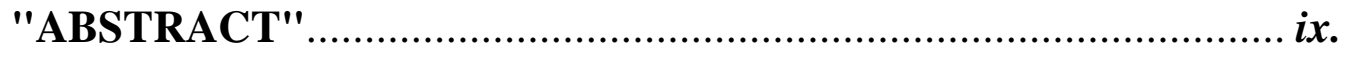

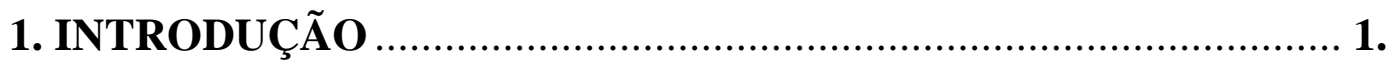

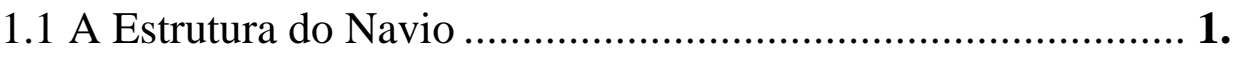

1.2 Evolução da Análise da Estrutura Transversal........................... 7.

1.2.1 Tratamento Atual para a Estrutura Transversal..............12.

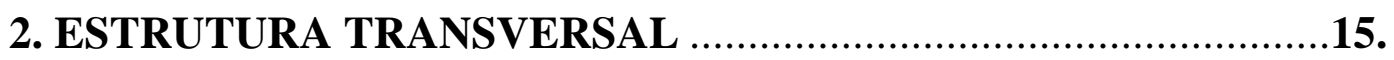

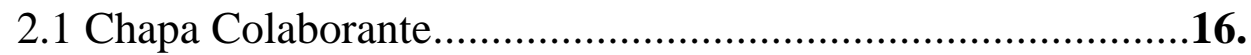

2.2 Modelagem da Estrutura Transversal .....................................18.

2.2.1 Modelo Tridimensional.................................................

2.2.2 Modelo Bidimensional...............................................22.

2.2.2.1 Cálculo do Apoio Elástico dos Longitudinais ....28.

2.2.2.2 Inclusão dos Extremos Rígidos.............................30. 
3.1 Modelo Utilizado 34.

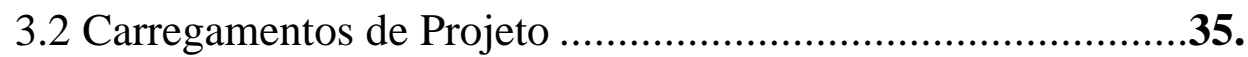

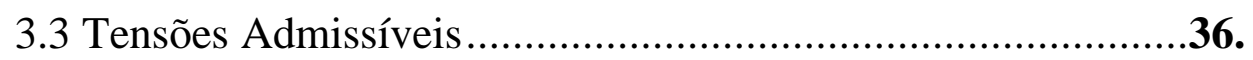

3.3.1 Teoria da Máxima Energia de Distorção ...........................36.

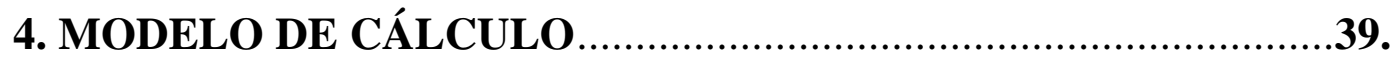

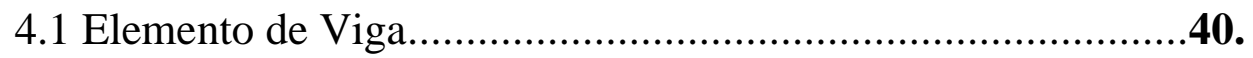

4.1.1 Matriz de Rigidez.......................................................

4.1.2 Vetor Carregamento para Elemento de Viga. ................44.

4.2 Elemento Finito de Cisalhamento..............................................47.

4.2.1 A Tensão de Cisalhamento.............................................48.

4.2.2.1 A Formulação do Elemento................................49.

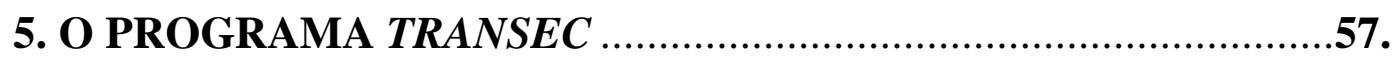

5.1 Funcionamento Básico do Programa ........................................58.

5.1.1 Módulo TRANSFIN.................................................59.

5.1.2 Módulo de Gerenciamento do Sistema ............................60.

5.1.2.1 Procedimento de Síntese .....................................66.

5.1.3 O Módulo TRANSPLT ...............................................70.

5.2 Comparação Entre os Modelos 2D e 3D .................................71.

5.2.1 Modelo Bidimensional ....................................................

5.2.2 Modelo Tridimensional.................................................73. 
5.3 Exemplos de Utilização da Opção Síntese.................................76.

5.3.1 Síntese da Caverna 17..............................................76.

5.3.2 Síntese de uma Caverna típica do

Compartimento 50/60 ................................................81.

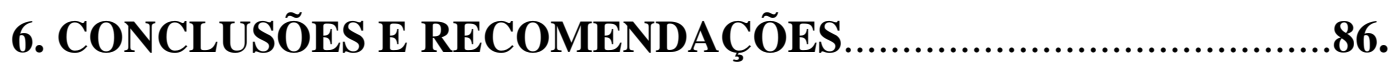

ANEXO A — CÁlCULO DOS COEFICIENTES DE RIGIDEZ .............89.

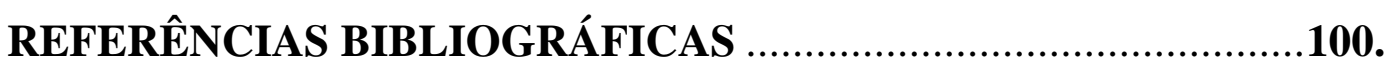

APÊNDICE A — APLICAÇÃO DO ELEMENTO DE CISALHAMENTO.

APÊNDICE B - ARQUIVOS DE DADOS. 


\section{LISTA DE SÍMBOLOS}

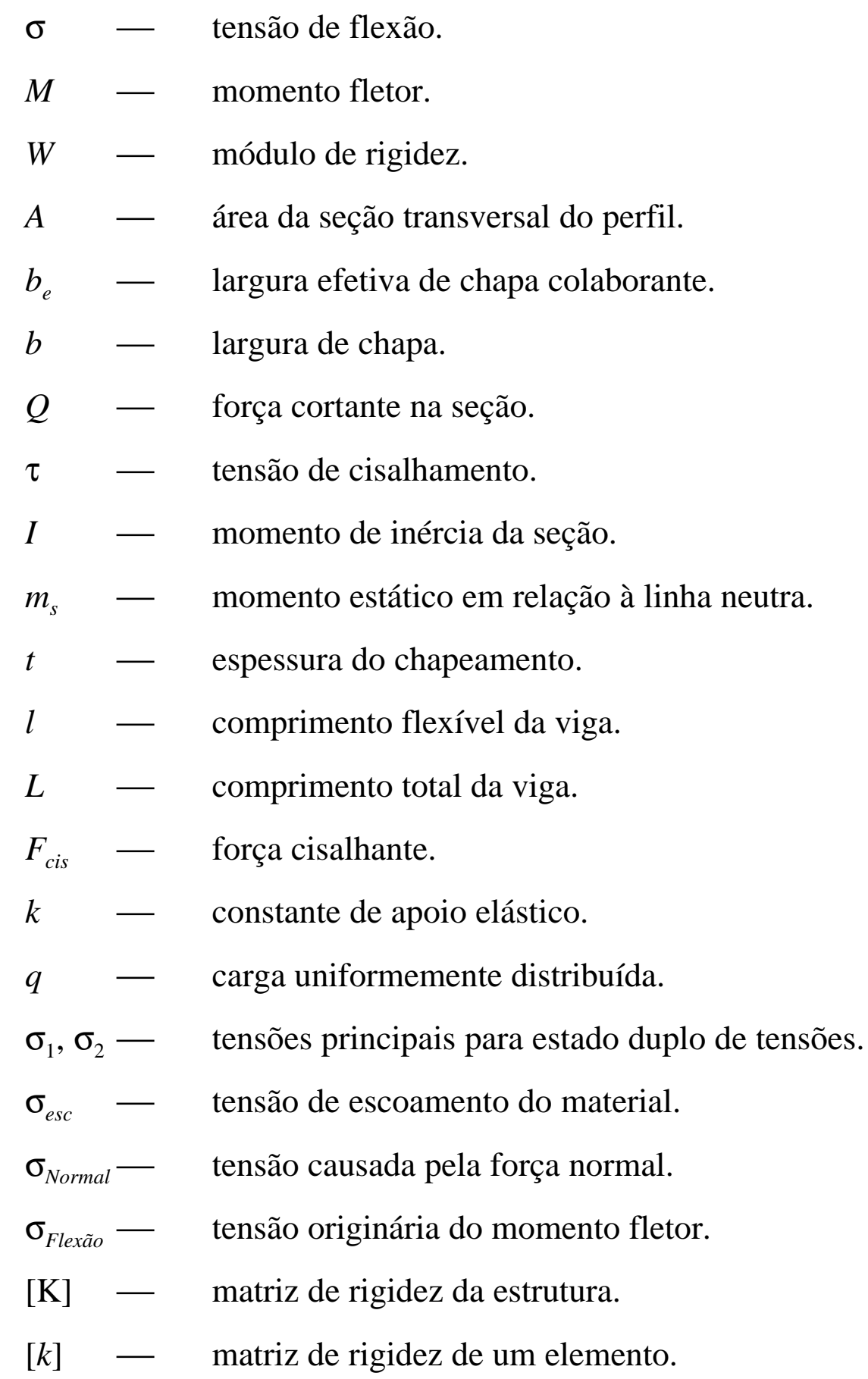


$[L] \quad$ - matriz de ligação.

$\{\delta\} \quad-\quad$ vetor de deslocamentos nodais.

$\{\mathrm{P}\} \quad-\quad$ vetor de carregamentos na estrutura.

$\{p\} \quad-\quad$ vetor de carregamentos no elemento.

$m \quad-\quad$ extremo rígido junto ao nó $i$.

$n \quad-\quad$ extremo rígido junto ao nó $j$.

P1 - valor do carregamento distribuído junto ao nó $i$.

$P 2 \quad$ - valor do carregamento distribuído junto ao nó $j$.

$\underline{p}_{i} \quad$ - carga equivalente nos extremos do comprimento flexível na direção do grau de liberdade $i$.

$p_{i} \quad$ - carga equivalente nos extremos da viga na direção do grau de liberdade $i$.

E - módulo de elasticidade volumétrica do material.

$G \quad-\quad$ módulo de elasticidade transversal.

$\gamma \quad$ - deformação angular do elemento de cisalhamento.

w - empenamento no elemento de cisalhamento.

$\bar{y} \quad$ - ordenada y em relação à linha neutra.

$\alpha \quad$ - orientação do elemento de cisalhamento no plano $x y$.

$s \quad$ - sistema de coordenadas locais para elemento de cisalhamento. 


\section{LISTA DE FIGURAS}

Fig.1.1 - Deformação Primária da Viga-Navio....................................... 3.

Fig.1.2 - Deformações Secundárias entre Anteparas. .............................. 3.

Fig.1.3 - Deformações Terciárias entre Cavernas. .................................. 3.

Fig.1.4 - Esforços Típicos na Flexão Primária. .................................... 4.

Fig.1.5 - Pontos de Máximas Tensões Terciárias para Chapa com os Lados Engastados............................................... 6.

Fig.1.6 - Esquema Típico do Fundo do Navio entre Anteparas. ................. 7.

Fig.1.7 - Seção Transversal considerada por Jenkins. ..........................8.

Fig.1.8 - Seção Transversal estudada por Bruhn. ....................................9.

Fig.1.9 - Exemplo de Carregamento no Anel Tranversal utilizado por Holt. .................................................................... 10.

Fig.2.1 - Efeito "Shear Lag" em Vigas tipo Caixa................................... 16.

Fig.2.2 - Largura Efetiva de Chapa Colaborante em Flanges Livres. ..... 18.

Fig.2.3 - Exemplo de Interação entre Anéis e uma Sicorda.................... 19.

Fig.2.4 - Eixos Centrais do Perfil. ...................................................21.

Fig.2.5 - Corte Típico de Chapeamento Reforçado por Cavernas........... 22.

Fig.2.6 - Resultantes no Anel da Viga-Compartimento sob Flexão ......... 25.

Fig.2.7 - Carregamento Típico do Anel Transversal. ............................. 26. 
Fig.2.8 - Exemplo de Apoio Elástico para Simular Rigidez do Costado. 28.

Fig.2.9 - Coeficiente de Mola para Carga Concentrada. 29.

Fig.2.10 - Forças Equivalentes ao Carregamento Uniforme. 30.

Fig.2.11 - Extremos Rígidos para Vigas com Almas Superpostas. 31.

Fig.2.12 - Hastilha Vasada - Região do Fundo 31.

Fig.2.13 - Modelo para Hastilha: Elementos de Viga com Extremos Rígidos de Dimensões Finitas. 32.

Fig.3.1 - Seção Transversal e Modelo Discretizado. 35.

Fig.3.2 - Critério de Escoamento Baseado na Máxima Energia de Distorção 37.

Fig.3.3 - Pontos Escolhidos para Cálculo das Tensões..... 38.

Fig.4.1 - Graus de Liberdade para Elemento de Viga no Plano. 41.

Fig.4.2 - Viga em Equilíbrio para Deslocamento Unitário no G.L.5........ 41.

Fig.4.3 - Equilíbrio da Viga com Extremos Rígidos. 43.

Fig.4.4 - Exemplos de Carregamentos na Viga. 44.

Fig.4.5 - Cargas Equivalentes para Carregamento Distribuído. 45.

Fig.4.6 - Cargas Equivalentes para Viga com Extremos Rígidos. 45.

Fig.4.7 - Exemplos de Seções Transversais de Vigas. 48.

Fig.4.8 - Equilíbrio de um Elemento de Viga. 49.

Fig.4.9 - Forças Normais e de Cisalhamento em Equilíbrio. 50.

Fig.4.10 - O Elemento de Cisalhamento. 52.

Fig.4.11 - A Rigidez do Elemento de Cisalhamento. 53.

Fig.4.12 - Carregamento do Elemento de Cisalhamento. 54. 
Fig.4.13 - Sistemas de Coordenadas Local e Global. 55.

Fig.5.1 - Orientação para Carregamentos e Esforços Solicitantes no Elemento de Viga. 59.

Fig.5.2 - Orientação para Esforços Solicitantes no Elemento de Treliça. 59.

Fig.5.3 - Orientação para Carregamentos e Esforços Solicitantes no Elemento de Cisalhamento. 60 .

Fig.5.4 - Tela Inicial do Programa TRANSEC. 61.

Fig.5.5 - Tela para Entrada de Dados Gerais. 62.

Fig.5.6 - Tela para Definição das Coordenadas Nodais 62.

Fig.5.7 - Tela para Incidência dos Elementos. 63.

Fig.5.8 - Tela para Entrada das Forças ou Desloc. Nodais. 63.

Fig.5.9 - Tela para Entrada dos Materiais 64.

Fig.5.10 - Tela para Entrada das Cargas Distribuídas. 64.

Fig.5.11 - Multiplicadores de Cargas 65.

Fig.5.12 - Tela para Entrada das Propriedades Geométricas. 66.

Fig.5.13 - Entrada das Chapas Colaborante dos Perfis 67.

Fig.5.14 - Fluxograma da Opção Síntese. 69.

Fig.5.15 - Deslocamentos Nodais na Estrutura. 70.

Fig.5.16 - Reações Nodais na Estrutura 70.

Fig.5.17 - Opções para desenhos do módulo TRANSPLT. 71.

Fig.5.18 - Navio-Caixa-Seção Transversal-Modelo 2D. 71.

Fig.5.19 - Navio-Caixa - Estrutura Deformada - Modelo 2D 72.

Fig.5.20 - Navio-Caixa — Dist. de Momentos Fletores - Modelo 2D.... 73. 
Fig.5.21 - Navio-Caixa — Estrutura Entre Anteparas — Modelo 3D..... 74.

Fig.5.22 - Cav.5 - Deslocamentos Nodais — Modelo 3D.................... 74.

Fig.5.23 - Cav.5 - Distribuição de Momentos Fletores — Modelo 3D................................................ 75.

Fig.5.24 - Navio-Caixa — Estrutura Deformada - Modelo 3D............... 75.

Fig.5.25 - Seção Típica das Cavernas 16,17,18 - Modelo 3D ................ 77.

Fig.5.26 - Cav.17 - Geometria e Carregamentos Laterais

— Modelo 2D................................................................ 78.

Fig.5.27 - Cav.17—Distribuição das Tensões Equivalentes Máximas — Modelo 2D.................................................. 79.

Fig.5.28 - Cav.17 — Deslocamentos na Estrutura - Modelo 2D. .........8.8.

Fig.5.29 - Dimensões da Seção Transversal do Perfil.............................80.

Fig.5.30 - Seção Típica das Cavernas do Compartimento 50/60 Modelo 3D......................................................................... 82.

Fig.5.31 - Cav.55 - Geometria e Carregamentos Laterais_-Modelo 2D ....................................................... 83.

Fig.5.32 - Cav.55 — Deslocamentos Nodais na Estrutura — Modelo 2D ...................................................8. 84.

Fig.5.33 - Cav.55 — Tensões Equivalentes Máximas — Modelo 2D...... 84. 


\section{LISTA DE TABELAS}

Tab.5.1 - Cav.17 - Resultados dos Modelos 2D e 3D............................. 81.

Tab.5.2 - Cav.55 - Resultados dos Modelos 2D e 3D............................. 85. 


\section{RESUMO}

Este trabalho apresenta os princípios básicos utilizados no desenvolvimento de um sistema especialista para síntese de cavernas de embarcações.

Uma fatia do navio, contendo o anel transversal a ser analisado, é extraída do restante da estrutura e modelada como bidimensional. A interação da fatia com a estrutura longitudinal é feita considerando os elementos longitudinais pesados como apoios elásticos nos pontos de interseção com a fatia. A interação com o chapeamento é representada por uma distribuição de tensões de cisalhamento ao longo dos elementos no anel. Consegue-se, assim, condições de contorno para o modelo bidimensional muito semelhantes àquelas encontradas em um modelo tridimensional.

O sistema desenvolvido, denominado TRANSEC, admite como dados de entrada a linha moldada da seção transversal, discretizada em elementos de viga, os carregamentos devido a pressão lateral ou concentrado, e uma tabela de perfis de onde o sistema buscará o perfil adequado para cada trecho de viga discretizado. $\mathrm{O}$ perfil adequado ou ótimo será aquele de menor peso e que resulte em solicitações estruturais enquadradas em uma faixa de tensões admissíveis previamente estabelecida pelo usuário. O sistema é composto por três módulos: um de elementos finitos, responsável pelos cálculos estruturais; um módulo gráfico, encarregado da elaboração de desenhos da estrutura; e um módulo de gerenciamento, com o objetivo de fornecer uma comunicação amigável com o usuário, além de gerenciar os outros dois módulos.

O programa foi utilizado para a síntese de duas estruturas anteriormente otimizadas por modelos tridimensionais em elementos finitos. Foram encontrados resultados similares pelas duas metodologias porém com uma diferença significativa: o tempo dispensado utilizando o sistema TRANSEC, poucas horas, contra semanas pelo modelo tridimensional.

O sistema TRANSEC se mostrou uma poderosa ferramenta, principalmente nas fases iniciais da espiral de projeto de embarcações. 


\section{"ABSTRACT"}

This work presents the basic principles used in the development of an expert system for ship's transversal frame synthesis.

A slice of the ship which contains the transversal frame is taken out from the remaining structure and modelled as a two-dimensional shape. The interaction of the transversal frame with the longitudinal structure is done considering the longitudinal stiffeners as elastic supports for the slice. The interaction with the shell plating is represented by a shear stress distribuition along the transverse frame. Based on this assumption, it is possible to get boundary conditions for the two-dimensional model similar to those associated with a three-dimensional model.

The developed system, named TRANSEC, accept as input data the transverse section molded line, discretized by beam elements; the load due to the lateral pressure and a beam cross section table from where the system chooses which one is suitable for each discrete piece of the beam. The suitable or optimum beam cross section will be the one with less weigh and which results in structural loads according to previouly adopted admissible stress levels. The system contains three units: one of Finite Element, that does structural calculus; one Graphic Module for the model's drawings and one Manager Module, aiming to provide a user friendly communication, besides controling the two other modules.

The program was applied on two structures synthesis that were optimized by three-dimesional Finite Element models. The obtained results are similar for both procedures, but with a significant difference: the time spent on using the expert system, few hours, is much less than the days spent on using threedimensinal models.

The TRANSEC system can be considered a powerful tool, mainly in the initial phase of ship transverse structural design. 


\section{CAPÍtULO 1}

\section{INTRODUCÃO}

\subsection{A ESTRUTURA DO NAVIO.}

A função principal da estrutura do navio é impedir que os diversos carregamentos aos quais estará submetido durante sua vida útil produzam esforços e deformações que ultrapassem os limites pré-estabelecidos de projeto. Para tanto, a estrutura é formada por um chapeamento sustentado através de perfis distribuídos longitudinal e transversalmente ao longo da embarcação.

O cálculo da espessura deste chapeamento e das dimensões dos perfis, de modo que garanta segurança e funcionalidade ao navio, é uma tarefa difícil. Entre os motivos podemos citar a complexidade da estrutura e a dificuldade de se determinar exatamente o carregamento imposto, uma vez que mesmo sabendo $a$ priori a distribuição de cargas nos porões e/ou conveses, o navio está sujeito a ondas de diferentes alturas, comprimentos e que atuam em várias direções, tornando impossível determinar o carregamento real aplicado ao navio.

Através de hipóteses simplificadoras é possível elaborar modelos teóricos e experimentais que simulem a realidade e produzam resultados aplicáveis à estrutura real. Assim, não resolvemos o problema em si, mas um modelo representativo deste. Uma das primeiras tentativas de aplicar uma análise teórica ao projeto de elementos estruturais do navio foi feita por Young, em 1814, quando estudou o emprego de diagonais de travamento na estrutura de navios de madeira. Segundo Robb[1], foi Young quem primeiro considerou claramente a 
flexão longitudinal do casco, definindo a diferença entre as curvas de peso e flutuação como sendo o diagrama de cargas, calculando a partir daí as forças cortantes e os momentos fletores longitudinais pela teoria simples de viga. Foi introduzido, então, o conceito de viga-navio. Fusco[2] mostra que o tratamento global da estrutura dos navios metálicos só foi conseguido em 1954, através de St.Denis, com o estabelecimento de um processo racional de cálculo. Para tanto, as deformações e tensões foram consideradas como decorrentes de três tipos de solicitações: a flexão longitudinal da viga-navio; a flexão dos grandes painéis, limitados pelos costado e por duas anteparas transversais consecutivas; e a flexão de pequenos painéis, constituídos pelos chapeamentos delimitados por duas hastilhas e por duas longarinas adjacentes. Definiram-se assim as estruturas primária, secundária e terciária do navio. Admitindo-se o regime de pequenas deflexões, através de um critério de resistência calculavam-se as tensões pela composição dos valores encontrados em cada uma das estruturas acima definidas.

A proposta de St. Denis admitia que inicialmente o navio se deformava como um todo, semelhante a uma viga — a deformação primária. A partir desta posição se dava outra deformação, composta de duas parcelas: deformação dos painéis entre as anteparas e depois a deformação dos longitudinais leves entre dois elementos transversais adjacentes —deformação secundária. Por fim uma deformação, devido a pressão lateral, das unidades de chapeamento deformação terciária — completaria a deformação total do navio. Observemos que a estrutura terciária faz parte da secundária e esta por sua vez tem elementos em comum com a estrutura primária. Uma porção de chapa do fundo do navio, por exemplo, pode sofrer deformações primárias quando analisamos a viga-navio, secundárias quando estudamos o comportamento entre anteparas e terciárias quando verificamos as unidades de chapeamento.

Este procedimento, ilustrado nas Figs.1.1, 1.2 e 1.3 recebeu grande aceitação entre os engenheiros navais e vem sendo utilizado com sucesso ao longo dos anos. 


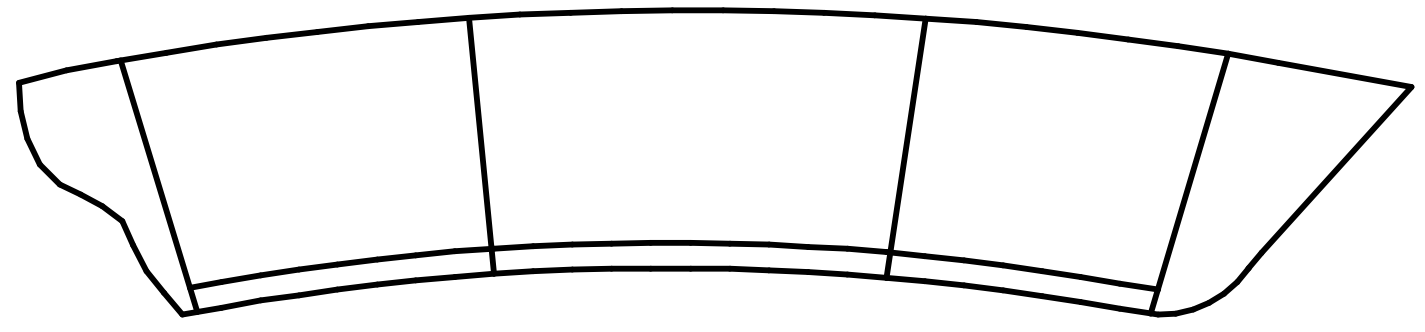

Fig.1.1 - Deformação Primária da Viga-Navio.

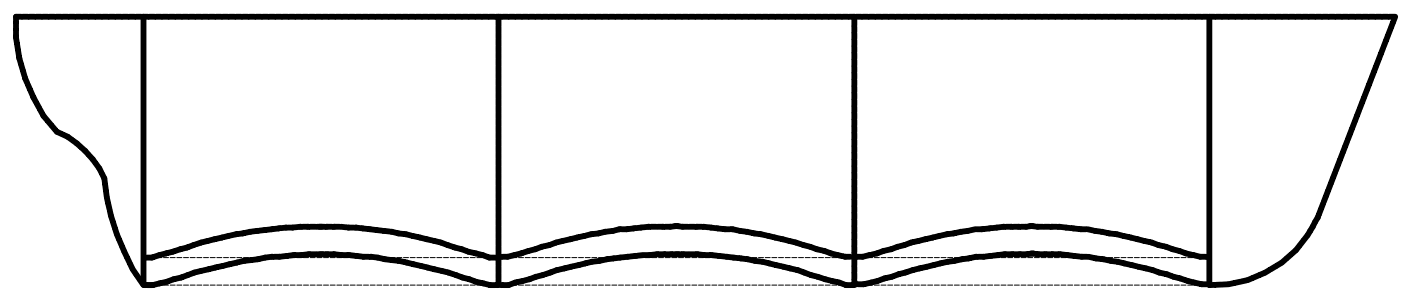

Fig.1.2 - Deformações Secundárias entre Anteparas.

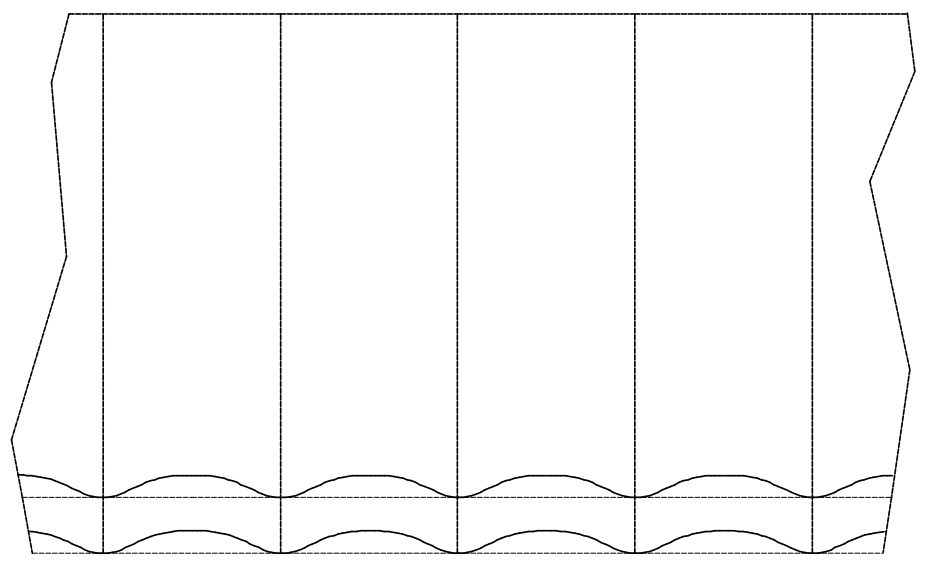

Fig.1.3 - Deformações Terciárias entre Cavernas.

Para o cálculo da deformação primária, considera-se o navio como uma viga, flutuando sem vínculos, submetido a um carregamento formado pela diferença entre a curva de flutuação e a curva de distribuição de pesos. Desta forma, é possível construir os diagramas de força cortante e momento fletor conforme esquematizado na Fig.1.4. As tensões primárias são determinadas admitindo-se flexão pura na teoria simples de viga. Apesar de, para alguns tipos de navio, não se verificar a hipótese de Navier $^{1}$, tal modelo fornece bons

${ }^{1}$ É a hipótese básica da teoria da flexão, desenvolvida por M.Navier. Pode ser estabelecida como segue: "em um viga as seções planas orientadas perpendicularmente ao seu eixo, permanecem planas quando a viga é submetida à flexão." 


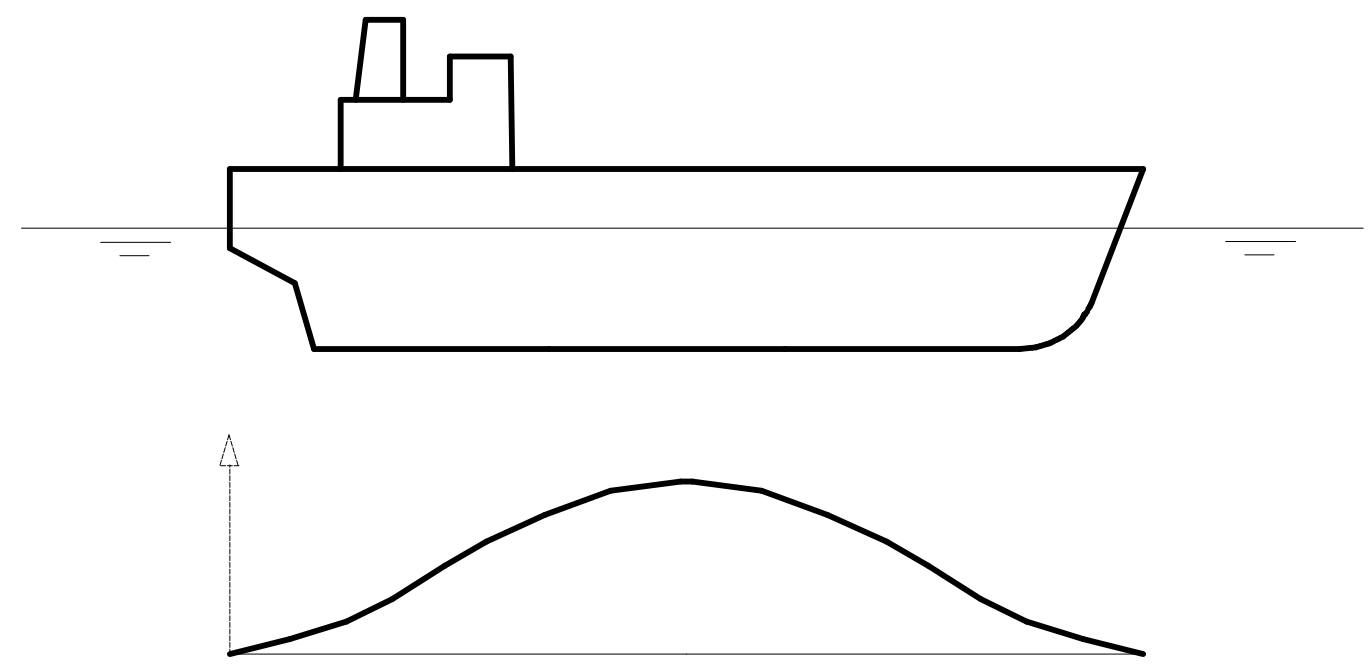

(a) Curva de Flutuabilidade

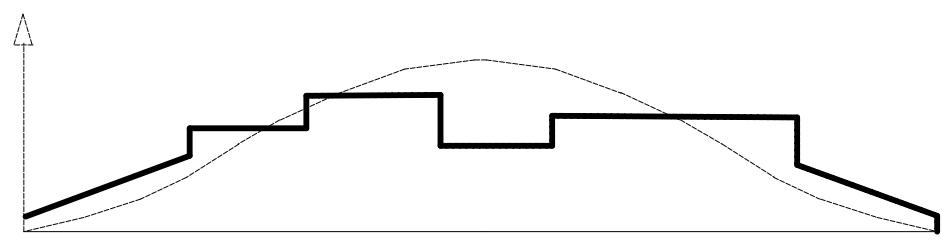

(b) Curva de Distribuição de Pesos

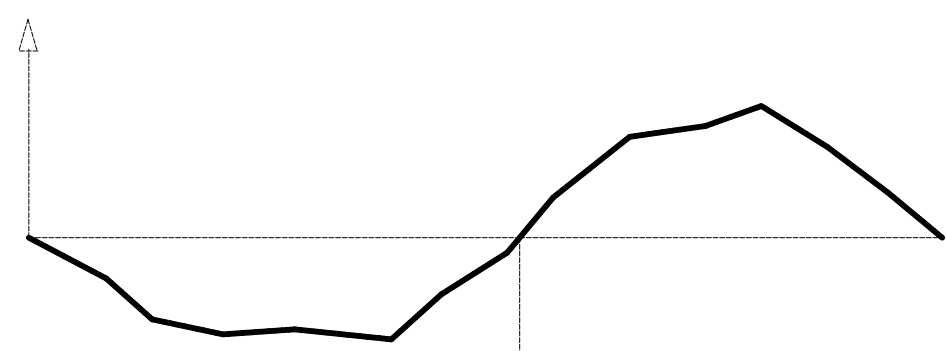

(c) Diagrama de Força Cortante

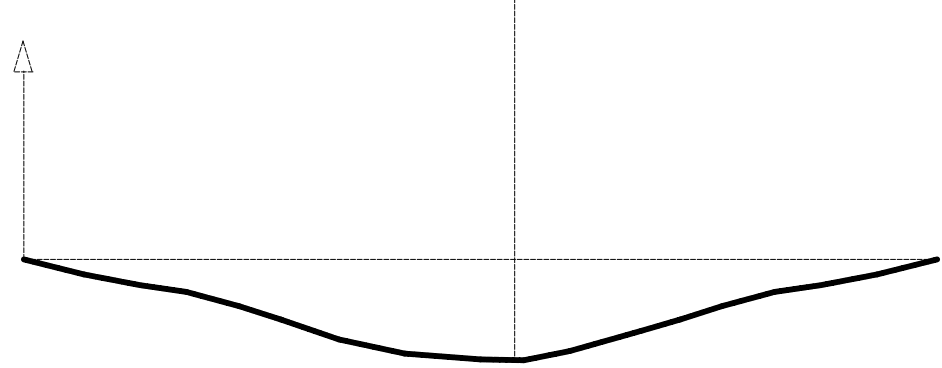

(d) Diagrama de Momento Fletor

Fig.1.4 - Esforços Típicos na Flexão Primária. 
resultados. As tensões de flexão podem ser determinadas pela expressão elementar

$$
\sigma=\frac{M}{W}
$$

sendo

$\sigma$ - tensão de flexão na viga navio.

$M$ - momento fletor longitudinal aplicado à viga navio.

$W$ - módulo de rigidez.

A estrutura primária é composta pelos elementos longitudinais contínuos que contribuem para a formação do módulo de rigidez. Exemplificam esses elementos os chapeamentos dos conveses, do costado, do fundo e teto do duplofundo, as anteparas longitudinais, quilhas, sicordas e longarinas.

A estrutura terciária é formada pelas unidades de chapeamento, isto é, chapas normalmente retangulares limitadas por enrijecedores adjacentes. A estrutura é projetada levando-se em consideração as tensões admissíveis e também problemas de instabilidade. $\mathrm{O}$ cálculo das tensões terciárias no chapeamento é feito tomando-se condições de simetria de carregamento, em geral apresentado pelas unidades de chapeamento, fazendo com que estas possam ser consideradas engastadas nos quatro bordos. Para as condições acima, observando o regime de pequenas deflexões, podemos determinar os pontos de máximas tensões, assinalados na Fig.1.5. Através da teoria de chapas esses valores podem ser calculados pela equação

$$
\sigma=k * \frac{p}{2} *\left(\frac{b}{t}\right)^{2}
$$

sendo

$\sigma$ - tensão de flexão na chapa.

$k$ - constante tabelada que depende da relação entre os lados e dos vínculos destes ${ }^{1}$.

$p$ - pressão lateral sobre a chapa.

$b$ - menor lado da chapa.

$t$ - espessura da chapa.

${ }^{1}$ A Ref.[3] apresenta o valor desta constante para várias casos. 
A estrutura secundária é formada pelo conjunto — chapeamento, perfis leves e pesados - normalmente considerado entre duas anteparas estruturais. Aqui, os longitudinais da estrutura primária aparecem entrelaçados com elementos dispostos transversalmente à embarcação formando uma malha que, juntamente com o chapeamento, vai resistir à pressão hidrostática e eventuais cargas nos porões e conveses. Portanto, além das sicordas, quilhas, longarinas, etc., na direção longitudinal, existem, na direção transversal, vaus gigantes, hastilhas, vaus de conveses, cavernas de costado, etc. As anteparas estanques possuem grande rigidez no seu próprio plano e também são consideradas como reforçadores transversais.

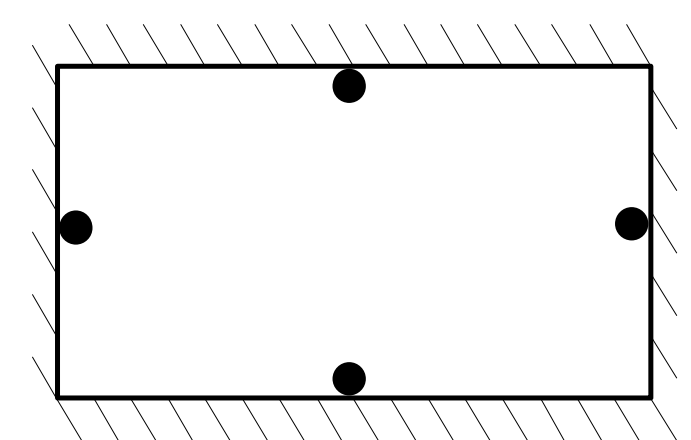

\section{Fig.1.5 - Pontos de Máximas Tensões Terciárias para Chapa com os Lados Engastados.}

A deformação secundária, conforme visto, se dará pela ação do carregamento sobre este conjunto de reforçadores originando as tensões secundárias. O cálculo dessas tensões, no entanto, é bem mais complexo do que o feito para as tensões primárias e terciárias. Como exemplo, observemos a Fig.1.6, onde apresentamos um painel típico da estrutura do fundo do navio. Todos os enrijecedores leves e pesados estão sujeitos a flexão devido às cargas laterais no chapeamento e, como estão ligados entre si, formam um conjunto para resistir a estas cargas, tornando sua análise mais laboriosa, dado o grande número de elementos que a envolve. Para os anéis transversais, responsáveis, junto com as anteparas, pela resistência transversal do navio, existe a dificuldade na modelagem da interação com os longitudinais pesados — seja na definição de carregamentos ou na imposição das condições de contorno- o que torna seu estudo igualmente trabalhoso. Uma análise cuidadosa deve ser feita, então, a fim de que se possa garantir uma resistência transversal adequada ao navio. A D.N.V., a exemplo de outras Sociedades Classificadoras, recomenda análises bi e 
tridimensional da estrutura transversal, a fim de que as tensões obtidas possam ser comparadas com respectivas tensões admissíveis.

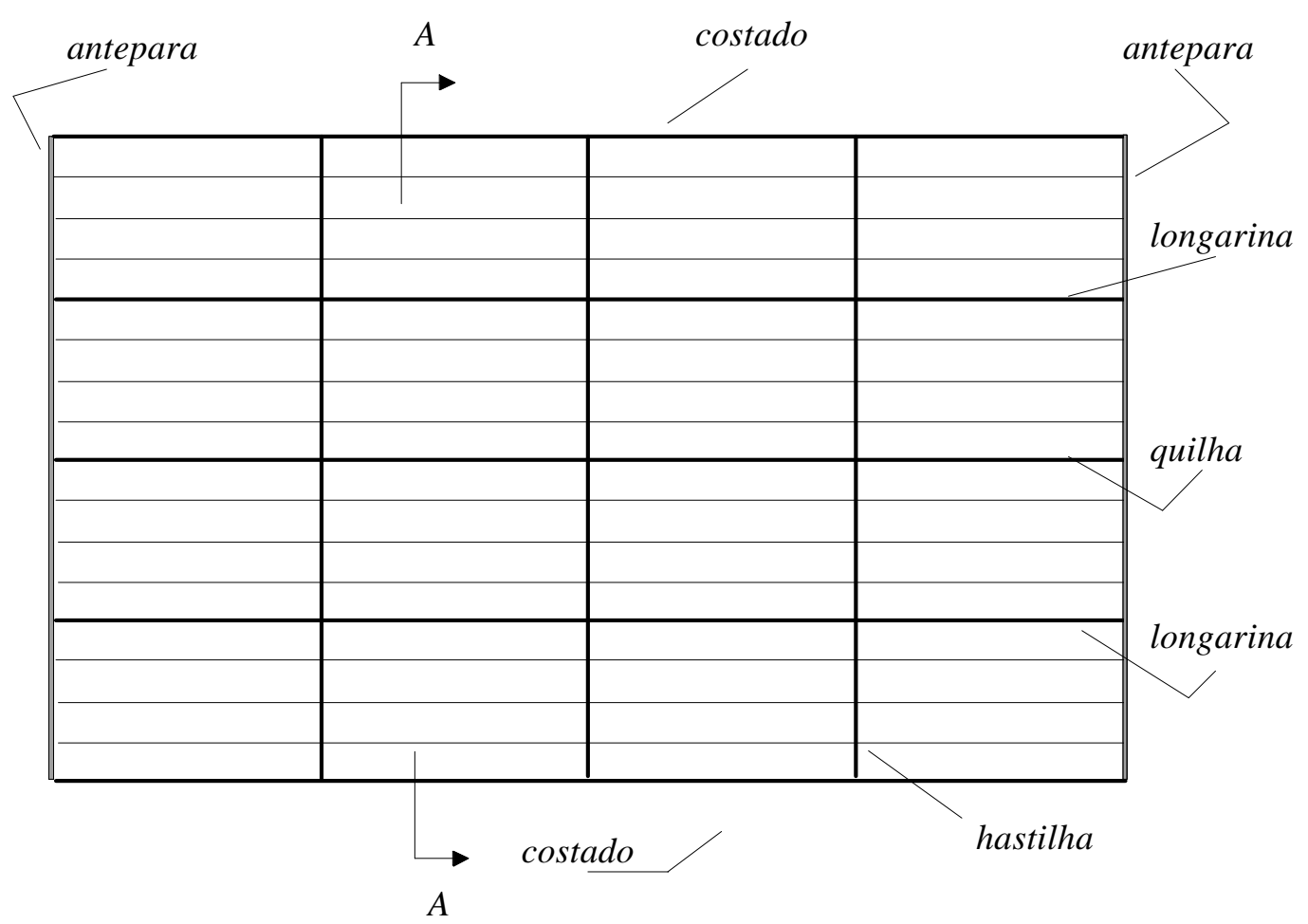

(a)

corte A-A teto do duplo fundo

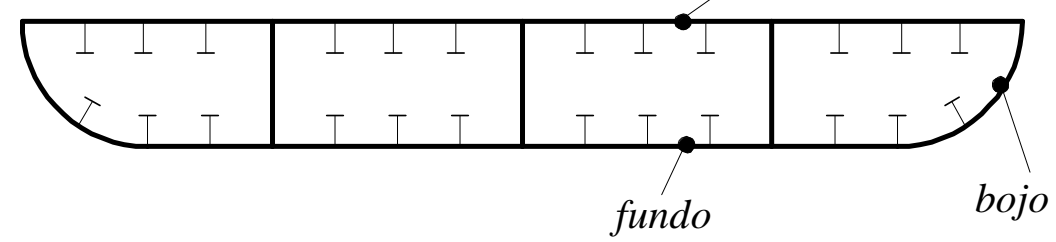

(b)

Fig.1.6 - Esquema Típico do Fundo do Navio entre Anteparas.

\subsection{EVOLUÇÃO DA ANÁLISE DA ESTRUTURA TRANSVERSAL.}

O primeiro estudo sobre a estrutura transversal data de 1882, em trabalho apresentado por Jenkins[4]. O cálculo foi efetuado considerando-se uma seção com dois conveses e pilares como mostra a Fig.1.7(a). O modelo admitia a situação de navio docado, com blocos sustentando somente a quilha central. Assim os lados do navio sofriam deformação até encontrar uma posição de equilíbrio. 


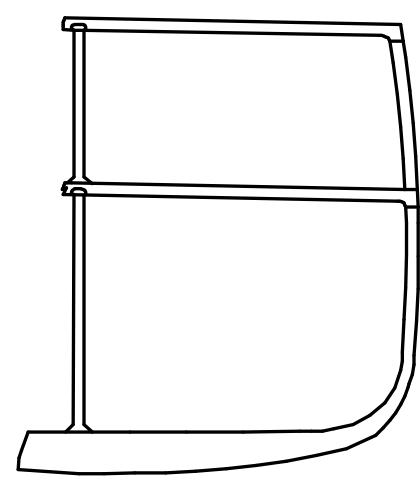

(a)

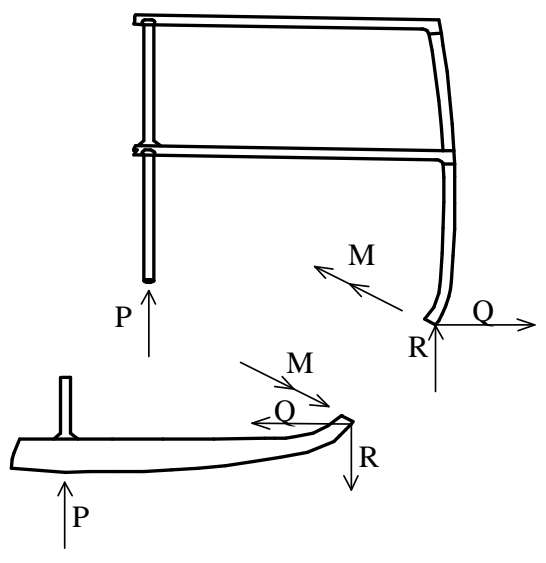

(b)

Fig.1.7 - Seção Transversal considerada por Jenkins.

Para determinar os esforços máximos na estrutura, Jenkins dividiu a seção em duas partes através de um corte na altura do bojo equilibrando-as por meio de um conjunto de forças e conjugados conforme mostrado na Fig.1.7(b). Os escantilhões foram escolhidos obedecendo as regras do Lloyd's Register e no modelo de cálculo não foi considerada nenhuma interação com o restante da estrutura. Três forças foram consideradas como carregamento: o peso próprio distribuído ao longo do comprimento, transformado em força mais momento, a força produzida pelos conveses e pelo costado sobre o fundo e a reação para cima na quilha. Utilizando-se de hipóteses simplificadoras e também de considerações a respeito da continuidade das deformações na seção de corte, o autor chegou a uma expressão para o momento fletor em qualquer ponto da estrutura em função das forças aplicadas. De posse da distribuição de momentos, o cálculo das tensões foi executado através da teoria simples de vigas, considerando-se flexão pura.

Em 1901, Bruhn[5] analisou os esforços no anel transversal de uma pequena embarcação de casco simples, sem pilares, com um convés somente, como mostrado na Fig.1.8. Da embarcação foi retirada uma "fatia" contendo os elementos do anel. Sobre esta, aplicou-se um carregamento que considerava a pressão estática e um carregamento adicional, também aplicado estaticamente, tentando representar o efeito das cargas dinâmicas às quais o navio estaria sujeito no mar. Para equilibrar verticalmente a "fatia", somou-se o peso do anel e das cargas internas ao carregamento hidrostático acima definido. Analogamente ao que fez Jenkins, o modelo foi dividido — no ponto $g$ representado na Fig.1.8 - e 
uma expressão foi obtida relacionando forças e o momento fletor em qualquer ponto da estrutura dividida em função dos valores correspondentes na posição da quilha e do carregamento distribuído no intervalo $k$ - $n$ da Fig.1.8. O problema foi resolvido pelo teorema de Castigliano ${ }^{1}$, até então muito aplicado na construção civil. Um modelo mais completo também foi analisado. Neste, o equilíbrio vertical não acontecia somente em função das forças anteriormente descritas, mas também da tensão de cisalhamento proveniente da interação do anel com o resto da estrutura. A resultante das forças consideradas no modelo anterior, na direção vertical, era agora equilibrada pela diferença entre forças cortantes atuando nos dois lados da "fatia". Para calcular essa força cortante, Bruhn utilizou o seguinte raciocínio: retirando-se toda a carga interna aplicada, mantendo-se o mesmo calado, a força cortante deve ser igual à carga retirada. A força cortante foi distribuída nas chapas posicionadas na direção vertical. O modelo foi resolvido da mesma forma que o anterior. Concluindo o trabalho, o autor fez uma análise qualitativa sobre a influência de anteparas e longitudinais pesados na distribuição de tensões na seção transversal.

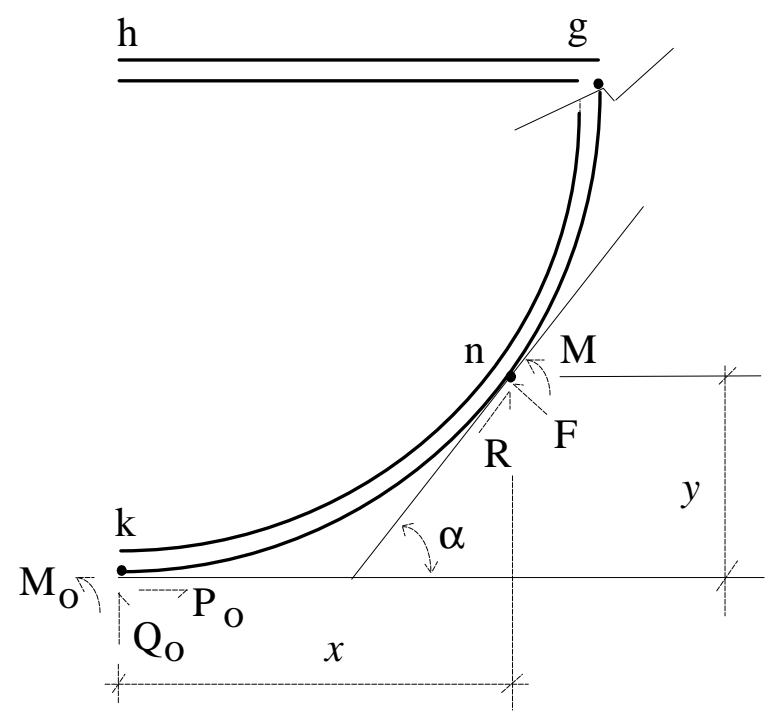

Fig.1.8 - Seção Transversal estudada por Bruhn.

Holt[7], em 1915, trabalhou no sentido de determinar um critério de resistência para navios mercantes, no tocante à estrutura transversal. Utilizando uma seção reta, mostrada na Fig.1.9, procurou estabelecer expressões genéricas para momentos e tensões, em função das condições de carregamento, espaçamento de cavernas, número de conveses, etc. Seu trabalho procurou

\footnotetext{
${ }^{1}$ A dedução desse teorema pode ser encontrada na Ref.[6].
} 
estabelecer uma sistematização, ainda que simples, no cálculo da estrutura transversal. Como inovação, elaborou um critério de resistência para o estudo dos transversais do costado baseado nas regras das Sociedades Classificadoras, com modificações para incluir os efeitos das cargas dinâmicas. Pelo critério apresentado, a equação clássica da Resistência dos Materiais, no que tange ao cálculo de tensões em vigas, foi reformulada com a inclusão de vários fatores empíricos na tentativa de considerar, através da mesma expressão, o espaçamento entre cavernas, o número de conveses e a densidade da carga sobre os conveses.

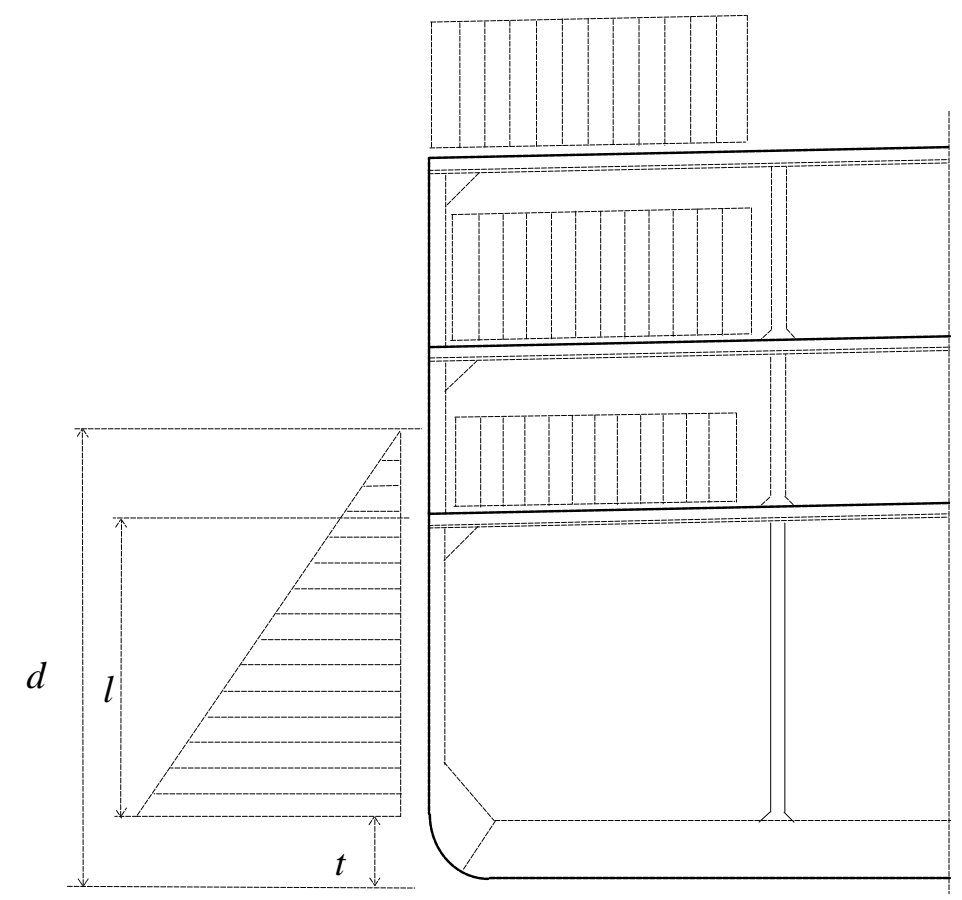

Fig.1.9 - Exemplo de Carregamento no Anel Tranversal utilizado por Holt.

Obteve, então, a expressão

$$
\sigma=\frac{12}{2.24} \cdot \frac{\left[M^{\prime}+C\right]}{I} \cdot y+\frac{P}{A}
$$

sendo

$M^{\prime}=s \cdot A(d-t) \cdot l^{n}+B$, sendo $A, B$ e $n$ constantes que dependem do número de conveses e da densidade de carga nestes; $s$ é o espaçamento entre cavernas; $d$ representa o calado, $t$ a altura do tanque no fundo e finalmente $l$ indicando a distância entre o convés mais próximo do fundo e o topo do 
tanque de fundo. A Fig.1.9 exemplifica esses valores para um caso de carregamento.

$I$ - momento de inércia da seção

$y$ - distância da linha neutra ao ponto considerado.

$P$ - carga vertical descarregada pelo convés.

$A$ - área da seção transversal do perfil do costado.

Hay[8], em 1945, apresentou um trabalho no qual analisava uma estrutura transversal simples para várias condições de carregamento. Duas seções transversais do navio foram estudadas: uma fechada com antepara longitudinal na linha de centro e outra com abertura de escotilha. O grande mérito deste trabalho foi utilizar o método de Cross para calcular os momentos fletores decorrentes de cada condição de carregamento.

Este método apresentava sensíveis vantagens em relação aos métodos de energia, até então empregados na análise das estruturas. Sendo um método iterativo, em cada passo podia-se visualizar a solução, com o cálculo se aproximando mais e mais do valor correto. Além disso, a solução não dependia do uso de um sistema de equações, que em geral era de grande porte.

As conclusões de Hay foram utilizadas por Adams[9] em 1950. Para tanto, o autor considerou duas seções típicas de um navio petroleiro, submetidas a diversas condições de carregamento. O trabalho serviu para afirmar o uso do método de Cross em estruturas navais.

A influência dos longitudinais foi considerada pela primeira vez por Thruston[10], em 1958. Desenvolveu uma expressão —em função do espaçamento de cavernas, comprimento do compartimento, deslocamento do anel transversal no ponto de intersecção com o longitudinal - para calcular a reação do longitudinal sobre o anel transversal no centro do compartimento. Em seguida, o anel foi analisado sob a ação do carregamento e também das reações dos longitudinais. Embora simplificado, foi o primeiro passo para considerar a interação entre os longitudinais e o anel transversal.

Uma das primeiras aplicações de programa de computador no cálculo da estrutura transversal aconteceu em 1960, no estudo de Yuille[11]. Um modelo tridimensional foi utilizado para representar o compartimento de um navio militar tipo fragata. Os perfis e o chapeamento foram modelados por elementos de viga e 
de membrana, respectivamente. O modelo foi resolvido pelo método da rigidez, implementado em um programa de computador com capacidade para resolver um sistema linear com ... 86 equações. No entanto, utilizando-se o Método de Eliminação de Gauss sistemas maiores podiam ser resolvidos, uma vez que somente duas equações por estágio precisavam ser carregadas na memória. Estava aberto um novo e irreversível caminho para análise da estrutura transversal do navio.

Paralelamente, o autor desenvolveu uma investigação experimental através de um modelo representando a estrutura engastada entre duas anteparas. Submeteu-o a dois carregamentos: uma carga concentrada no centro da quilha e, em outra situação, cargas aplicadas a meio vão dos longitudinais de bojo. Através de "strain gages" foram medidas deformações na estrutura deduzindo-se a partir destas as tensões. A comparação entre as tensões calculadas e medidas forneceu um resultado suficiente para justificar o método empregado na análise da estrutura.

\subsubsection{TRATAMENTO ATUAL DA ESTRUTURA TRANSVERSAL.}

Com o progressivo aumento das dimensões principais do navio a análise da estrutura transversal tornou-se tão importante quanto a da estrutura longitudinal. Os compartimentos, a boca e o pontal atingiram dimensões que obrigavam a utilização de perfis cada vez maiores na estrutura transversal. Em consequiência, o projetista tinha agora a preocupação de equacionar $o$ espaçamento dos transversais com as dimensões dos perfis, visando a redução do peso da estrutura e conseqüentemente do custo.

Abriu-se um novo campo de estudos dentro da análise da estrutura secundária onde não bastava somente garantir a resistência transversal: era necessário também que o conjunto de perfis utilizados fosse, dentro das limitações, o mais eficiente, principalmente em relação ao peso da estrutura. Paralelamente, a evolução dos computadores eletrônicos, do ponto de vista de velocidade de processamento e armazenamento de dados, tornava possível a implementação de programas de computador com maior capacidade de cálculo. $\mathrm{O}$ Método dos Elementos Finitos (MEF), até então teórico, apareceria agora como alternativa prática para determinar esforços nas estruturas, inaugurando uma nova era na análise não só da estrutura transversal, mas de todo tipo de estrutura. Segundo Cook[12], em 1961 foram publicados 10 artigos sobre elementos finitos, 
134 em 1966 e 844 em 1971. Em 1976, duas décadas depois das primeiras aplicações do método na engenharia, o número de trabalhos chegava à casa dos 7.000. Em 1986, o total ultrapassava 20.000.

Os primeiros trabalhos visando encarar o projeto do navio sob o aspecto da otimização procuravam caracterizá-lo através da utilização de técnicas de programação matemática. Evans[13] e Hughes[14] se empenharam com destaque nesta tarefa. Especificamente sobre o projeto da estrutura transversal temos os trabalhos de Mansour[15] e Finifter[16], que utilizaram o MEF na análise de anéis transversais de petroleiros simulados através de modelos bidimensionais. $\mathrm{Na}$ década de 80 Hughes[17] apresentou o programa de síntese estrutural MAESTRO. O programa executava a otimização de uma função matemática, representando, por exemplo, o peso da estrutura, sujeita às restrições de tensões admissíveis, flambagem, altura dos perfis, espaçamentos mínimos e máximos entre anteparas ou entre cavernas, etc.

Dentro deste contexto de otimização estrutural, apresentamos no presente trabalho as ferramentas necessárias para elaboração de um procedimento racional capaz de sintetizar a estrutura transversal de embarcações. Entendemos por síntese da estrutura a busca iterativa de um conjunto de perfis que satisfaçam as restrições impostas, de tal sorte que o conjunto final seja, dentro das limitações do modelo, o mais otimizado do ponto de vista de esforços na estrutura. Como é sabido, este processo se efetuado por meio de um modelo tridimensional é trabalhoso, seja pela montagem do modelo, seja pela análise dos resultados. $\mathrm{O}$ cálculo "manual", através de um modelo bidimensional, também é inviável, dado o grande volume de cálculos envolvidos. Portanto, moldamos o procedimento de síntese na forma de um programa de computador, denominado TRANSEC, que através de um modelo bidimensional procura maximizar os níveis de solicitação na estrutura até o nível da tensão admissível.

Iniciando, apresentamos no capítulo 2 os dois modelos físicos clássicos utilizados na análise da estrutura transversal. No primeiro a análise é feita tomando-se o compartimento entre duas anteparas ${ }^{1}$. No segundo caso a análise se dá em um anel contendo a estrutura transversal considerando sua interação com os longitudinais e com o chapeamento nos planos de corte. As hipóteses básicas são apresentadas e uma ênfase maior é dada ao último modelo, por ser

\footnotetext{
${ }^{1} \mathrm{O}$ compartimento não necessariamente é delimitado por duas anteparas estanques. O conceito é de compartimento estrutural, que pode ser delimitado, por exemplo, por uma antepara e uma caverna gigante.
} 
este o utilizado para executar a modelagem física que fundamenta o programa TRANSEC.

O capítulo 3 mostra os critérios utilizados na elaboração do problema. Definimos o modelo utilizado para representar o problema real, os carregamentos e também um critério de resistência visando obter uma expressão para cálculo de tensões equivalentes no conjunto perfil e chapa colaborante.

Ao capítulo 4 foi reservada a modelagem matemática utilizada para resolver o modelo físico bidimensional. Será utilizado o $\mathrm{MEF}$ —através dos elementos de viga e cisalhamento_ para uma análise linear estática. O elemento de viga é utilizado para representar os tramos que compõem a estrutura transversal. $O$ cisalhamento resultante da diferença das tensões normais longitudinais que atuam nos dois planos de corte será representado por um elemento de cisalhamento, necessário uma vez que em muitas seções não é possível determinar diretamente a distribuição das tensões de cisalhamento, devido a presença de células fechadas.

O programa TRANSEC é apresentado no capítulo 5. Descreve-se o funcionamento dos módulos que compõem o programa, procurando-se fornecer um visão qualitativa do mesmo. Para obter uma descrição do como utilizar o programa deve-se recorrer ao seu manual. São apresentados exemplos para os módulos de cálculo e de projeto, comparando-se os resultados obtidos com valores conseguidos por estudos anteriores através de modelos tridimensionais.

Por fim, no capítulo 6 são apresentadas as principais conclusões e recomendações decorrentes deste trabalho. 


\section{CAPÍTULO 2}

\section{ESTRUTURA TRANSVERSAL}

Sob carga, os enrijecedores longitudinais do navio, juntamente com o chapeamento, não são capazes de manter a forma da embarcação, além de serem pouco eficazes no que diz respeito à flambagem. No primeiro caso, seria um problema análogo ao cálculo de uma viga-caixão que apresentasse comprimento, largura e altura muito maiores que a espessura das paredes. No caso do chapeamento, estaríamos tratando de uma chapa cujo comprimento seria muito maior que a largura. Nos dois casos a carga crítica de flambagem seria facilmente atingida com carregamentos muito menores que os de projeto. Conseqüentemente, a estrutura longitudinal precisa ser reforçada espaçadamente por meio de anéis transversais.

As anteparas estanques e as cavernas transversais da embarcação compõem o que chamamos de estrutura transversal ${ }^{1}$ do navio. Sua função é reduzir o vão livre, aumentando a resistência à flambagem e mantendo as tensões e deformações dentro dos limites admissíveis.

Conforme será visto no item 2.2, tanto os modelos bidimensionais como os tridimensionais utilizam vigas para representar os perfis existentes nos anéis transversais. Admite-se ainda que o carregamento é resistido não somente pelos perfis mas também por uma porção conveniente do chapeamento que associada

\footnotetext{
${ }^{1} \mathrm{Na}$ nomenclatura utilizada no texto, a menos que esteja explícito o contrário, são sinônimos: caverna, estrutura transversal e anel transversal.
} 
ao perfil funciona como flange deste. Dada a sua importância, essa porção, chamada de chapa colaborante, será analisada no próximo item.

\subsection{CHAPA COLABORANTE.}

Da teoria elementar de vigas sabemos que as tensões de flexão são diretamente proporcionais à distância do ponto considerado ao eixo neutro. Logo, em qualquer viga formada por alma e flanges, as tensões devem ser constantes ao longo dos flanges. Entretanto, em muitos problemas a flexão não é causada por um binário de forças nas extremidades da viga e sim por cargas transversais que são absorvidas pela alma da viga e não pelos flanges. Sob o efeito das cargas, a alma da viga é curvada induzindo deformações nos flanges. Essas deformações se originam na alma e somente atingem o flange por causa do cisalhamento. Esse fenômeno é ilustrado na Fig.2.1, que mostra uma seção de uma viga tipo caixa, em balanço, com uma carga concentrada na extremidade livre.

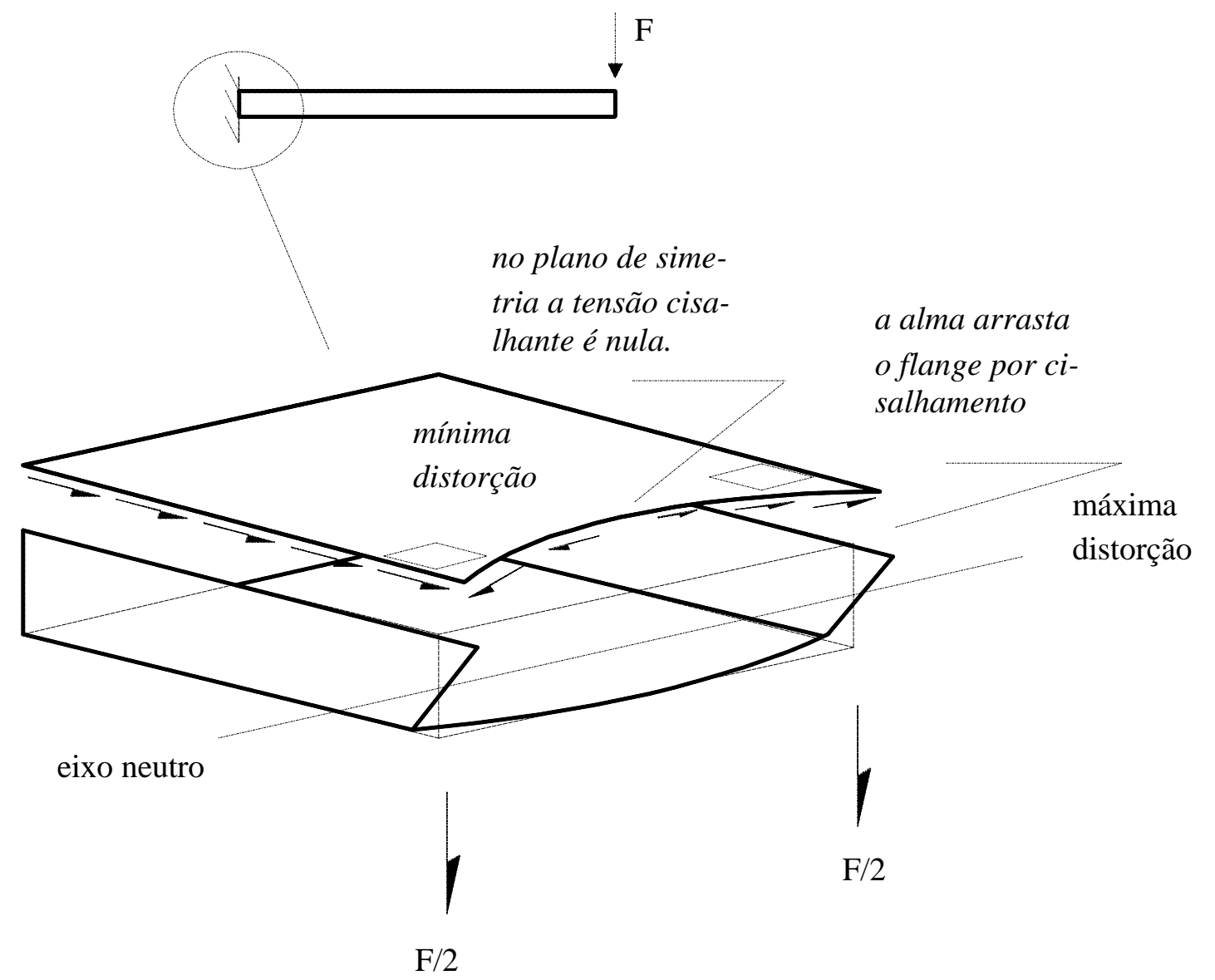

Fig.2.1 - Efeito "Shear Lag" em Vigas tipo Caixa. 
A força é resistida pelas almas, que se curvam de forma a alongar e a encurtar, respectivamente, os extremos superior e inferior da viga. Por simplicidade a curvatura não está ali representada. O contorno alongado da alma traciona consigo o chapeamento do flange através de forças de cisalhamento o que resulta em tensões de cisalhamento nos flanges. Estas tensões de cisalhamento distorcem o flange e esta distorção é tal que o lado do elemento retangular mais próximo da alma da viga deve se esticar, ou seja, a deformação no sentido longitudinal é menor no lado interno e portanto também o é a tensão longitudinal. Este mesmo fenômeno ocorrerá em cada elemento, do canto até a linha de centro, embora ele paulatinamente diminua até desaparecer na linha de centro onde a tensão de cisalhamento é nula. Em conseqüência, o flange sofre uma distorção no plano longitudinal e portanto as seções planas não permanecem planas. Esta distorção, comumente chamada de empenamento, tem como aspecto mais significativo a presença de menores tensões de flexão nas regiões mais afastadas do flange, ou seja, ocorre um "atraso" em relação às tensões mais próximas da alma. Esse fenômeno foi batizado de "shear lag" e ocorre em vigas com flanges largos sob cargas laterais.

Para considerar o efeito "shear lag" em painéis reforçados faz-se uso do conceito de largura efetiva de chapa, doravante chamada de $b_{e}$, ilustrado na Fig.2.2:

a largura da chapa da qual, quando utilizada no cálculo do momento de inércia da seção transversal do perfil, resultará o valor "correto" da tensão de flexão na junção alma-flange, pela teoria simples de viga.

Assim obtemos,

$$
b_{e} \sigma_{\max }=\int_{0}^{b} \sigma_{x} d z
$$

ou

$$
b_{e}=\frac{\int_{0}^{b} \sigma_{x} d z}{\sigma_{\max }}
$$

isto é, na Fig.2.2(b) $b_{e}$ é a largura que iguala as áreas hachuradas. 


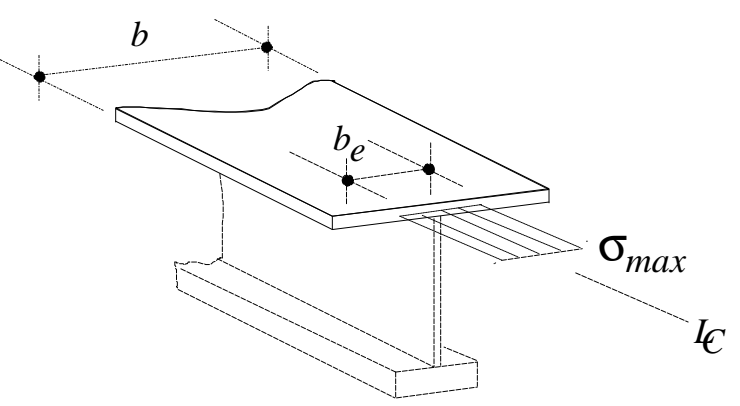

(a)

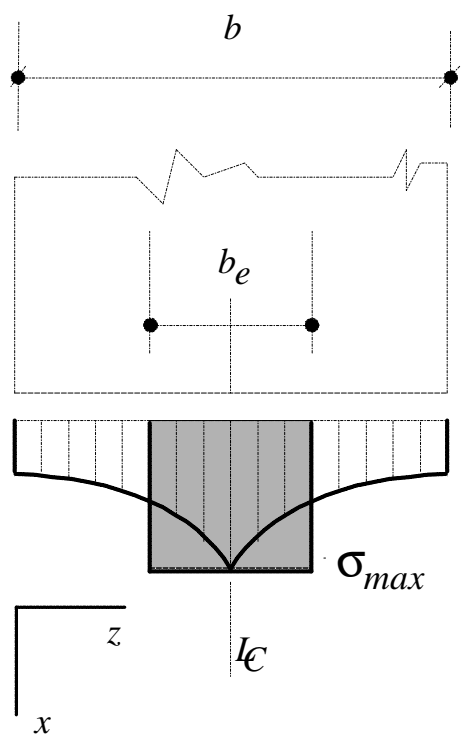

(b)

Fig.2.2 - Largura Efetiva de Chapa Colaborante em Flanges Livres.

Schade[18] desenvolveu a solução da Eq.2.2 para diversos tipos de carregamentos. Embora tenha utilizado várias hipóteses simplificadoras —entre elas a de largura efetiva constante ao longo do comprimento da viga e equiespaçamento dos reforços paralelos_-, os gráficos e tabelas desenvolvidos representam uma maneira prática muito utilizada na determinação da largura efetiva da chapa colaborante.

\subsection{MODELAGEM DA ESTRUTURA TRANSVERSAL.}

$\mathrm{Na}$ análise estática de qualquer tipo de estrutura, em especial das estruturas com geometrias complexas, a precisão dos resultados dependerá, e muito, da representatividade do modelo adotado para resolver o problema. No caso da estrutura transversal, por exemplo, considerar sua interação com os membros longitudinais pesados é essencial para se evitar uma estrutura superdimensionada. A Fig.2.3 mostra um compartimento tomado entre duas anteparas, que serão consideradas rígidas no plano próprio, ou seja, não se deformam na direção transversal do navio. Considerando apenas a sicorda da figura, por exemplo, sabemos que esta terá deflexão nula junto às anteparas e uma deflexão ao longo do compartimento. A deflexão da sicorda junto ao anel transversal $A$ é diferente da deflexão daquela junto ao anel $B$ e o efeito disto será uma diferente distribuição de momentos nos membros transversais em $A$ quando comparado com B. A distribuição de momentos fletores em cada anel, portanto, será 
influenciada pela posição que este ocupa em relação ao comprimento do compartimento. O cálculo desta influência será visto no item 2.2.2.1.

Outro fator importante na análise da estrutura transversal é sua interação com o chapeamento. Isto porque um modelo contendo somente os perfis, distribuídos longitudinal e transversalmente no compartimento, se distancia em muito da realidade da estrutura secundária do navio. É necessário considerar também a existência do chapeamento, dado que este contribui significativamente para a rigidez quando uma caverna tenta se deslocar em relação a outra.

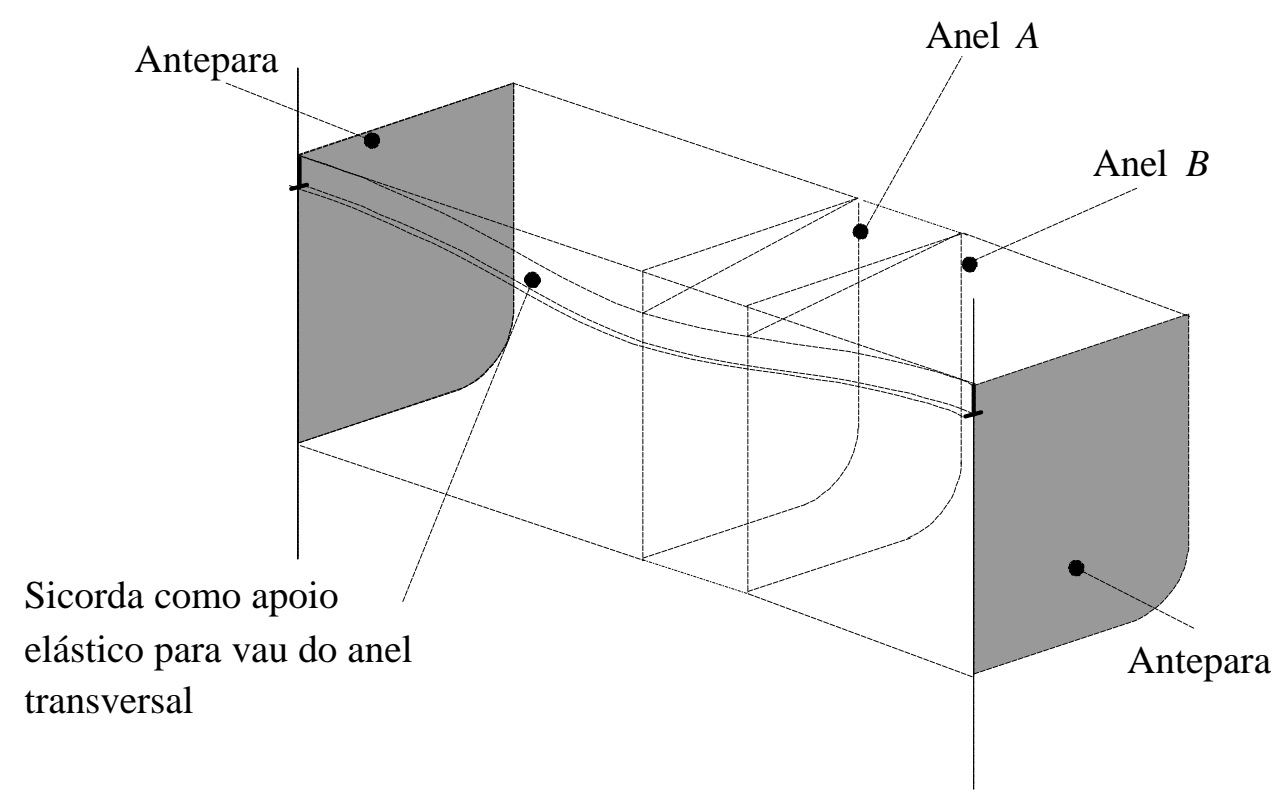

\section{Fig.2.3 - Exemplo de Interação entre Anéis e uma Sicorda.}

Assim, para determinar tensões e deslocamentos na estrutura transversal, um bom modelo deve observar a sua interação com o restante da estrutura. Nestes termos, um modelo tridimensional, considerando o compartimento inteiro entre as anteparas, pode ser a solução para o estudo da estrutura transversal. Paga-se o preço de um modelo complexo, que para os ciclos iniciais de projeto incorreria em grande demanda de tempo para ajustar a estrutura dentro dos valores admissíveis de tensões. Para elaborar a Ref.[19], por exemplo, os autores demoraram aproximadamente dois meses, o mesmo valendo para a Ref.[20], com conseqüência óbvia nos custos. Um modelo bidimensional —reduzindo-se assim o problema para um estrutura plana— desde que bem elaborado pode fornecer resultados similares aos obtidos pelo modelo anterior a um custo menor e de uma 
forma mais simples. Vamos analisar, portanto, as principais características que os modelos citados devem possuir para bem representar a estrutura real.

\subsubsection{MODELO TRIDIMENSIONAL.}

Junto com a evolução dos computadores, poderosos programas de cálculo estrutural ${ }^{1}$, baseados no MEF, foram colocados no mercado, tornando possível a análise de estruturas complexas —como a estrutura secundária do navio.

O modelo tridimensional considera um compartimento estrutural, que pode ser limitado por duas anteparas ou, por exemplo, por uma antepara e uma caverna gigante. Considerações de simetria de comportamento da estrutura, de carregamento e de geometria, permitem que analisemos apenas um bordo da seção. Admitindo ainda que os compartimentos adjacentes possuam comprimentos e carregamentos semelhantes ao do compartimento analisado, podemos considerar os longitudinais pesados engastados nos extremos do compartimento estrutural adotado.

A modelagem desta estrutura é feita considerando-se os perfis pesados, tanto longitudinais como transversais, e o chapeamento, no qual se considera os longitudinais leves com suas áreas "diluídas" na espessura da chapa. Nesta abordagem os elementos longitudinais pesados são representados mais apropriadamente e o papel do chapeamento, como elemento de ligação entre os anéis, é melhor caracterizado em relação ao modelo bidimensional. Além disso, na modelagem tridimensional as cavernas que compõem o compartimento podem ser individualmente representadas quanto às propriedades geométricas e aos carregamentos. Os elementos longitudinais pesados e os anéis transversais são modelados como vigas enquanto o chapeamento é tratado como elemento de membrana.

Em geral, a maioria dos programas comerciais existentes possui em sua biblioteca um elemento de viga semelhante ao que será explicitado item 4.1. No cálculo da matriz de rigidez desse elemento é utilizado o momento de inércia à flexão em relação aos eixos centrais, que definem também os planos de carregamentos para o elemento, conforme mostra a Fig.2.4. No entanto, na construção naval predominam os perfis assimétricos que, juntos com a chapa colaborante, trazem-lhes uma dupla excentricidade. A flexão —que na realidade

1 SAP IV, ANSYS, NASTRAN, mais recentemente SAP90, ALGOR e outros . 
é oblíqua para esses perfis - é, portanto, tratada de modo simplificado, admitindo-se o momento de inércia em relação ao eixo baricêntrico paralelo ao chapeamento. Essa aproximação é ilustrada na Fig.2.5 e, de acordo com Fusco[2], não produz diferenças significativas em relação ao comportamento real.

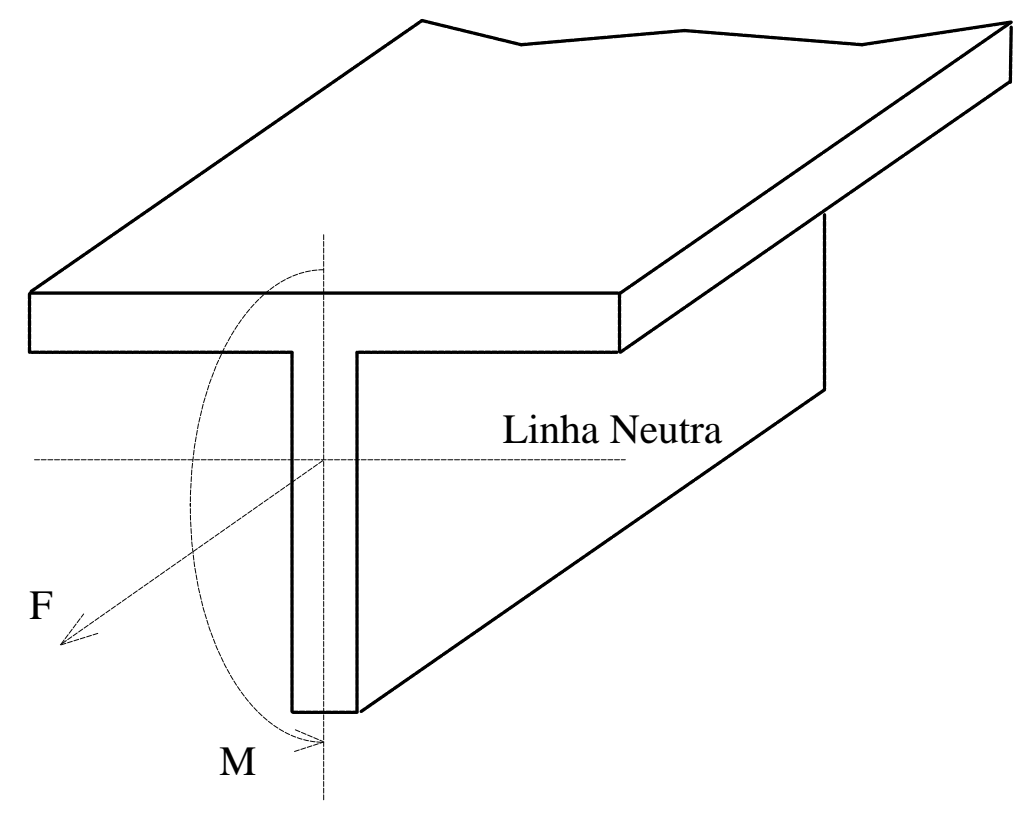

Fig.2.4 - Eixos Centrais do Perfil.

Ainda em relação aos elementos de viga, sabe-se que sua representação geométrica é feita por uma linha coincidente com seu eixo neutro. Em consequência, na discretização da estrutura os nós que definem os elementos de viga são os mesmos utilizados na definição do elemento de membrana, o que leva a uma modificação em relação à geometria real. Assim, no cálculo do momento de inércia da seção, considera-se o perfil associado à sua chapa colaborante enquanto para a área, inclui-se apenas a do perfil, já que elementos de viga e de membrana compartilham nós comuns. Evita-se, deste modo, computar o dobro da área de chapa no cálculo da rigidez à extensão e compressão do painel reforçado. Buelta[21] apresenta estudo de um elemento de viga excêntrico, definindo uma opção de modelagem para chapeamentos reforçados na qual a aproximação anteriormente descrita não precisa ser adotada. 


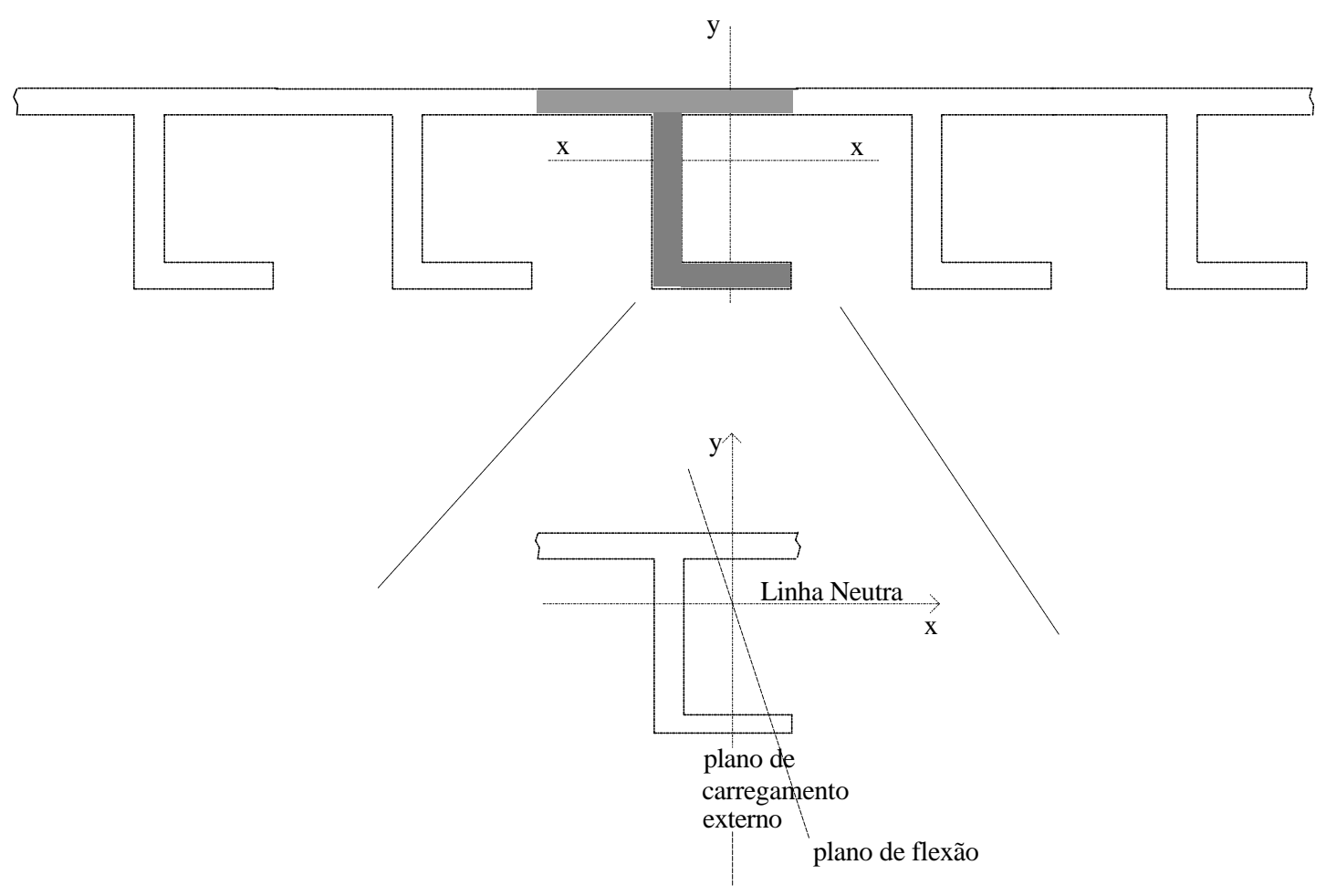

Fig.2.5 - Corte Típico de Chapeamento Reforçado por Cavernas.

\subsubsection{MODELO BIDIMENSIONAL.}

O modelo bidimensional consiste numa simplificação no tratamento da estrutura transversal. Considera-se aqui que uma porção da estrutura contendo o anel transversal é suficiente para o cálculo de deformações e tensões na estrutura, diferentemente do modelo apresentado no item 2.2.1 onde foi necessário considerar o compartimento inteiro para determinar os esforços nas cavernas.

Conforme vimos no capítulo anterior, esta idéia não é recente e os primeiros trabalhos — Refs.[4], [5], [7], [8], [9] e [10]— sobre a estrutura transversal já a consideravam em um modelo plano. Embora isto se deva em grande parte à limitação imposta pela inexistência de um ferramental matemático prático —os primeiros programas para resolução de estruturas surgiram no final da década de 50-, talvez esse seja o modelo mais intuitivo para a estrutura transversal.

O trabalho apresentado por Bruhn[5] demonstrava preocupações no tratamento do modelo bidimensional que não iam além do plano teórico, face às limitações de cálculo então existentes. A grande capacidade de cálculo das 
máquinas disponíveis e a existência de técnicas como o MEF nos permitem hoje elaborar e resolver um modelo semelhante ao apresentado por Bruhn.

No modelo utilizado para desenvolver o programa TRANSEC procuramos reproduzir as interações com a estrutura longitudinal e com o chapeamento.

A interação que existe entre o anel transversal e os longitudinais deve ser tratada de modo diferenciado quando se considera os longitudinais leves e os pesados.

A interação dos longitudinais leves com o anel tranversal pode ser modelada facilmente. Neste caso, como a rigidez à flexão do anel é muitas vezes superior à rigidez à flexão do longitudinal leve, é fácil concluir que o anel serve de apoio, praticamente indeslocável, para o longitudinal leve entre dois anéis adjacentes. Considerando que os anéis estão igualmente espaçados pode-se calcular o longitudinal leve, com razoável precisão, admitindo-o engastado em dois anéis adjacentes.

No caso da interação do anel com os longitudinais pesados esta hipótese não mais se aplica pois ambos possuem dimensões, e conseqüentemente rigidez à flexão, com valores muito próximos, o que torna difícil estabelecer quem serve de apoio a quem. A melhor maneira de se tratar o problema é admitir que o longitudinal pesado atua como um apoio elástico para o anel. A questão remanesce em qual valor deverá ser adotado para a constante elástica do apoio, e será discutida no próximo item.

Para analisar a interação entre a "fatia" que contém o anel e o chapeamento, vamos admitir que todo o compartimento, submetido às cargas de pressão, se deforma em duas fases distintas. Na primeira, todo o compartimento, entre anteparas, sofre uma flexão tal qual uma viga com os extremos engastados. No caso, o plano que contém a seção transversal se desloca, mantendo o seu contorno indeformado, e gira em torno de um eixo ortogonal ao comprimento do navio. Após sofrer esta deformação podemos imaginar que, nesta posição de referência, a seção completa a segunda fase, se deformando em seu próprio plano, fletindo os elementos que compõem o anel.

Pensando-se deste modo, a primeira componente de deformação é devida à flexão de uma viga da qual tiramos uma fatia: o anel que está sendo analisado. Neste caso, como na teoria simples de viga no plano, a resultante das forças na fatia isolada deve ser equilibrada pela resultante das tensões de cisalhamento: a 
força cortante. Logo, quando cortamos a fatia não devemos pensar que as forças nela atuantes se originam somente das cargas de pressão e eventuais carregamentos internos. De acordo com o exposto, deverá haver também uma distribuição de tensões cisalhantes ao longo do chapeamento e nos perfis pesados, com resultante na direção vertical equilibrando a resultante das forças de pressão lateral atuantes na estrutura. Sendo o modelo uma viga em flexão, a distribuição destas tensões de cisalhamento segue modelo idêntico ao da distribuição das tensões de cisalhamento primárias, pois trata-se da flexão de um trecho da viga-compartimento limitada pelas anteparas, conforme mostra a Fig.2.6.

Esse equilíbrio ${ }^{1}$ representa a hipótese fundamental do modelo apresentado neste trabalho e pode ser obtido de modo simples. Considerando a componente vertical das forças atuantes na estrutura, representadas na Fig.2.7, tem-se:

$$
P+Q+\sum_{i} R_{i}=0
$$

sendo

$$
Q=\int_{\text {contorno }} t \cdot \tau \cdot \operatorname{sen}(\alpha) \cdot d c
$$

a resultante das forças de cisalhamento.

$$
P=\int_{\text {contorno }} s \cdot p(c) \cdot \cos (\alpha) \cdot d c
$$

a resultante das forças de pressão.

$R_{i}$ são apoios elásticos representando os longitudinais pesados; $s$ e $t$ são, respectivamente, o espaçamento entre cavernas e a espessura do chapeamento.

Observando-se hipótese fundamental e a Eq.2.3 chegamos a

$$
\sum_{i} R_{i}=0
$$

\footnotetext{
${ }^{1}$ Este procedimento foi utilizado no projeto de navios hoje em operação. Refs.[22] e [23].
} 


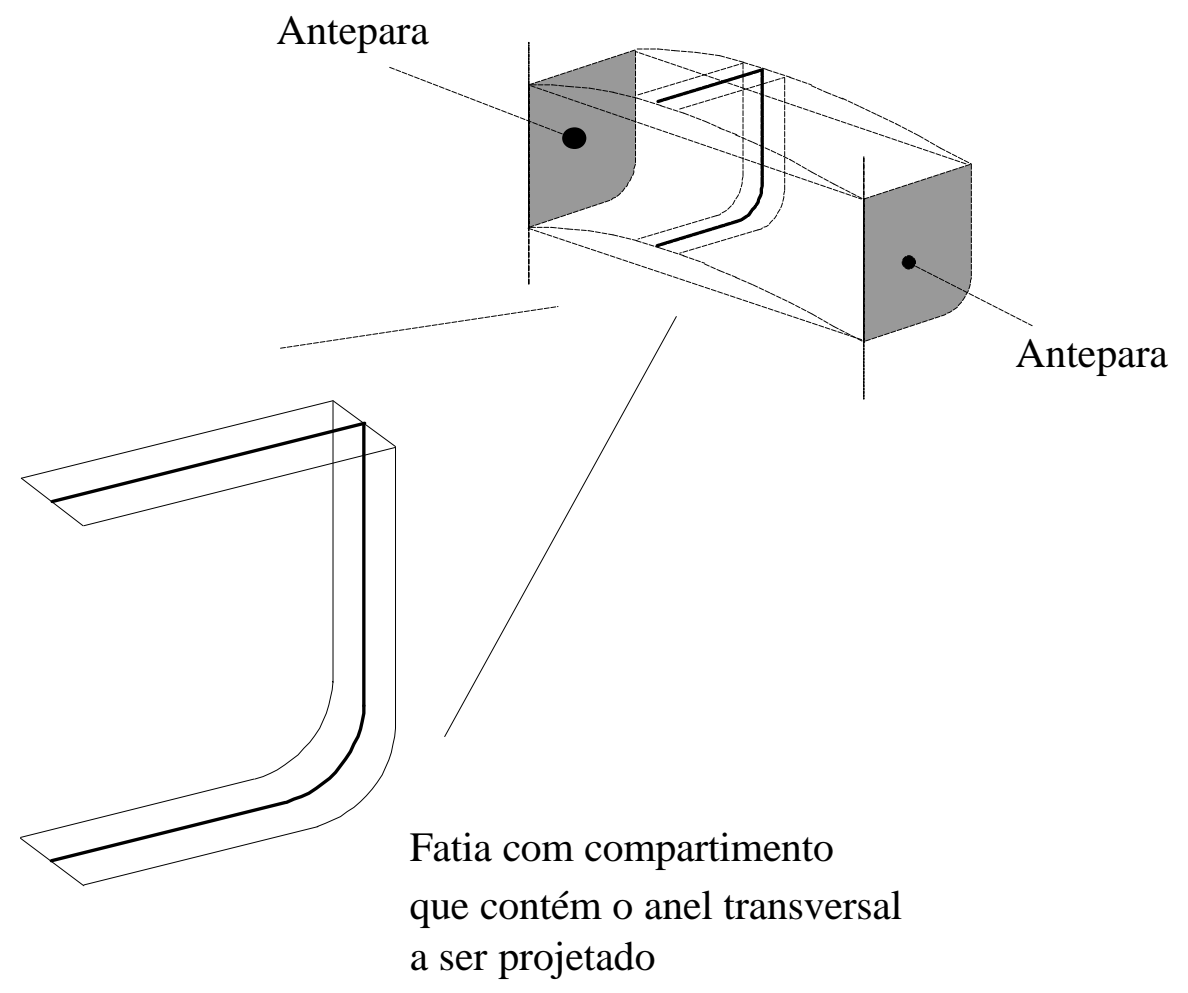

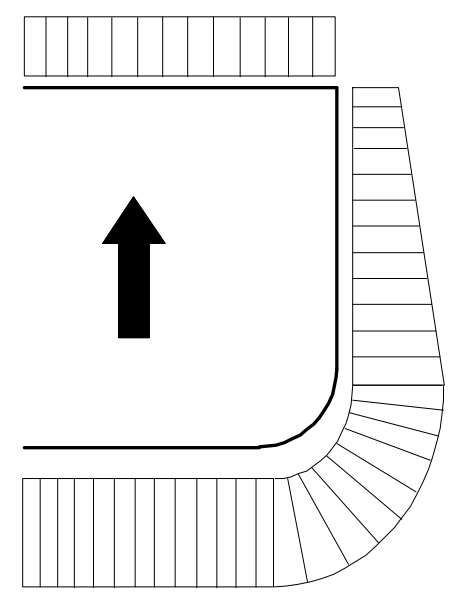

Resultante das forças

de pressão

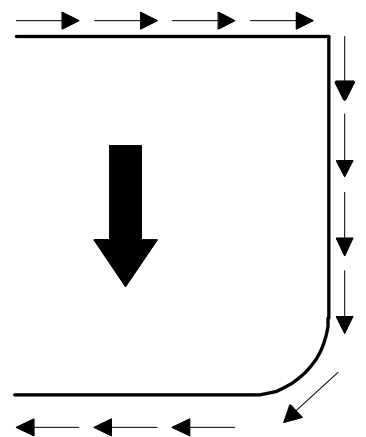

Resultante das forças

de cisalhamento

Fig.2.6 Resultantes no Anel da Viga-Compartimento sob Flexão. 


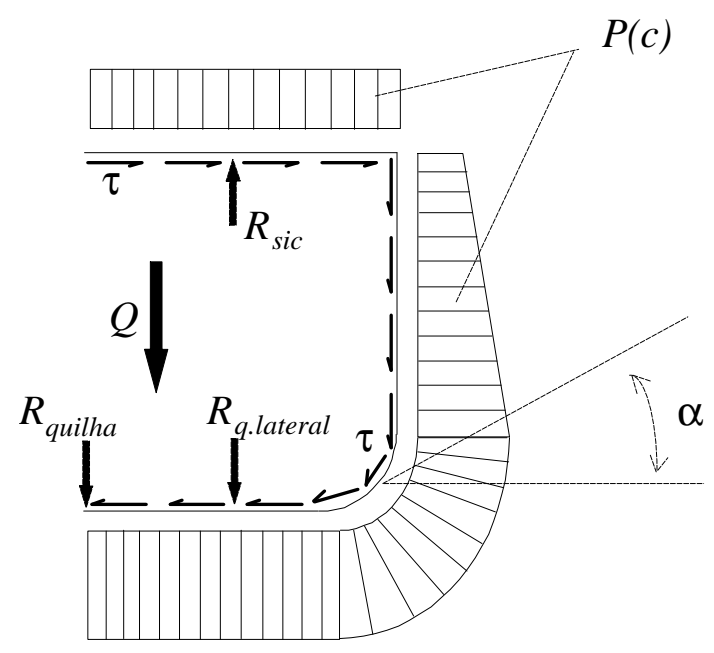

Fig.2.7 - Carregamento Típico do Anel Transversal.

Admitindo um comportamento linear para a estrutura, cada reação $R_{i}$ pode ser decomposta na forma

$$
R_{i}=R_{i}^{\text {pressão }}+\lambda \cdot R_{i}^{\text {cisalhamento }}
$$

sendo $\lambda$ uma constante de ajuste para satisfazer a Eq.2.6.

Logo:

$$
\lambda=-\frac{\sum_{i} R_{i}^{\text {pressão }}}{\sum_{i} R_{i}^{\text {cisalhamento }}}
$$

O valor da constante $\lambda$ pode ser determinado pelo seguinte procedimento:

- calcula-se $\sum_{i} R_{i}^{\text {pressão }}$ com a estrutura submetida somente às forças de pressão.

- para a distribuição de cisalhamento expressa na Eq.2.9, com força cortante unitária, calcula-se $\sum_{i} R_{i}^{\text {cisalhamento }}$ com a estrutura submetida somente ao carregamento de cisalhamento.

- determina-se o fator $\lambda$ e finalmente a estrutura pode ser calculada com a superposição dos carregamentos de pressão e $\lambda *$ cisalhamento. 
A distribuição das tensões de cisalhamento adotada é dada por

$$
\tau=\frac{Q \cdot m_{s}}{I . t}
$$

sendo

$Q$ - força cortante atuando na seção;

$m_{s}$ - momento estático em relação à linha neutra

I - momento de inércia da seção;

$t$ - espessura do chapeamento no ponto onde se deseja o valor da tensão de cisalhamento.

Sendo I constante e $Q$ arbitrário —adotado igual a 1 -, podemos calcular a força cisalhante por unidade de comprimento pela equação

$$
F_{c i s}=t . \tau=\frac{m_{s}}{I}
$$

Para seções transversais simples, o cálculo das tensões de cisalhamento por conseguinte da força cisalhante- pode ser facilmente executado. No entanto, as seções transversais dos navios geralmente apresentam células fechadas para as quais a Eq.2.10 não pode ser utilizada. Para estes casos a solução é encontrada resolvendo o problema em partes e depois superpondo os valores encontrados ${ }^{1}$. Esta metodologia é útil para o cálculo manual das tensões de cisalhamento em vigas com poucas células. Nos casos em que a seção transversal apresenta muitas células, o volume de cálculo inviabiliza a utilização deste método. Como o cálculo dessas tensões é fundamental para aplicação do modelo aqui exposto, no capítulo 4 será apresentado um procedimento para calculá-las numericamente.

Uma última consideração sobre o chapeamento diz respeito aos pequenos deslocamentos, na estrutura real, que ocorrem no plano das chapas, o que torna costados e conveses extremamente rígidos a deslocamentos tangenciais à chapa. Por isso, quando necessário, vamos considerar essa rigidez no modelo através de um elemento de apoio elástico na direção do plano da chapa, conforme

\footnotetext{
${ }^{1}$ A Ref.[17] detalha este procedimento.
} 
exemplificado na Fig.2.8. O cálculo deste apoio pode ser feito de modo análogo ao utilizado para os longitudinais pesados, descrito no próximo item.

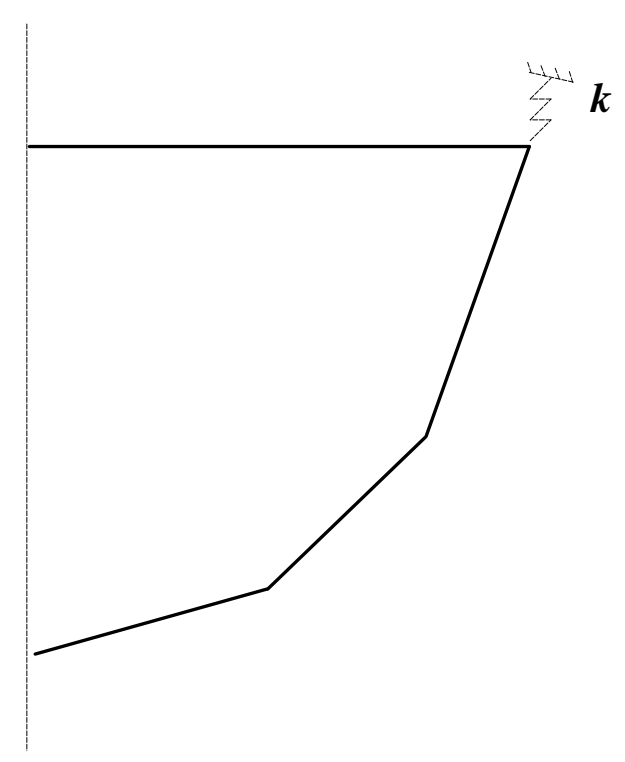

Fig.2.8 - Exemplo de Apoio Elástico para Simular Rigidez do Costado.

\subsubsection{CÁLCULO DO APOIO ELÁSTICO DOS LONGITUDINAIS.}

Conforme visto anteriormente, para representar a interação entre os longitudinais e as cavernas podemos admitir aqueles como apoios elásticos destas. $\mathrm{O}$ cálculo do coeficiente de rigidez, aqui chamado de $k$, merece especial atenção visto que os resultados obtidos pelo modelo dependem do valor deste coeficiente. Uma forma de determinar essa constante é admitir o elemento longitudinal engastado nas anteparas que delimitam o compartimento. Aplicandose uma força unitária na direção da alma do perfil no ponto de cruzamento do anel com o longitudinal, para um anel localizado a uma distância $a$ de um dos extremos do compartimento de comprimento $L$, conforme ilustrado na Fig.2.9, obtem-se o valor da constante por

$$
k=\frac{3 E I(L+2 a)^{2}}{2(L-a)^{2} \cdot a^{3}}
$$

em que o cálculo do momento de inércia de área deverá considerar a área do perfil com a chapa colaborante associada. Como regra para o cálculo desta largura de chapa é comum utilizar-se o método de Shade[18]. 


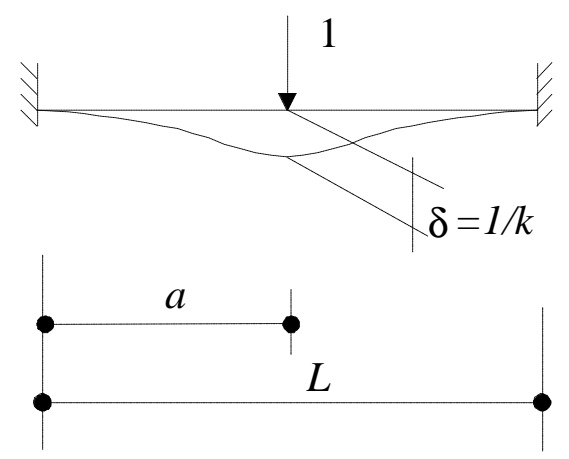

Fig.2.9 - Coeficiente de Mola para Carga Concentrada.

Esse cálculo, no entanto, é conservador, uma vez que ao longo do compartimento existem outros anéis que também interagem com os longitudinais. Cada anel existente no compartimento impõe um deslocamento no longitudinal na posição do anel em estudo. Assim, antes de considerar a interação entre o anel analisado e o longitudinal, este já possuirá um deslocamento $\delta^{\prime}$ devido aos outros anéis transversais. Nestas condições, vai-se calcular a constante de rigidez $k$ para um determinado longitudinal pesado considerando-o engastado nos extremos do compartimento. Além disso, será admitido que todos os elementos gigantes transversais possuem as mesmas características do ponto de vista de interação com o longitudinal pesado.

Na Fig.2.10, moldamos o longitudinal com cada gigante aplicando-lhe uma força $F$. Chamando de $v_{i}$ o deslocamento vertical na posição da caverna $i$, define-se rigidez equivalente do longitudinal na posição $i$ por

$$
k_{i}=\frac{F}{v_{i}}
$$

Supondo que a força $F$ seja a resultante de uma força distribuída uniforme $q$, conforme mostra a Fig.2.10, podemos escrever

$$
F=q . s
$$

Considerando as cavernas equi-espaçadas no compartimento, ao tomarmos $m$ espaçamentos, temos

$$
L=m \cdot s
$$

onde $L$ é o comprimento do compartimento e $s$ é o espaçamento das cavernas. 
O campo de deslocamentos de uma viga engastada submetida a um carregamento uniformemente distribuído, de intensidade $q$, é

$$
v(x)=\frac{q}{24 E I} \cdot\left(x^{4}-2 L x^{3}+L^{2} x^{2}\right)
$$

Como discretizamos a carga distribuída, os pontos onde aplicaremos Eq.2.4, representando as posições das cavernas, podem ser dados por

$$
x=n . s
$$

onde $n$ é a posição da caverna desejada para o cálculo de $v_{i}$ e conseqüentemente de $k_{i}$.

Substituindo as Eqs.2.13, 2.14, 2.15 e 2.16 na Eq.2.12 obtemos

$$
k_{i}=k_{i}(m, n)=\frac{24 E I}{s^{3} n^{2}(m-n)^{2}}
$$

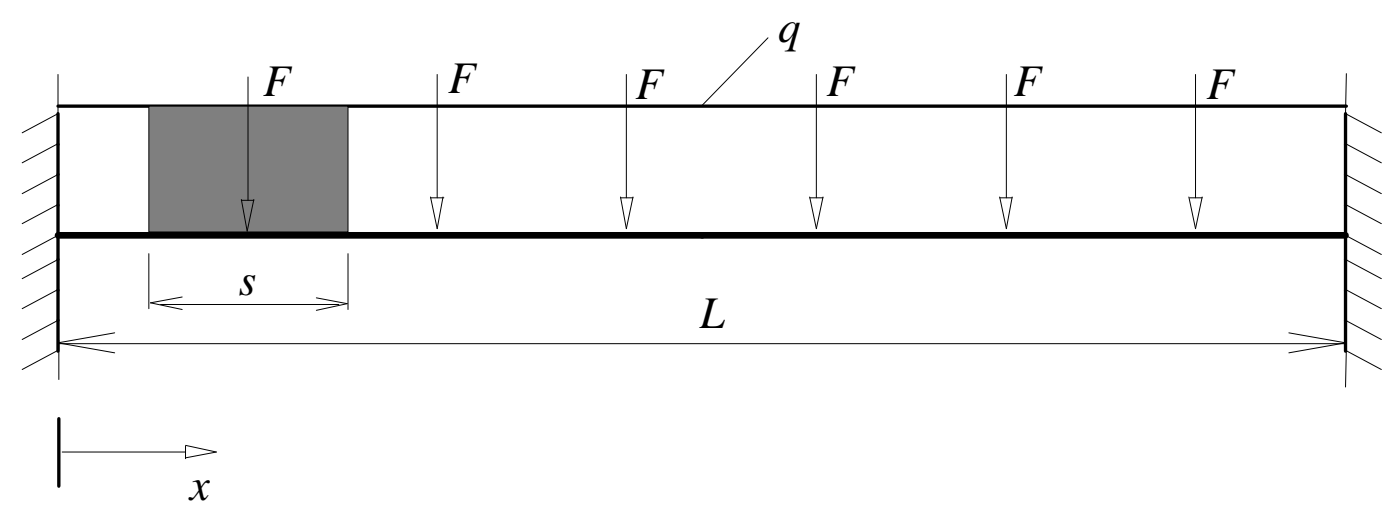

Fig.2.10 - Forças Equivalentes ao Carregamento Uniforme.

\subsubsection{INCLUSÃO DOS EXTREMOS RÍGIDOS.}

Na construção, as vigas que compõem a caverna são soldadas e, em geral, unidas por uma borboleta nas regiões com direções não coincidentes, como mostra a Fig.2.11. Esse efeito é significativo pois a viga adquire nesta região uma rigidez muito maior que a existente no vão, reduzindo o seu comprimento flexível. O cálculo do comprimento de viga sob o efeito desta rigidez maior pode ser feito considerando-se a altura e a largura da borboleta, conforme ilustrado na Fig.2.11. 


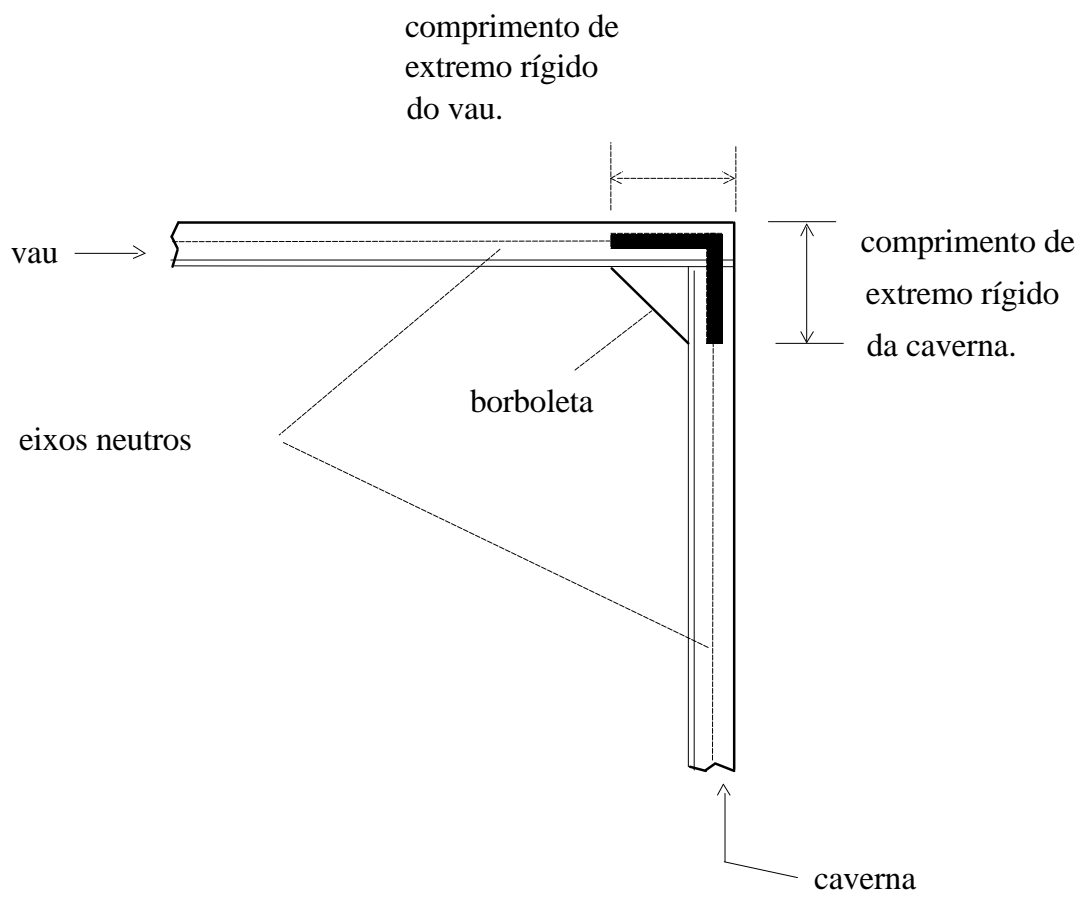

Fig.2.11 - Extremos Rígidos para Vigas com Almas Superpostas.

Outra situação muito comum na análise da estrutura transversal de embarcações é a presença de hastilhas na região do fundo. Essas hastilhas geralmente possuem furos para alívio de peso, trazendo para a modelagem o problema de como caracterizar a geometria desta região. Como na situação anterior, aqui também podemos utilizar o conceito de extremo rígido, arbitrando um conjunto de vigas rígidas e vigas que apresentem um vão flexível. As Figs.2.12 e 2.13 ilustram esse modelo para as hastilhas.

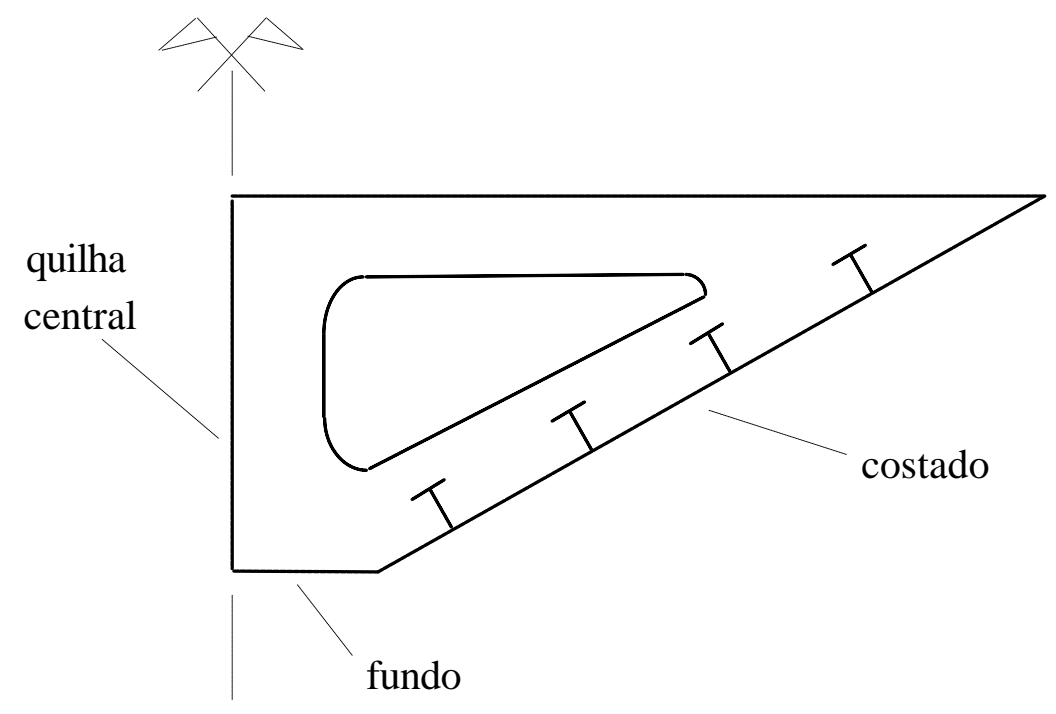

Fig.2.12 - Hastilha Vasada - Região do Fundo. 


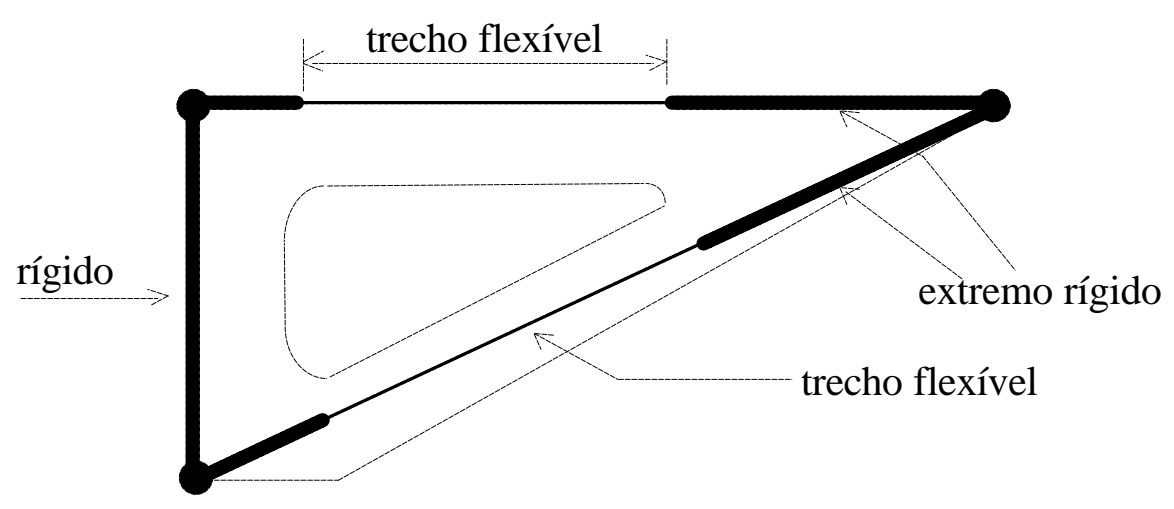

Fig.2.13 - Modelo para Hastilha: Elementos de Viga com Extremos Rígidos de Dimensões Finitas.

Concluindo, o modelo físico utilizado neste trabalho para a análise e síntese da estrutura transversal de embarcações possui as seguintes características:

é bidimensional, obtido extraindo-se do compartimento uma fatia que contém um anel transversal típico;

a resultante dos carregamentos devido a pressão lateral, na direção vertical, é integralmente equilibrada pela distribuição das tensões de cisalhamento na flexão da viga-compartimento.

apoios elásticos nas interseções do anel com os longitudinais pesados;

apoios elásticos, quando necessários, nas direções dos planos que contém conveses e costados.

Este modelo físico, em parte abstraído da teoria simples de viga, será utilizado como base para o algoritmo de cálculo implementado no programa TRANSEC, conforme será visto no capítulo 5. 


\section{CAPÍTULO 3}

\section{CRITÉRIOS DE PROJETO}

O projeto estrutural do navio, na evolução da construção naval, vem sendo realizado conforme as regras de Sociedades Classificadoras, normalmente aplicadas a navios mercantes, e através da mecânica das estruturas, principalmente para navios não convencionais, como por exemplo, os navios de guerra.

Enquanto as Sociedades Classificadoras propõem um receituário de fórmulas para projetar os componentes estruturais separadamente, quase sempre não permitindo ao usuário uma noção física do que está utilizando ${ }^{1}$, o "projeto racional" prega a utilização de um critério de projeto, ou seja, um procedimento destinado a avaliar a priori se uma determinada falha pode ou não ocorrer na estrutura. Neste trabalho as falhas consideradas são o escoamento do material e as flambagens: global da viga como coluna, e locais da alma e dos flanges. Torna-se importante, então, determinar os fatores que devem compor os critérios de projeto de modo a garantir segurança e funcionalidade ao navio.

O problema básico no cálculo da estrutura transversal é dimensionar os perfis que, submetidos ao carregamento, satisfaçam às restrições impostas pelo projetista. Uma estrutura submetida a diferentes carregamentos, apresenta diferentes estados de tensão, para um mesmo modelo. Invertendo, o mesmo carregamento atuando em diferentes modelos de uma mesma estrutura também

\footnotetext{
${ }^{1}$ Só recentemente as Sociedades Classificadoras passaram a admitir e utilizar análises pelo MEF.
} 
implica diferentes estados de tensão. Portanto, para estabelecer um critério de projeto que represente o estado real da estrutura devemos considerar simultaneamente os seguintes fatores:

- $\quad$ Os carregamentos de projeto da estrutura, que devem refletir os valores máximos de solicitação aos quais a embarcação estará submetida durante sua vida útil. Neste trabalho, consideraremos o carregamento aplicado estaticamente assim como a análise efetuada é estática. Eventuais efeitos dinâmicos devem ser aplicados na forma de uma fator de correção ao valor estático considerado.

- Os modelos para análise da estrutura. Dada a impossibilidade, quase sempre existente, de se resolver o problema real, torna-se necessário representá-lo através de um modelo físico que possa ser resolvido. O modelo deve ser representativo o suficiente para que os resultados obtidos possam ser aplicados ao problema real. Caso seja necessário, outras hipóteses simplificadoras podem ser introduzidas vizando facilitar —ou até mesmo viabilizar-o cálculo do modelo físico adotado.

- As tensões admissíveis. As incertezas provocadas pelas hipóteses introduzidas no modelo, bem como o grau de segurança associado à estrutura devem estar embutidos no que chamamos de coeficiente de segurança. Este coeficiente pode estar contabilizado no carregamento ou nas tensões admissíveis, sendo mais comum nesta última. Normalmente, para encontrarmos o valor admissível para as tensões consideramos o limite de escoamento e as cargas críticas de flambagem.

\subsection{MODELO UTILIZADO.}

O modelo físico adotado foi descrito no capítulo 2: bidimensional, composto por uma fatia do compartimento contendo o anel a ser analisado ou projetado. No modelo consideramos os longitudinais pesados atuando como apoios elásticos, com valor da constante de rigidez $k$ calculada para uma viga biengastada nas extremidades, de acordo com a Eq.2.17. Costados e conveses deverão ter, quando necessário, rigidez a deslocamentos no próprio plano simulados de modo semelhante aos elementos longitudinais. Como modelo matemático para o cálculo das tensões nos elementos que compõem o anel 
transversal utilizamos o MEF. As características dos elementos utilizados são colocadas no capítulo 4 e implementadas no módulo de cálculo — TRANSFIN_apresentado no capítulo 5. Devido ao uso deste módulo em particular, além das hipóteses inerentes ao MEF — Refs. [12] e [24]— estaremos limitados a:

a) a seção deverá ser discretizada em elementos prismáticos de viga, conforme exemplo mostrado na Fig.3.1, podendo ter extremos rígidos de dimensões finitas (E.R.D.F.).

b) carregamentos distribuídos, nas direções normal e tangencial variando linearmente ao longo do vão. O carregamento tangencial se origina na distribuição das tensões cisalhantes no casco descritas no capítulo 2 .

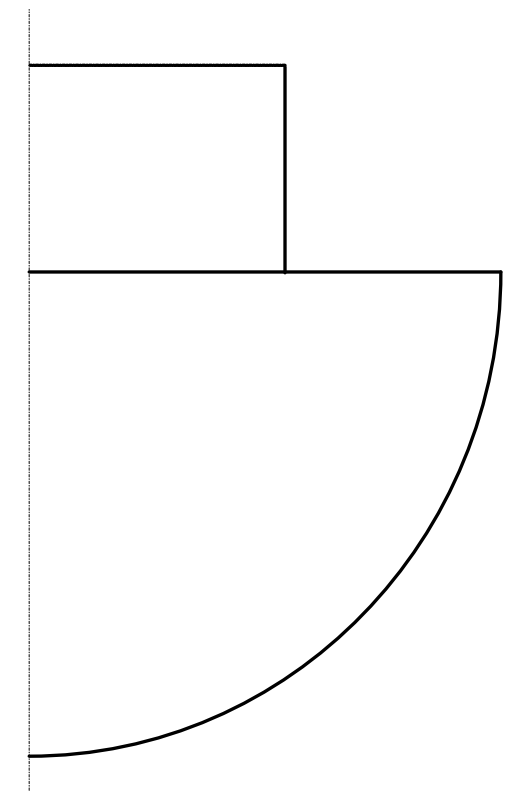

(a)

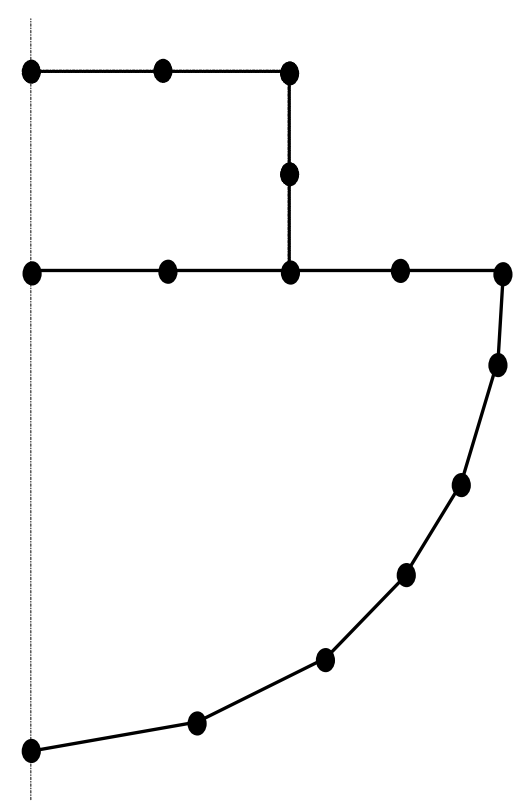

(b)

Fig.3.1 - Seção Transversal e Modelo Discretizado.

\subsection{CARREGAMENTOS DE PROJETO.}

Como carregamento vamos admitir a pressão hidrostática atuante na fatia retirada do compartimento. $\mathrm{O}$ valor da pressão multiplicado pela largura da fatia fornece o carregamento distribuído ao longo de cada elemento unifilar da viga que representa um trecho do anel transversal. As cargas tangenciais aos 
elementos de viga têm origem nas tensões de cisalhamento no chapeamento, calculadas conforme visto no item 2.2.2.

\subsection{TENSÕES ADMISSÍVEIS.}

A tensão admissível é um número com dimensão de tensão que funciona como indicador limitante de uma falha ou conjunto de falhas. Considera-se, então, que ocorrerá falha sempre que as tensões atuantes em qualquer ponto da estrutura superar o valor admissível. Para determinar as tensões atuantes em um ponto existem diversas teorias considerando o escoamento e a ruptura de materiais sob estado multiaxial de tensões. Uma teoria muito utilizada no comportamento de materiais dúcteis sob tensões combinadas é a que considera da máxima energia de distorção. Esta teoria será empregada neste trabalho para determinar o estado de tensões em um ponto da viga.

\subsubsection{TEORIA DA MÁXIMA ENERGIA DE DISTORÇÃO.}

Idealizada para materiais dúcteis e isótropos, esta teoria é baseada em conceitos de energia. Neste método, a energia elástica total é dividida em duas partes: a primeira é associada às variações volumétricas do material, e a outra é que provoca distorções por cisalhamento. Igualando a energia de distorção por cisalhamento no limite em tração simples à relativa à ação de tensões combinadas, fica estabelecido o critério de escoamento para tensões combinadas.

Pode-se demonstrar ${ }^{1}$ que a condição de escoamento para um material idealmente elástico em estado de tensão triaxial pode ser expressa, em termos das tensões principais, por

$$
\left(\sigma_{1}-\sigma_{2}\right)^{2}+\left(\sigma_{2}-\sigma_{3}\right)^{2}+\left(\sigma_{3}-\sigma_{1}\right)^{2}=2 \sigma_{e s c}^{2}
$$

Para o estado plano de tensão, de interesse neste trabalho, $\sigma_{3}=0$ e a Eq.3.1, sob forma adimensional, assume a forma

$$
\left(\frac{\sigma_{1}}{\sigma_{e s c}}\right)^{2}-\left(\frac{\sigma_{1} \cdot \sigma_{2}}{\sigma_{e s c}^{2}}\right)+\left(\frac{\sigma_{2}}{\sigma_{e s c}}\right)^{2}=1
$$

${ }^{1}$ Ref.[7]. 
Esta é a equação de uma elipse, representada na Fig.3.2. Qualquer ponto situado no interior desta elipse confere um comportamento elástico para o material. Pontos situados sobre a elipse ou fora desta indicam que o material se acha em escoamento.

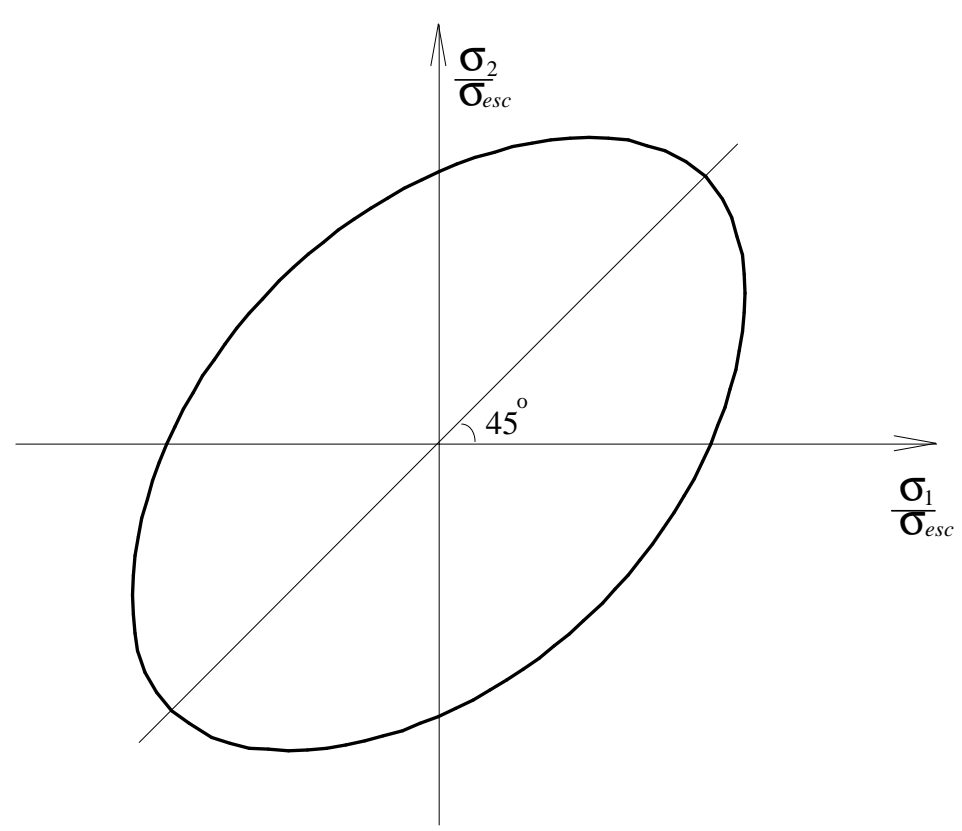

Fig.3.2 - Critério de Escoamento Baseado na Máxima Energia de Distorção.

Particularizando para a estrutura transversal, adotaremos como valor admissível $\sigma_{a d m}$ a tensão de escoamento reduzida de um fator de segurança $\boldsymbol{f} \boldsymbol{s}$ a critério do usuário. Assim, as tensões equivalentes na estrutura transversal podem ser determinadas pela equação

$$
\sqrt{\left(\sigma_{\text {Normal }}+\sigma_{\text {Flexão }}\right)^{2}+3 \tau^{2}} \leq \frac{\sigma_{e s c}}{f s}=\sigma_{a d m}
$$

sendo

$\sigma_{e s c}$ - tensão de escoamento do material.

$\sigma_{\text {Normal }}$ - tensão normal na viga.

$\sigma_{\text {Flexão }}$ - tensão de flexão na viga.

$\tau$ - tensão de cisalhamento. 
Esta teoria é chamada também de teoria de escoamento de Huber-Hencky-Mises, ou simplesmente, condição de escoamento de Von-Mises.

As tensões serão calculadas nos extremos do comprimento flexível das vigas e também na seção onde o momento fletor for máximo. $\mathrm{Na}$ seção transversal, as tensões equivalentes serão calculadas nos pontos indicados na Fig.3.3. O ponto 2 está sobre a linha neutra, onde a tensão de cisalhamento é máxima. Nos pontos 1 e 3 os valores das tensões de flexão não são máximos seriam nas fibras externas dos flanges. Os pontos 1 e 3 foram escolhidos porque as tensões de cisalhamento neste pontos são maiores que nas fibras externas dos flanges. Como a variação da tensão de flexão na espessura do flange (ou do chapeamento) é pequena, é mais razoável compor as tensões nesses pontos.

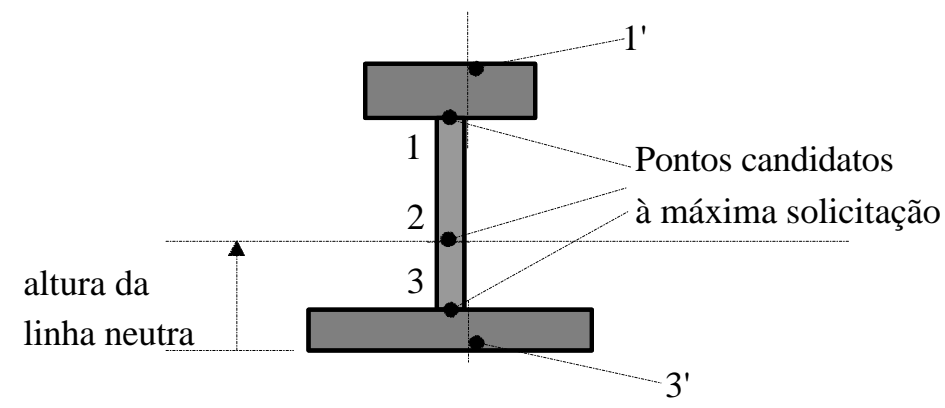

Obs: os pontos 1' e 3' podem ser pontos de máximas tensões de cisalhamento dependendo das relações entre as espessuras alma/flange ou alma/chapa.

Figura 3.3 - Pontos Escolhidos para Cálculo das Tensões. 


\section{CAPÍTULO 4}

\section{MODELO DE CÁLCULO}

O modelo de cálculo para determinar os esforços na estrutura idealizada no capítulo 2 é formado, basicamente, por elementos de viga e elementos finitos de cisalhamento. O elemento de viga possibilita o cálculo dos esforços solicitantes na estrutura enquanto o elemento finito de cisalhamento tem por função determinar a distribuição do fluxo de cisalhamento que equilibra verticalmente as cargas laterais aplicadas no anel, conforme procedimento descrito no item 2.2.2. Esses elementos foram incorporados à biblioteca do módulo TRANSFIN, detalhado no próximo capítulo.

O problema fundamental na análise de uma estrutura discretizada é resolver a equação de equilíbrio abaixo:

$$
[\mathrm{K}] .\{\delta\}=\{\mathrm{P}\}+\{\mathrm{Po}\}
$$

sendo

[K] - matriz de rigidez da estrutura.

$\{\delta\}$ - vetor de deslocamentos nodais da estrutura.

$\{\mathrm{P}\}$ - vetor de carregamentos nodais da estrutura.

$\{\mathrm{Po}\}$ - vetor de carregamentos nodais equivalentes da estrutura.

Sendo $\{\delta\}$ a incógnita do problema, a solução resume-se em resolver o sistema de equações embutido na Eq.4.1. Para tanto, vamos admitir regime elástico linear para o material e também considerar pequenas deflexões. Assim, o comportamento da estrutura pode ser analisado como linear e com isso os 
deslocamentos podem ser superpostos. Antes, porém, é necessário se conhecer a matriz de rigidez $[\mathrm{K}]$ e também os vetores de carregamentos $\{\mathrm{P}\}$ e $\left\{\mathrm{P}_{\mathrm{o}}\right\}$.

\subsection{ELEMENTO DE VIGA.}

Uma viga pode ser definida como um membro estrutural longo, esbelto, geralmente sujeito a carregamentos cujos efeitos significativos são os de flexão. Entretanto, em muitos casos a altura do perfil chega a ser $10 \%$ do comprimento da viga — por exemplo, na quilha do navio_, fazendo com que os efeitos da força cortante produzam deslocamentos transversais à seção da viga da mesma ordem de grandeza que os produzidos pelos momentos fletores. É de bom tom, portanto, incluir este efeito na matriz de rigidez do elemento.

A Eq.4.1 traduz o equilíbrio da estrutura. Logo, todos os elementos que a compõe estão em equilíbrio e, para um elemento, podemos escrever

$$
[k] .\{\delta\}=\{p\}+\left\{p_{o}\right\}
$$

sendo

[k] - matriz de rigidez do elemento.

$\{\delta\}$ - vetor de deslocamentos nodais do elemento.

$\{p\}$ - vetor de carregamentos nodais do elemento.

$\left\{p_{o}\right\}$ - vetor de carregamentos nodais equivalentes do elemento.

Resolver a Eq.4.1.a significa encontrar os deslocamentos nodais $\delta$. Para tanto é necessário conhecer a matriz de rigidez $[k]$ e os vetores de carregamentos $\{p\}$ e $\left\{p_{o}\right\}$.

O processo para determinar a matriz de rigidez e o vetor de carregamentos de uma estrutura formada por vigas, a partir de cada um dos membros que a compõe, é encontrado facilmente na literatura ${ }^{1}$. A matriz de rigidez $[k]$ do elemento de viga, necessária para reproduzir as características físicas do modelo —efeito do cisalhamento na flexão e inclusão de extremos rígidos—, no entanto,

\footnotetext{
1 Por exemplo, Refs. [12] e [24].
} 
raramente é encontrada na bibliografia especializada e por isso será aqui detalhada. Tratamento análogo será dado ao vetor de carregamentos $\left\{p_{o}\right\}$ do elemento.

\subsubsection{MATRIZ DE RIGIDEZ.}

Para determinar os coeficientes de rigidez da viga exibida na Fig.4.1, nas condições citadas no parágrafo anterior, será utilizado o método direto, ou seja, pela definição formal do coeficiente de rigidez $k_{i j}$. Assim, vamos impor um deslocamento unitário a um grau de liberdade (G.L.) e calcular os esforços, neste e nos outros graus de liberdade, necessários para manter em equilíbrio a viga deformada. Repetindo o procedimento para todos os graus de liberdade, montamos a matriz de rigidez do elemento.

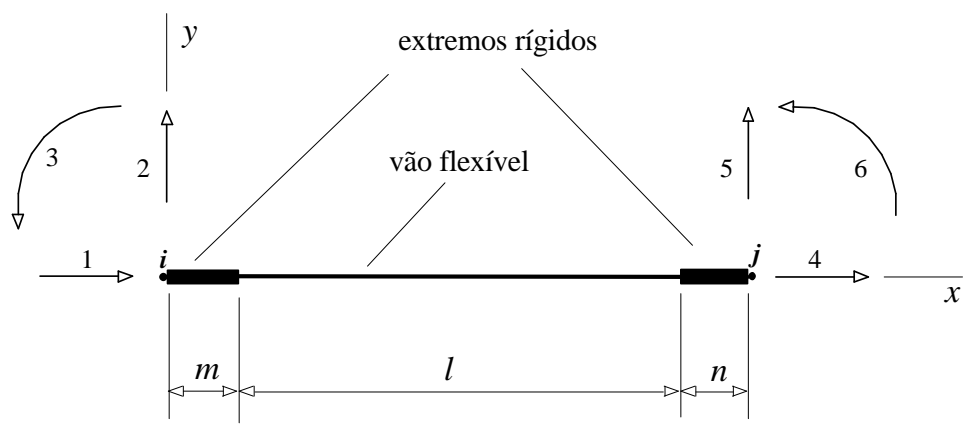

Fig.4.1 - Graus de Liberdade para Elemento de Viga no Plano.

A viga apresentada na Fig.4.1, posicionada em relação a um sistema de coordenadas locais, tem seu eixo centroidal coincidindo com o eixo $\boldsymbol{x}$, positivo de $\boldsymbol{i}$ para $\boldsymbol{j}$. Por definição, a rigidez de membro $\boldsymbol{k}_{i j}$ é a força que aparece no grau de liberdade $\boldsymbol{i}$ quando impomos um deslocamento (translação ou rotação) unitário no grau de liberdade $\boldsymbol{j}$, mantendo todos os outros deslocamentos nulos. Por exemplo, a Fig.4.2 ilustra a configuração de equilíbrio para um deslocamento unitário de translação da extremidade $\boldsymbol{j}$ na direção positiva de $\boldsymbol{y}$ enquanto todos os outros deslocamentos são nulos.

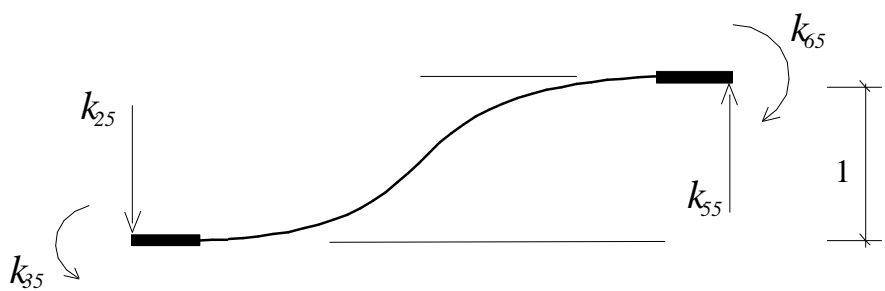

Fig.4.2 - Viga em Equilíbrio para Deslocamento Unitário no G.L. 5. 
A matriz será montada a partir dos coeficientes de rigidez ligados o nó $\boldsymbol{j}$, ou seja, vamos particionar a matriz segundo os coeficientes de rigidez ligados aos nós $\boldsymbol{i}$ e $\boldsymbol{j}$. Sendo [k] a matriz de rigidez do elemento, com ordem $6 \times 6$ em problemas planos, podemos escrever:

$$
[k]=\left[\begin{array}{l:l}
{\left[k_{i i}\right]} & {\left[k_{i j}\right]} \\
\hdashline\left[k_{j i}\right] & {\left[k_{j j}\right]}
\end{array}\right]
$$

onde os diversos $\left[k_{p q}\right]$ possuem ordem 3 x $3 . \mathrm{O}$ anexo $A$ apresenta o cálculo dos coeficientes da sub-matriz $\left[k_{j j}\right]$ apresentada na Eq.4.3.

$$
\left[k_{j j}\right]=\left[\begin{array}{ccc}
\frac{E A}{l} & 0 & 0 \\
0 & \frac{12 E I}{l^{3}(1+\phi)} & -\frac{6 E I(l+2 n)}{l^{3}(1+\phi)} \\
0 & -\frac{6 E I(l+2 n)}{l^{3}(1+\phi)} & \frac{E I\left((4+\phi) l^{2}+12 n l+12 n^{2}\right)}{(1+\phi) l^{3}}
\end{array}\right]
$$

De posse de $\left[k_{j j}\right]$ calculamos os outros $\left[k_{p q}\right]$ através das relações:

$$
\begin{aligned}
& {\left[k_{j i}\right]=\left[k_{j j}\right] .[L]} \\
& {\left[k_{i j}\right]=\left[k_{j i}\right]^{T}} \\
& {\left[k_{i i}\right]=\left[k_{i j}\right] .[L]}
\end{aligned}
$$

onde a matriz de ligação $[L]$, obtida através de relações de equilíbrio estático, é dada por

$$
[L]=\left[\begin{array}{rrr}
-1 & 0 & 0 \\
0 & -1 & -L \\
0 & 0 & -1
\end{array}\right]
$$

sendo $L$ o comprimento total da viga.

A matriz de rigidez da viga com extremos rígidos também poderia ser obtida a partir da matriz de rigidez de uma viga com seção constante. Por considerações de equilíbrio, conforme ilustrado na Fig.4.3, chega-se à mesma matriz exposta na Eq.4.3. Na figura os coeficientes $\underline{k}_{i j}$ são relativos à viga prismática enquanto os coeficientes $k_{i j}$ representam a barra com extremos rígidos. 

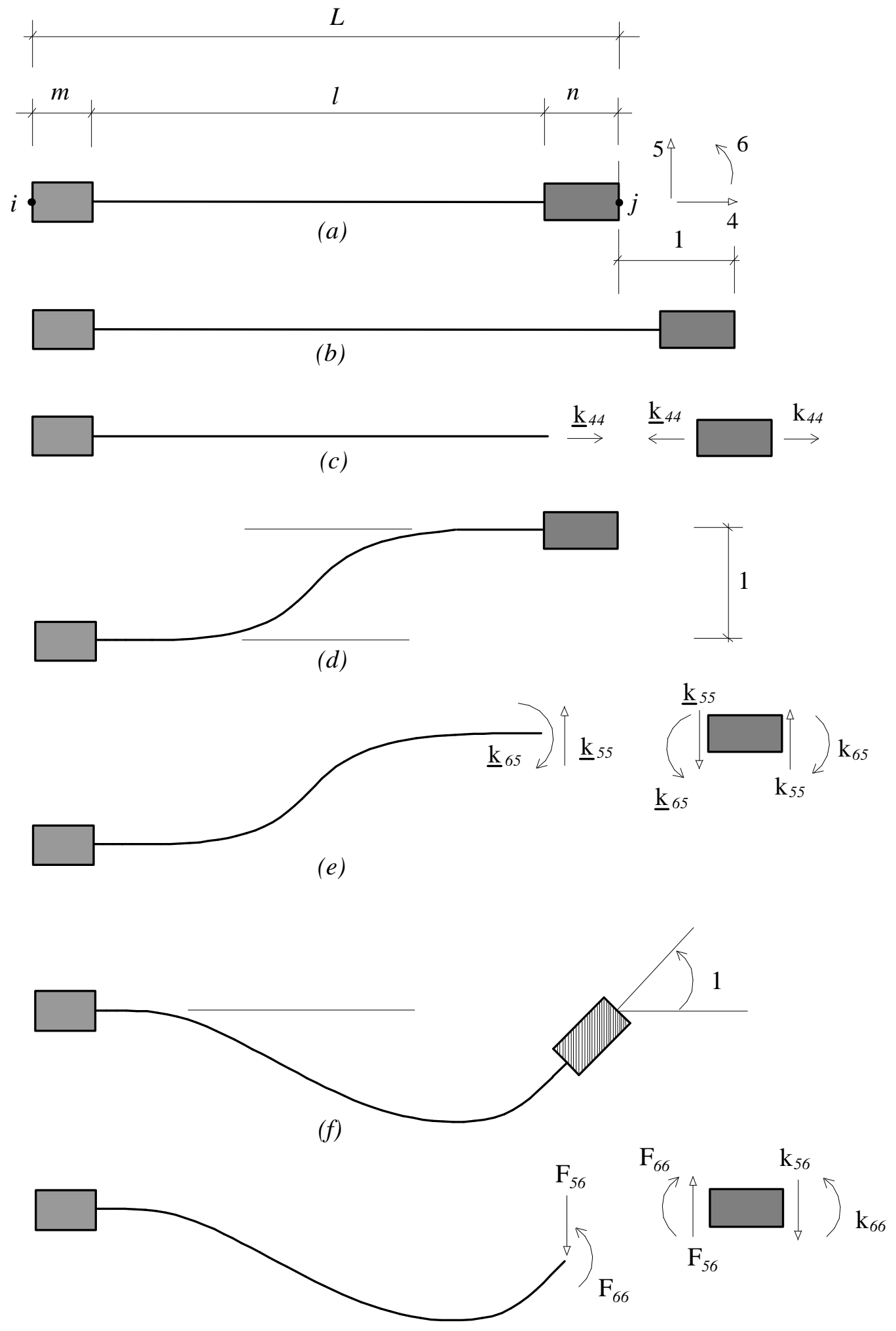

$(g)$

Fig.4.3 - Equilíbrio da Viga com Extremos Rígidos. 


\subsubsection{VETOR CARREGAMENTO PARA ELEMENTO DE VIGA.}

Dois tipos distintos de carregamento devem ser considerados na viga: as cargas que agem diretamente nos nós, conforme Fig.4.4(a), e as cargas que atuam no vão da viga, ilustradas na Fig.4.4(b). Esse tratamento diferenciado é porque as cargas nodais estão prontas para serem colocadas de imediato no vetor das ações (forças e momentos) a ser usado na solução, enquanto as cargas fora dos nós precisam ser "transportadas" para os nós. O "transporte" é feito considerando-se as reações de engastamento que as cargas não nodais produzem.

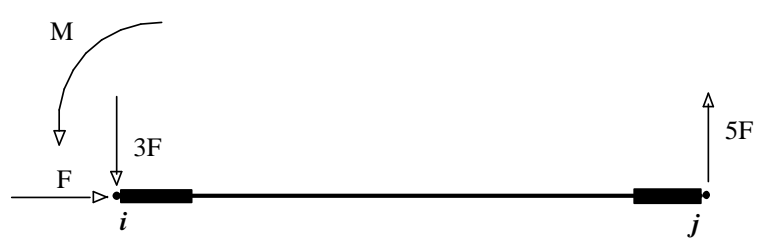

(a)

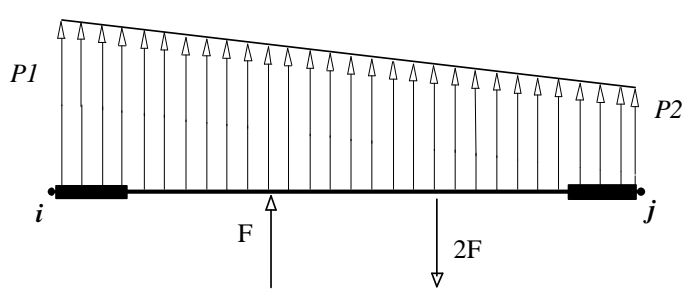

(b)

Fig.4.4 - Exemplos de Carregamentos na Viga.

Esse modelo de engastamento, exemplificado na Fig.4.5 tem por objetivo assegurar que os deslocamentos resultantes nos nós da barra sejam os mesmos deslocamentos produzidos pelas cargas reais. Invertendo o sentido das reações obtem-se as cargas nodais equivalentes.

$\mathrm{O}$ carregamento predominante nos elementos que formam a estrutura do navio é a pressão hidrostática lateral. No modelo de vigas essa pressão pode ser traduzida como um carregamento distribuído ao longo do elemento. 


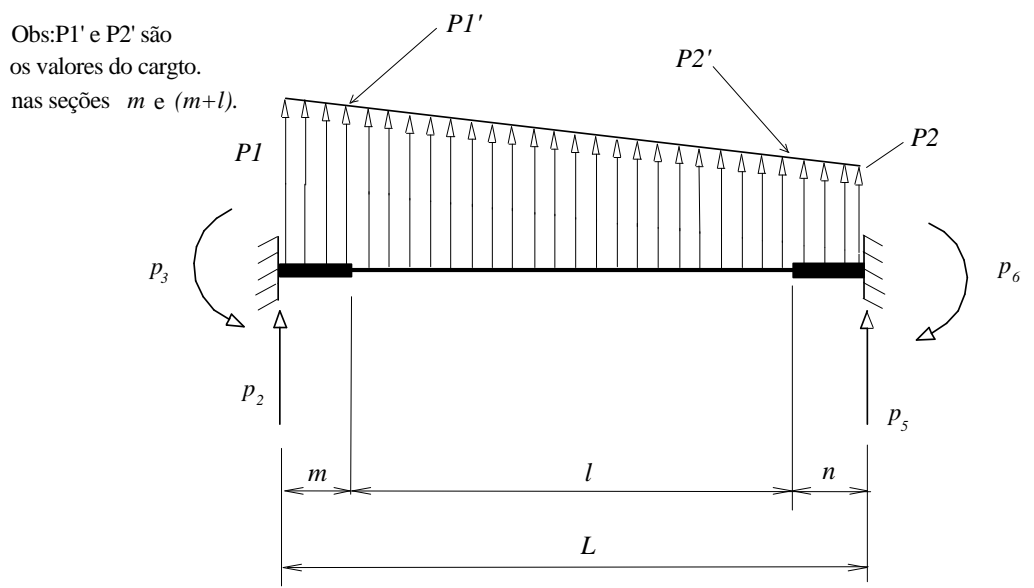

Fig.4.5 - Cargas Equivalentes para Carregamento Distribuído.

O cálculo das cargas nodais equivalentes pode ser feito conforme o procedimento executado para os coeficientes de rigidez. No entanto, para um carregamento distribuído, como o da Fig.4.5, o diagrama de momentos da estrutura real ${ }^{1}$ torna o volume de cálculos enfadonho. $\mathrm{O}$ processo alternativo apresentado para determinar os coeficientes de rigidez a partir dos valores conhecidos para uma viga prismática, ilustrado anteriormente na Fig.4.3, soa como uma opção razoável para o cálculo das cargas nodais equivalentes.

Vamos considerar a viga com extremos rígidos, em equilíbrio, apresentada na Fig.4.6. Os termos sublinhados são relativos a uma viga prismática de comprimento $l$. Para o carregamento apresentado na Fig.4.5 temos:

$$
\begin{aligned}
& P 1^{\prime}=P_{1}+\frac{\left(P_{2}-P_{1}\right) \cdot m}{L} \\
& P 2^{\prime}=P_{1}+\frac{\left(P_{2}-P_{1}\right) \cdot(m+l)}{L}
\end{aligned}
$$
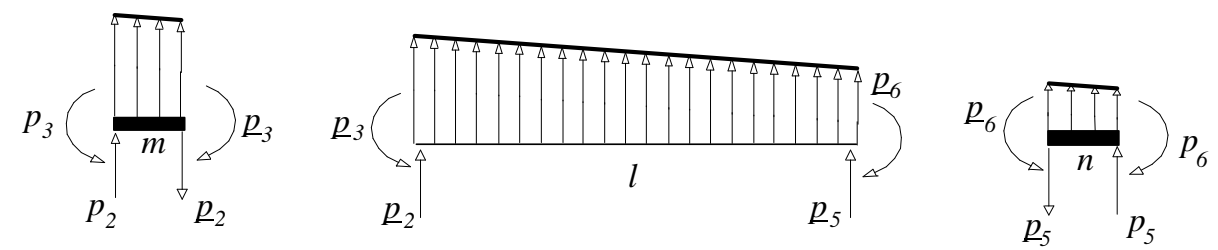

Fig.4.6 - Cargas Equivalentes para Viga com Extremos Rígidos.

\footnotetext{
${ }^{1}$ Necessário para determinar os esforços pelo Método da Carga Unitária.
} 
As cargas equivalentes para o vão flexível, representadas na Fig.4.6, tomam a forma:

$$
\begin{aligned}
& \underline{p}_{2}=\frac{l}{20}\left(7 P 1^{\prime}+3 P 2^{\prime}\right) \\
& \underline{p}_{5}=\frac{3 \cdot l}{20}\left(P 1^{\prime}-P 2^{\prime}\right) \\
& \underline{p}_{3}=\frac{P 1^{\prime} \cdot l^{2}}{20}+\frac{P 2^{\prime} \cdot l^{2}}{30} \\
& \underline{p}_{6}=-\frac{P 1^{\prime} \cdot l^{2}}{30}-\frac{P 2^{\prime} \cdot l^{2}}{20}
\end{aligned}
$$

Definindo $P 1$ e $P 2$ como sendo os valores dos carregamentos juntos aos nós $i$ e $j$, respectivamente, conforme ilustra a Fig.4.5, podemos estabelecer a relação

$$
p_{3}=\underline{p}_{3}+\underline{p}_{2} \cdot m+\frac{1}{3}\left(\frac{P_{2}-P_{1}}{L}\right) m^{3}+P_{1} \cdot \frac{m^{2}}{2}
$$

pelo somatório de momentos no extremo $m$.

Considerando-se o equilíbrio vertical chegamos a

$$
p_{2}=\underline{p}_{2}-\frac{m^{2}}{2}\left(\frac{P_{2}-P_{1}}{L}\right)-P_{1} \cdot m
$$

Analogamente para os G.L. 5 e 6 obtemos as relações

$$
p_{5}=\underline{p}_{5}-\left(\frac{P_{2}-P_{1}}{2 L}\right) \cdot(l+m) \cdot n-\left(P_{2}+P_{1}\right) \cdot \frac{n}{2}
$$

e

$$
p_{6}=\underline{p}_{6}+\underline{p}_{5} \cdot n+\frac{P_{1} n^{2}}{6}\left(1-\frac{m}{L}-\frac{l}{L}\right)+\frac{P_{2} n^{2}}{6}\left(1+\frac{m}{2 L}+\frac{l}{2 L}\right)
$$

Para os G.L. 1 e 4, admitindo um carregamento tangencial ao eixo da viga de valores $Q 1$ e $Q 2$ junto aos nós $\boldsymbol{i}$ e $\boldsymbol{j}$, respectivamente, podemos, de modo análogo ao efetuado para os outros G.L., estabelecer as seguintes relações: 


$$
p_{1}=Q_{1} \cdot\left(\frac{l}{3}-\frac{m^{2}}{2 \cdot l}+\frac{m}{2}\right)+Q_{2} \cdot\left(\frac{l}{6}+\frac{m^{2}}{2 . l}+\frac{m}{2}\right)
$$

$\mathrm{e}$

$$
p_{4}=Q_{1} \cdot\left(\frac{l}{6}-\frac{n \cdot m}{2 \cdot l}+\frac{m}{2}\right)+Q_{2} \cdot\left(\frac{l}{3}+n+\frac{n \cdot m}{2 \cdot l}+\frac{m}{2}\right)
$$

As Eqs.4.11 a 4.16 definem o vetor de carregamentos equivalentes para a viga. Esse vetor, somado ao vetor dos carregamentos nodais, fornece o vetor carregamento total. A matriz de rigidez, obtida a partir da Eq.4.3, e o vetor de carregamentos total caracterizam o elemento de viga que será implementado no módulo de cálculos TRANSFIN, conforme será visto no item 5.1.1.

\subsection{ELEMENTO FINITO DE CISALHAMENTO.}

As seções transversais das vigas apresentadas na Fig.4.7(a) são estaticamente determinadas para o cálculo da distribuição das tensões de cisalhamento, ou seja, pode-se aplicar a relação

$$
\tau=\frac{Q \cdot m_{s}}{I . t}
$$

sendo

$Q$ - força de cisalhamento;

$m_{s}$ - momento da área da parte cortada da seção onde a tensão está sendo calculada;

I - momento de inércia da área da seção transversal relativo à linha neutra;

$t$ - espessura na linha do corte.

As seções transversais do navio, no entanto, geralmente são hiperestáticas para o cálculo das tensões de cisalhamento e, nestes casos, a Eq.4.17 não pode ser aplicada. Quando o número de células é pequeno, a distribuição das tensões cisalhantes nas seções estaticamente indeterminadas pode ser calculada com relativa facilidade. Para seções com muitas células o volume de cálculos inviabiliza o processo. A solução numérica surge, então, como forma de tornar o cálculo sistemático, independente da forma seção transversal, seja ela isostática ou hiperestática.

Sob este ponto de vista, desenvolveu-se um elemento finito para cálculo das tensões de cisalhamento em seções formadas por painéis reforçados. 


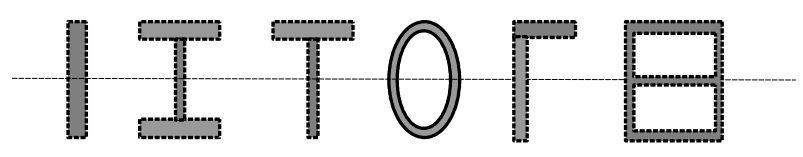

(a)

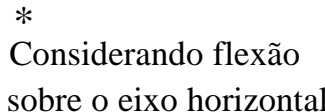

sobre o eixo horizontal
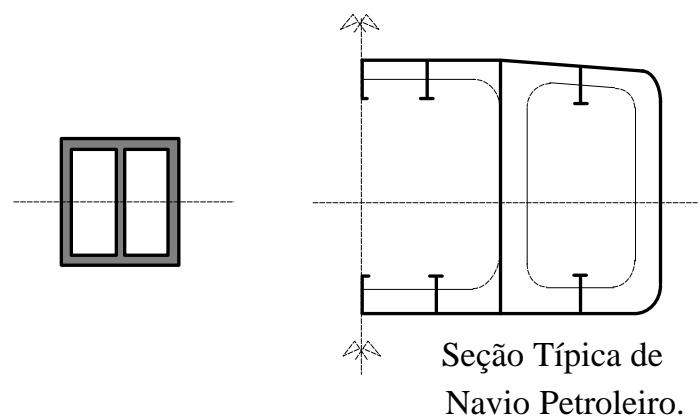

(b)

Fig.4.7 - Exemplos de Seções Transversais de Vigas.

\subsubsection{A TENSÃO DE CISALHAMENTO.}

A Fig.4.8(a) mostra uma viga submetida a um carregamento qualquer. Considerando que a viga esteja em equilíbrio, da teoria simples de viga tem-se que a força cortante em uma seção é igual a variação do momento fletor, conforme ilustrado na Fig.4.8(b). Assim o equilíbrio de momentos em relação a um ponto qualquer no plano $\mathrm{YZ}$ ordem produz a seguinte expressão:

$$
\Delta M=Q \cdot \Delta z
$$

Admitindo flexão pura podemos calcular a distribuição de tensões normais devido ao momento fletor $M$ é pela relação:

$$
\sigma=\frac{M}{I} \cdot \bar{y}
$$

sendo:

$M$ - o momento fletor;

$\bar{y}$ - distância do ponto onde está sendo calculado a tensão à linha neutra.

I - momento de inércia da área seção transversal da viga em relação à linha neutra. 
Observando que a variação mostrada na Eq.4.18 se dá ao longo do comprimento da viga podemos expressar a variação da tensão normal combinando as Eqs.4.18 e 4.19. Portanto:

$$
\Delta \sigma=\left(\frac{Q \cdot \bar{y}}{I}\right) \Delta z
$$

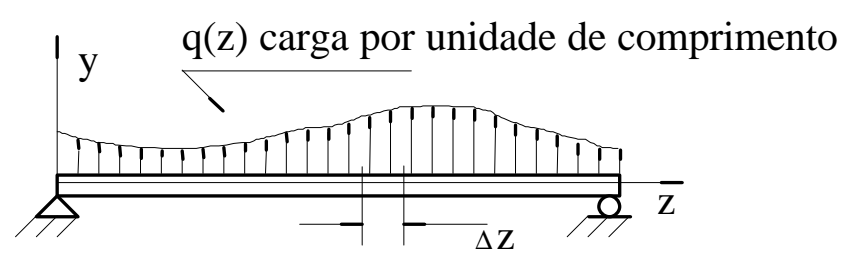

(a)

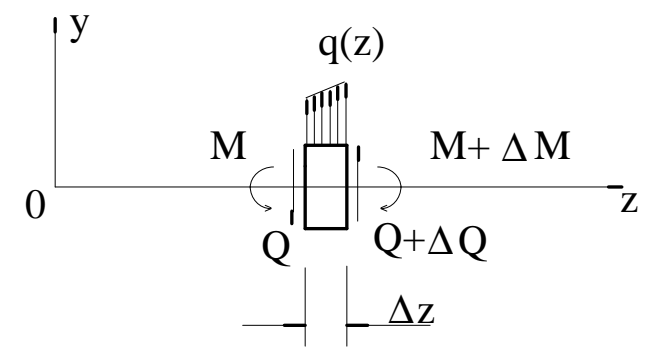

(b)

\subsection{Equilíbrio de um Elemento de Viga.}

A Fig.4.9(a) apresenta um pequeno trecho da viga-navio de onde foi retirada uma "fatia" do convés. As forças agentes nas duas seções do corte estão desequilibradas conforme mostra a Fig.4.9(b). A diferença $\Delta \mathrm{F}$ é equilibrada pela presença da tensão de cisalhamento distribuída longitudinalmente ao longo do comprimento $\Delta$ z, Fig.4.9(c).

\subsubsection{A FORMULAÇÃO DO ELEMENTO.}

Analogamente ao exposto no item 4.1.1, a formulação do elemento finito de cisalhamento é encaminhada pelo método direto, isto é, sua matriz de rigidez será explicitada por considerações de equilíbrio, utilizando-se a definição de coeficiente de rigidez.

Retomando a Eq.4.1.a temos: 


$$
[k]\{\delta\}=\{f\}=\{p\}+\left\{p_{o}\right\}
$$

sendo:

$[k]$ - matriz de rigidez do elemento.

$\{\delta\}$ - vetor de deslocamentos nodais do elemento.

$\{f\}$ - vetor de todas as cargas aplicadas do elemento.

$\{p\}$ - vetor de cargas aplicadas nodais do elemento.

$\left\{p_{o}\right\}$ - vetor de cargas nodais equivalentes às cargas distribuídas ao longo do domínio.

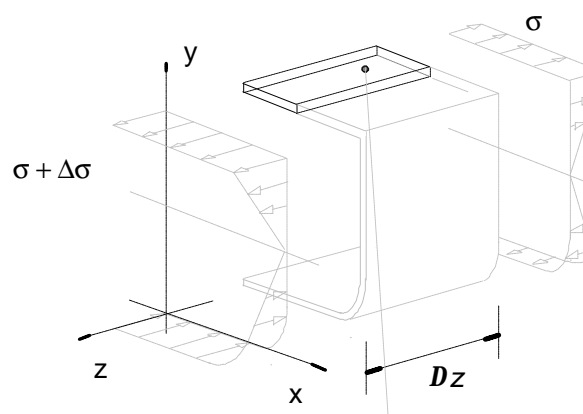

(a)

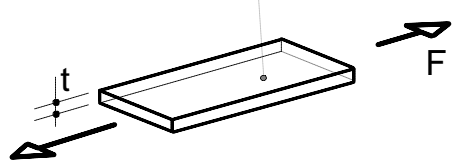

(b)

$\mathrm{F}+\Delta \mathrm{F}$

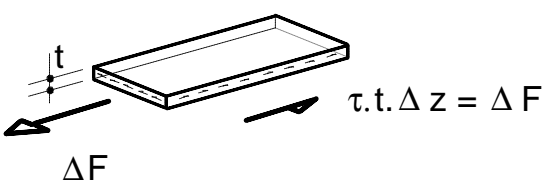

(c)

Fig.4.9 Forças Normais e de Cisalhamento em Equilíbrio. 
A Fig.4.10 esquematiza as principais características do elemento. Vamos chamar o empenamento de $w(z)$ e supor que o elemento de cisalhamento é unidimensional de dois nós, no plano $x y$, com um campo de deslocamentos linear no interior do elemento. O sistema local de coordenadas $s$ está orientado do nó 1 para o nó 2 . Assim o vetor de deslocamentos nodais pode ser expresso por

$$
\{\delta\}=\left\{\begin{array}{l}
w_{1} \\
w_{2}
\end{array}\right\}
$$

Com o intuito de considerar a presença dos longitudinais vamos admitir uma área concentrada por nó simulando a seção do perfil longitudinal, evitando assim "diluir" a área do perfil na espessura do chapeamento. Admitiremos que a espessura do chapeamento é constante ao longo do perímetro do elemento, o que normalmente é observado nas estruturas reais.

A Eq.4.21 pode ser expandida tomando a seguinte forma:

$$
\left[\begin{array}{ll}
k_{11} & k_{12} \\
k_{21} & k_{22}
\end{array}\right]\left\{\begin{array}{l}
w_{1} \\
w_{2}
\end{array}\right\}=\left\{\begin{array}{l}
f_{1} \\
f_{2}
\end{array}\right\}=\left\{\begin{array}{l}
p_{1} \\
p_{2}
\end{array}\right\}+\left\{\begin{array}{l}
p_{01} \\
p_{02}
\end{array}\right\}
$$

O campo de deslocamentos no interior do elemento foi admitido como linear e, portanto, a deformação angular do elemento será constante, ou seja,

$$
\gamma=\frac{d w}{d s}=\frac{\Delta w}{\Delta s}=\frac{w_{2}-w_{1}}{l}=\text { Constante }
$$

e em consequência a tensão de cisalhamento também será constante, um vez que

$$
\tau=\mathrm{G} . \gamma
$$

Portanto, definindo os deslocamentos $w_{1}$ e $w_{2}$ determinamos a tensão de cisalhamento no elemento.

O primeiro passo é determinar os coeficientes de rigidez $k_{i j}$ da Eq.4.23, o que pode ser feito pela definição apresentada no item 4.1.1. A Fig.4.11 ilustra o procedimento: impomos um empenamento unitário no nó 1 e consideramos que a força cisalhante resultante é aplicada no mesmo. Assim, temos:

$$
f_{l}=k_{l l}=|\tau| \text {.t. } \Delta z=\mathrm{G} \cdot\left(\frac{1}{l}\right) \mathrm{t} \cdot \Delta z
$$




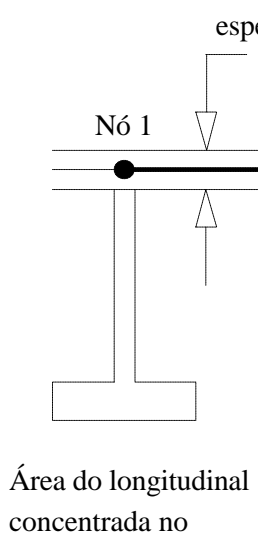

nó 1 .

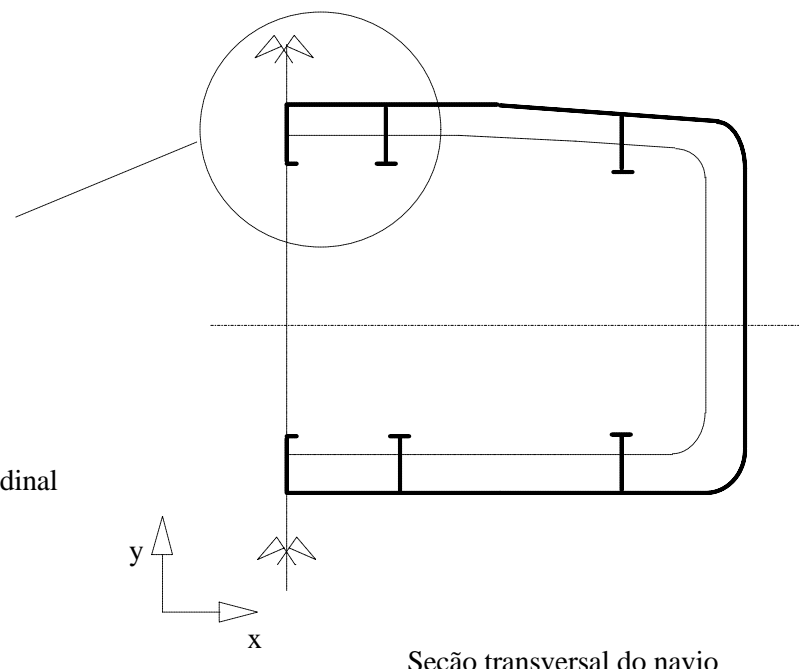

Seção transversal do navio

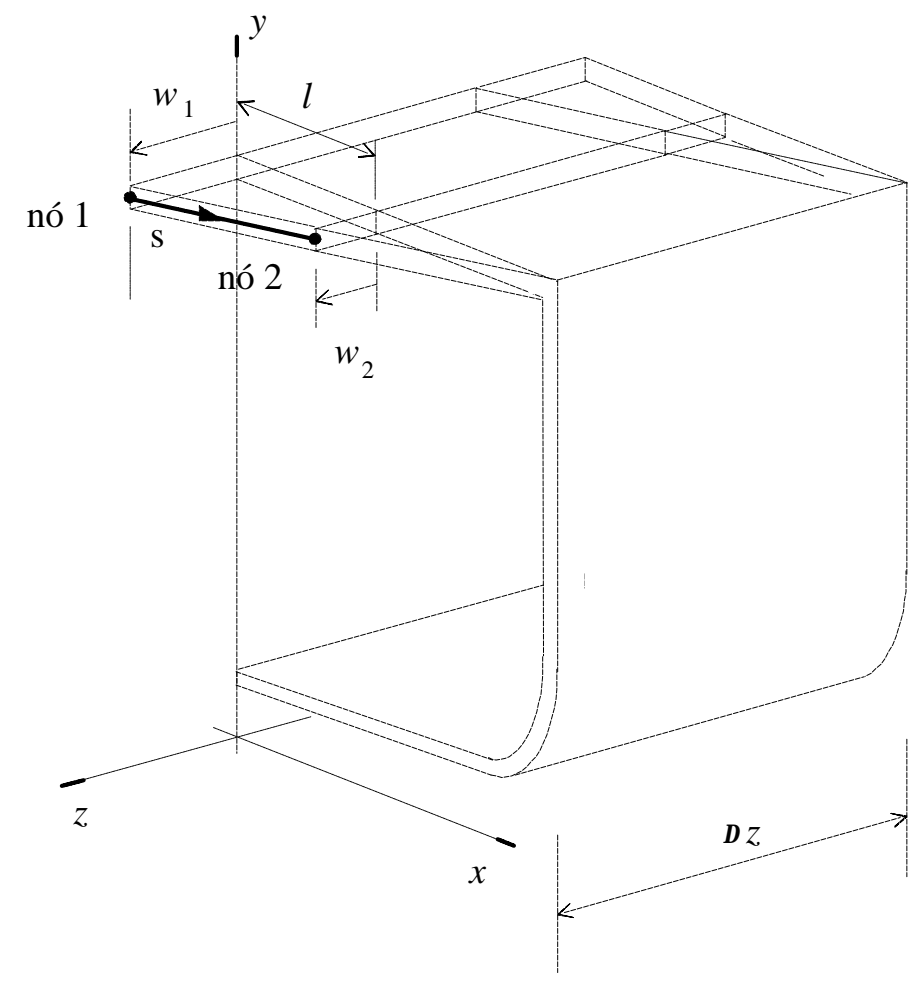

Fig.4.10 O Elemento de Cisalhamento. 

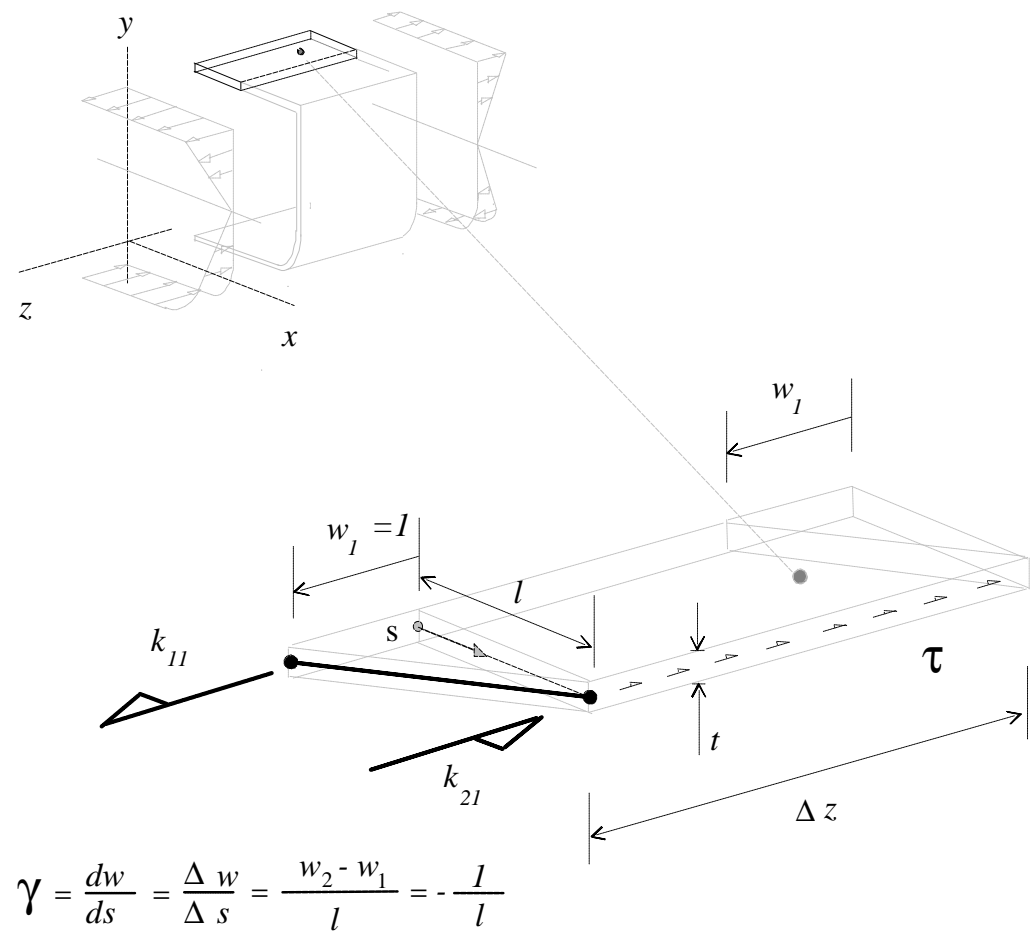

Fig.4.11 A Rigidez do Elemento de Cisalhamento.

Considerando que o elemento está em equilíbrio chegamos a

$$
k_{21}=-k_{11}
$$

Os outros dois coeficientes são obtidos de modo análogo, impondo um empenamento unitário no nó 2 . A matriz de rigidez completa é dada por

$$
\left[\begin{array}{cc}
1 & -1 \\
-1 & 1
\end{array}\right] \cdot \frac{G \cdot t}{l} \cdot \Delta z
$$

O carregamento agindo no elemento é gerado pela variação da tensão normal $\Delta \sigma$. A força nodal discretizada representa a soma da carga equivalente ao carregamento distribuído sobre o elemento com as cargas concentradas em cada nó. Observando a Fig.4.12, tomando o somatório dos momentos em relação ao nó 2 temos que

$$
\text { l. } f_{l}=l\left(\Delta \sigma \cdot A_{l}\right)+\int_{0}^{l}[(l-s) \cdot(\Delta \sigma \cdot t)] d s
$$




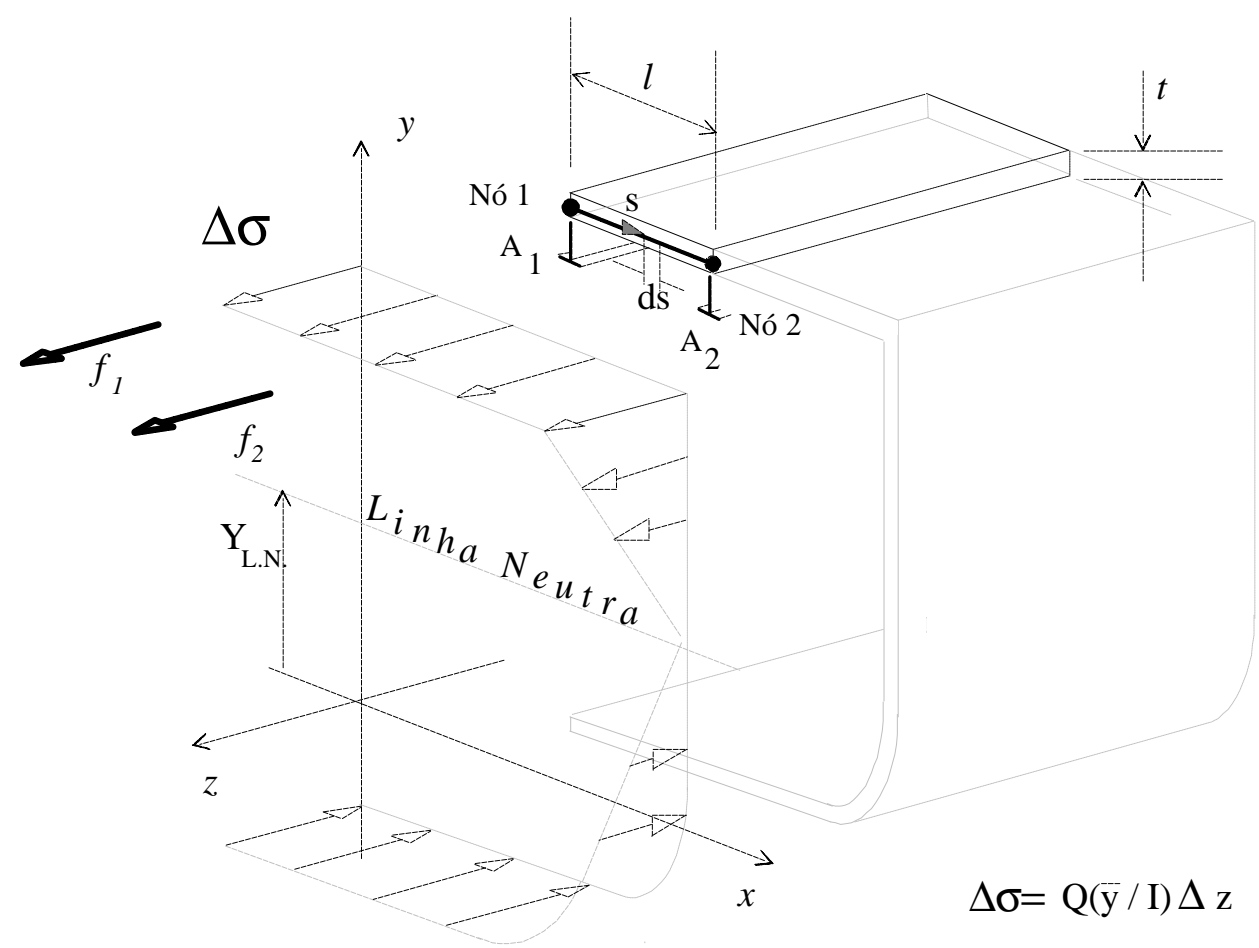

Fig.4.12 Carregamento do Elemento de Cisalhamento.

$\mathrm{O}$ termo entre parênteses na primeira parcela do segundo membro da Eq.4.29 é uma aproximação pela qual impomos que as tensões longitudinais $\Delta \sigma$ atuantes na seção do perfil longitudinal pesado podem ser "concentradas" multiplicando-as pela área transversal do longitudinal— na forma de uma força no nó 1. Define-se assim o valor de $p_{1}$ na Eq.4.23. O segundo termo contabiliza a carga distribuída ao longo do elemento. Para efetuar a integração ao longo do perímetro $s$ devemos inicialmente escrever a tensão normal $\Delta \sigma$ em termos do sistema local de coordenadas. Na Fig.4.13, um ponto localizado a uma distância $s$ no sistema local de coordenadas do elemento, tem sua ordenada $y$ no sistema global de coordenadas determinada por

$$
y=y_{1}+\sin \alpha
$$

Em relação à linha neutra temos:

$$
\bar{y}=\bar{y}_{1}+s \cdot \sin \alpha
$$

sendo

$\bar{y}_{1}=\left(y_{1}-y_{L N}\right)-$ distância do nó 1 à linha neutra da seção. 
$\alpha$ - ângulo do elemento com o eixo neutro da seção, que foi adotado como paralelo ao eixo global $x$.

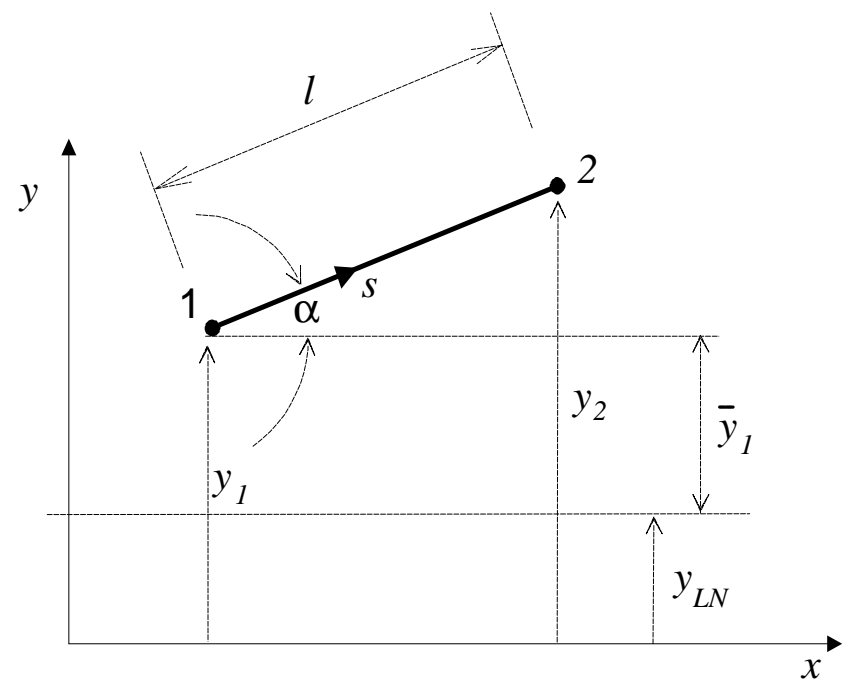

Fig.4.13 Sistemas de Coordenadas Local e Global.

Substituindo a Eq.4.31 na Eq.4.20 chegamos à equação

$$
\Delta \sigma=\frac{Q}{I}\left(\bar{y}_{1}+s \cdot \sin \alpha\right) . \Delta z
$$

Substituindo a Eq.4.32 na Eq.4.29, efetuando a integração e dividindo o resultado por $l$ chegamos ao valor de $f_{1}$ :

$$
f_{l}=\frac{Q \cdot \bar{y}_{1} \cdot A_{1}}{I} \cdot \Delta z+\left\{\bar{y}_{1}+\frac{l}{3} \sin \alpha\right\} \frac{Q \cdot l \cdot t}{2 I} \cdot \Delta z
$$

Analogamente para o nó 2 obtemos

$$
f_{2}=\frac{Q \cdot \bar{y}_{2} A_{2}}{I} \cdot \Delta z+\left\{\bar{y}_{1}+\frac{2 \cdot l}{3} \sin \alpha\right\} \frac{Q \cdot l \cdot t}{2 I} \Delta z
$$

Introduzindo as Eqs.4.28, 4.33 e 4.34 na Eq.4.23, lembrando que $\Delta z$ deve ser diferente de zero chegamos a 


$$
\frac{G . t}{l}\left[\begin{array}{cc}
1 & -1 \\
-1 & 1
\end{array}\right]\left\{\begin{array}{l}
w_{1} \\
w_{2}
\end{array}\right\}=\left\{\begin{array}{l}
- \\
y_{1}+\frac{l}{3} \sin \alpha \\
- \\
y_{1}+\frac{2 \cdot l}{3} \sin \alpha
\end{array}\right\} \cdot \frac{l \cdot t}{2} \cdot \frac{Q}{I}+\left\{\begin{array}{l}
A_{1} \cdot \overline{y_{1}} \\
- \\
A_{2} \cdot \bar{y}_{2}
\end{array}\right\} \frac{Q}{I}
$$

O termo $Q / I$ no segundo membro da equação acima é característico da seção como um todo e pode ser visto como um fator de escala. Sendo a inércia $I$ uma constante da seção, e como nosso interesse se restringe à distribuição das tensões de cisalhamento, adotaremos $Q$ igual a unidade.

Obtemos assim, um procedimento para determinar numericamente a distribuição das tensões de cisalhamento na seção transversal. Multiplicando-se o valor das tensões em cada elemento pela espessura do mesmo obtemos o fluxo de cisalhamento, ou seja, a carga por unidade de comprimento que equilibrará, na direção transversal, o carregamento externo.

O apêndice $\boldsymbol{A}$ apresenta um teste de convergência e também exemplos de aplicação para o elemento de cisalhamento desenvolvido. 


\section{CAPÍTULO 5}

\section{O PROGRAMA TRANSEC}

Conforme visto no capítulo 1, a necessidade acentuada de se obter uma estrutura com peso reduzido direcionou o estudo da estrutura transversal para a utilização de métodos de otimização. Os três capítulos seguintes enfocaram as premissas básicas e as ferramentas necessárias na elaboração de um processo automatizado para determinar deslocamentos e tensões na estrutura transversal de embarcações. Completando, no presente capítulo estabelecemos o procedimento para promover o cálculo otimizado dos escantilhões desta estrutura.

Esse cálculo está diretamente associado ao conceito de síntese estrutural, ou seja, a partir dos carregamentos, linha moldada e valores admissíveis para o material utilizado, inicia-se uma série de ciclos de projeto visando obter uma estrutura que apresente deformações e tensões dentro da faixa de valores admissíveis. Para tanto, admite-se uma configuração inicial de perfis e, através de sucessivas análises ${ }^{1}$ e alterações de perfis, determinam-se os escantilhões que satisfaçam os valores admissíveis, sem garantias, porém, de que esse conjunto de perfis resulte numa estrutura de mínimo peso.

O programa de computador aqui desenvolvido, denominado TRANSEC, utiliza o conceito abordado no parágrafo anterior, porém, com uma busca direcionada visando encontrar a estrutura com menor peso. Conforme será visto adiante, o programa permite, através da opção Síntese, otimizar a estrutura

1 análise, portanto, é o cálculo dos deslocamentos, deformações e tensões em uma estrutura que apresenta os carregamentos, a geometria e os valores admissíveis previamente definidos. 
transversal pelo método denominado "fully stressed", ou seja, procura aproximar ao máximo as tensões equivalentes calculadas na estrutura dos valores de tensões admissíveis.

\subsection{FUNCIONAMENTO BÁSICO DO PROGRAMA.}

O programa TRANSEC foi elaborado com o objetivo de promover análise e/ou síntese de estruturas que possam ser representadas pelo modelo bidimensional apresentado no capítulo 2. É composto de três módulos: um módulo de gerenciamento do sistema; um módulo para cálculo da estrutura e um terceiro módulo para pré e pós processamento gráfico. Os dois últimos foram estabelecidos de modo a operarem independentemente do sistema, ou seja, se o usuário tem o arquivo de dados e deseja executar o módulo de cálculo, isto pode ser feito fora do sistema. Cada módulo apresenta características próprias e por isso vamos abordá-los em separado.

\subsubsection{MÓDULO TRANSFIN.}

O módulo TRANSFIN compõe um programa de elementos finitos desenvolvido para o cálculo da estrutura transversal. Pode ser utilizado também para cálculo de estruturas que se enquadrem nas suas limitações. Possui uma biblioteca com três tipos de elementos:

- elemento de viga;

- elemento de mola ou treliça e

- elemento de cisalhamento.

O elemento de viga possui 2 nós, apresentando 3 graus de liberdade por nó $-\delta x, \delta y$ e $\theta z$ - Sua matriz de rigidez foi desenvolvida no item 4.1.1. O carregamento no elemento pode ser aplicado nos nós ou através de cargas linearmente distribuídas ao longo do vão, orientados de acordo com a Fig.5.1.a. Como resultado o programa fornece os esforços solicitantes - força normal, cortante e momento fletor- com orientação positiva conforme a Fig.5.1.b.

O elemento de treliça possui 2 nós, que apresentam, por nó, 2 graus de liberdade $-\delta \mathrm{x}$ e $\delta \mathrm{y}$. Pode também ser definido como um elemento de mola, bastando para isso fornecer área nula no cartão de propriedade geométrica do elemento. A matriz de rigidez desse elemento pode ser obtida daquela 
apresentada no item 4.1.1, bastando considerar somente os graus de liberdade tangenciais ao comprimento da viga. A Fig.5.2 apresenta o sentido positivo para a força normal, único esforço solicitante no elemento.

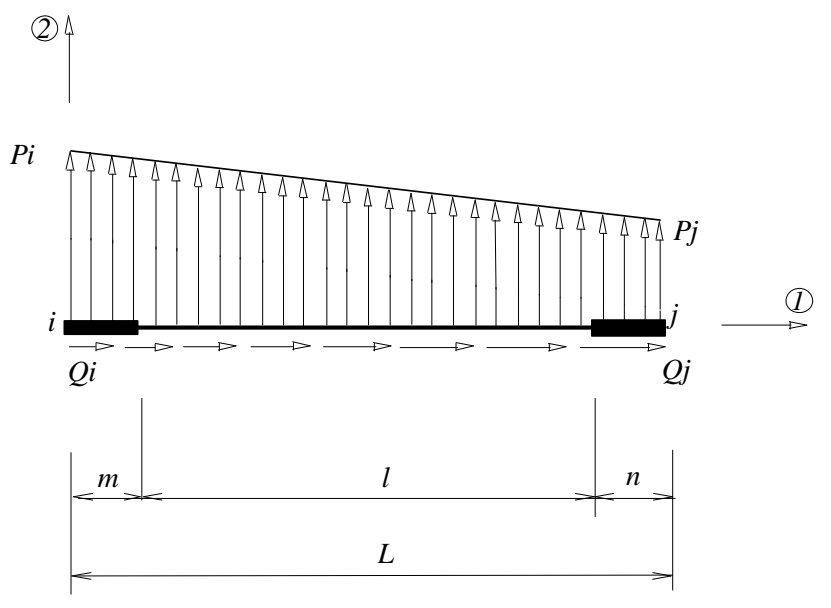

(a)
Sentidos Positivos para

Esforços Solicitantes
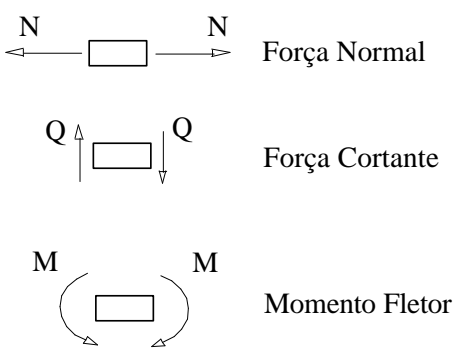

(b)

Fig.5.1 - Orientação para Carregamentos e Esforços Solicitantes no Elemento de Viga.

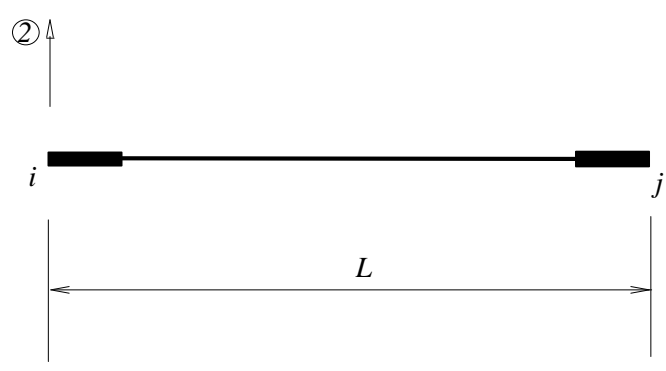

Sentidos Positivos para

Esforços Solicitantes

Fig.5.2 - Orientação para Esforços Solicitantes no Elemento de Treliça.

Com o elemento de cisalhamento pode-se calcular a distribuição das tensões de cisalhamento devido a flexão em vigas com seções transversais multicelulares. O elemento possui 2 nós, com 1 grau de liberdade por nó $-\delta z$. Além disso, pode-se incluir áreas concentradas nos nós. Fornece como resultado a tensão de cisalhamento ao longo do elemento. A matriz de rigidez considerada 
foi apresentada no item 4.2.1. A orientação positiva para a tensão de cisalhamento no elemento está representada na Fig.5.3.

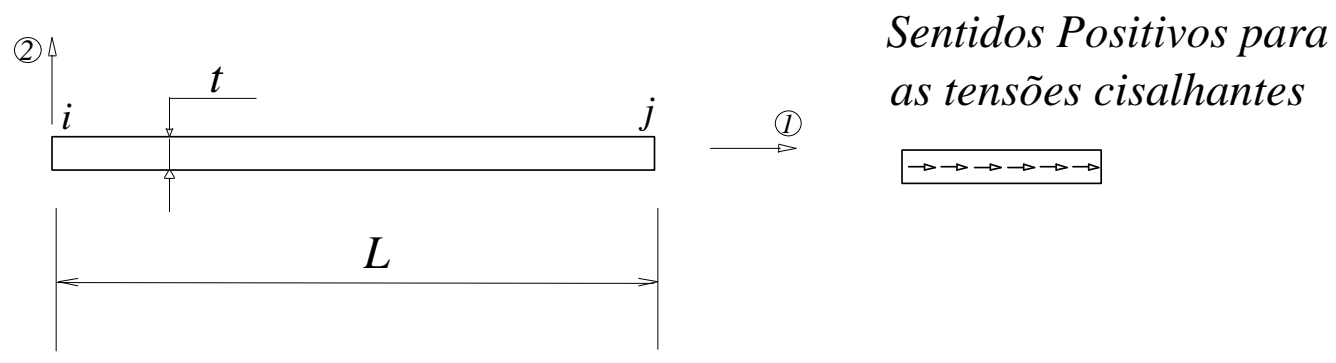

Fig.5.3 - Orientação para Carregamentos e Esforços Solicitantes no Elemento de Cisalhamento.

O módulo TRANSFIN fornece ainda os arquivos com os resultados da síntese (ou análise) —deslocamentos e reações nodais, esforços solicitantes e as tensões nos pontos indicados na Fig.3.3 - e também arquivos para os desenhos executados pelo módulo TRANSPLT.

\subsubsection{MÓDULO DE GERENCIAMENTO DO SISTEMA.}

O módulo de gerenciamento do sistema permite ao usuário estabelecer acesso rápido aos dados, à solução e ao desenho da estrutura. Este módulo possibilita que o usuário forneça os dados do problema na seguinte forma:

1. A geometria discretizada da seção a ser sintetizada (ou analisada). Entenda-se por geometria discretizada como sendo os pontos nodais e os elementos que conectam estes pontos. Os elementos são de viga de eixo reto. A cada elemento de viga deverá ser associado uma chapa colaborante - largura e espessura- e um carregamento resultante da pressão lateral, este com dimensão de força por unidade de comprimento. Logo, para obtê-lo, basta multiplicar o valor da pressão por uma largura conveniente de carga.

2. As condições de contorno. Dentro do que chamamos de condições de contorno, incluímos aquelas de vinculam a estrutura e também as provenientes da interação do anel com o restante da estrutura longitudinal. Temos, então, as constantes elásticas de mola dos elementos longitudinais pesados que interceptam o anel transversal e, 
eventualmente, as relativas à flexão de costados e conveses em seus próprios planos.

3. uma tabela de perfis sem chapa colaborante da qual o sistema buscará os perfis a serem utilizados na síntese da seção. Se for um problema de análise esta tabela não é necessária.

4. uma faixa de valores admissíveis para as máximas tensões nos elementos de viga com os perfis escolhidos pelo programa.

Esta inclusão de dados é efetuada de forma "amigável" através de menus auto-explicativos. A Fig.5.4 mostra a tela com o menu principal com as opções para o usuário. Os dados podem ser colocados em qualquer ordem. No entanto, o programa só saberá quais os graus de liberdade envolvidos no problema $\longrightarrow$ que afeta o formato das tabelas de algumas das outras opções- quando o usuário escolher os tipos de elementos que serão utilizados no problema ou fornecer os dados dos elementos.

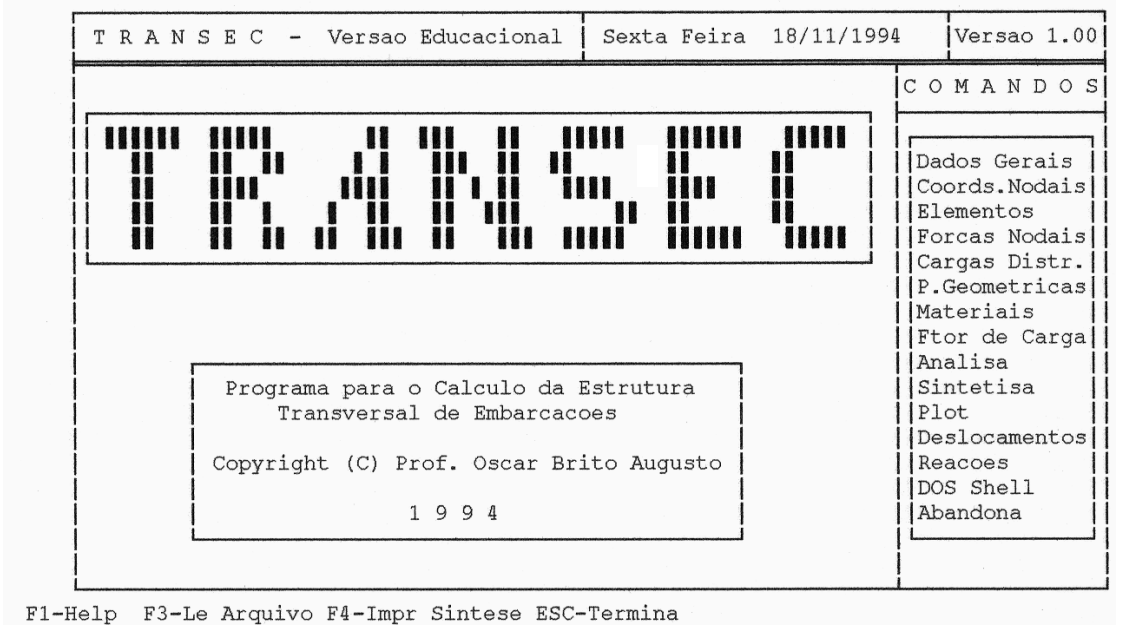

Fig.5.4 - Tela Inicial do Programa TRANSEC.

A Fig.5.5 mostra a tela que define os Dados Gerais do problema. Esta tela é utilizada para a seleção de um nome para o arquivo de dados, um título para o problema e a definição dos tipos de elementos utilizados no presente cálculo. A escolha do tipo de elemento, neste estágio, afeta a forma das tabelas de dados dos demais módulos, quanto aos graus de liberdade por nó envolvidos no problema. Se o problema possui elementos de cisalhamento, o único grau de liberdade existente será $\delta z$. Caso exista elementos de treliça somente, os graus de liberdade existentes serão $\delta \mathrm{x}$ e $\delta \mathrm{y}$. Para problemas que possuem elementos de vigas, ou vigas e treliças, os graus de liberdade existentes serão $\delta x, \delta y$ e $\theta z$. 


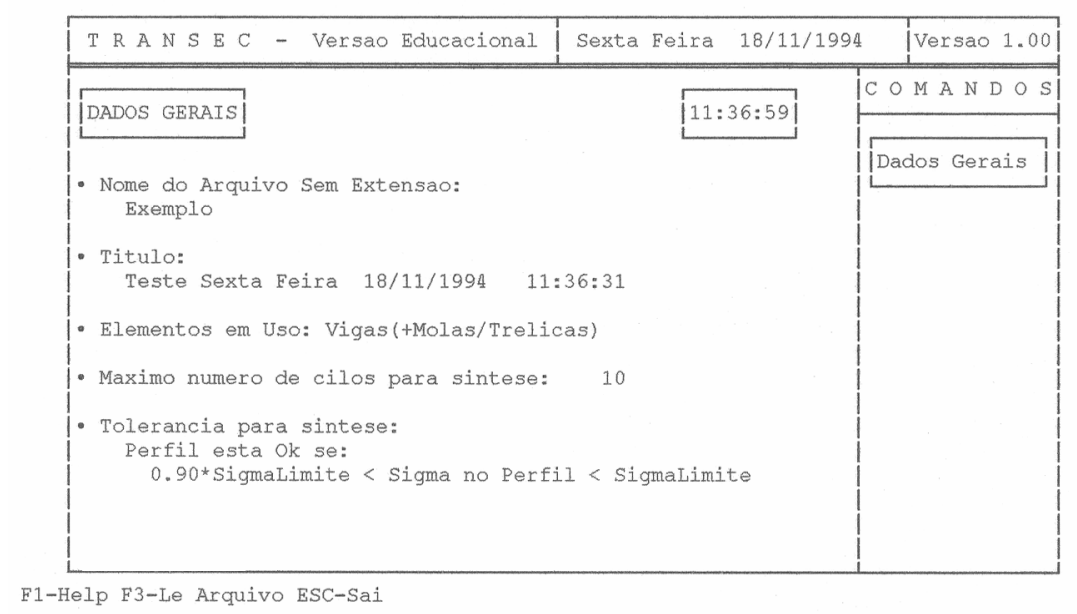

Fig.5.5 - Tela para Entrada de Dados Gerais.

Na Fig.5.6 ilustramos tela de entrada de Coordenadas Nodais com suas respectivas condições de contorno. As condições de contorno são os códigos normalmente utilizados nos programas de elementos finitos:

0 - grau de liberdade livre.

1 - grau de liberdade restrito.

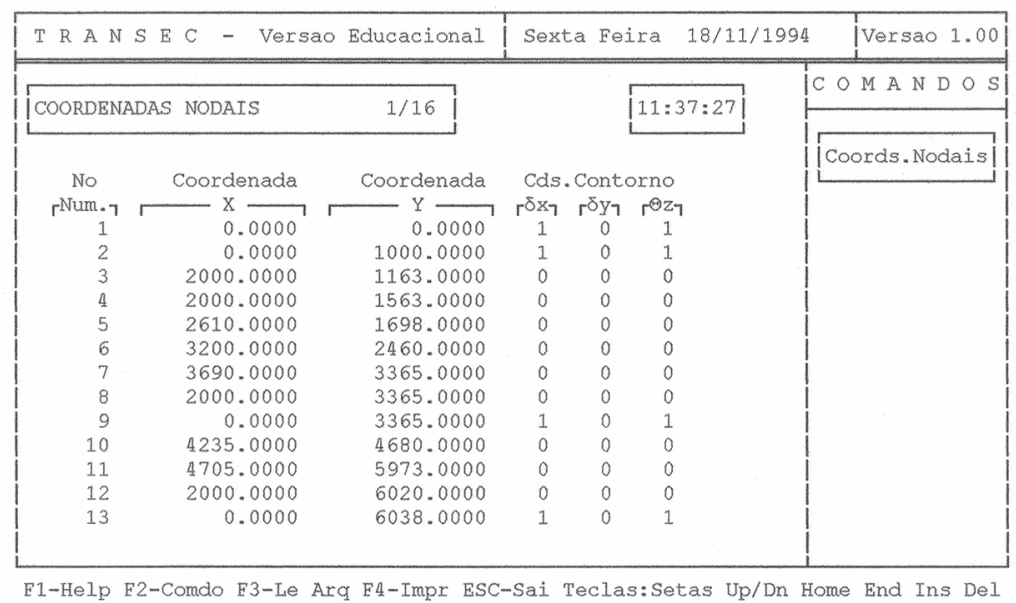

Fig.5.6 - Tela para Definição das Coordenadas Nodais.

A Fig.5.7 mostra a tela para as Incidências dos Elementos. Nos dados fornecidos para os elementos constam, além da incidência, os códigos que associam para cada elemento o seu tipo —mola/treliça (1), viga (2) ou cisalhamento (3)_-, o código relativo ao material utilizado, a propriedade geométrica e, finalmente, os carregamentos. Os elementos de mola/treliça e viga 
são compatíveis em uma mesma corrida, enquanto o elemento de cisalhamento deve ser usado isoladamente.

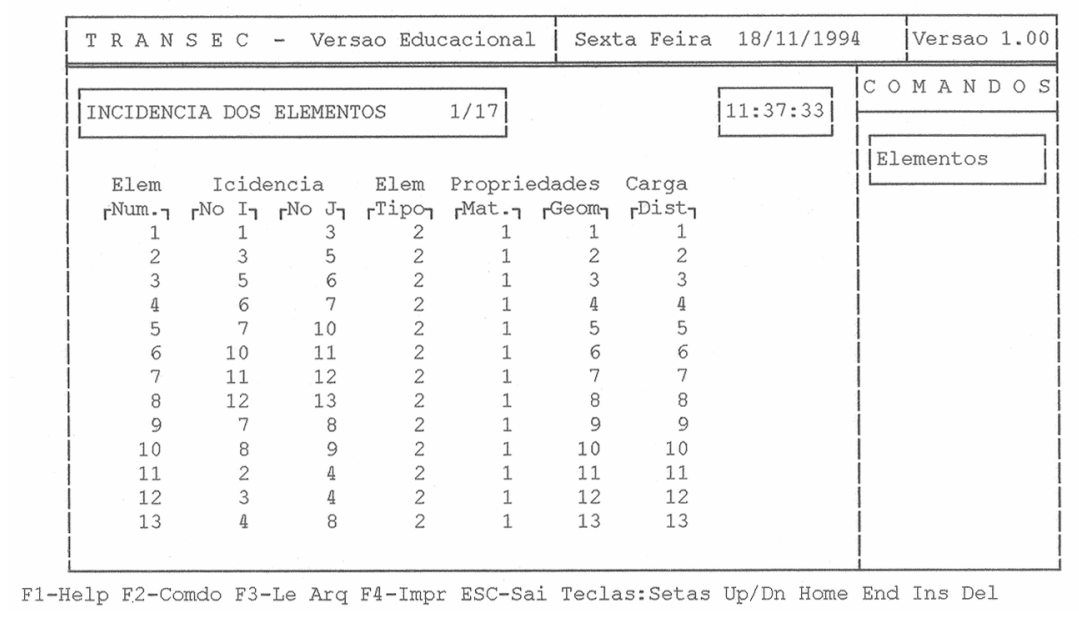

Fig.5.7 - Tela para Incidência dos Elementos.

As forças aplicadas diretamente nos nós e/ou deslocamentos impostos são consideradas pelo programa através na opção Forças Nodais. A Fig.5.8 mostra a tela de entrada para este caso. São possíveis aplicar por nó forças nas direções $x$ e $y$ e momentos fletores na direção $z$. Para deslocamentos, podem ser impostas translações nas direções $x$ e $y$ e rotações na direção $z$. O programa distingue se a entidade imposta é força ou deslocamento simplesmente verificando os vínculos dos nós. A um G.L. vinculado somente pode ser imposto um deslocamento, enquanto para um G.L. livre, somente uma força pode ser imposta.

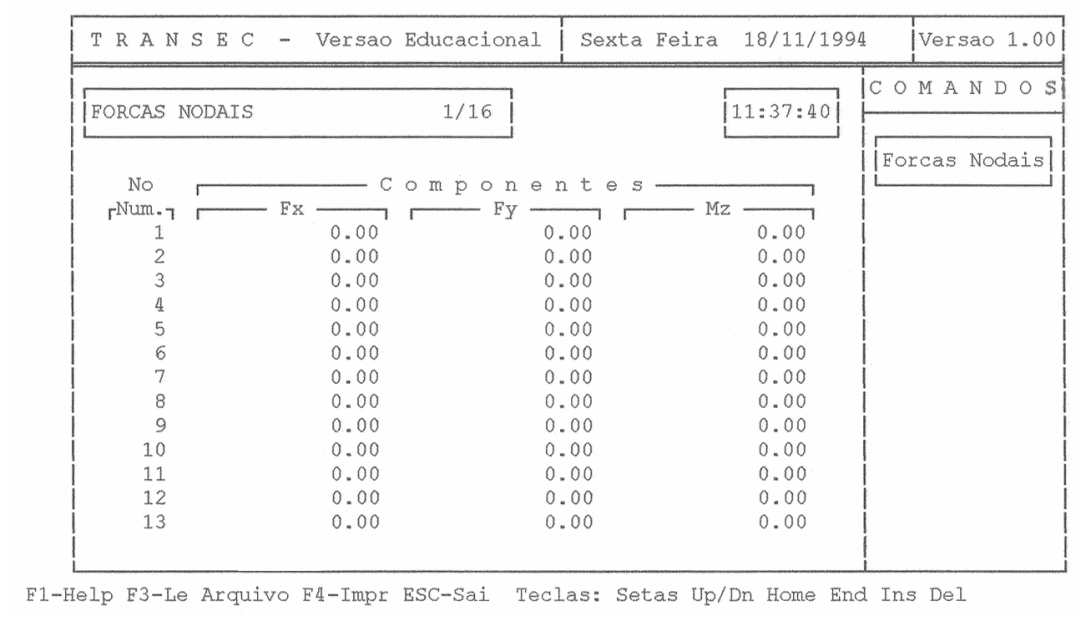

Fig.5.8 - Tela para Entrada das Forças ou Desloc. Nodais. 
Outra opção do menu principal, apresentado na Fig.5.4, é a de entrada dos dados relativos aos materiais. A Fig.5.9 mostra a tela para entrada das Propriedades dos Materiais. A única obrigatoriedade é o módulo de elasticidade $E$. As demais são opcionais para cada tipo de problema. Por exemplo, no caso de síntese a tensão admissível também é obrigatória.

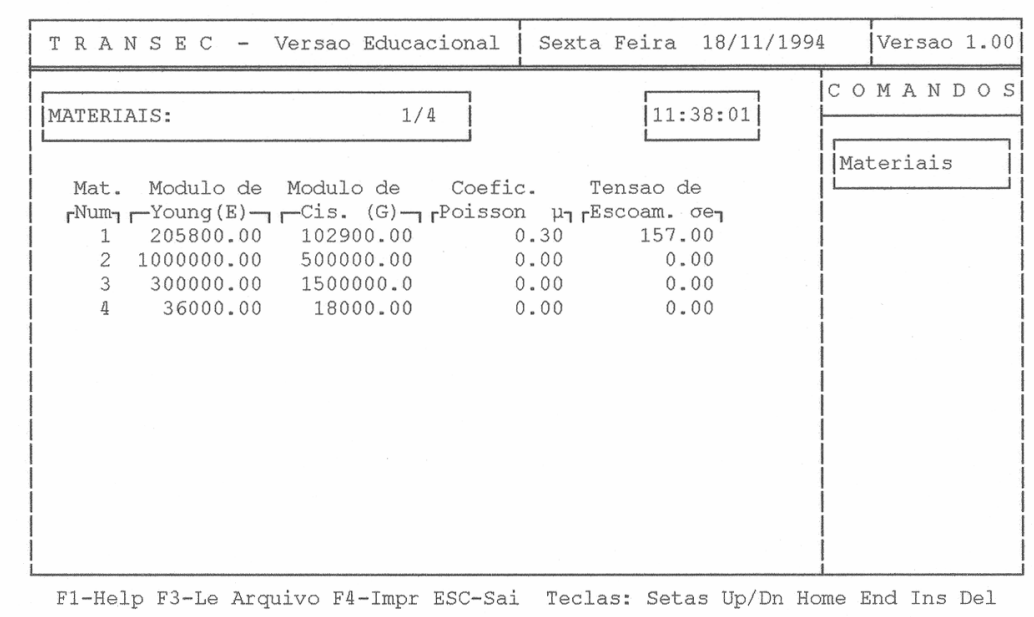

Fig.5.9 - Tela para Entrada dos Materiais.

Seguindo, apresentamos na Fig.5.10 a tela para entrada das Cargas Distribuídas. Essas cargas podem ser de dois tipos: cargas tangenciais e cargas normais ao vão do elemento. Os valores devem ser fornecidos por nó, sendo a variação no interior do elemento linear ao longo do vão.

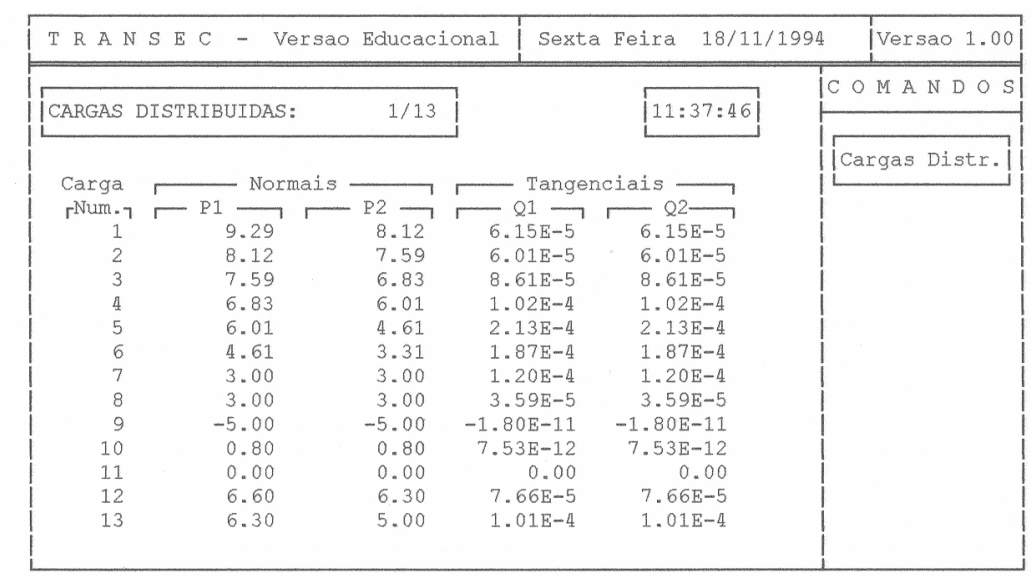

F1-Help F3-Le Arquivo ESC-Sai Teclas: Setas Up/Dn Home End Ins Del

Fig.5.10 - Tela para Entrada das Cargas Distribuídas. 
As cargas distribuídas apresentadas serão multiplicadas por um Fator de Carga, exemplificado na Fig.5.11. Isto facilita a utilização de vários carregamentos sem a necessidade de alterar todos os valores na opção de cargas distribuídas. Pode-se, por exemplo, fornecer um valor de pressão como carga distribuída para as vigas e corrigir esse valor colocando uma largura como fator de carga.

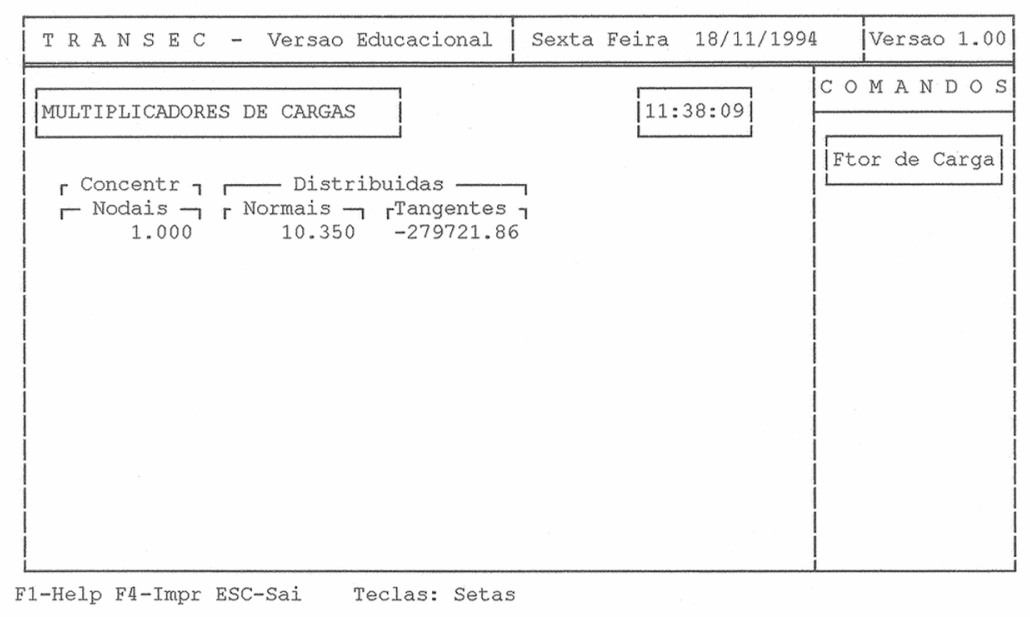

Fig.5.11 - Multiplicadores de Cargas.

A Fig.5.12 apresenta a tela para entrada das Propriedades Geométricas ${ }^{1}$ dos elementos utilizados. Para problemas de Análise que utilizam elementos de viga, é necessário colocar a área e o momento de inércia do conjunto perfil mais chapa colaborante, a área considerada resistente à força cortante e os comprimentos de extremos rígidos, caso existam. Na opção de Síntese, a área e o momento de inércia não precisam ser definidos pois o programa utilizará os valores de uma tabela de perfis. O programa calcula para cada tramo o módulo de resistência e um fator de cisalhamento para cada um dos três pontos escolhidos para cálculo de tensões equivalentes. Quando multiplicados, respectivamente, pelo momento fletor e força cortante atuantes na seção, fornecem as tensões de flexão e de cisalhamento para cada ponto considerado. Nos problemas envolvendo somente elementos de treliça a única propriedade geométrica necessária é a área da seção transversal. O programa distingue mola de treliça através da propriedade geométrica de área. Para elemento de mola, a área deve

1 Os extremos rígidos também são definidos por meio desta tela., bastando, para isso, "rolar" a tela para a direita. 
ter valor zero e o valor da constante elástica fornecido no campo de módulo de elasticidade. Para os casos que utilizam apenas o elemento de cisalhamento, é necessário entrar com a espessura do chapeamento e, caso existam, os valores das áreas concentradas nos nós.

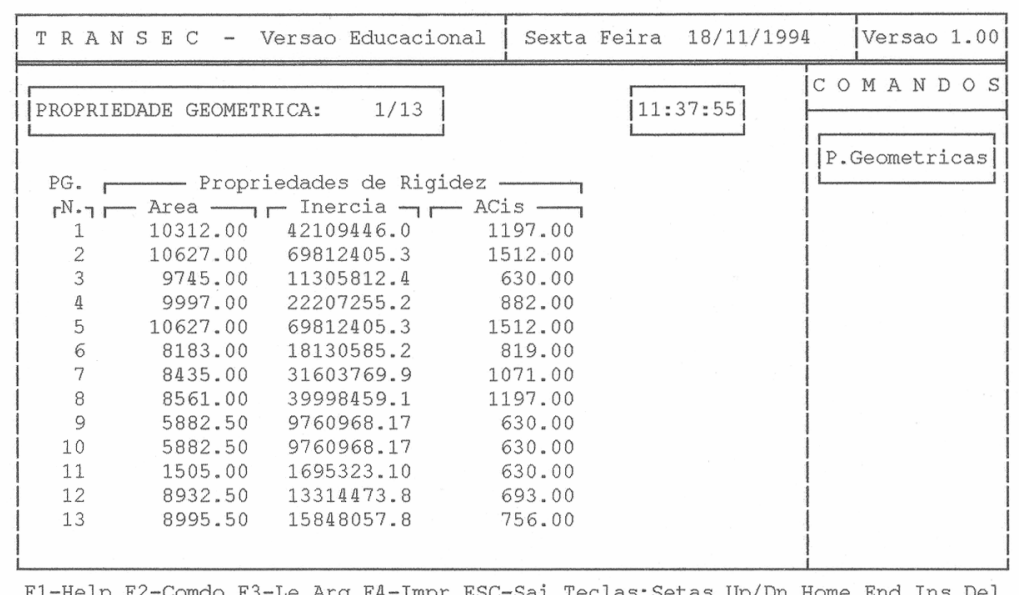

Fig.5.12 - Tela para Entrada das Propriedades Geométricas.

\subsubsection{PROCEDIMENTO DE SÍNTESE.}

Quando o usuário escolhe a opção Síntese, surge a tela representada na Fig.5.13, onde ele deverá definir para cada elemento de viga largura e espessura para a chapa colaborante associada. Definidos esses valores o usuário deve entrar com uma tabela de perfis, necessariamente em ordem crescente de inércia, da qual o programa buscará, para cada tramo, valores para compor o módulo mínimo exigido em cada iteração. Como primeira aproximação para o perfil de cada tramo de viga, o programa utiliza para a estimativa do módulo de resistência a seguinte expressão

$$
W=\frac{q . L^{2}}{8 . \sigma_{a d m}}
$$

que é o caso de uma viga biapoiada de comprimento $L$ com carga uniforme $q$ no vão. 


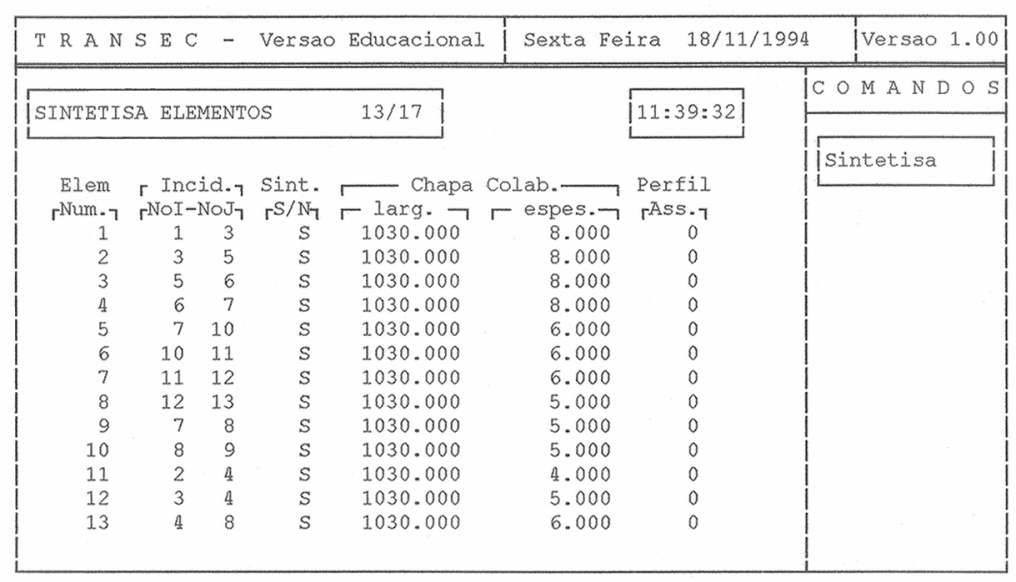

F1-Help F3-Le Arqvo F4-Impr ESC-Sai Teclas: Setas Up/Dn Home End Ins Del

Fig.5.13 - Entrada das Chapas Colaborante dos Perfis.

De posse deste módulo mínimo o programa procura na tabela operfil mais leve que associado a chapa colaborante para aquele tramo resulte em um módulo maior ou igual ao estimado pela Eq.5.1.

A seguir, o programa calcula a distribuição das tensões de cisalhamento ao longo do chapeamento da seção transversal utilizando força cortante unitária. Para tanto é gerada uma malha com a discretização fornecida, associada ao elemento de cisalhamento, ou seja, o programa roda o problema considerando todos os elementos como sendo de cisalhamento. Calculada a distribuição das tensões de cisalhamento, basta multiplicar o valor destas, em cada elemento, pela espessura do chapeamento para se obter o fluxo de cisalhamento (carga por unidade de comprimento) que será utilizado como carregamento tangencial ao tramo da viga.

$\mathrm{O}$ anel transversal está pronto para ser analisado. Temos as propriedades geométricas de cada tramo de viga, os carregamentos que neles atuam e as condições de contorno. Com isto o programa prepara os dados para uma corrida do módulo TRANSFIN a fim de equilibrar a seção transversal do navio que contém o anel —equilíbrio entre força cortante e resultante das forças de pressão, na direção vertical—, calculando também as tensões nos elementos de viga.

Com os valores das tensões em todos os elementos o programa verifica:

1. em quais tramos as tensões equivalentes máximas ultrapassam as tensões admissíveis. 
2. se houver algum, o programa, a partir dos esforços solicitantes atuantes no tramo, procura no banco de dados de perfis aquele que satisfaz o novo módulo mínimo de resistência. Caso não encontre um perfil compatível, uma mensagem é emitida, o maior perfil disponível da tabela é adotado para o tramo e a síntese dos outros elementos continua.

3. de posse dos novos perfis processa novo cálculo.

Esta seqüência é repetida até que em todos os perfis as tensões equivalentes máximas, calculadas nos pontos 1, 2 e 3 da Fig.3.3, sejam menores que o valor máximo admissível. Encerrado o processo, o programa faz uma nova verificação para o limite inferior das tensões, procurando reduzir os escantilhões de perfis que durante o processo de síntese tiveram sua solicitação diminuída, atingindo valores abaixo de

$$
\sigma_{a d m}(1-\alpha)
$$

onde o fator $\alpha$ varia entre 0 e 1 e é fornecido na opção Dados Gerais. Este fator serve para impor um limite inferior para as tensões admissíveis.

O programa encerra o processo de síntese se todos os perfis estiverem dentro da faixa de tensões adotada ou se o número máximo de ciclos escolhido na opção Dados Gerais for atingido. Além disso, se para duas iterações sucessivas não houver modificações nos perfis associados a um tramo, então o perfil em questão será adotado como solução para aquele tramo. O processo descrito está esquematizado na Fig.5.14.

A opção Plot do Menu Principal permite ao usuário acessar graficamente os dados e resultados de uma síntese ou análise.

As opções Deslocamento e Reações fornecem os valores para cada nó segundo os graus de liberdade do elemento e também os valores máximos, conforme ilustrado nas Figs.5.15 e 5.16.

Finalizando o menu apresentado na Fig.5.4, as opções DOS Shell e Abandona permitem ao usuário sair do programa para o sistema operacional, sendo que pela primeira é possível voltar ao programa digitando-se EXIT. 


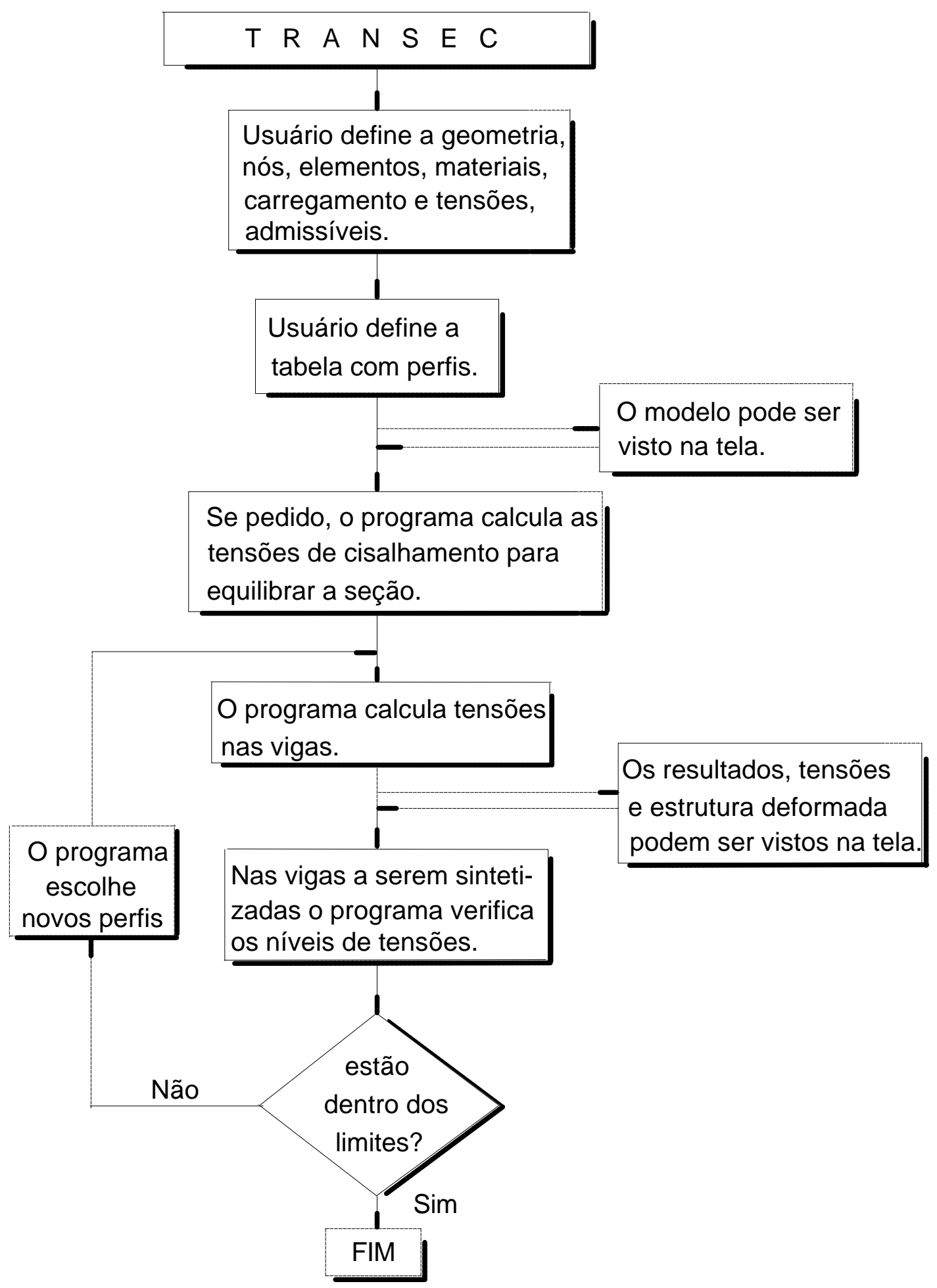

Fig.5.14 - Fluxograma da Opção Síntese. 


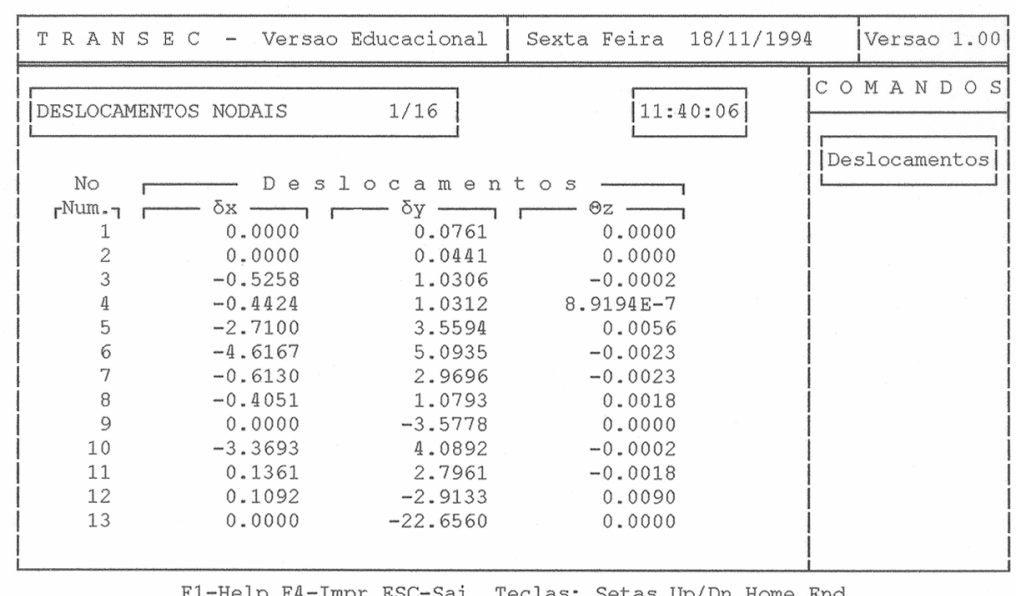

Fig.5.15 - Deslocamentos Nodais na Estrutura.

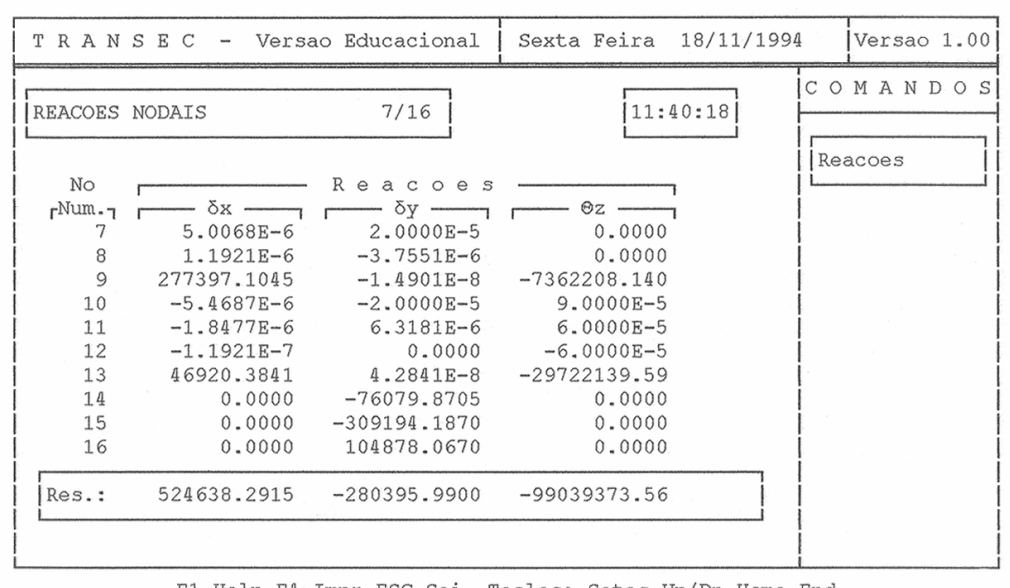

Fig.5.16 - Reações Nodais na Estrutura.

\subsubsection{O MÓDULO TRANSPLT.}

O terceiro módulo, TRANSPLT, acionado a partir da opção Plot do módulo de gerenciamento do sistema, permite a visualização na tela do modelo — malha, numeração de elementos e de nós, carregamentos, etc.-, acrescentando-se ainda, após uma análise ou síntese, a possibilidade de obter a estrutura deformada, a distribuição de momentos fletores, forças cortantes e normais além das distribuições das tensões equivalentes nos pontos 1, 2 e 3 da Fig.3.3.

Na Fig.5.17 estão representados os principais comandos necessários para se obter as características do modelo. 


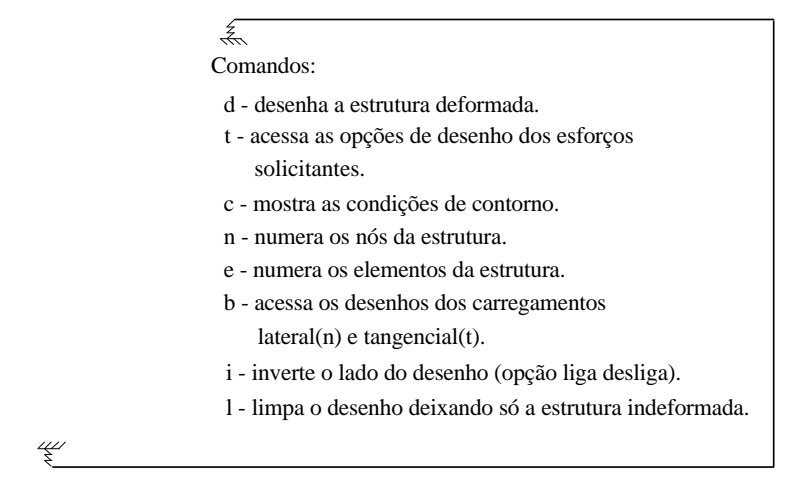

Fig.5.17 - Opções para desenhos do módulo TRANSPLT.

\subsection{COMPARAÇÃO ENTRE OS MODELOS 2D E 3D.}

Com a finalidade de avaliar os resultados obtidos pelo modelo 2D, efetuou-se a análise, pelo programa de elementos finitos $S A P 90$ [25], da estrutura de um navio hipotético utilizando um modelo tridimensional. O objeto de estudo foi uma estrutura semelhante a um "navio-caixa", conforme ilustra a Fig.5.18.

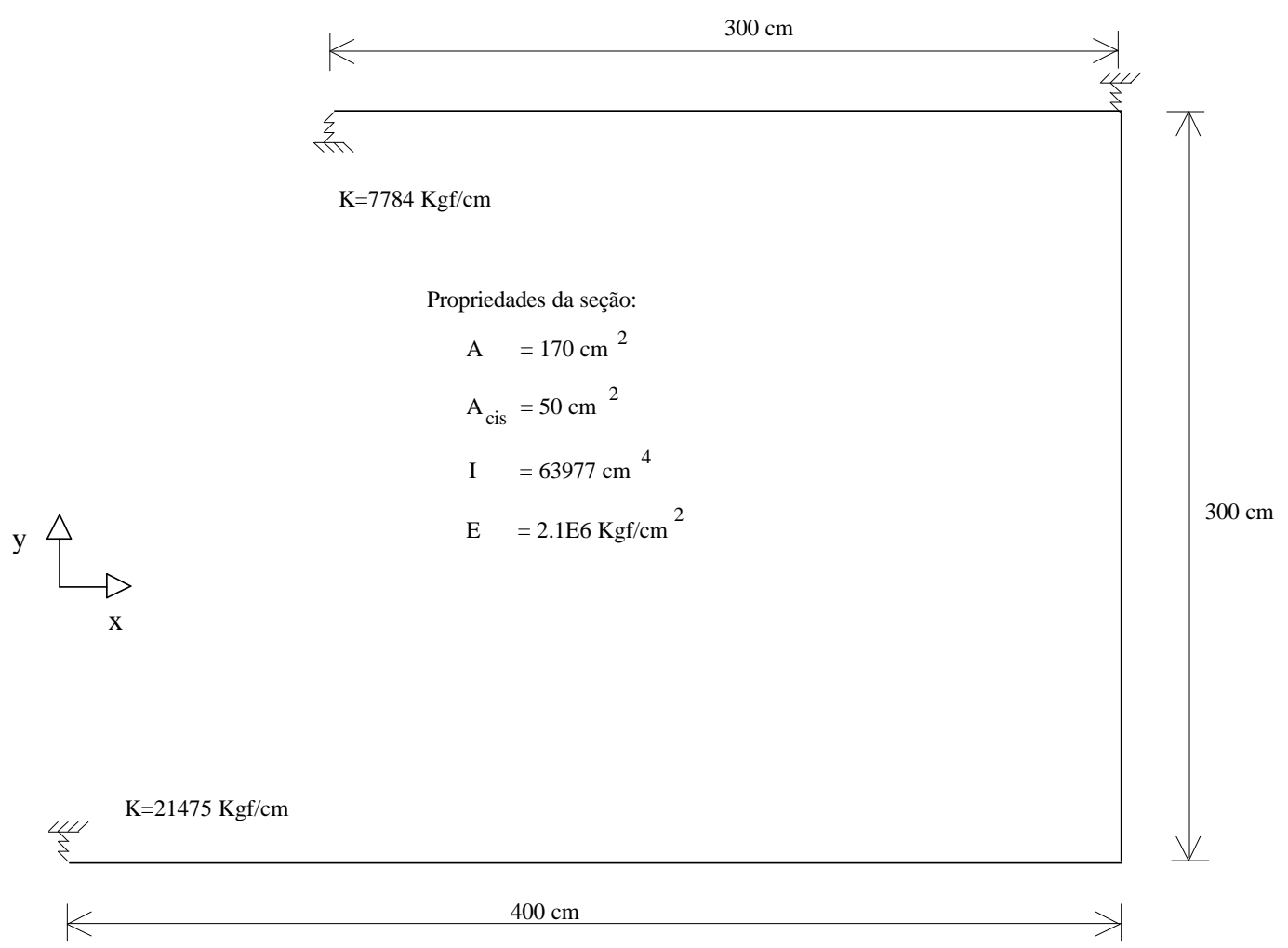

Fig.5.18 - Navio-Caixa - Seção Transversal-Modelo 2D. 


\subsubsection{MODELO BIDIMENSIONAL.}

O modelo bidimensional foi calculado utilizando-se o programa TRANSEC. A seção, apresentada na Fig.5.18, é formada pelo anel transversal com a chapa colaborante e possui dois longitudinais, um na quilha outro no convés, atuando como apoios elásticos para o anel. Além disso, a rigidez do costado foi representada por um apoio elástico na direção transversal. Estes apoios foram calculados de acordo com a Eq.2.17. Considerações de simetria em relação ao carregamento e à geometria nos permitem modelar apenas meia seção. A estrutura foi discretizada em 40 elementos de mesmo comprimento. Para representar as vigas seriam suficientes apenas três elementos, mas para calcular distribuição de cisalhamento foi necessário uma discretização maior. Antes de executar a opção Análise procedemos com uma corrida da estrutura com o elemento de cisalhamento para obter o carregamento tangencial que equilibra a resultante das forças de pressão na direção vertical. No apêndice $B$ as tabelas $B .1$ a $B .5$ apresentam os arquivos de entrada definindo o problema.

A comparação se dará pelo campo de deslocamentos e pela distribuição dos momentos fletores no anel. Assim, executando a opção Análise do programa TRANSEC, obtivemos os resultados apresentados nas Figs.5.19 e 5.20. A primeira representa os deslocamentos nodais da estrutura, enquanto a outra focaliza a distribuição de momentos fletores obtida pelo programa. Os resultados fornecidos pelo programa estão nas Tabs.B.6 a B.8 do apêndice $B$.

$$
0.031 \mathrm{~cm}
$$

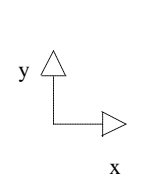

$0.043 \mathrm{~cm}$

Fig.5.19 - Navio-Caixa - Deslocamentos na Estrutura-Modelo 2D. 


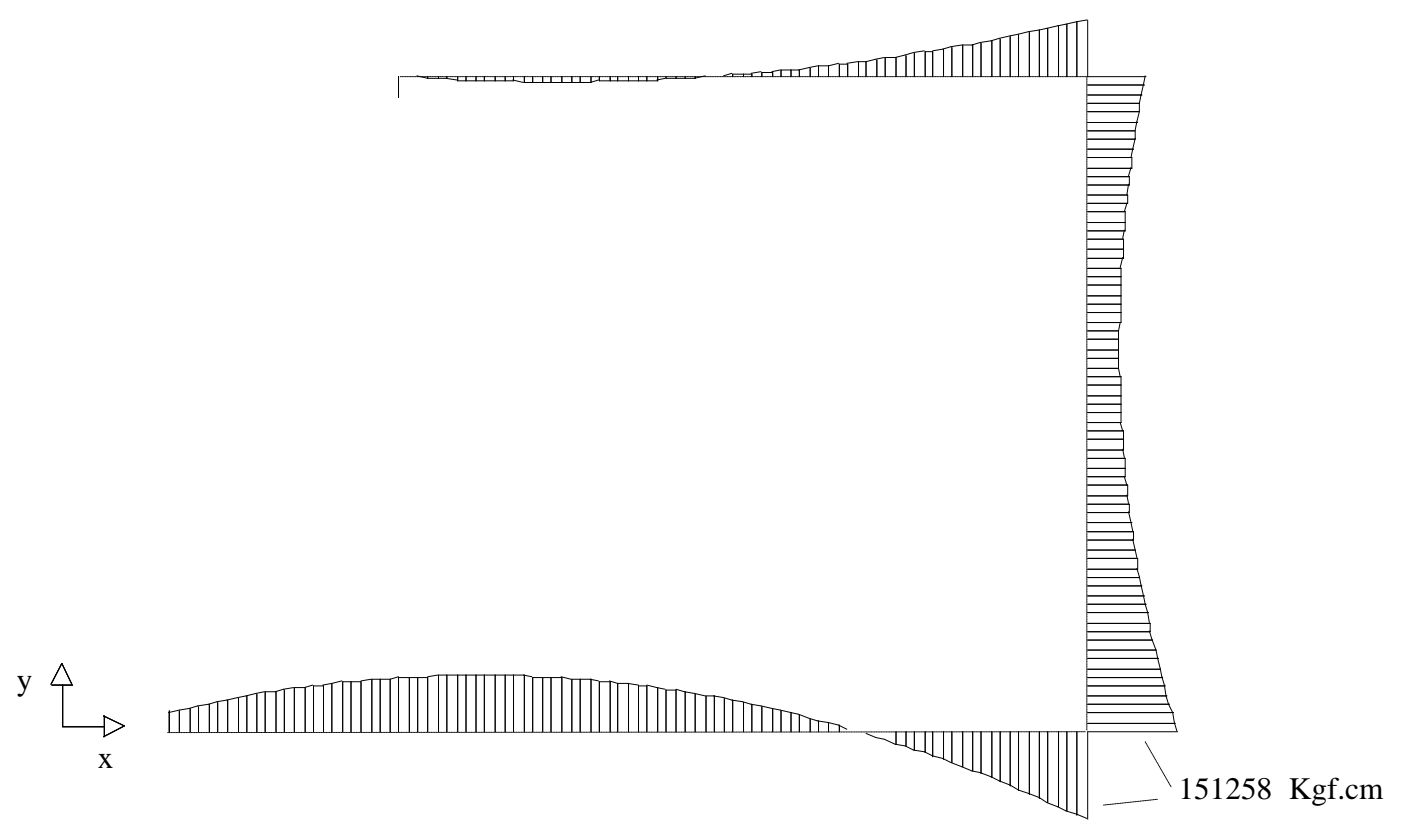

Fig.5.20 - Navio-Caixa -Dist. de Momentos Fletores-Modelo 2D.

\subsubsection{MODELO TRIDIMENSIONAL.}

$\mathrm{Na}$ análise tridimensional, executada através do programa de elementos finitos $S A P 90$, admitimos as características de geometria e carregamento do anel analisado pelo programa TRANSEC para todas as cavernas do compartimento. Assim, consideramos nove cavernas separadas pela distância de 1 metro, totalizando um comprimento de compartimento de 10 metros. As cavernas possuem a mesma discretização do modelo anterior e são representadas por elementos de viga. Os chapeamentos do fundo, costado e convés foram modelados como elementos de membrana. Os longitudinais também foram modelados por elementos de viga, engastados nas extremidades do compartimento. Para evitar sobrecarregar o desenho, a Fig.5.21 ilustra o compartimento somente com os elementos de viga. Os elementos de membrana são formados por nós consecutivos numa mesma caverna os correspondentes na caverna adjacente.

Como resultado da execução do programa $S A P 90$ apresentamos as Figs.5.22, 5.23 e 5.24. As duas primeiras representam os deslocamentos e a distribuição de momentos fletores para comparação como o modelo 2D. A Fig.5.24 apresenta a configuração deformada do compartimento. A caverna 5 indicada na figura foi a utilizada na análise pelo modelo 2D. 


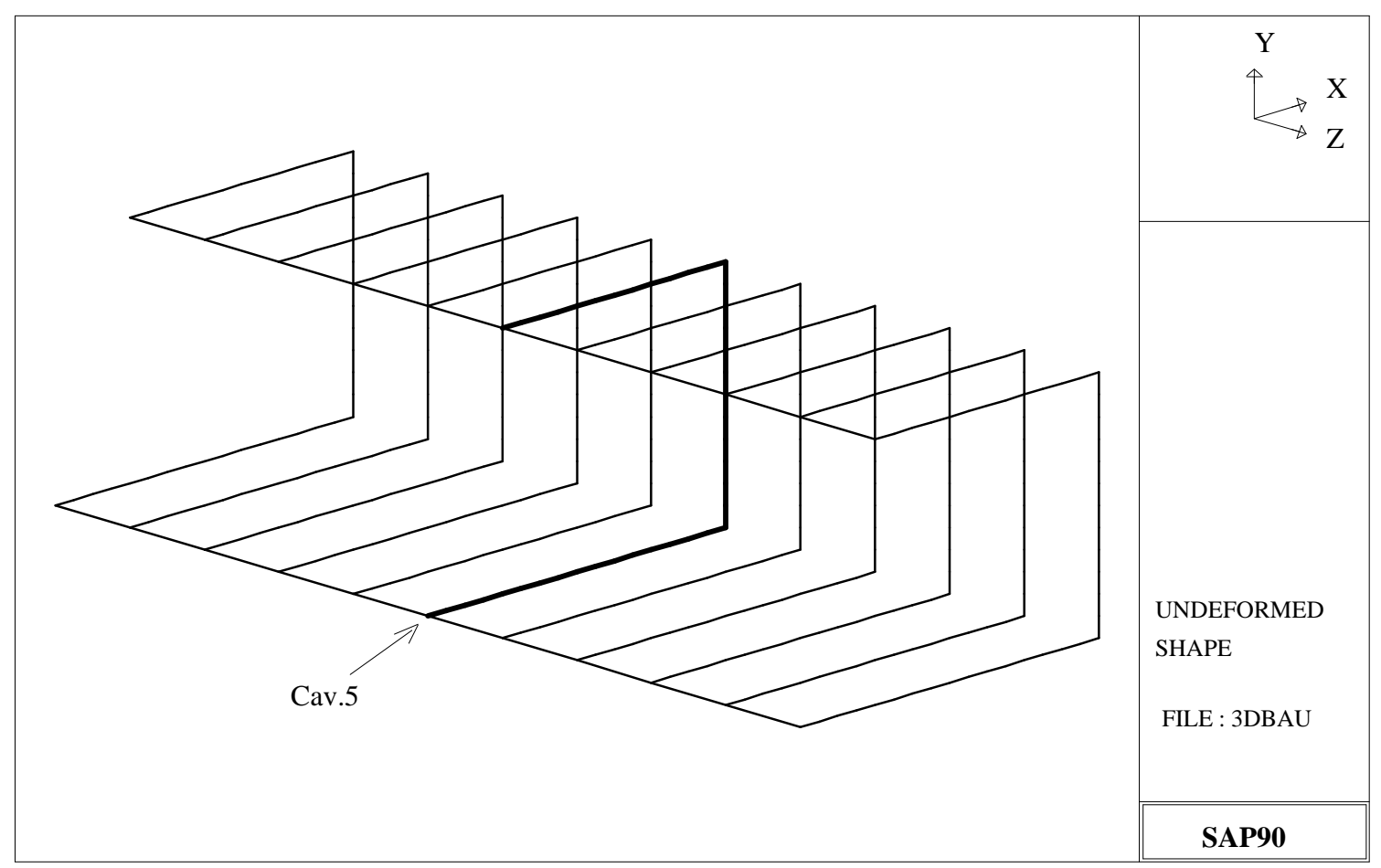

Fig.5.21 - Navio-Caixa - Estrutura Entre Anteparas - Modelo 3D.

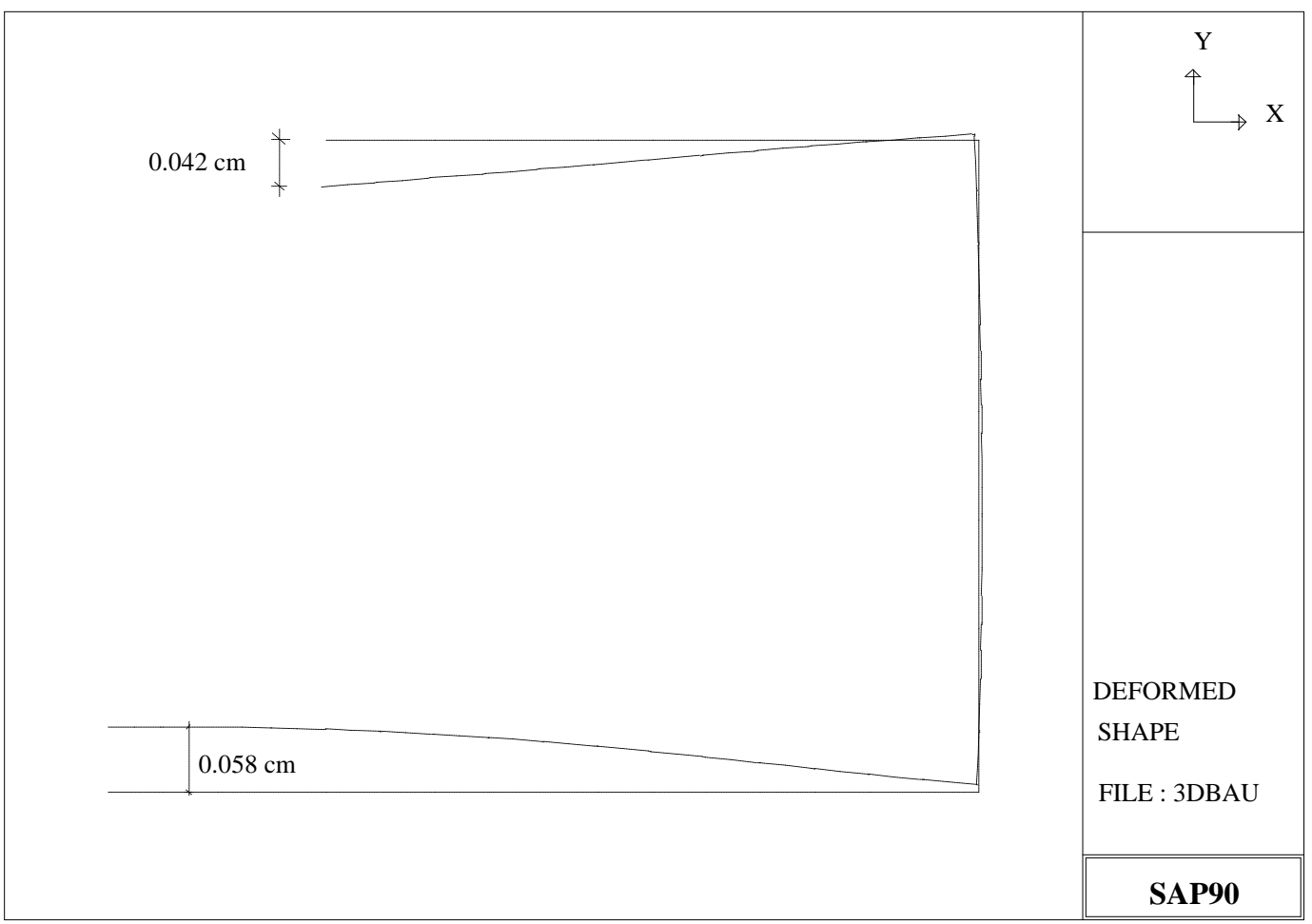

Fig.5.22 - Cav.5 - Deslocamentos Nodais-Modelo 3D. 


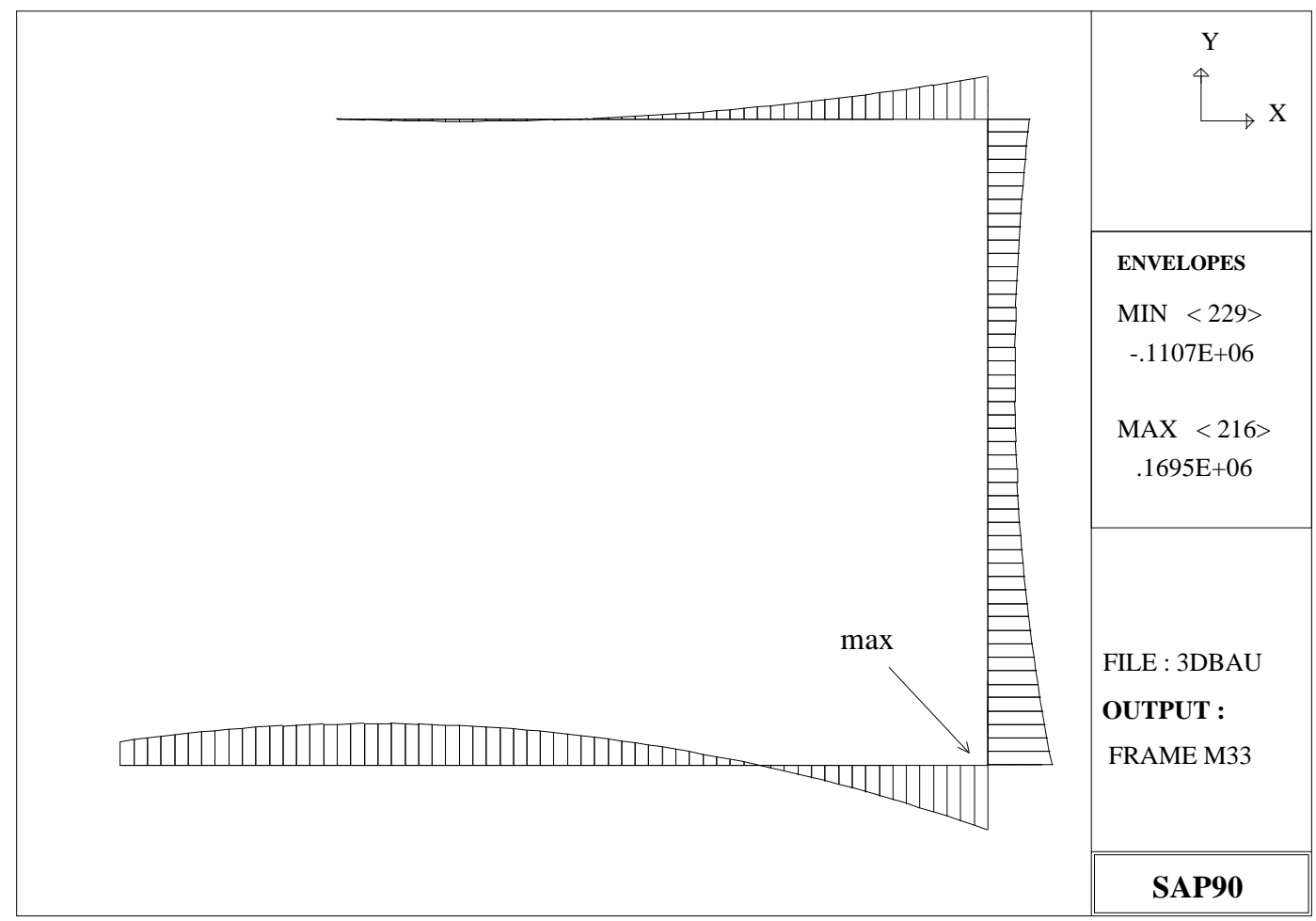

Fig.5.23 - Cav.5 - Distribuição de Momentos Fletores - Modelo 3D.

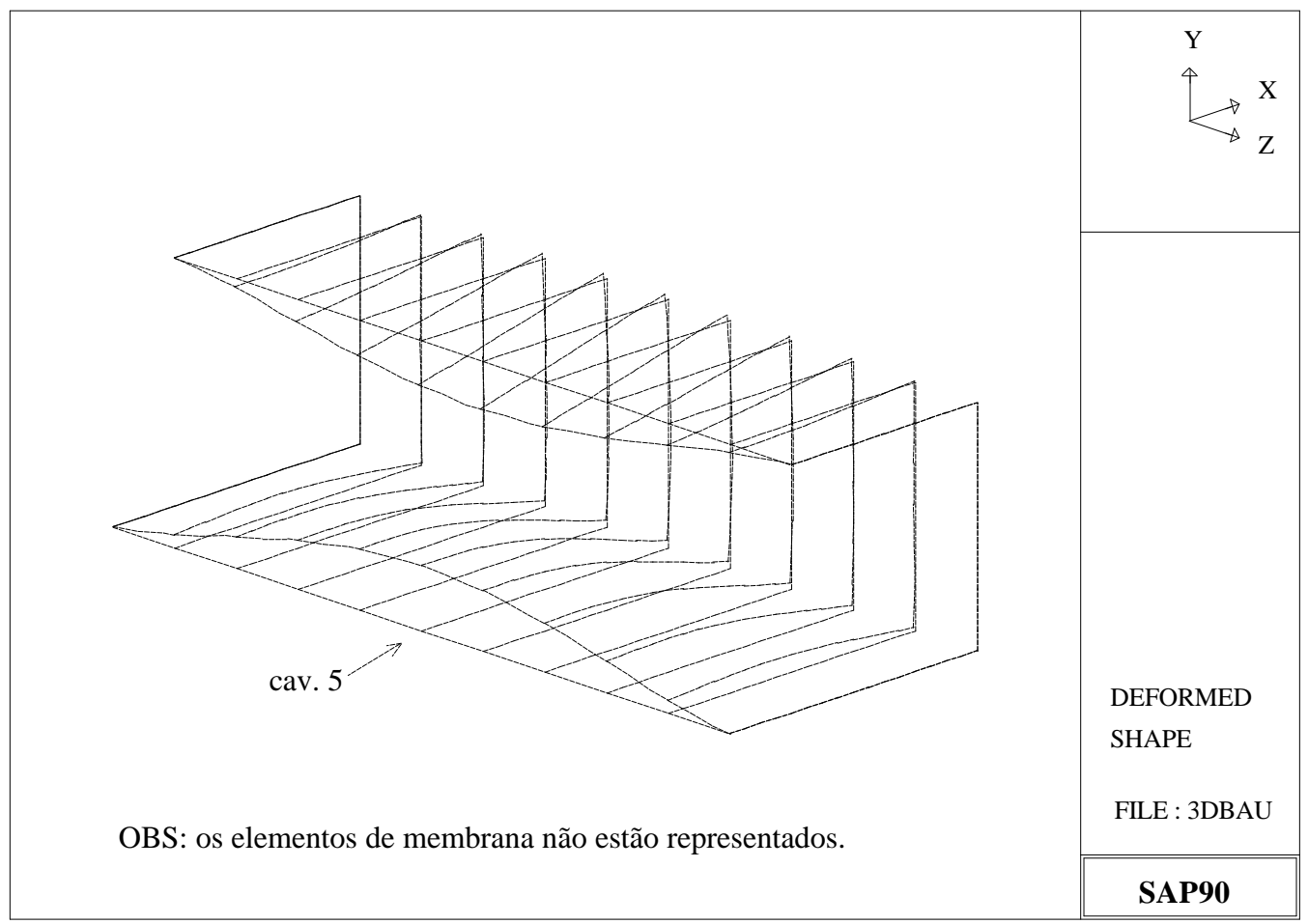

Fig.5.24 - Navio-Caixa -Estrutura Deformada-Modelo 3D. 
Os resultados obtidos com o modelo $2 \mathrm{D}$, para as constantes elásticas adotadas no item 5.2.1, produziram diferenças aceitáveis em relação aos valores encontrados no modelo 3D: $10 \%$ para os momentos fletores e $25 \%$ para os deslocamentos máximos. No entanto, outros testes efetuados variando-se os valores das constantes elásticas conduziram a resultados muito diferentes dos produzidos pelo modelo 3D - por exemplo, calculando-se os valores das constantes pela Eq.2.11, os momentos e deslocamentos resultantes passam a diferir de $52 \%$ e $81 \%$, respectivamente, em relação ao modelo 3D. Para este exemplo em particular, no primeiro caso o modelo 3D apresentou-se conservador ${ }^{1}$ em relação ao modelo $2 \mathrm{D}$ e no segundo ocorreu o inverso, ou seja, a qualidade dos resultados fornecidos pelo modelo 2D é função do bom ajuste dos valores dos apoios elásticos. Nos testes e exemplos utilizados ao longo da elaboração deste trabalho, os resultados conseguidos com os apoios elásticos calculados pela Eq.2.17 apresentaram coerência com os resultados dos respectivos modelos tridimensionais. Esses mesmos testes e exemplos nos permitiram validar o modelo aqui proposto como uma boa ferramenta para o cálculo e projeto da estrutura.

\subsection{EXEMPLOS DE UTILIZAÇÃO DA OPÇÃO SÍNTESE.}

O programa TRANSEC foi utilizado para executar a síntese da estrutura transversal de dois compartimentos de um navio-patrulha. Esses compartimentos foram sintetizados —Refs.[19] e [20]— através de modelos tridimensionais, utilizando-se o MEF.

\subsubsection{SÍNTESE DA CAVERNA 17.}

A Ref.[19] apresenta a análise tridimensional do compartimento de vante de um navio patrulha. Tal compartimento foi considerado através de duas seções típicas em função da variação da geometria do casco na região analisada. Foi admitido que o compartimento pudesse ser suficientemente representado por estas cavernas típicas. Como primeiro exemplo de utilização da opção Síntese foram consideradas as seções típicas que definem as cavernas 16 a 18 do navio patrulha, doravante chamada de caverna 17.

${ }^{1}$ Consideramos que um modelo é conservador em relação a outro quando as tensões obtidas pelo primeiro são maiores que para o outro. 
A Fig.5.25, extraída da Ref.[19], mostra os escantilhões finais para a caverna 17 obtidos por uma análise tridimensional do compartimento, executada pelo programa de elementos finitos SAPIV[26]. Cavernas e longitudinais foram modelados como elementos de viga e o chapeamento como elementos de membrana. O carregamento utilizado está representado na Fig.5.26 e é o mesmo para o modelo bidimensional.

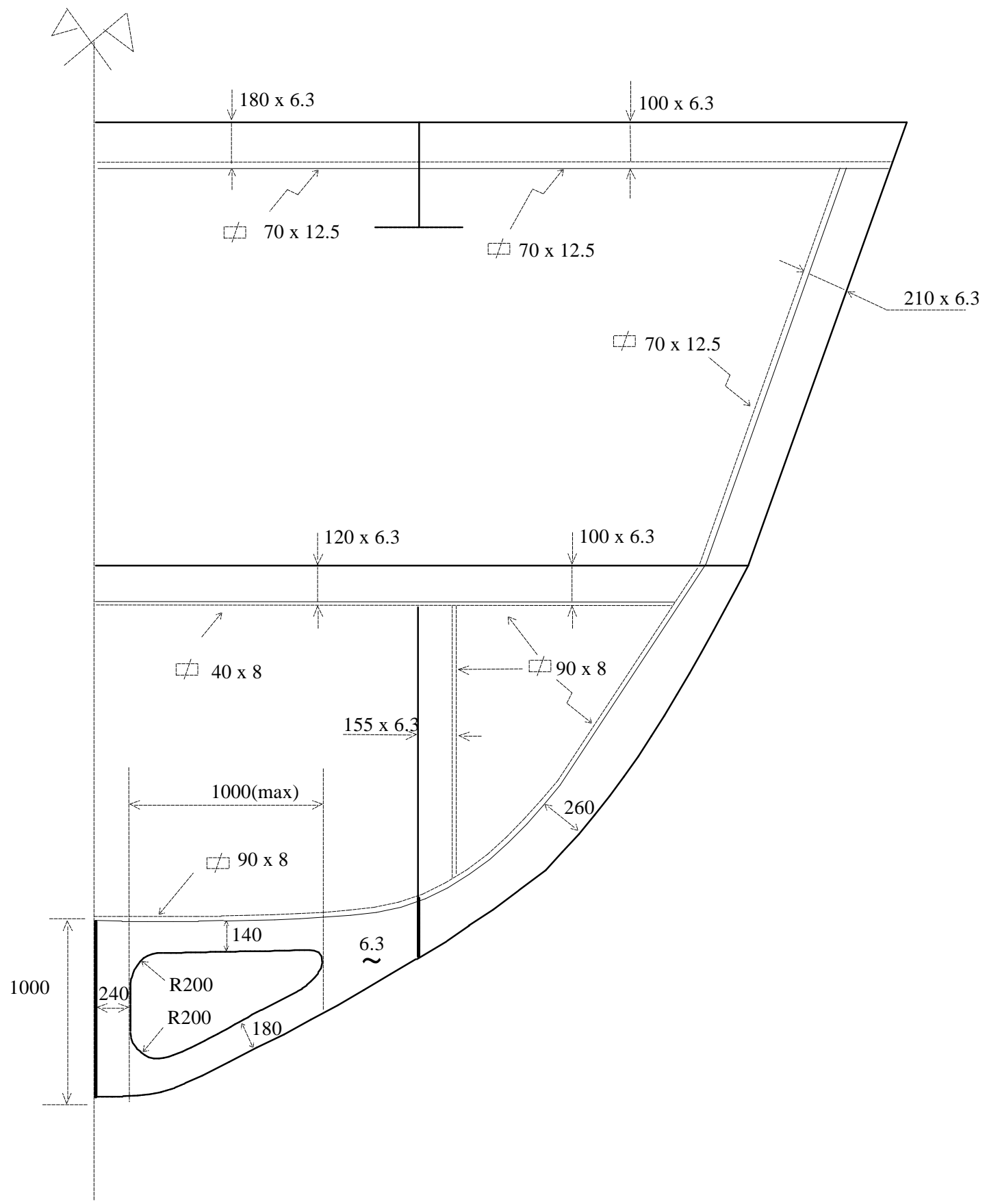

Fig.5.25 - Seção Típica das Cavernas 16,17,18 - Modelo 3D. 
Na Fig.5.26 estão representadas as principais características do modelo 2D utilizado para representar a caverna 17. Os apoios elásticos simulando a interação do anel com os longitudinais pesados foram calculados de acordo com a Eq.2.17.

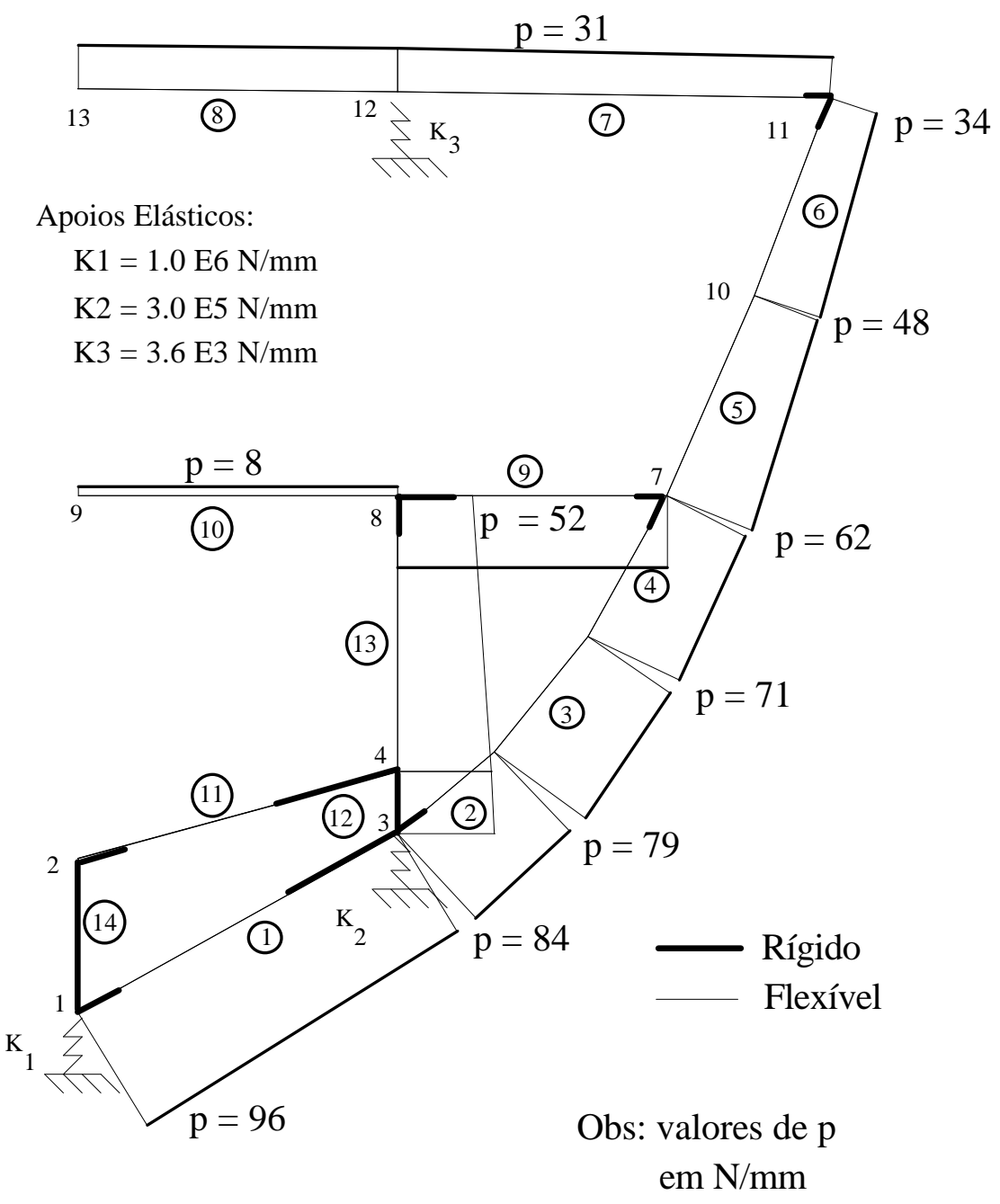

Fig.5.26 - Cav.17-Geometria e Carregamentos Laterais - Modelo 2D.

Os dados de entrada para o módulo TRANSFIN, estão representados nas Tabs.B.9 a B.13 do apêndice B. As tabelas B.14 e B.15 apresentam os perfis disponíveis para a síntese e as dimensões da chapa colaborante. Os perfis são do tipo $T$, todos com flange idênticos de $70 \mathrm{~mm} \times 12.5 \mathrm{~mm}$, alma com espessura igual a $6.3 \mathrm{~mm}$ e altura variando de $100 \mathrm{~mm}$ a $300 \mathrm{~mm}$ com um passo de $10 \mathrm{~mm}$. As tensões admissíveis estão na faixa de 141 a $157 \mathrm{MPa}$.

As tabelas $B .16$ a $B .22$ apresentam os principais resultados fornecidos pelo programa TRANSEC. 
As tensões equivalentes máximas apresentadas no último ciclo da Tab.B.20 estão representadas na Fig.5.27. Os valores abaixo do valor mínimo estipulado $-141 \mathrm{MPa}$ — indicam que, na tabela de perfis utilizada, o menor perfil disponível ainda oferece um módulo de resistência maior que o necessário para o tramo. Acrescentando-se na tabela perfis "menores" que o primeiro lá apresentado, estes seriam utilizados para os tramos onde o valor foi abaixo do mínimo desejado pelo usuário.

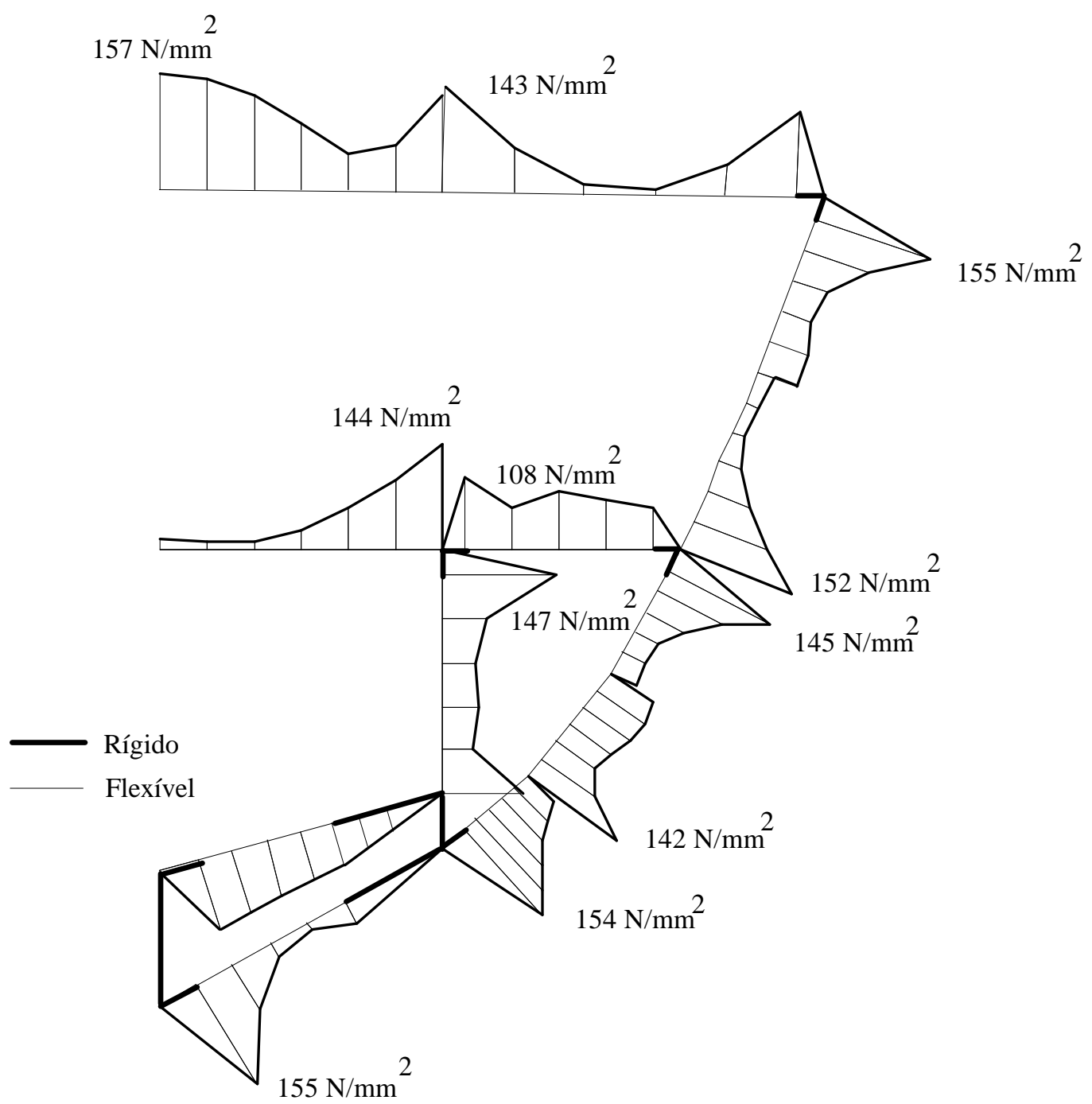

Fig.5.27 - Cav.17-Dist. das Tensões Equivalentes Máximas - Modelo 2D. 
A Fig.5.28, gerada pelo módulo TRANSPLT, ilustra os deslocamentos nodais da estrutura.

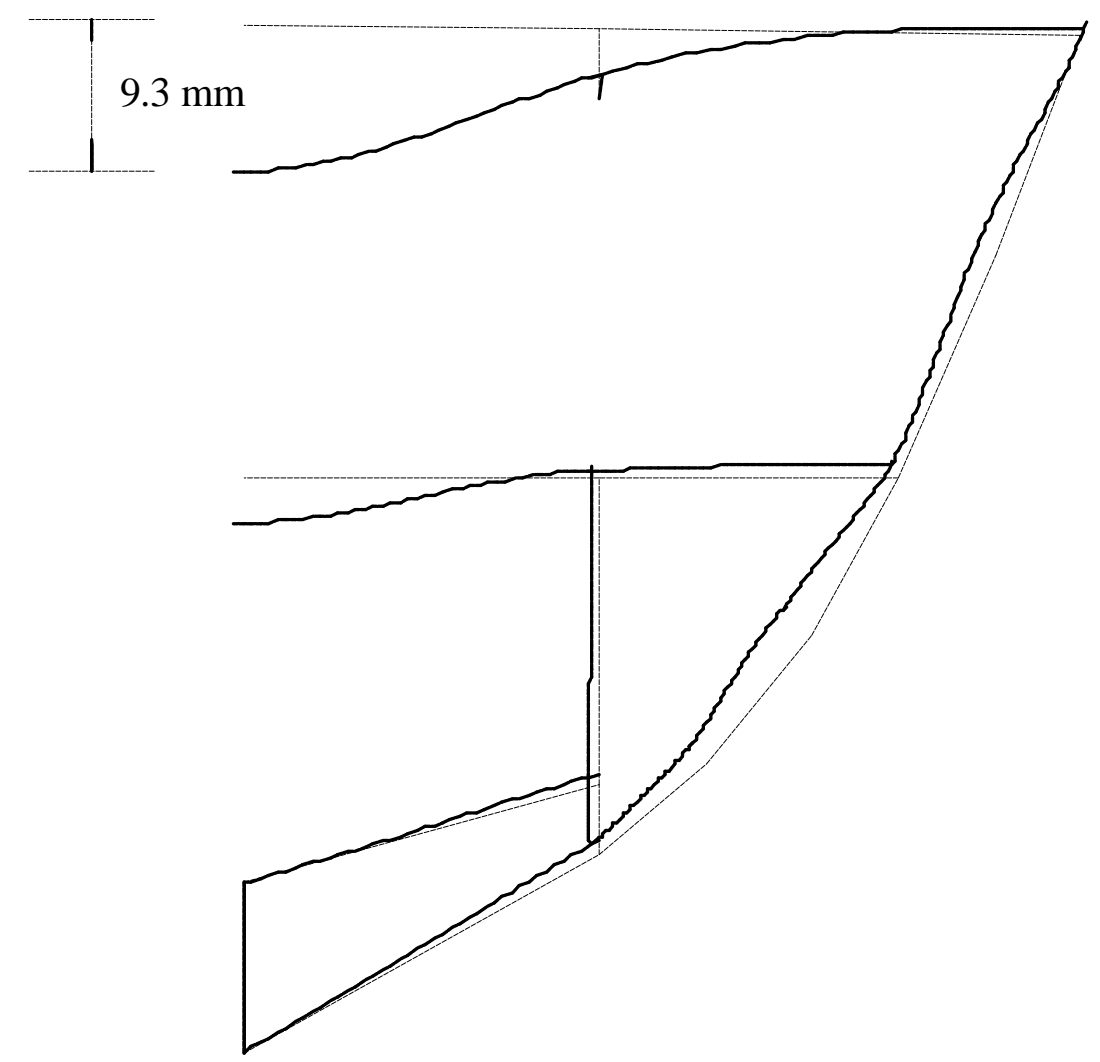

Fig.5.28 - Cav.17 - Deslocamentos na Estrutura - Modelo 2D.

A Tab.5.1 mostra os perfis obtidos na análise tridimensional e pelo programa TRANSEC. A notação está de acordo com o mostrado na Fig.5.29.

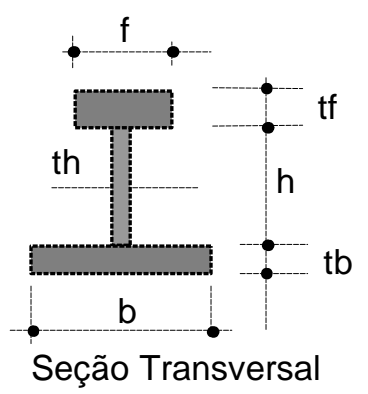

Fig.5.29 - Dimensões da Seção Transversal do Perfil. 
Tab. 5.1 - Cav.17 - Resultados dos Modelos 2D e 3D.

\begin{tabular}{||c||c|c|c|c|c|c||}
\hline \multirow{2}{*}{ Prf } & \multicolumn{3}{c|}{$T R A N S E C$} & \multicolumn{2}{c||}{ Modelo Tridimensional } \\
\hline N. & bxtb $^{*} 1$ & hxth & fxtf & bxtb & hxth & fxtf \\
\hline \hline 1 & $1030 \times 8.0$ & $190 \times 6.3$ & $70 \times 12.5$ & $1030 \times 8.0$ & $180 \times 6.3$ & - \\
\hline 2 & $1030 \times 8.0$ & $240 \times 6.3$ & $70 \times 12.5$ & $1030 \times 8.0$ & $260 \times 6.3$ & $90 \times 8.0$ \\
\hline 3 & $1030 \times 8.0$ & $100 \times 6.3$ & $70 \times 12.5$ & $1030 \times 8.0$ & $260 \times 6.3$ & $90 \times 8.0$ \\
\hline 4 & $1030 \times 8.0$ & $140 \times 6.3$ & $70 \times 12.5$ & $1030 \times 8.0$ & $260 \times 6.3$ & $90 \times 8.0$ \\
\hline 5 & $1030 \times 8.0$ & $240 \times 6.3$ & $70 \times 12.5$ & $1030 \times 8.0$ & $210 \times 6.3$ & $70 \times 12.5$ \\
\hline 6 & $1030 \times 6.3$ & $130 \times 6.3$ & $70 \times 12.5$ & $1030 \times 6.3$ & $210 \times 6.3$ & $70 \times 12.5$ \\
\hline 7 & $1030 \times 6.3$ & $170 \times 6.3$ & $70 \times 12.5$ & $1030 \times 6.3$ & $200 \times 6.3$ & $70 \times 12.5$ \\
\hline 8 & $1030 \times 6.3$ & $190 \times 6.3$ & $70 \times 12.5$ & $1030 \times 6.3$ & $180 \times 6.3$ & $70 \times 12.5$ \\
\hline 9 & $1030 \times 4.3$ & $100 \times 6.3$ & $70 \times 12.5$ & $1030 \times 4.3$ & $100 \times 6.3$ & $90 \times 8.0$ \\
\hline 10 & $1030 \times 4.3$ & $100 \times 6.3$ & $70 \times 12.5$ & $1030 \times 4.3$ & $120 \times 6.3$ & $40 \times 8.0$ \\
\hline 11 & - & $100 \times 6.3$ & $70 \times 12.5$ & - & $140 \times 6.3$ & $90 \times 8.0$ \\
\hline 12 & - & - & - & - & - & - \\
\hline 13 & $1030 \times 7.2$ & $120 \times 6.3$ & $70 \times 12.5$ & $1030 \times 7.2$ & $155 \times 6.3$ & $90 \times 8.0$ \\
\hline \hline
\end{tabular}

1. largura efetiva fornecida pelo usuário.

Os perfis obtidos pelo modelo tridimensional, expostos na Tab.5.1, representam os valores já uniformizados tendo em vista a construção. Ainda assim, os valores fornecidos pelo programa TRANSEC são muito próximos dos respectivos valores no modelo tridimensional.

\subsubsection{SÍNTESE DE UMA CAV. TÍPICA DO COMPARTIMENTO 50/60.}

Este exemplo foi tomado a partir da Ref.[20], que apresenta a síntese do compartimento de ré de um navio patrulha, formado no vão compreendido entre as cavernas 50 e 60. Foi utilizado um modelo tridimensional, corrido no programa de elementos finitos SAPIV. Os escantilhões obtidos estão representados na Fig.5.30.

Os dados de entrada para o módulo TRANSFIN, estão representados nas Tabs.B.23 a B.27 do apêndice $B$. Os perfis disponíveis para a síntese e as dimensões da chapa colaborante estão apresentados, respectivamente, nas Tabs.B.28 e B.29. A Fig.5.31 esquematiza a geometria discretizada e os carregamentos laterais na estrutura. Analogamente ao caso anterior, os perfis são do tipo $T$, com flanges de $70 \mathrm{~mm}$ x $12.5 \mathrm{~mm}$, alma de espessura igual a 6.3 mm e altura variando de $100 \mathrm{~mm}$ a $700 \mathrm{~mm}$ com passos de $10 \mathrm{~mm}$ e $50 \mathrm{~mm}$. A faixa de tensões admissíveis é a mesma do exemplo anterior, ou seja, de 141 a $157 \mathrm{MPa}$. 


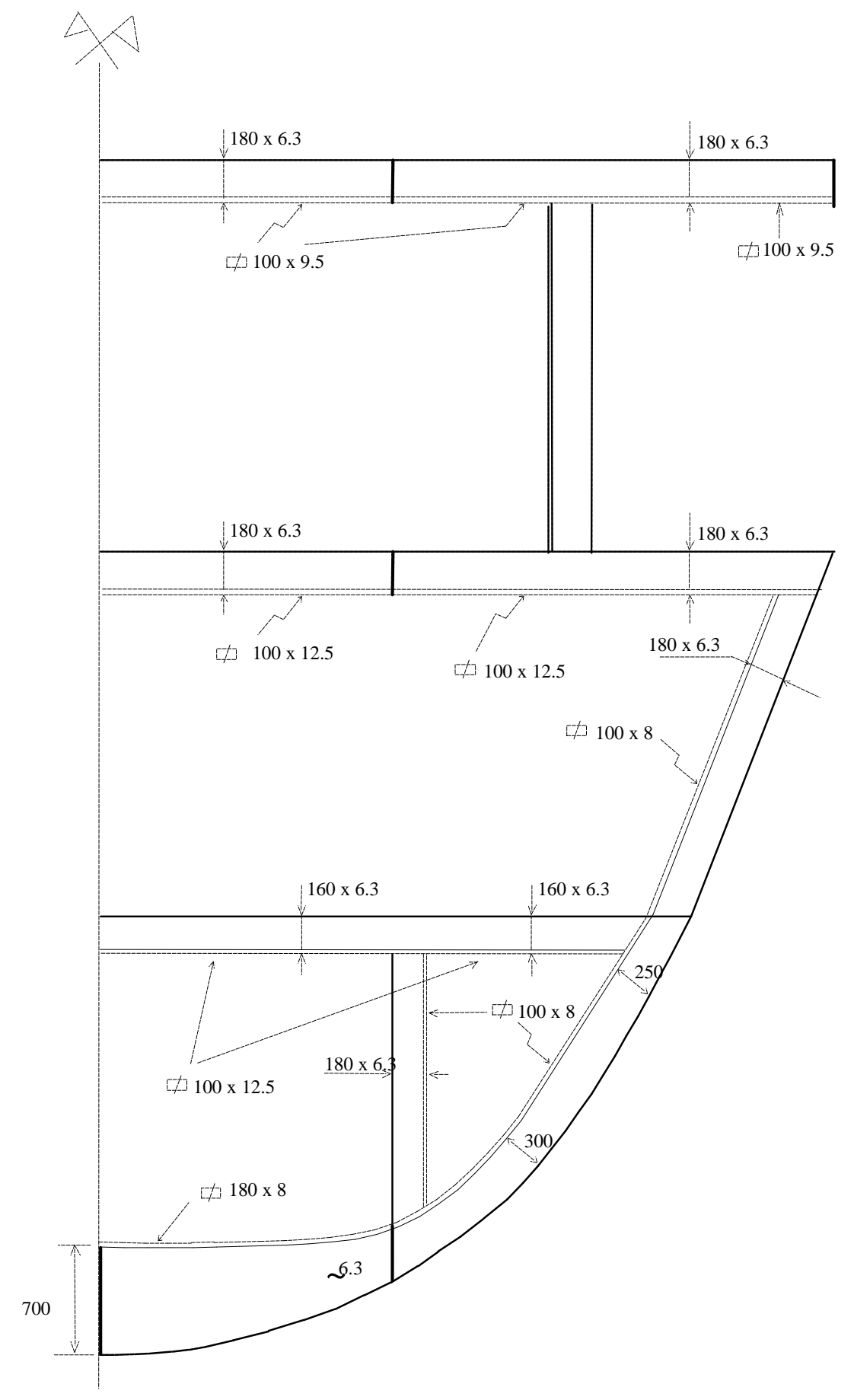

Fig.5.30 - Seção Típica das Cavs. do Compartimento 50/60 - Modelo 3D. 


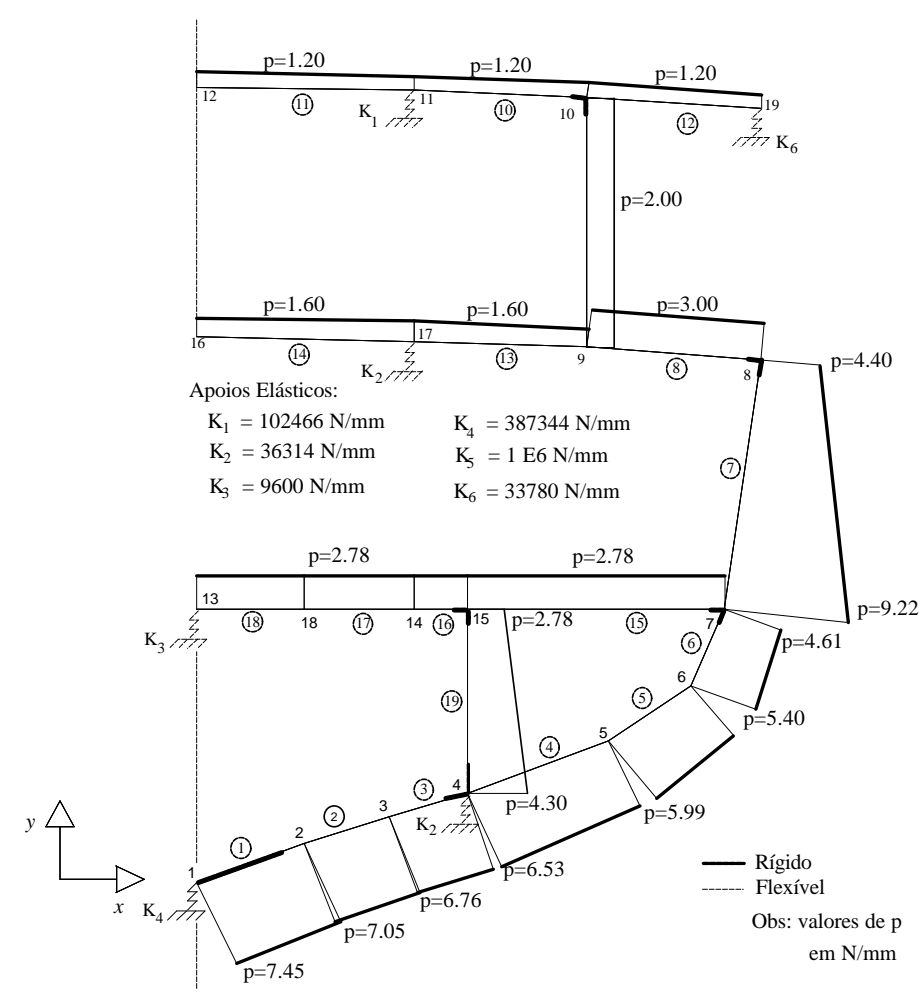

Fig.5.31 - Cav.55 - Geometria e Carregamentos Laterais - Modelo 2D.

As Tabs.B.30 a B.36 apresentam os principais resultados fornecidos pelo programa TRANSEC. Nas Figs.5.32 e 5.33 estão representados os deslocamentos nodais da estrutura e a distribuição das tensões equivalentes máximas obtidas pelo programa, correspondente ao último ciclo de valores apresentados na Tab.B.34.

A Tab.5.2 apresenta os perfis obtidos pelos dois modelos. A nomenclatura utilizada esta de acordo com o mostrado na Fig.5.29. 


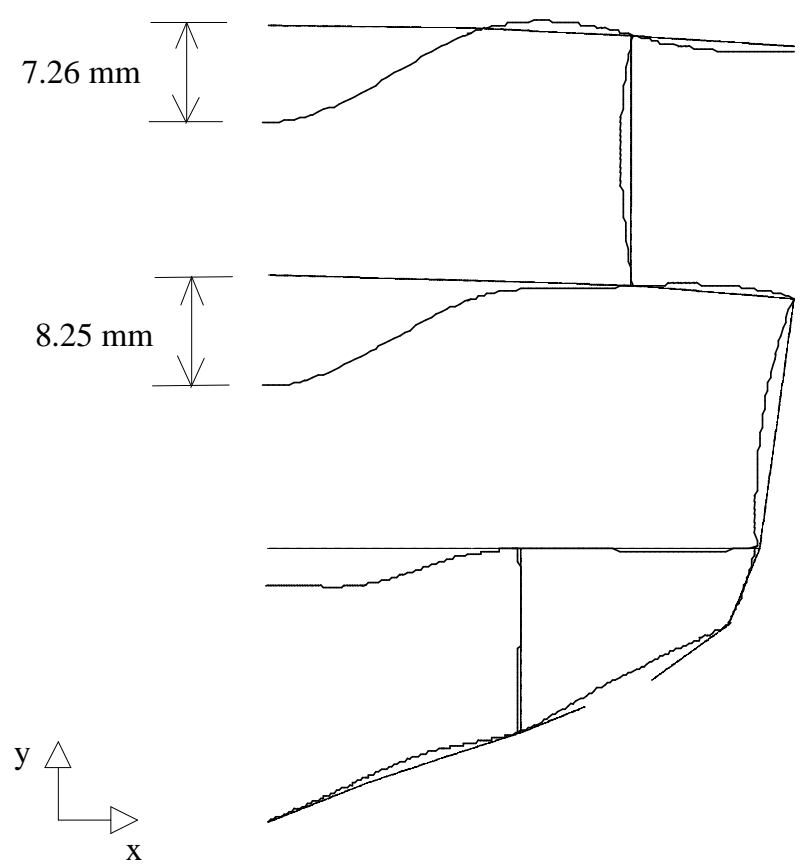

Fig.5.32 - Cav.55 - Deslocamentos Nodais na Estrutura-Modelo 2D

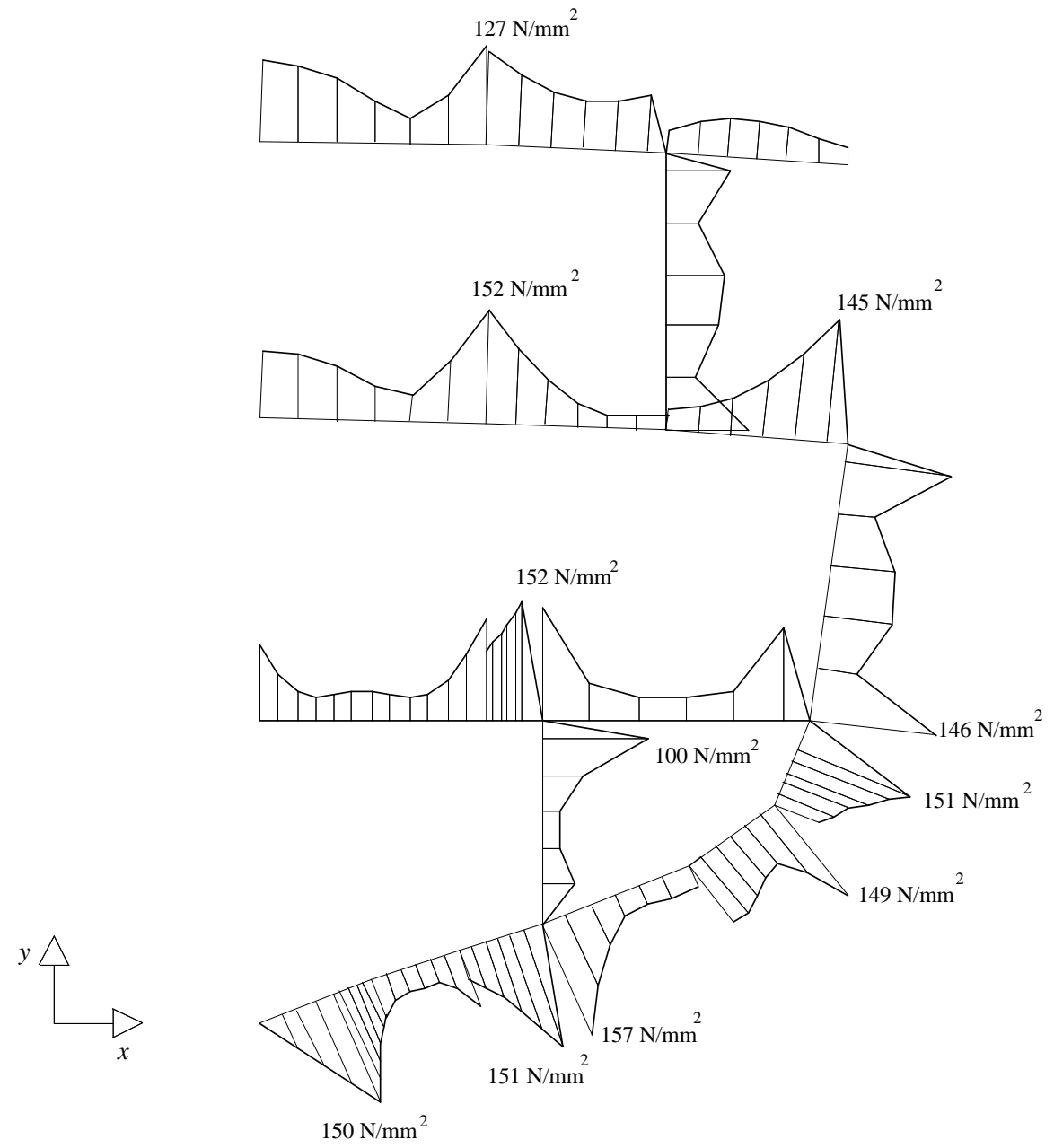

Fig.5.33 - Cav.55 - Tensões Equivalentes Máximas - Modelo 2D. 
Tab.5.2 - Cav.55 - Resultados dos modelos 2D e 3D.

\begin{tabular}{||c||c|c|c|c|c|c||}
\hline \multirow{2}{*}{ Prf } & \multicolumn{2}{|c|}{ Modelo Tridimensional } & \multicolumn{3}{c|}{$T R A N S E C$} \\
\hline N. & bxtb ${ }^{*} 1$ & hxth & fxtf & bxtb & hxth & fxtf \\
\hline \hline 1 & $1030 \times 8.0$ & $700 \times 6.3$ & $180 \times 8.0$ & $1030 \times 8.0$ & $140 \times 6.3$ & $70 \times 12.5$ \\
\hline 2 & $1030 \times 8.0$ & $550 \times 6.3$ & $180 \times 8.0$ & $1030 \times 8.0$ & $100 \times 6.3$ & $70 \times 12.5$ \\
\hline 3 & $1030 \times 8.0$ & $430 \times 6.3$ & $180 \times 8.0$ & $1030 \times 8.0$ & $230 \times 6.3$ & $70 \times 12.5$ \\
\hline 4 & $1030 \times 8.0$ & $300 \times 6.3$ & $100 \times 8.0$ & $1030 \times 8.0$ & $240 \times 6.3$ & $70 \times 12.5$ \\
\hline 5 & $1030 \times 8.0$ & $275 \times 6.3$ & $100 \times 8.0$ & $1030 \times 8.0$ & $100 \times 6.3$ & $70 \times 12.5$ \\
\hline 6 & $1030 \times 8.0$ & $250 \times 6.3$ & $100 \times 8.0$ & $1030 \times 8.0$ & $190 \times 6.3$ & $70 \times 12.5$ \\
\hline 7 & $1030 \times 6.3$ & $180 \times 6.3$ & $100 \times 8.0$ & $1030 \times 6.3$ & $210 \times 6.3$ & $70 \times 12.5$ \\
\hline 8 & $1030 \times 5.0$ & $180 \times 6.3$ & $100 \times 12.5$ & $1030 \times 5.0$ & $200 \times 6.3$ & $70 \times 12.5$ \\
\hline 9 & $1030 \times 6.3$ & $160 \times 5.0$ & $100 \times 8.0$ & $1030 \times 6.3$ & $100 \times 6.3$ & $70 \times 12.5$ \\
\hline 10 & $1030 \times 8.0$ & $180 \times 6.3$ & $100 \times 9.5$ & $1030 \times 8.0$ & $100 \times 6.3$ & $70 \times 12.5$ \\
\hline 11 & $1030 \times 8.0$ & $180 \times 6.3$ & $100 \times 9.5$ & $1030 \times 8.0$ & $100 \times 6.3$ & $70 \times 12.5$ \\
\hline 12 & $1030 \times 8.0$ & $180 \times 6.3$ & $100 \times 9.5$ & $1030 \times 8.0$ & $100 \times 6.3$ & $70 \times 12.5$ \\
\hline 13 & $1030 \times 5.0$ & $180 \times 6.3$ & $100 \times 12.5$ & $1030 \times 5.0$ & $120 \times 6.3$ & $70 \times 12.5$ \\
\hline 14 & $1030 \times 5.0$ & $180 \times 6.3$ & $100 \times 12.5$ & $1030 \times 5.0$ & $120 \times 6.3$ & $70 \times 12.5$ \\
\hline 15 & $1030 \times 6.3$ & $160 \times 6.3$ & $100 \times 12.5$ & $1030 \times 6.3$ & $100 \times 6.3$ & $70 \times 12.5$ \\
\hline 16 & $1030 \times 6.3$ & $160 \times 6.3$ & $100 \times 12.5$ & $1030 \times 6.3$ & $150 \times 6.3$ & $70 \times 12.5$ \\
\hline 17 & $1030 \times 6.3$ & $160 \times 6.3$ & $100 \times 12.5$ & $1030 \times 6.3$ & $100 \times 6.3$ & $70 \times 12.5$ \\
\hline 18 & $1030 \times 6.3$ & $160 \times 6.3$ & $100 \times 12.5$ & $1030 \times 6.3$ & $100 \times 6.3$ & $70 \times 12.5$ \\
\hline 19 & $1030 \times 7.2$ & $180 \times 6.3$ & $100 \times 8.0$ & $1030 \times 7.2$ & $100 \times 6.3$ & $70 \times 12.5$ \\
\hline & & & & & & \\
\hline
\end{tabular}

1. largura efetiva fornecida pelo usuário.

Os valores obtidos pelos dois modelos apresentam diferenças significativas para alguns perfis. Isto porque os perfis obtidos com o modelo tridimensional, tal como estão colocados na Tab.5.2, representam os valores uniformizados para construção, ou seja, esses perfis foram escolhidos não somente pelo cunho estrutural que possuem, mas também para facilitar a construção. Por exemplo, para os tramos 4, 5 e 6 , o modelo 3D fornece valores decrescentes de tamanho de alma, notadamente visando estabelecer uma transição "suave" entre a região mais próxima da quilha e a parte superior do costado. No primeiro tramo, a diferença gritante é explicada de modo semelhante: na construção é prática comum que o transversal e a quilha tenham a mesma altura, no caso $700 \mathrm{~mm}$.

No modelo 3D, em cada convés, as alturas de alma dos perfis que os compõem são iguais, o que não ocorre nos perfis selecionados pelo programa TRANSEC. Resumindo, o programa TRANSEC fornece os valores de perfis baseado pura e simplesmente nos limites de tensões admíssiveis, enquanto os escantilhões disponíveis para comparação, dados na Tab.5.2, foram revisados no sentido de atender não somente aos requisitos estruturais mas também aos construtivos. 


\section{CAPÍTULO 6}

\section{CONCLUSÕES E RECOMENDACÕES}

A utilização de um modelo plano no cálculo da estrutura transversal, assim como acontece com qualquer outro modelo, possui vantagens e desvantagens. Quando abandonamos o estudo do compartimento completo para investirmos no modelo bidimensional, passamos a estudar, em essência, um pórtico plano. Os longitudinais pesados e o chapeamento, mais apropriadamente representados no modelo 3D, foram colocados no modelo 2D como condições de contorno. Conforme visto, essas condições de contorno visavam representar as interações do anel transversal com os longitudinais pesados e o chapeamento. Foi necessário, então, através de hipóteses, arbitrar como funcionavam essas interações. Deste modo, consegue-se um modelo mais simples, tanto na modelagem como na análise de resultados, mas, em contrapartida, estes resultados podem não reproduzir suficientemente bem os valores conseguidos como o modelo tridimensional, sabidamente mais precisos.

$\mathrm{O}$ caráter conservador ${ }^{1}$, normalmente evidenciado no modelo $2 \mathrm{D}$ para a estrutura transversal, aqui nem sempre se mostrou verdadeiro. A hipótese da interação do anel junto aos longitudinais pesados através de apoios elásticos, embora seja muito razoável, traz consigo o problema de como calculá-los. Assim, dependendo dos valores adotados para estes apoios, o modelo 2D pode determinar estruturas superdimensionadas, em relação ao modelo $3 \mathrm{D}$, ou pode ocorrer o contrário, ou seja, o indicador de um "bom modelo" 2D está no cálculo

\footnotetext{
${ }^{1}$ Em relação ao modelo 3D, conforme observado em trabalhos anteriores, por exemplo na Ref.[27].
} 
dos apoios elásticos. Os resultados obtidos nos exemplos utilizados, nos levaram a validar o uso da Eq.2.17 para o cálculo destes apoios.

A utilização de apoio elástico no costado não pode ser generalizada. $\mathrm{Na}$ elaboração do exemplo do navio-caixa apresentado no capítulo 5 foi necessário introduzir o apoio elástico no costado, dado que os resultados sem a presença do apoio não conduzia aos resultados apresentados pelo modelo 3D. No primeiro modelo de síntese, a presença de um apoio elástico, na direção do plano do costado, gerou resultados praticamente iguais aos fornecidos pelo modelo sem o apoio elástico_este é o que está lá representado. Para o segundo exemplo de síntese os resultados obtidos com o apoio elástico no costado levaram a uma estrutura mais leve que o modelo sem o referido apoio. Ambos, porém, se aproximaram dos resultados pelos modelos tridimensionais. A experiência adquirida ao longo da elaboração deste trabalho recomenda que o usuário tenha bom senso na hora de elaborar seu modelo, principamente no que tange às condições de contorno, pois delas dependerão os deslocamentos e, conseqüentemente, todas as outras grandezas envolvidas no problema.

O trabalho apresentado não pretende abolir o uso de modelos tridimensionais muito menos esgotar o estudo sobre a estrutura transversal de embarcações. Nosso objetivo é fornecer aos engenheiros que venham a executar tal estudo uma ferramenta valiosa para fazê-lo de modo simples e rápido. Os dois modelos tem sua utilidade durante os ciclos de projeto da estrutura transversal do navio. O modelo plano, mais simples e com menores custos, permite uma rápida sintetização dos escantilhões das cavernas consideradas típicas do compartimento. Já o modelo tridimensional, serve para uma verificação — através de uma análise - da estrutura projetada, pois permite contabilizar as características de cada caverna, bem como a ação mais precisa dos elementos longitudinais pesados e do chapeamento.

As cavernas - 17 e 55- sintetizadas pelo modelo 2D no capítulo 5 são exemplos típicos para aplicação da idéia contida no parágrafo anterior: nas Refs.[19] e [20] a síntese pelo modelo tridimensional poderia partir dos perfis obtidos pelo programa TRANSEC, apresentados nas Tabs.5.1 e 5.2. Os dois meses dispendidos para elaborar cada uma das referências citadas seriam substituídos por algumas poucas semanas de trabalho.

Embora a síntese com o modelo aqui proposto seja fruto de um método de otimização baseado na intuição — procura-se maximizar os níveis de solicitação da estrutura—, os resultados obtidos nos permitem avaliar o programa TRANSEC 
como uma poderosa ferramenta no cálculo da estrutura transversal de embarcações.

Algumas limitações por nós observadas no decorrer da elaboração do trabalho podem ser colocadas como sugestões para futuras continuações. São elas:

- no processo de síntese, o programa parte de um valor inicial para o perfil -Eq.5.1—, buscando os perfis numa tabela de perfis. Isto exige que a tabela contenha pelo menos um perfil que satisfaça as tensões admissíveis em cada tramo. Uma outra possibilidade (e esta é a sugestão) é colocar uma rotina para "construir" o perfil, caso o programa não consiga encontrar um perfil satisfatório na tabela.

- a síntese da estrutura do navio compreende, basicamente, a síntese da estrutura transversal e a síntese da estrutura longitudinal. O programa TRANSEC poderia, portanto, ser utilizado na construção de um programa maior, destinado a sintetizar integralmente a estrutura do navio.

- nos modelos sintetizados nos exemplos do capítulo 5, não existiu uma uniformização dos perfis em um mesmo convés. No entanto, para facilitar a construção, é comum se utilizar um mesmo perfil em cada convés. Para a transição fundo-costado, normalmente feita de forma "contínua", não cabem os perfis escolhidos para os tramos 4, 5 e 6 do segundo exemplo de síntese. O programa TRANSEC sintetiza os perfis baseado em critérios estruturais somente, ou seja, não existe implícito no programa qualquer relação entre os perfis sintetizados. A sugestão é incluir no programa uma rotina que permita resolver esses problemas. 
ANEXO A

\section{CÁLCULO DOS COEFICIENTES DE RIGIDEZ}

\section{A.1 CÁlCULO DO COEFICIENTE $\boldsymbol{k}_{55^{*}}$.}

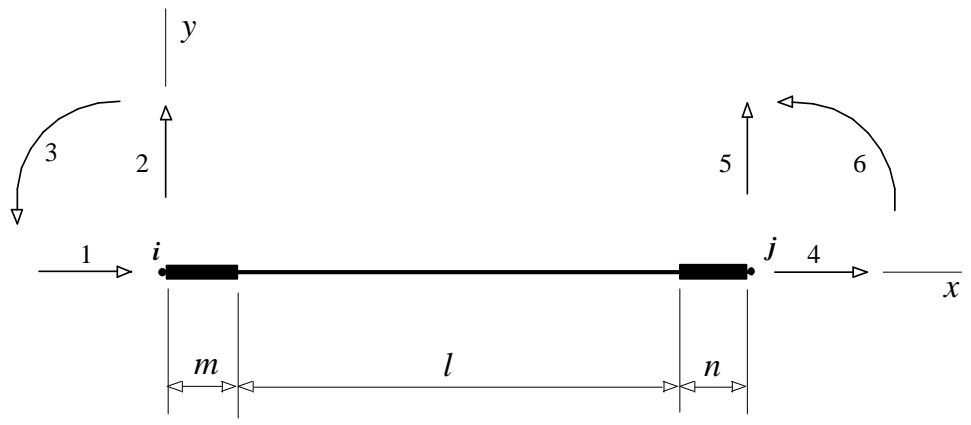

Fig.A.1 - Graus de Liberdade para Elemento de Viga no Plano.

Pela definição devemos impor um deslocamento no grau de liberdade 5, Fig.A.1, o que pode ser feito aplicando-se um momento fletor e uma força conforme mostra a Fig. A.2. Fazendo este deslocamento igual a um, a força $F$ se iguala ao coeficiente $k_{55}$.

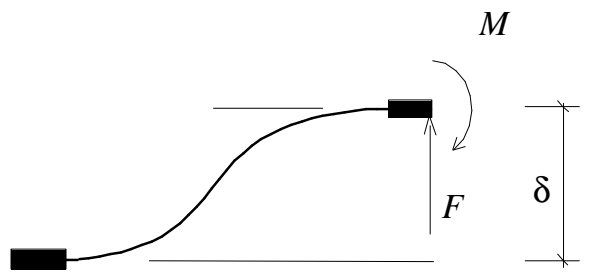

Fig.A.2 - Esforços de Extremidade para Deslocamento $\delta$. 
Sendo a viga estaticamente indeterminada, e o princípio da superposição válido, vamos dividir o problema em dois, conforme mostra a Fig.A.3, e compatibilizar os deslocamentos e rotações para obter o deslocamento $\delta$. Portanto, a viga sofre uma deflexão e uma rotação ocasionadas pela a força $F$ $\delta_{F}$ e $\theta_{F}$, respectivamente- e a deflexão $\delta_{M}$ e rotação $\theta_{M}$ causadas pelo momento fletor $M$. Como condição de compatibilidade devemos impor

$$
\theta_{F}+\theta_{M}=0
$$

e

$$
\delta_{F}+\delta_{M}=\delta
$$

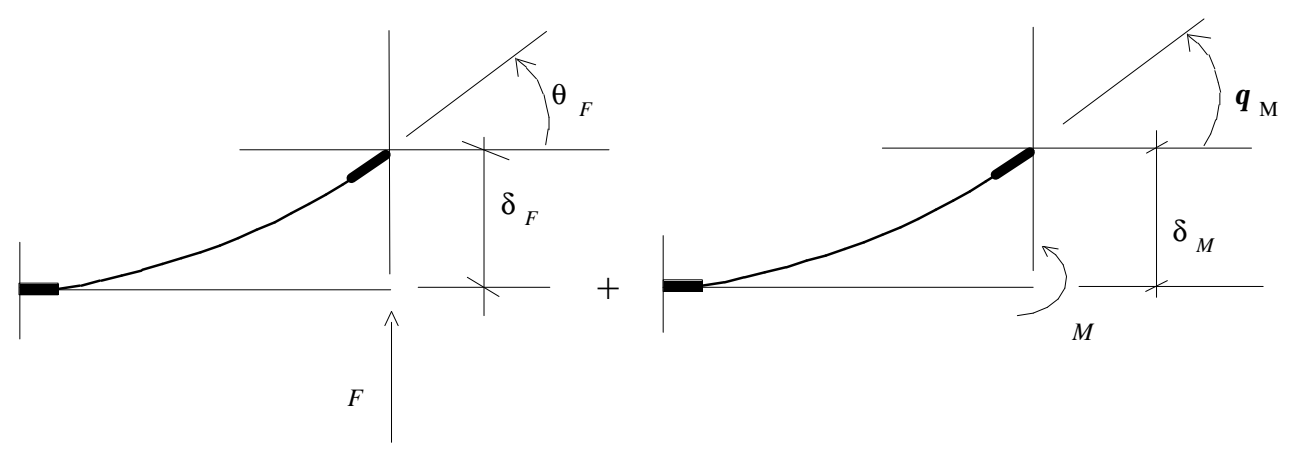

Fig.A.3 - Força e Momento Aplicados Independentemente.

O cálculo dos deslocamentos será feito pelo Método da Carga Unitária ${ }^{1}$, adotando como hipótese a linearidade do material e supondo ser válido o princípio da superposição. $O$ deslocamento em qualquer ponto da viga, considerando-se os efeitos de flexão e de cisalhamento, é dado pela equação

$$
\delta=\int_{0}^{L} \frac{M_{U} \cdot M_{L}}{E I} d x+\int_{0}^{L} \frac{V_{U} \cdot V_{L}}{G A_{C I S}} d x
$$

sendo

$M_{U}$ momento unitário aplicado no ponto onde se deseja calcular o deslocamento.

$M_{L} \quad$ momento devido ao carregamento real.

\footnotetext{
${ }^{1}$ A referência [28] apresenta estudo detalhado deste método.
} 
$V_{U}$ força unitária aplicada aplicado no ponto onde se deseja calcular o deslocamento.

$V_{L} \quad$ força cortante devido ao carregamento real.

E módulo de elasticidade do material.

I momento de inércia da seção transversal.

G módulo de cisalhamento.

$A_{c i s} \quad$ área de cisalhamento definida por $\frac{A}{I^{2}} \cdot \int_{A} \frac{m_{s}^{2}}{t^{2}} \cdot d A$, com $A=$ área da seção.

Inicialmente vamos determinar os deslocamentos devidos à força $F$. Os termos da integral apresentada na Eq.A.3 podem ser determinados considerandose a Fig.A.4.
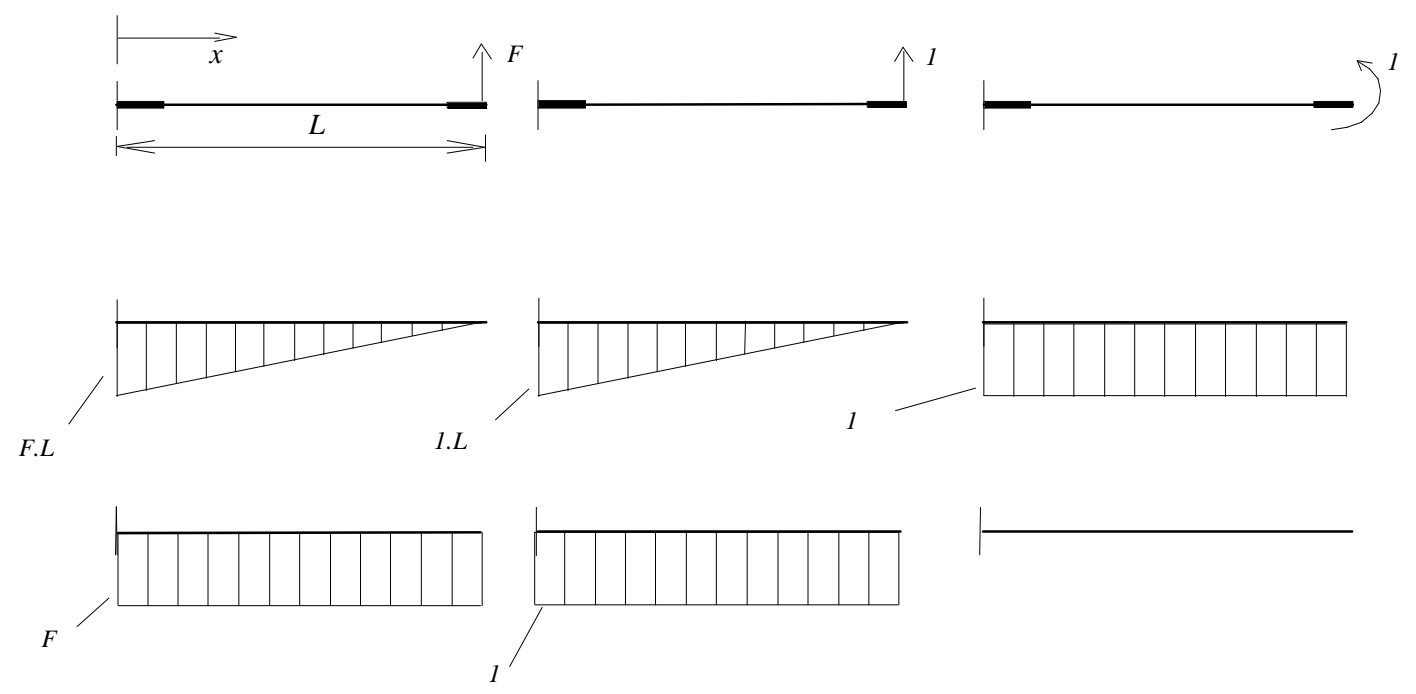

Fig.A.4 - Diagramas para Cálculo dos Deslocamentos devido a F.

Na Fig.A.4 a primeira linha de diagramas fornece os momentos fletores $M_{L}$ e $M_{U}$, devidos ao carregamento real e à carga unitária, respectivamente. A força unitária possibilita calcular do coeficiente de rigidez segundo o G.L.5 e o momento unitário permitirá, no próximo item, o cálculo do coeficiente segundo o G.L.6.

A Eq.A.3, integrada ao longo do comprimento da viga, será divida em três partes uma vez que a seção da viga não é constante.

Assim: 


$$
\begin{aligned}
\delta_{F}= & \int_{0}^{m} \frac{M_{U} \cdot M_{L}}{E I_{m}} d x+\int_{0}^{m} \frac{V_{U} \cdot V_{L}}{G A_{C I S_{m}}} d x+\int_{m}^{L-n} \frac{M_{U} \cdot M_{L}}{E I_{l}} d x+ \\
& \int_{m}^{L-n} \frac{V_{U} \cdot V_{L}}{G A_{C I S_{l}}} d x+\int_{L-n}^{L} \frac{M_{U} \cdot M_{L}}{E I_{n}} d x+\int_{L-n}^{L} \frac{V_{U} \cdot V_{L}}{G A_{C I S_{n}}} d x
\end{aligned}
$$

Na Eq.A.4 as integrais avaliadas ao longo dos extremos rígidos são nulas. Reescrevendo a Eq.A.4 tem-se que

$$
\delta_{F}=\int_{m}^{L-n} \frac{M_{U} \cdot M_{L}}{E I} d x+\int_{m}^{L-n} \frac{V_{U} \cdot V_{L}}{G A_{C I S}} d x
$$

onde os produtos $E I_{l}$ e $G A_{C I S_{l}}$ doravante serão designados por $E I$ e $G A_{C I S}$.

Os diagramas de momentos fletores na Fig.A.4 devidos às forças $F$ e 1 podem ser escritos na forma

$$
\begin{aligned}
& M(F, x)=-F \cdot(L-x) \\
& e \\
& M(1, x)=-1 .(L-x)
\end{aligned}
$$

Portanto, substituindo os valores das Eqs.A.6 no primeiro termo do segundo membro da Eq.A.5 temos:

$$
\begin{aligned}
& \delta_{F I}=\int_{m}^{L-n} \frac{F(L-x)^{2}}{E I} d x \\
& =-\left.\frac{1}{3}(L-x)^{3}\right|_{m} ^{L-n} \\
& =-\frac{1}{3}[L-(L-n)]^{3}+\frac{1}{3}(L-m)^{3} \\
& =-\frac{1}{3} n^{3}+\frac{1}{3}(l+m+n-m)^{3} \\
& =\frac{1}{3}\left(-n^{3}+l^{3}+3 l^{2} n+3 n l^{2}+n^{3}\right)
\end{aligned}
$$

ou seja,

$$
\delta_{F 1}=\frac{F}{E I} \cdot\left(\frac{l^{3}}{3}+l^{2} n+n l^{2}\right)
$$


As forças cortantes, mostradas na segunda linha de digramas da Fig.A.4 são constantes iguais a $F$ e 1 e nula na aplicação do momento $M$. Substituindo os valores na segunda integral da Eq.A.5 temos

$$
\begin{aligned}
& \delta_{F 2}=\int_{m}^{L-n} \frac{F .1}{G A_{C I S}} d x \\
& =\left.x\right|_{m} ^{L-n} \\
& =\left.x\right|_{m} ^{(l+m+n)-n} \\
& =\frac{F \cdot l}{G A_{C I S}}
\end{aligned}
$$

ou

$$
\delta_{F 2}=\frac{F \cdot l}{G A_{C I S}}
$$

Substituindo as Eqs.A.8 e A.10 na Eq.A.5 obtem-se

$$
\delta_{F}=\frac{F}{E I}\left(\frac{l^{3}}{3}+l^{2} n+n^{2} l\right)+\frac{F . l}{G A_{C I S}}
$$

O cálculo de $\theta_{F}$ pode ser feito de modo análogo, bastando substituir os diagramas correspondentes à força unitária por aqueles causados pelo momento unitário, ou seja,

$$
\theta_{F}=\int_{m}^{L-n} \frac{M_{U} \cdot M_{L}}{E I} d x+\int_{m}^{L-n} \frac{V_{U} \cdot V_{L}}{G A_{C I S}} d x
$$

Os diagramas de momentos fletores na Fig.A.4 devidos à força $F$ e ao momento unitário podem ser escritos na forma

$$
\begin{aligned}
& M(F, x)=-F \cdot(L-x) \\
& e^{M(1, x)=-1}
\end{aligned}
$$

Portanto, substituindo os valores das Eqs.A.13 no primeiro termo do segundo membro da Eq.A.12 obtemos: 


$$
\begin{aligned}
& \theta_{F I}=\int_{m}^{L-n} \frac{F(L-x)}{E I} d x \\
& =-\left.\frac{1}{2}(L-x)^{2}\right|_{m} ^{L-n} \\
& =-\frac{1}{2}[L-(L-n)]^{2}+\frac{1}{2}(L-m)^{2} \\
& =-\frac{1}{2} n^{2}+\frac{1}{2}(l+m+n-m)^{2} \\
& =\frac{1}{2}\left(-n^{2}+l^{2}+2 n l+n^{2}\right)
\end{aligned}
$$

ou seja,

$$
\theta_{F I}=\frac{F . l}{2 E I} .(l+2 n)
$$

A segundo integral na Eq.A.12 é nula pois o momento fletor unitário é constante. Assim,

$$
\theta_{F}=\theta_{F 1}=\frac{F \cdot l}{2 E I} .(l+2 n)
$$

O procedimento adotado para calcular a influência da força $F$ no deslocamento deve ser repetido para o momento fletor $M$, ou seja, vamos calcular

$$
\delta_{M}=\int_{m}^{L-n} \frac{M_{U} \cdot M_{L}}{E I} d x+\int_{m}^{L-n} \frac{V_{U} \cdot V_{L}}{G A_{C I S}} d x
$$

Para tanto, vamos considerar os momentos fletores apresentados na Fig.A.5, que podem ser escritos na forma

$$
\begin{aligned}
& M(M, x)=-M \\
& M(1, x)=-1 .(L-x) \\
& e \\
& M(1, x)=-1
\end{aligned}
$$

respectivamente para o momento fletor $M$, a força unitária 1 e o momento unitário 1 . 

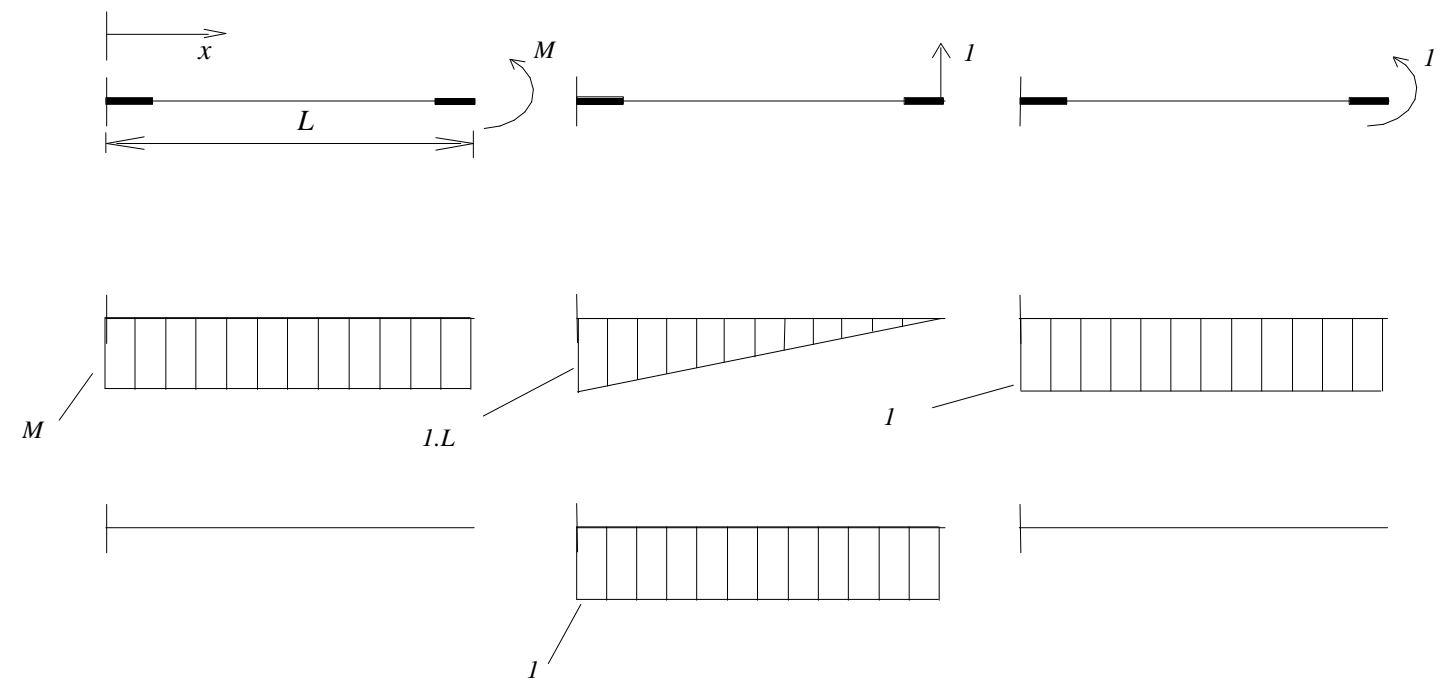

Fig.A.5 Diagramas para Cálculo do Deslocamento devido ao Momento M.

Substituindo os valores das Eqs.A.18 no primeiro termo do segundo membro da Eq.A.17 temos:

$$
\begin{aligned}
& \delta_{M 1}=\int_{m}^{L-n} \frac{M(L-x)}{E I} d x \\
& =-\left.\frac{1}{2}(L-x)^{2}\right|_{m} ^{L-n} \\
& =-\frac{1}{2}[L-(L-n)]^{2}+\frac{1}{2}(L-m)^{2} \\
& =-\frac{1}{2} n^{2}+\frac{1}{2}(l+m+n-m)^{2} \\
& =\frac{1}{2}\left(-n^{2}+l^{2}+2 n l+n^{2}\right)
\end{aligned}
$$

ou seja,

$$
\delta_{M}=\delta_{M I}=-\frac{M}{2 E I} .(l+2 n)
$$

uma vez que o momento fletor $M$ é constante.

O valor de $\theta_{M 1}$ pode ser determinado por

$$
\theta_{M I}=\int_{m}^{L-n} \frac{(-M)(-1)}{E I} d x
$$


$\mathrm{ou}$

$$
\theta_{M}=\theta_{M I}=\frac{M . l}{E I}
$$

Novamente aqui a contribuição da força cortante para os deslocamentos é nula pois o momento $M$ é constante.

Substituindo os valores das Eqs.A.21 e A.16 na Eq.A.1 temos:

$$
\frac{M \cdot l}{E I}+\frac{F \cdot l}{2 E I} \cdot(l+2 n)=0
$$

isolando $M$ obtem-se

$$
M=-\frac{F}{2}(l+2 n)
$$

Substituindo as Eqs.A.20 e A.11 na Eq.A.2, lembrando a relação entre $F$ e $M$ dada pela Eq.A.23 chegamos a

$$
\begin{aligned}
\delta & =\frac{F}{E I}\left(\frac{l^{3}}{3}+l^{2} n+n^{2} l\right)+\frac{F \cdot l}{G A_{C I S}}-\frac{F \cdot l}{4 E I} \cdot(l+2 n) .(l+2 n) \\
& =\left(\frac{l^{3}}{3}+l^{2} n+n^{2} l\right) \frac{F}{E I}+\frac{F \cdot l}{G A_{C I S}}-\frac{F}{4 E I}\left(4 n^{2}+4 n l+l^{2}\right)
\end{aligned}
$$

Reduzindo os termos semelhantes obtem-se

$$
\delta=\frac{F l^{3}}{12 E I}(1+\phi)
$$

sendo

$$
\phi=\frac{12 E I}{l^{2} \cdot G A_{C I S}}
$$

Para $\delta=1, F=k_{55}$, ou seja

$$
k_{55}=\frac{12 E I}{l^{3}} \cdot(1+\phi)
$$




\section{A.2 CÁlCULO DO COEFICIENTE $k_{65}$.}

O coeficiente $k_{65}$ é determinado isolando-se a força $F$ na Eq.A.22

$$
F=-\frac{2 M}{(l+2 n)}
$$

Substituindo as Eqs.A.20 e A.11 na Eq.A.2 chegamos a

$$
\begin{aligned}
\delta & =-\frac{2 M}{E I(l+2 n)}\left(\frac{l^{3}}{3}+l^{2} n+n^{2} l\right)-\frac{2 M}{(l+2 n)} \cdot \frac{l}{G A_{C I S}}+\frac{M \cdot l}{2 E I}(l+2 n) \\
& =-\frac{M}{E I} \cdot\left(\frac{2}{l+2 n}\right)\left(\frac{l^{3}+3 l^{2} n+3 n^{2} l}{3}\right)-\frac{M \cdot \phi \cdot l^{3}}{6 E I(l+2 n)}+\frac{M}{E I}\left(\frac{l^{2}+2 n l}{2}\right)
\end{aligned}
$$

Desenvolvendo os produtos chegamos a

$$
=-\frac{M\left(4 l^{3}+12 l^{2} n+12 n^{2} l+\phi \cdot l^{3}-12 l^{2} n-12 n^{2} l-3 l^{3}\right)}{6 E I(l+2 n)}
$$

Simplificando temos

$$
\delta=-\frac{M l^{3}(1+\phi)}{6 E I(l+2 n)}
$$

Para $\delta=1, M=k_{65}$ :

$$
k_{65}=-\frac{6 E I(l+2 n)}{l^{3}(1+\phi)}
$$

sendo $\phi$ definido pela Eq.A.25.

\section{A.3 CÁlCULO DO COEFICIENTE $\boldsymbol{k}_{66^{\circ}}$}

O cálculo do coeficiente de rigidez $k_{66}$ é feito utilizando as equações já desenvolvidas, modificando-se apenas as condições de compatibilidade que passam a ser

$$
\theta_{F}+\theta_{M}=\theta
$$




$$
\delta_{F}+\delta_{M}=0
$$

Substituindo as Eqs.A.11 e A.20 na Eq.A.31 temos

$$
\frac{F}{E I}\left(\frac{l^{3}}{3}+l^{2} n+n^{2} l+\frac{\phi \cdot l^{3}}{12}\right)+\frac{M \cdot l}{2 E I}(l+2 n)=0
$$

ou

$$
F=-\frac{M \cdot l}{2}(l+2 n) \cdot \frac{12}{\left(4 l^{3}+12 l^{2} n+12 n^{2} l+\phi \cdot l^{3}\right)}
$$

Substituindo-se as Eqs.A.16 , A.21e A.33 na Eq.A.30 obtem-se

$$
\begin{aligned}
& \theta=\frac{M l}{E I}-\frac{l}{E I} \cdot \frac{(l+2 n)}{2} \cdot \frac{M \cdot l}{2}(l+2 n) \cdot \frac{12}{\left(4 l^{3}+12 l^{2} n+12 n^{2} l+\phi \cdot l^{3}\right)} \\
& \theta=-\frac{M l}{E I}+\frac{M}{E I} \frac{\left(12 n^{2} l^{2}+12 n l^{3}+3 l^{4}\right)}{\left(4 l^{3}+12 l^{2} n+12 n^{2} l+\phi \cdot l^{3}\right)} \\
& \theta=-\frac{M l^{3}}{E I} \cdot \frac{(1+\phi)}{\left.\left[(4+\phi) l^{2}+12 n l+12 n^{2}\right)\right]} \\
& \text { Para } \theta=1, M=k_{66} . \text { Portanto: } \\
& k_{66}=\frac{\left.E I .\left[(4+\phi) l^{2}+12 n l+12 n^{2}\right)\right]}{(1+\phi)}
\end{aligned}
$$

e $\phi$ conforme definido na Eq.A.25.

\section{A.4 CÁLCULO DO COEFICIENTE $\boldsymbol{k}_{44^{*}}$}

O cálculo do coeficiente de rigidez $k_{44}$ é mais simples que os feitos até agora. Somente esforços normais são levados em consideração quando aplicamos um deslocamento unitário na direção do grau de liberdade 4. Analogamente ao feito para os coeficientes anteriores, para calcular $k_{44}$ serão admitidas deformações apenas no vão flexível $l$. Assim, a equação para cálculo de deslocamentos toma a forma 


$$
\delta=\int_{m}^{L-n} \frac{N_{U} \cdot N_{L}}{E A} d x
$$

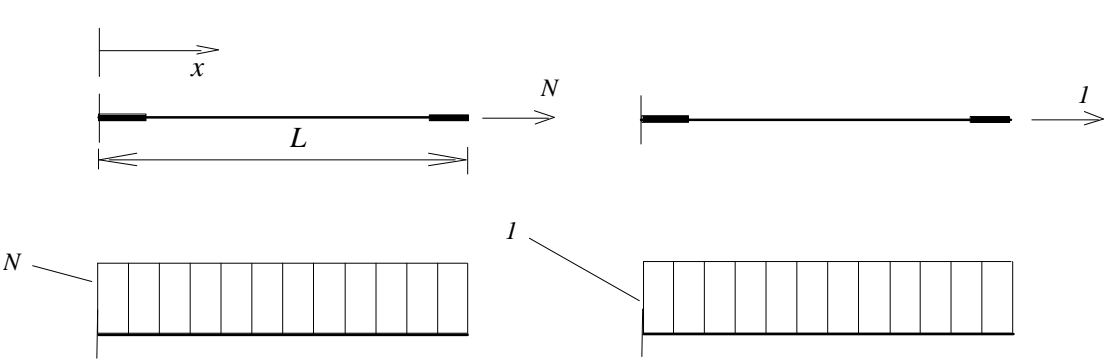

Fig.A.6 Diagramas para Cálculo do Deslocamento devido à Força N.

Substituindo as forças normais constantes na Eq.A.36 temos:

$$
\delta=\frac{N l}{E A}
$$

Para $\delta=1, N=k_{44}$ :

$$
k_{44}=\frac{E A}{l}
$$

Os coeficientes calculados neste anexo são suficientes para montar a submatriz de rigidez $\left[k_{j j}\right]$ 


\section{REFERÊNCIAS BIBLIOGRÁFICAS}

[1] ROBB, A.M., - Theory of Naval Architecture—, Londres, Charles Griffin, 1952.

[2] FUSCO, P.B., - Critérios de Projeto Estrutural dos Navios de

Superfície-, Tese de Doutoramento. Escola Politécnica da USP, São Paulo, 1967.

[3] SÁ FREITAS, E., - Curvas, Tabelas e Notas para projeto - Departamento de Engenharia Naval, EPUSP, São Paulo, 1977.

[4] JENKINS, P., and READ, T.C.,-On the Transverse Strains in IronMerchant Ships-, Trans. I.N.A., 1882, p.174.

[5] BRUHN, J.,-On the Transverse Strength of Ships—, Trans. I.N.A., 1901, p.270.

[6] POPOV, E.P., —Introdução à Mecânica dos Sólidos—, tradução Mauro O.C. Amorelli, São Paulo, Edgard Blücher, 1978.

[7] HOLT, C.F., — On the Strength and Spacing of Transverse Frames-, Trans. I.N.A., 1915, p.70.

[8] HAY, W. I., —Some Notes on Ship's Structural Members—, Trans. I.N.A, 1945, p. 81.

[9] ADAMS, H.J., 一Notes on Stresses in Tanker Members-Trans I.N.A., 1950, p. 262.

[10] THURSTON, J.W.G., —Transverse Strength—, Trans. I.N.A., 1958, p.407.

[11] YUILLE, I.M. and WILSON, L.B., - Transverse Strength of Single Hulled Ships—, Trans. I.N.A., 1960. 
[12] COOK, R.D., - Concepts and Aplications of Finite Element Analysis-

New York, John Wiley \& Sons, 1989.

[13] EVANS, J.H. and KHOUSHY, D., - Optimized Design of Midship Section Structure-, New York, SNAME, 1963.

[14] HUGHES, O.W. at..., - A Practical Method for the Rational Design of Ship Structures—, Journal of Ship Research, Vol.24, Jun. 1980, pp.101113.

[15] MANSOUR, A. and JONES, N., - Elastic and Plastic Analysis of a Tanker Web Frame—- Journal of Ship Research, Vol.17, Sep. 1973, pp.147-161.

[16] FINIFTER, D. and MANSOUR, A., —Finite Element Analysis and Optimization of aWeb Frame of a Tanker With Isolated Ballast Systems—, Journal of Ship Research, Vol.18, Jun. 1974, pp. 85-95.

[17] HUGHES, O.F., —Ship Structural Design A Rationally-Based, Computer-Aided, Optimization Approach—, New York, John Wiley \& Sons, 1983.

[18] SCHADE, H.A., —Bending Theory of Ship Bottom Structure-, SNAME Transactions, Volume 46, pp. 176-187.

[19] NUNES DIAS, C.A., AUGUSTO, O.B., —Análise Tridimensional da Estrutura de Cavernas do Compartimento entre as Cavernas 9 e 19, Visando a Redução do Peso Estrutural do Navio Patrulha-, Relatório Técnico 002/A/407, DEN/MB - Diretoria de Engenharia da Marinha do Brasil, 1987.

[20] NUNES DIAS, C.A., AUGUSTO, O.B., —Análise Tridimensional da Estrutura de Cavernas do Compartimento entre as Cavernas 50 e 60, Visando a Redução do Peso Estrutural do Navio Patrulha-, Relatório Técnico 003/407, DEN/MB - Diretoria de Engenharia da Marinha do Brasil, 1987.

[21] BUELTA, M.A.M., 一Um Modelo de Placas e Vigas Excêntricas para a Análise de Chapeamentos Reforçados - Dissertação de Mestrado. Escola Politécnica da USP, São Paulo,1977. 
[22] NUNES DIAS, C.A., AUGUSTO, O.B., -Projeto das Cavernas da Região de Vante das Praças de Máquinas do Navio Patrulha-, Relatório Técnico 009/4001, DEN/MB - Diretoria de Engenharia da Marinha do Brasil, 1986.

[23] NUNES DIAS, C.A., AUGUSTO, O.B., -Análise da Estrutura de Cavernas de Seções Típicas 5 e 69, visando Redução do Peso Estrutural do Navio Patrulha.-, Relatório Técnico n.005/A/407, DEN/MB - Diretoria de Engenharia da Marinha do Brasil, 1987.

[24] ZIENCIEWICZ,.O.C., — The Finite Element Method-, Vol. 1, Basic Formulation and Linear Problems, London, McGRaw-Grill Book Co., 1989.

[25] WILSON, E.L. and HABIBULLAH, A. - SAP90 - A Series of Computer Programs for the Static and Dynamic Finite Element Analysis of Sttructures, User's Manual — , Berkeley, Califórnia, Computers \& Structures Inc, 1988.

[26] WILSON, E.L., BATHE, K.J. , PETERSON, F.E. - SAPIV - A Structural Analysis Program for Static and Dynamic Finite Element Responses of Linear Sistems — , College of Engineering of Califórnia, 1974.

[27] NUNES DIAS, C.A., AUGUSTO, O.B., -Análise Tridimensional da Estrutura de Cavernas do Compartimento de Vante das Praças de Máquinas (entre Cavernas 19 e 29) visando Redução do Peso Estrutural do Navio Patrulha.- Relatório Técnico CEPEN n.001/407, DEN-Diretoria de Engenharia da Marinha do Brasil, 1987.

[28] TIMONSHENKO, S.P.; GERE,J.E., —Mecânica dos Sólidos—, Trad. de José Rodrigues de Carvalho. Rio de Janeiro, LTC - Livros Técnicos e Científicos, 1984.

[29] POPOV, E.P., —Resistência dos Materiais—, Rio de Janeiro, Prentice-all do Brasil, 1984. 


\section{APÊNDICE A}

\section{APLICACÃO DO ELEMENTO DE CISALHAMENTO}

O elemento de cisalhamento desenvolvido no item 4.2 não é comum na literatura clássica existente sobre o MEF. Visando verificar o elemento elaborado, incluímos neste apêndice um teste de convergência para uma viga de seção retangular com resultado teórico conhecido. Seguindo, apresentamos um exemplo do cálculo da distribuição das tensões de cisalhamento em uma seção típica de navio petroleiro. Para os fins aqui estabelecidos o elemento apresentou resultados satisfatórios.

\section{A.1 TESTE DE CONVERGÊNCIA.}

Para verificar a convergência, vamos considerar a Fig.A.1. Admitindo que a seção mostrada na Fig.A.1(a) esteja sob flexão em relação ao eixo $x$, temos que a distribuição analítica das tensões de cisalhamento pode ser dada ${ }^{1}$ pela equação

$$
\tau=\frac{3\left(\mathrm{H}^{2}-4 \mathrm{y}^{2}\right)}{2 \mathrm{BH}^{3}}
$$

sendo que a força de cisalhamento foi tomada como unitária.

Sendo o comportamento da viga simétrico podemos modelar apenas metade da seção transversal como mostra a Fig.A.1(b). Para uma discretização de 40 elementos o resultado numérico praticamente iguala o valor teórico esperado.

${ }^{1}$ A Ref.[29] apresenta a dedução deste equação. 
A Fig.A.1(c) apresenta essa comparação, onde a diferença média obtida foi menor que 3\%, chegando a praticamente zero na região próxima à linha neutra. Para propósitos práticos os valores obtidos são razoáveis.

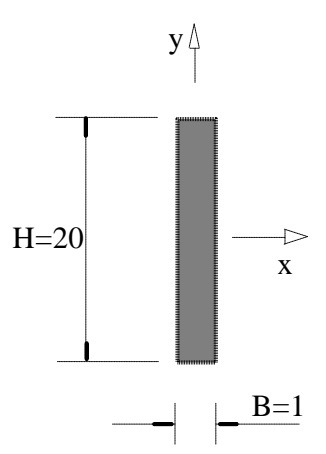

seção transversal da viga.

(a)

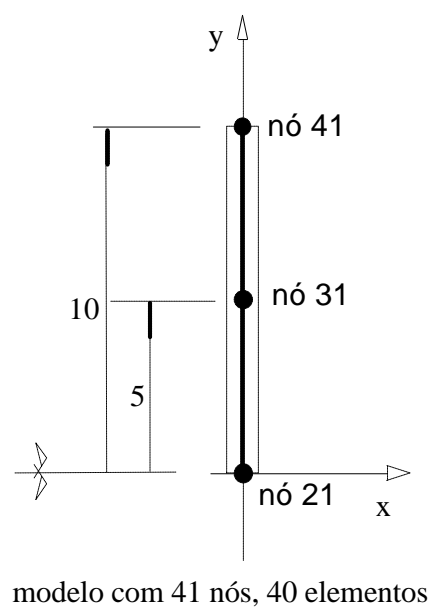

simetria em relação ao eixo $\mathrm{x}$

(b)

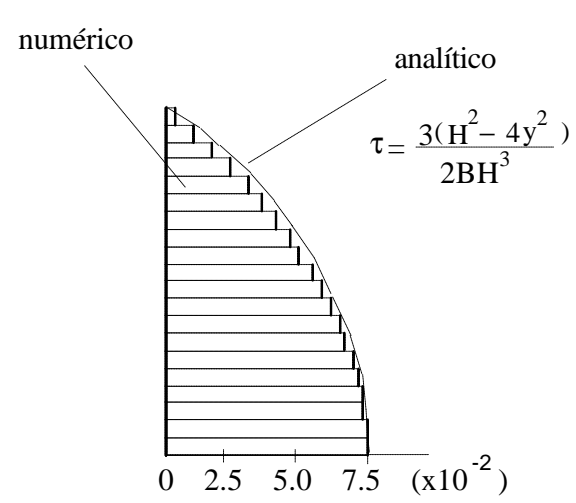

distribuição das tensões de cisalhamento

(c)

Fig. A.1- Tensões de Cisalhamento para Viga de Seção Retangular.

\section{A.2 EXEMPLO DE APLICAÇÃO.}

Como exemplo de utilização do elemento de cisalhamento calculamos a distribuição das tensões de cisalhamento de uma seção hipotética, típica de petroleiros. A Fig.A.2. apresenta a seção bem como as principais características dos elementos que a compõe.

$\mathrm{Na}$ modelagem foram utilizados 111 elementos de cisalhamento para discretizar a seção, ou seja, um nó para cada longitudinal —leve ou pesado. Com isso foi possível considerar cada longitudinal como área concentrada para o elemento de cisalhamento. A distribuição de tensões de cisalhamento obtida pelo programa está representada na Fig.A.3. 


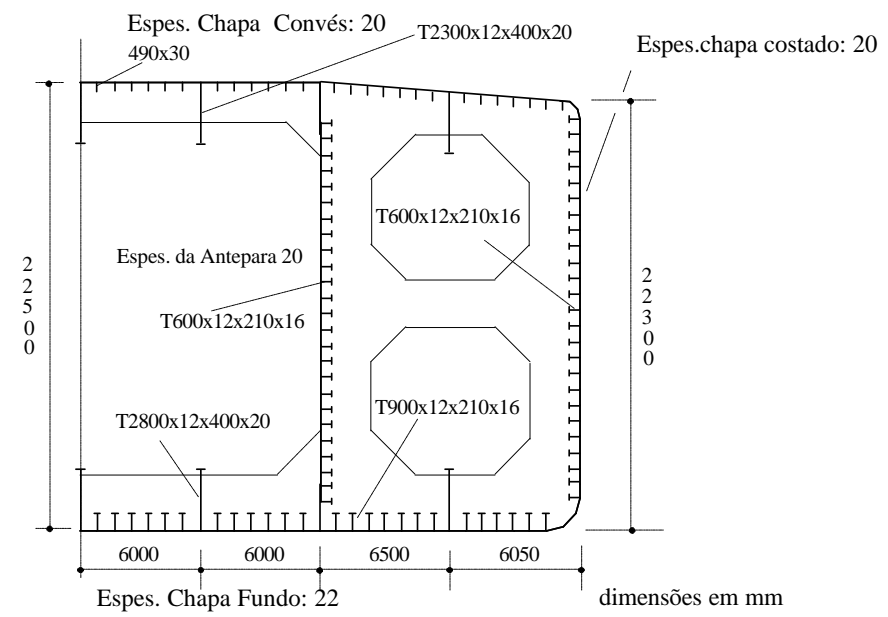

Fig. A.2 - Modelo para Cálculo da Distribuição de Cisalhamento.

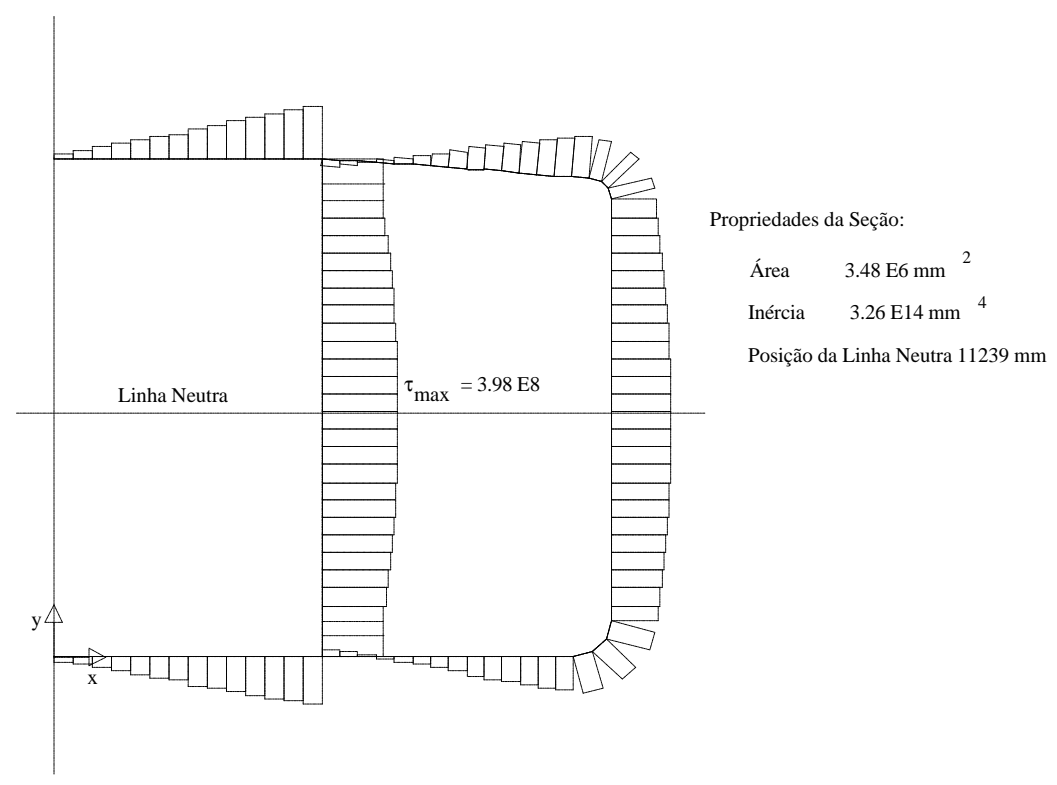

Fig.A.3 - Distribuição das Tensões de Cisalhamento. 
B.1

APÊNDICE B

ARQUIVOS DE DADOS

Este apêndice contém os dados de entrada dos exemplos desenvolvidos no capítulo 5. Os principais arquivos de saída fornecidos pelo programa TRANSEC também estão incluídos. 


\section{B.1 NAVIO-CAIXA.}

Tab.B.1 - Navio-Caixa - Coordenadas Nodais e Condições de Contorno.

\begin{tabular}{|c|c|c|c|}
\hline T R A N S E C & Sexta & 04/11/1994 & $23: 45$ \\
\hline
\end{tabular}

Exemplo : Navio-Caixa

COORDENADAS NODAIS

\begin{tabular}{|c|c|c|c|c|c|}
\hline Nó & $\Gamma$ Coord & das & & ontc & $\neg$ \\
\hline$\left.\Gamma^{\text {Num. }}\right\rceil$ & $\Gamma x-$ & $-\mathrm{Y} \rightarrow$ & $\Gamma^{\prime} \mathrm{x}$ & & 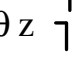 \\
\hline 1 & 0.0 & 0.0 & 1 & 0 & 1 \\
\hline 2 & 25.0 & 0.0 & 0 & 0 & 0 \\
\hline 3 & 50.0 & 0.0 & 0 & 0 & 0 \\
\hline 4 & 75.0 & 0.0 & 0 & 0 & 0 \\
\hline 5 & 100.0 & 0.0 & 0 & 0 & 0 \\
\hline 6 & 125.0 & 0.0 & 0 & 0 & 0 \\
\hline 7 & 150.0 & 0.0 & 0 & 0 & 0 \\
\hline 8 & 175.0 & 0.0 & 0 & 0 & 0 \\
\hline 9 & 200.0 & 0.0 & 0 & 0 & 0 \\
\hline 10 & 225.0 & 0.0 & 0 & 0 & 0 \\
\hline 11 & 250.0 & 0.0 & 0 & 0 & 0 \\
\hline 12 & 275.0 & 0.0 & 0 & 0 & 0 \\
\hline 13 & 300.0 & 0.0 & 0 & 0 & 0 \\
\hline 14 & 325.0 & 0.0 & 0 & 0 & 0 \\
\hline 15 & 350.0 & 0.0 & 0 & 0 & 0 \\
\hline 16 & 375.0 & 0.0 & 0 & 0 & 0 \\
\hline 17 & 400.0 & 0.0 & 0 & 0 & 0 \\
\hline 18 & 400.0 & 25.0 & 0 & 0 & 0 \\
\hline 19 & 400.0 & 50.0 & 0 & 0 & 0 \\
\hline 20 & 400.0 & 75.0 & 0 & 0 & 0 \\
\hline 21 & 400.0 & 100.0 & 0 & 0 & 0 \\
\hline 22 & 400.0 & 125.0 & 0 & 0 & 0 \\
\hline 23 & 400.0 & 150.0 & 0 & 0 & 0 \\
\hline 24 & 400.0 & 175.0 & 0 & 0 & 0 \\
\hline 25 & 400.0 & 200.0 & 0 & 0 & 0 \\
\hline 26 & 400.0 & 225.0 & 0 & 0 & 0 \\
\hline 27 & 400.0 & 250.0 & 0 & 0 & 0 \\
\hline 28 & 400.0 & 275.0 & 0 & 0 & 0 \\
\hline 29 & 400.0 & 300.0 & 1 & 1 & 0 \\
\hline 30 & 375.0 & 300.0 & 0 & 0 & 0 \\
\hline 31 & 350.0 & 300.0 & 0 & 0 & 0 \\
\hline 32 & 325.0 & 300.0 & 0 & 0 & 0 \\
\hline 33 & 300.0 & 300.0 & 0 & 0 & 0 \\
\hline 34 & 275.0 & 300.0 & 0 & 0 & 0 \\
\hline 35 & 250.0 & 300.0 & 0 & 0 & 0 \\
\hline
\end{tabular}


B.3

$\begin{array}{rrrrrr}36 & 225.0 & 300.0 & 0 & 0 & 0 \\ 37 & 200.0 & 300.0 & 0 & 0 & 0 \\ 38 & 175.0 & 300.0 & 0 & 0 & 0 \\ 39 & 150.0 & 300.0 & 0 & 0 & 0 \\ 40 & 125.0 & 300.0 & 0 & 0 & 0 \\ 41 & 100.0 & 300.0 & 1 & 0 & 0 \\ 42 & 0.0 & 100.0 & 1 & 1 & 1 \\ 43 & 100.0 & 290.0 & 1 & 1 & 1\end{array}$


B.4

Tab.B.2 - Navio-Caixa - Propriedades dos Materiais Utilizados.

\begin{tabular}{|llll|}
\hline T R A N S E C & Sábado & $19 / 11 / 1994$ & $16: 27$ \\
\hline
\end{tabular}

Exemplo : Navio-Caixa.

MATERIAIS

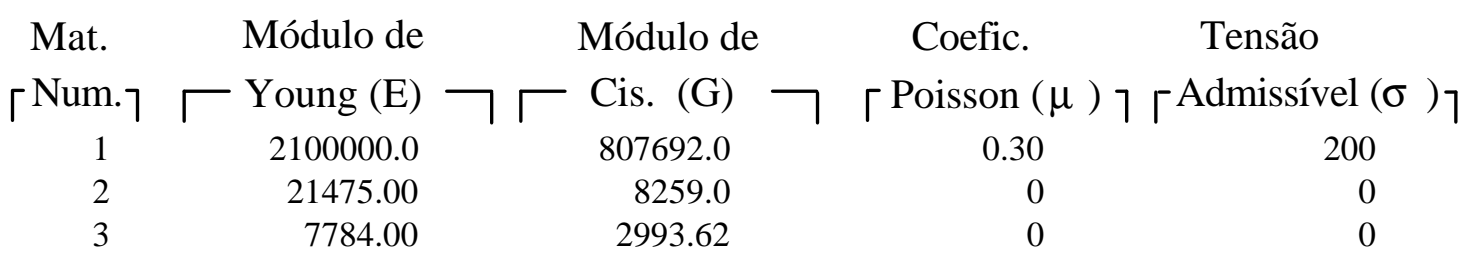


Tab.B.3 - Navio-Caixa - Cargas Distribuídas.

\begin{tabular}{|llll|}
\hline T R A N S E C & Sexta & $04 / 11 / 1994$ & $23: 45$ \\
\hline
\end{tabular}

Exemplo : Navio-Caixa

\section{CARGAS DISTRIBUÍDAS}

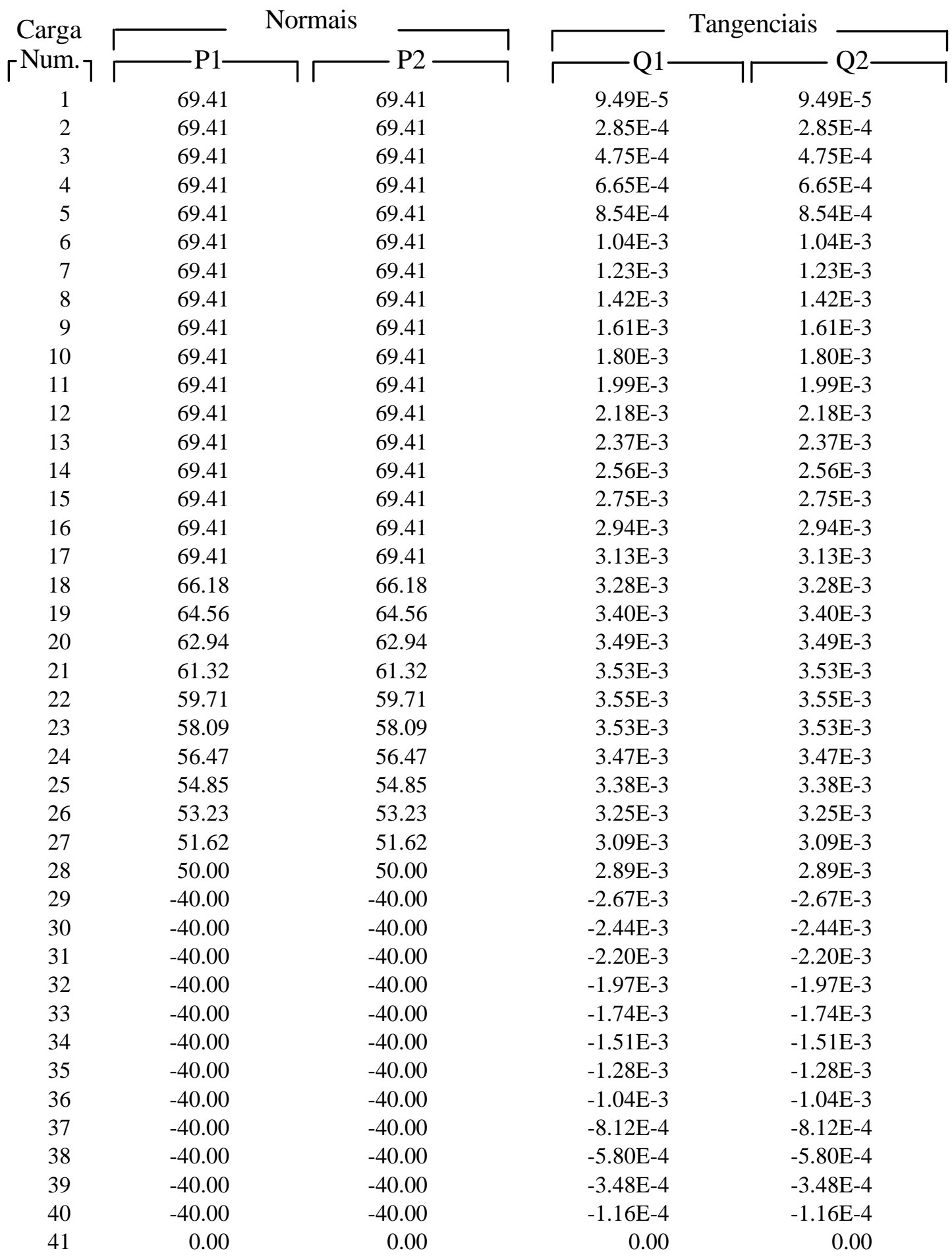




\section{B.6}

Tab.B.4 - Navio-Caixa - Incidência dos Elementos.

$\begin{array}{llll}\text { T R A N S E C } & \text { Sábado } & 19 / 11 / 1994\end{array}$

Exemplo : Navio-Caixa

INCIDÊNCIA DOS ELEMENTOS

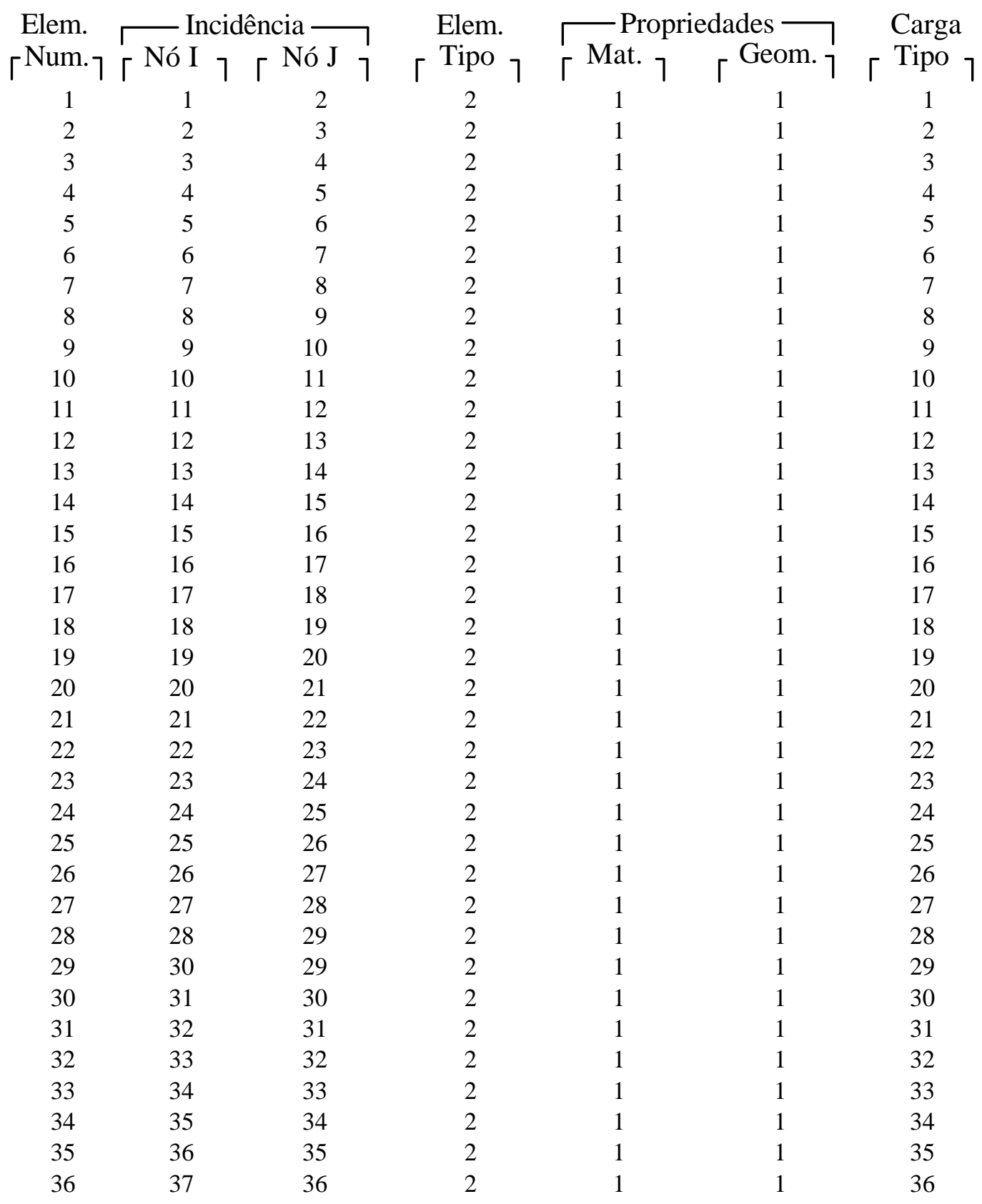


B. 7

$\begin{array}{rrrrrrr}37 & 38 & 37 & 2 & 1 & 1 & 37 \\ 38 & 39 & 38 & 2 & 1 & 1 & 38 \\ 39 & 40 & 39 & 2 & 1 & 1 & 39 \\ 40 & 41 & 40 & 2 & 1 & 1 & 40 \\ 41 & 1 & 42 & 1 & 2 & 2 & 41 \\ 42 & 41 & 43 & 1 & 3 & 2 & 41\end{array}$


B.8

Tab.B.5- Navio-Caixa - Multiplicadores de Cargas.

\begin{tabular}{|llll|}
\hline T R A N S E C & Sábado & $19 / 11 / 1994$ & $16: 27$ \\
\hline
\end{tabular}

Exemplo : Navio-Caixa

FATORES DE CARGA

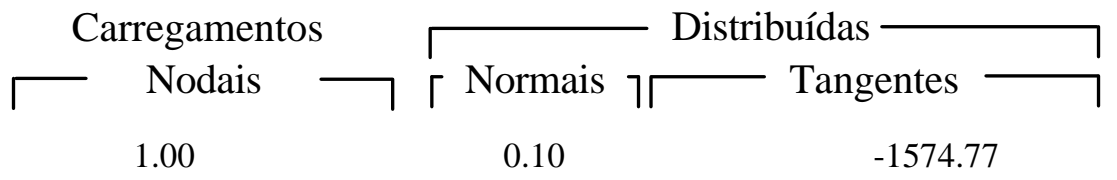


Tab.B.6 - Navio-Caixa - Deslocamentos Nodais da Estrutura.

\begin{tabular}{|llll|}
\hline T R A N S E C & Sábado & $19 / 11 / 1994$ & $16: 27$ \\
\hline
\end{tabular}

Exemplo : Navio-Caixa

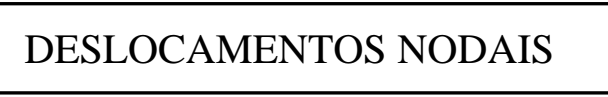

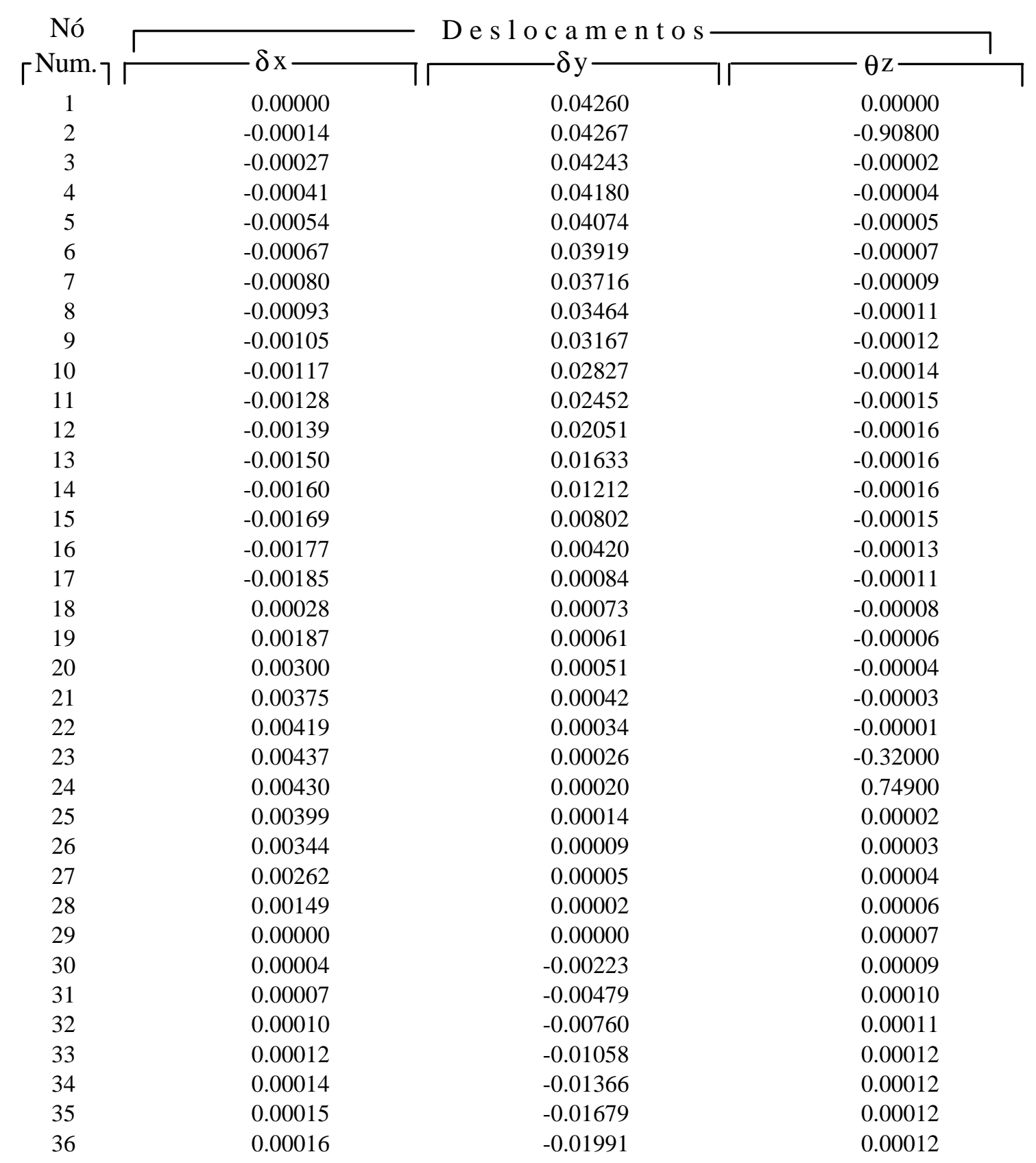


B.10

$\begin{array}{llrl}37 & 0.00017 & -0.02300 & 0.00012 \\ 38 & 0.00017 & -0.02604 & 0.00012 \\ 39 & 0.00017 & -0.02902 & 0.00012 \\ 40 & 0.00017 & -0.03194 & 0.00012 \\ 41 & 0.00017 & -0.03481 & 0.00012 \\ 42 & 0.00000 & 0.00000 & 0.00000\end{array}$


Tab.B.7 - Navio-Caixa - Reações Nodais.

\begin{tabular}{|llll|}
\hline T R A N S E C & Sábado & $19 / 11 / 1994$ & $16: 27$ \\
\hline
\end{tabular}

Exemplo: Navio-Caixa

REAÇÕES NODAIS

\begin{tabular}{|c|c|c|c|}
\hline \begin{tabular}{c|} 
Nó \\
「um.
\end{tabular} & $-\mathrm{Rx}-$ & $\begin{array}{l}\mathrm{R} \text { e a ç õ e s } \\
\text { Ry }\end{array}$ & $-\mathrm{Mz}-$ \\
\hline 1 & 2065.96018 & $-7.26 \mathrm{E}-03$ & 38064.71138 \\
\hline 2 & $-7.45 \mathrm{E}-04$ & $1.23 \mathrm{E}-02$ & $3.58 \mathrm{E}-02$ \\
\hline 3 & 3.73E-04 & $1.10 \mathrm{E}-02$ & $-4.77 \mathrm{E}-02$ \\
\hline 4 & $-5.59 \mathrm{E}-04$ & $1.30 \mathrm{E}-02$ & $2.62 \mathrm{E}-01$ \\
\hline 5 & $1.86 \mathrm{E}-04$ & $-5.46 \mathrm{E}-02$ & $-2.38 \mathrm{E}-02$ \\
\hline 6 & $-1.86 \mathrm{E}-04$ & 7.62E-02 & $2.38 \mathrm{E}-01$ \\
\hline 7 & $1.49 \mathrm{E}-03$ & $-2.10 \mathrm{E}-02$ & $2.38 \mathrm{E}-01$ \\
\hline 8 & $-9.31 \mathrm{E}-04$ & $-8.38 \mathrm{E}-03$ & $-1.91 \mathrm{E}-01$ \\
\hline 9 & $1.12 \mathrm{E}-03$ & $1.40 \mathrm{E}-02$ & $-9.54 \mathrm{E}-02$ \\
\hline 10 & $-2.79 \mathrm{E}-03$ & $-7.64 \mathrm{E}-03$ & $-2.86 \mathrm{E}-01$ \\
\hline 11 & $-7.45 \mathrm{E}-04$ & $-3.91 \mathrm{E}-03$ & $-1.91 \mathrm{E}-01$ \\
\hline 12 & $2.61 \mathrm{E}-03$ & $5.03 \mathrm{E}-03$ & $-9.54 \mathrm{E}-02$ \\
\hline 13 & $1.86 \mathrm{E}-04$ & $-1.12 \mathrm{E}-02$ & $-1.91 \mathrm{E}-01$ \\
\hline 14 & $-2.24 \mathrm{E}-03$ & 3.73E-03 & $-9.54 \mathrm{E}-02$ \\
\hline 15 & $1.30 \mathrm{E}-03$ & $2.24 \mathrm{E}-03$ & $-1.91 \mathrm{E}-01$ \\
\hline 16 & $-1.12 \mathrm{E}-03$ & $-7.45 \mathrm{E}-04$ & $9.54 \mathrm{E}-02$ \\
\hline 17 & $2.24 \mathrm{E}-03$ & $-1.30 \mathrm{E}-03$ & $-4.77 \mathrm{E}-02$ \\
\hline 18 & 7.45E-04 & $-1.30 \mathrm{E}-03$ & $5.96 \mathrm{E}-02$ \\
\hline 19 & $-1.96 \mathrm{E}-03$ & $9.31 \mathrm{E}-04$ & $1.19 \mathrm{E}-01$ \\
\hline 20 & $-1.12 \mathrm{E}-03$ & $-1.12 \mathrm{E}-03$ & $2.38 \mathrm{E}-02$ \\
\hline 21 & $8.85 \mathrm{E}-04$ & $1.68 \mathrm{E}-03$ & $3.58 \mathrm{E}-02$ \\
\hline 22 & $-6.05 \mathrm{E}-04$ & $-9.31 \mathrm{E}-04$ & $4.77 \mathrm{E}-02$ \\
\hline 23 & $-7.22 \mathrm{E}-04$ & $9.31 \mathrm{E}-04$ & $2.98 \mathrm{E}-02$ \\
\hline 24 & $2.18 \mathrm{E}-03$ & $-6.52 \mathrm{E}-04$ & $5.96 \mathrm{E}-02$ \\
\hline 25 & $1.37 \mathrm{E}-03$ & 4.66E-04 & $-2.98 \mathrm{E}-02$ \\
\hline 26 & $-3.12 \mathrm{E}-03$ & $-9.31 \mathrm{E}-05$ & $-8.34 \mathrm{E}-02$ \\
\hline 27 & $1.12 \mathrm{E}-03$ & 0.00000 & 0.00000 \\
\hline 28 & $5.59 \mathrm{E}-04$ & $-4.66 \mathrm{E}-05$ & $9.54 \mathrm{E}-02$ \\
\hline 29 & 2.53867 & 641.87982 & $-2.62 \mathrm{E}-01$ \\
\hline 30 & 0.00000 & $-1.49 \mathrm{E}-03$ & $-4.77 \mathrm{E}-02$ \\
\hline 31 & $2.33 \mathrm{E}-04$ & $-8.20 \mathrm{E}-03$ & $9.54 \mathrm{E}-02$ \\
\hline 32 & $-9.31 \mathrm{E}-05$ & $1.27 \mathrm{E}-02$ & 0.00000 \\
\hline 33 & $-9.31 \mathrm{E}-05$ & $-3.73 \mathrm{E}-03$ & 4.77E- 02 \\
\hline 34 & $9.31 \mathrm{E}-05$ & $-2.98 \mathrm{E}-03$ & $-9.54 \mathrm{E}-02$ \\
\hline 35 & $-2.56 \mathrm{E}-04$ & $2.53 \mathrm{E}-02$ & $-9.54 \mathrm{E}-02$ \\
\hline 36 & $6.29 \mathrm{E}-04$ & $-3.28 \mathrm{E}-02$ & $9.54 \mathrm{E}-02$ \\
\hline
\end{tabular}


B.12

$\begin{array}{rrrr}37 & -1.86 \mathrm{E}-04 & 2.61 \mathrm{E}-02 & -9.54 \mathrm{E}-02 \\ 38 & -3.67 \mathrm{E}-04 & -1.94 \mathrm{E}-02 & -1.91 \mathrm{E}-01 \\ 39 & 2.50 \mathrm{E}-04 & 1.12 \mathrm{E}-02 & -1.91 \mathrm{E}-01 \\ 40 & 1.25 \mathrm{E}-04 & -2.68 \mathrm{E}-02 & 1.91 \mathrm{E}-01 \\ 41 & -1.55 \mathrm{E}-04 & 4.00 \mathrm{E}-03 & -2.54 \mathrm{E}-01 \\ 42 & 0.00000 & -914.89144 & 0.00000 \\ 43 & 0.00000 & 270.98793 & 0.00000\end{array}$


Tab.B.8- Navio-Caixa - Esforços Solicitantes na Estrutura.

$\begin{array}{llll}\text { T R A N S E C } \quad \text { Sábado } & 19 / 11 / 1994\end{array}$

Exemplo: Navio-Caixa.

ESFORÇOS NOS ELEMENTOS DE VIGAS

Elem.

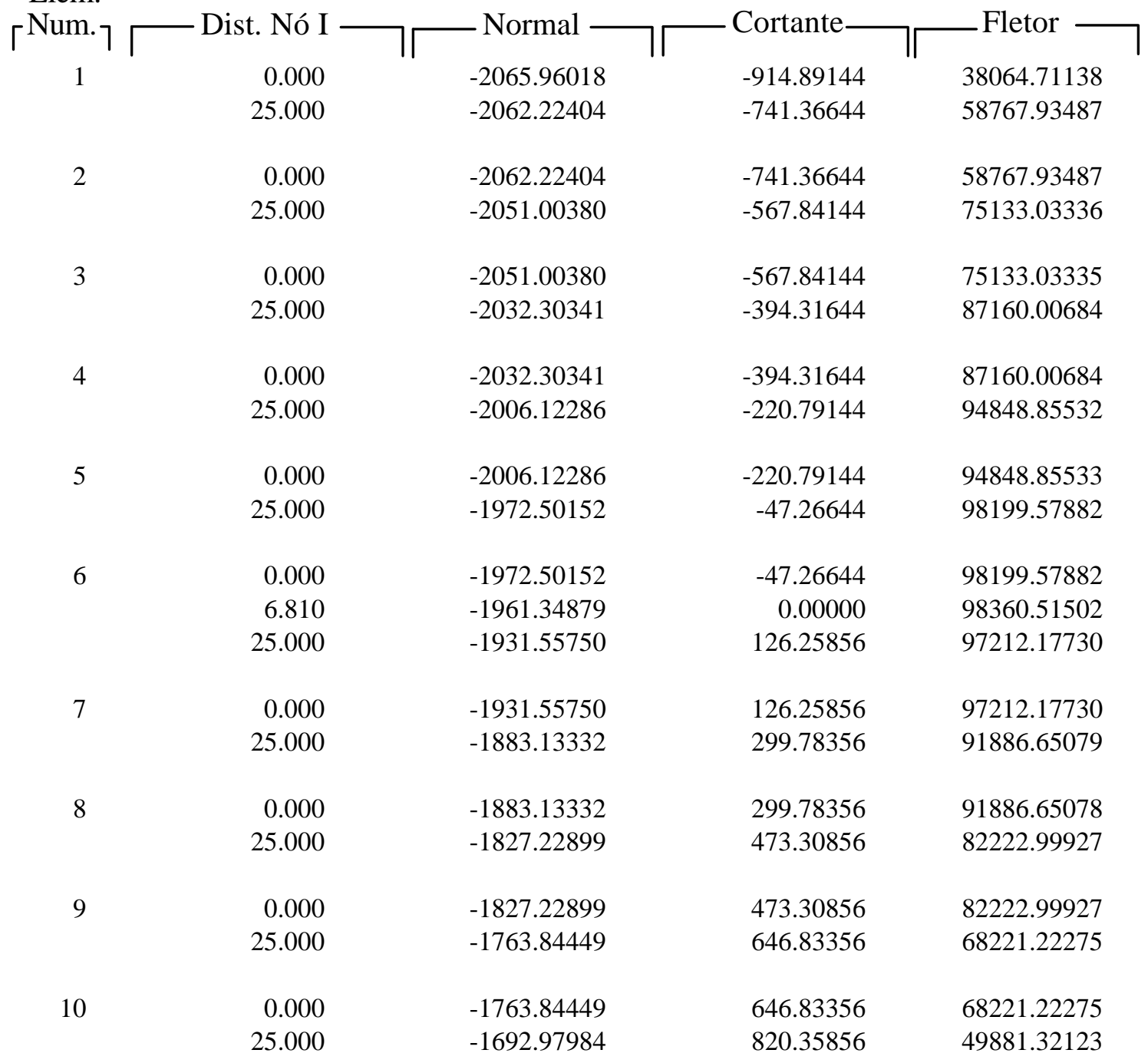




\begin{tabular}{|c|c|c|c|c|}
\hline 11 & $\begin{array}{r}0.000 \\
25.000\end{array}$ & $\begin{array}{l}-1692.97984 \\
-1614.63504\end{array}$ & $\begin{array}{l}820.35856 \\
993.88356\end{array}$ & $\begin{array}{l}49881.32123 \\
27203.29471\end{array}$ \\
\hline 12 & $\begin{array}{r}0.000 \\
25.000\end{array}$ & $\begin{array}{l}-1614.63504 \\
-1528.81007\end{array}$ & $\begin{array}{r}993.88356 \\
1167.40856\end{array}$ & $\begin{array}{r}27203.29471 \\
187.14319\end{array}$ \\
\hline 13 & $\begin{array}{r}0.000 \\
25.000\end{array}$ & $\begin{array}{l}-1528.81007 \\
-1435.50495\end{array}$ & $\begin{array}{l}1167.40856 \\
1340.93356\end{array}$ & $\begin{array}{r}187.14320 \\
-31167.13332\end{array}$ \\
\hline 14 & $\begin{array}{r}0.000 \\
25.000\end{array}$ & $\begin{array}{l}-1435.50495 \\
-1334.71967\end{array}$ & $\begin{array}{l}1340.93356 \\
1514.45856\end{array}$ & $\begin{array}{l}-31167.13332 \\
-66859.53484\end{array}$ \\
\hline 15 & $\begin{array}{r}0.000 \\
25.000\end{array}$ & $\begin{array}{l}-1334.71967 \\
-1226.45423\end{array}$ & $\begin{array}{l}1514.45856 \\
1687.98356\end{array}$ & $\begin{array}{r}-66859.53484 \\
-106890.06136\end{array}$ \\
\hline 16 & $\begin{array}{r}0.000 \\
25.000\end{array}$ & $\begin{array}{l}-1226.45423 \\
-1110.70864\end{array}$ & $\begin{array}{l}1687.98356 \\
1861.50856\end{array}$ & $\begin{array}{l}-106890.06136 \\
-151258.71287\end{array}$ \\
\hline 17 & $\begin{array}{r}0.000 \\
25.000\end{array}$ & $\begin{array}{l}-1861.50856 \\
-1738.28281\end{array}$ & $\begin{array}{r}-1110.70864 \\
-937.18364\end{array}$ & $\begin{array}{l}-151258.71287 \\
-125660.05947\end{array}$ \\
\hline 18 & $\begin{array}{r}0.000 \\
25.000\end{array}$ & $\begin{array}{l}-1738.28281 \\
-1609.15167\end{array}$ & $\begin{array}{l}-937.18364 \\
-771.73364\end{array}$ & $\begin{array}{l}-125660.05947 \\
-104298.59357\end{array}$ \\
\hline 19 & $\begin{array}{r}0.000 \\
25.000\end{array}$ & $\begin{array}{l}-1609.15167 \\
-1475.29622\end{array}$ & $\begin{array}{l}-771.73364 \\
-610.33364\end{array}$ & $\begin{array}{r}-104298.59357 \\
-87022.75268\end{array}$ \\
\hline 20 & $\begin{array}{r}0.000 \\
25.000\end{array}$ & $\begin{array}{l}-1475.29622 \\
-1337.89754\end{array}$ & $\begin{array}{l}-610.33364 \\
-452.98364\end{array}$ & $\begin{array}{l}-87022.75268 \\
-73731.28678\end{array}$ \\
\hline 21 & $\begin{array}{r}0.000 \\
25.000\end{array}$ & $\begin{array}{l}-1337.89754 \\
-1198.92408\end{array}$ & $\begin{array}{l}-452.98364 \\
-299.68364\end{array}$ & $\begin{array}{l}-73731.28678 \\
-64322.94588\end{array}$ \\
\hline 22 & $\begin{array}{r}0.000 \\
25.000\end{array}$ & $\begin{array}{l}-1198.92408 \\
-1059.16325\end{array}$ & $\begin{array}{l}-299.68364 \\
-150.40864\end{array}$ & $\begin{array}{l}-64322.94588 \\
-58696.79248\end{array}$ \\
\hline 23 & $\begin{array}{r}0.000 \\
25.000\end{array}$ & $\begin{array}{r}-1059.16325 \\
-920.18979\end{array}$ & $\begin{array}{r}-150.40864 \\
-5.18364\end{array}$ & $\begin{array}{l}-58696.79248 \\
-56751.88909\end{array}$ \\
\hline 24 & $\begin{array}{r}0.000 \\
0.918 \\
25.000\end{array}$ & $\begin{array}{l}-920.18979 \\
-915.17373 \\
-783.57850\end{array}$ & $\begin{array}{r}-5.18364 \\
0.00000 \\
135.99136\end{array}$ & $\begin{array}{l}-56751.88909 \\
-56749.50994 \\
-58386.98569\end{array}$ \\
\hline 25 & $\begin{array}{r}0.000 \\
25.000\end{array}$ & $\begin{array}{l}-783.57850 \\
-650.51043\end{array}$ & $\begin{array}{l}135.99136 \\
273.11636\end{array}$ & $\begin{array}{l}-58386.98569 \\
-63500.83229\end{array}$ \\
\hline 26 & $\begin{array}{r}0.000 \\
25.000\end{array}$ & $\begin{array}{l}-650.51043 \\
-522.56037\end{array}$ & $\begin{array}{l}273.11636 \\
406.19136\end{array}$ & $\begin{array}{l}-63500.83229 \\
-71992.17889\end{array}$ \\
\hline 27 & $\begin{array}{r}0.000 \\
25.000\end{array}$ & $\begin{array}{l}-522.56037 \\
-400.90939\end{array}$ & $\begin{array}{l}406.19136 \\
535.24136\end{array}$ & $\begin{array}{l}-71992.17889 \\
-83760.08800\end{array}$ \\
\hline
\end{tabular}


28

29

30

31

32

33

34

35

36

37

38

39

40
0.000

25.000

0.000

25.000

0.000

25.000

0.000

25.000

0.000

25.000

0.000

25.000

0.000

25.000

0.000

25.000

0.000

25.000

0.000

25.000

0.000

17.747

25.000

0.000

25.000

0.000

25.000
$-400.90939$

$-287.13225$

$-552.58679$

$-657.70269$

$-456.52582$

$-552.58679$

$-369.91347$

$-456.52582$

$-292.35605$

$-369.91347$

$-223.85356$

$-292.35605$

$-164.40599$

$-223.85356$

$-114.01335$

$-164.40599$

$-73.06933$

$-114.01335$

$-41.10150$

$-73.06933$

$-18.26733$

$-34.47683$

$-41.10150$

$-4.56683$

$-18.26733$

0.00000

$-4.56683$
535.24136

660.24136

$-829.01207$

$-929.01207$

$-729.01207$

$-829.01207$

$-629.01207$

$-729.01207$

$-529.01207$

$-629.01207$

$-429.01207$

$-529.01207$

$-329.01207$

$-429.01207$

$-229.01207$

$-329.01207$

$-129.01207$

$-229.01207$

$-29.01207$

$-129.01207$

70.98793

0.00000

$-29.01207$

170.98793

70.98793

270.98793

170.98793
$-83760.08800$

$-98703.62210$

76728.32026

98703.62210

57253.01842

76728.32026

40277.71658

57253.01842

25802.41474

40277.71658

13827.11289

25802.41473

4351.81105

13827.11289

$-2623.49079$

4351.81105

$-7098.79263$

$-2623.49080$

$-9074.09448$

$-7098.79263$

$-8549.39632$

$-9179.30703$

$-9074.09448$

$-5524.69816$

$-8549.39632$

$-0.00000$

$-5524.69817$ 


\section{B.2 CAVERNA 17.}

Tab.B.9 - Cav.17 - Coord. Nodais e Condições de Contorno.

$\begin{array}{llll}\text { T R A N S E C } & \text { Sábado } & \text { 08/10/1994 }\end{array}$

Projeto da Caverna 17 - Navio Patrulha

COORDENADAS NODAIS

\begin{tabular}{|c|c|c|c|c|c|}
\hline Nó & \multirow{2}{*}{\multicolumn{2}{|c|}{ - Coordenadas -}} & \multicolumn{3}{|c|}{$\lceil$ Cds.Contorno $\neg$} \\
\hline$\lceil\mathrm{Num}\rceil$. & & & $\Gamma \delta x$ & & $\theta \mathrm{z}\rceil$ \\
\hline 1 & 0.00 & 0.00 & 1 & 0 & 1 \\
\hline 2 & 0.00 & 1000.00 & 1 & 0 & 1 \\
\hline 3 & 2000.00 & 1163.00 & 0 & 0 & 0 \\
\hline 4 & 2000.00 & 1563.00 & 0 & 0 & 0 \\
\hline 5 & 2610.00 & 1698.00 & 0 & 0 & 0 \\
\hline 6 & 3200.00 & 2460.00 & 0 & 0 & 0 \\
\hline 7 & 3690.00 & 3365.00 & 0 & 0 & 0 \\
\hline 8 & 2000.00 & 3365.00 & 0 & 0 & 0 \\
\hline 9 & 0.00 & 3365.00 & 1 & 0 & 1 \\
\hline 10 & 4235.00 & 4680.00 & 0 & 0 & 0 \\
\hline 11 & 4705.00 & 5973.00 & 0 & 0 & 0 \\
\hline 12 & 2000.00 & 6020.00 & 0 & 0 & 0 \\
\hline 13 & 0.00 & 6038.00 & 1 & 0 & 1 \\
\hline 14 & 0.00 & -400.00 & 1 & 1 & 1 \\
\hline 15 & 2000.00 & 800.00 & 1 & 1 & 1 \\
\hline 16 & 2000.00 & 5600.00 & 1 & 1 & 1 \\
\hline
\end{tabular}


Tab.B.10 - Cav.17 - Propriedades dos Materiais Utilizados.

\begin{tabular}{|llll|}
\hline T R A N S E C & Sábado & $08 / 10 / 1994$ & $11: 11$ \\
\hline
\end{tabular}

Projeto da Caverna 17 - Navio Patrulha

MATERIAIS

\begin{tabular}{|c|c|c|c|c|}
\hline $\begin{array}{l}\text { Mat. } \\
\lceil\text { Num. }\rceil\end{array}$ & $\begin{array}{r}\text { Módulo de } \\
\qquad \text { Young (E) }\end{array}$ & $\begin{array}{l}\text { Módulo de } \\
\text { Cis. (G) }\end{array}$ & $\begin{array}{c}\text { Coefic. } \\
\text { 「 Poisson }(\mu)\end{array}$ & $\begin{array}{c}\text { Tensão } \\
\lceil\text { Admissível }(\sigma)\rceil\end{array}$ \\
\hline 1 & 205800.00 & 102900.00 & 0.30 & 157.00 \\
\hline 2 & 1000000.00 & 500000.00 & 0.00 & 0.00 \\
\hline 3 & 300000.00 & 100000.00 & 0.00 & 0.00 \\
\hline 4 & 36000.00 & 18000.00 & 0.00 & 0.00 \\
\hline
\end{tabular}


Tab.B.11 - Cav.17 - Cargas Distribuídas.

\begin{tabular}{|llll|}
\hline T R A N S E C & Sábado & $08 / 10 / 1994$ & $11: 11$ \\
\hline
\end{tabular}

Projeto da Caverna 17 - Navio Patrulha

CARGAS DISTRIBUÍDAS

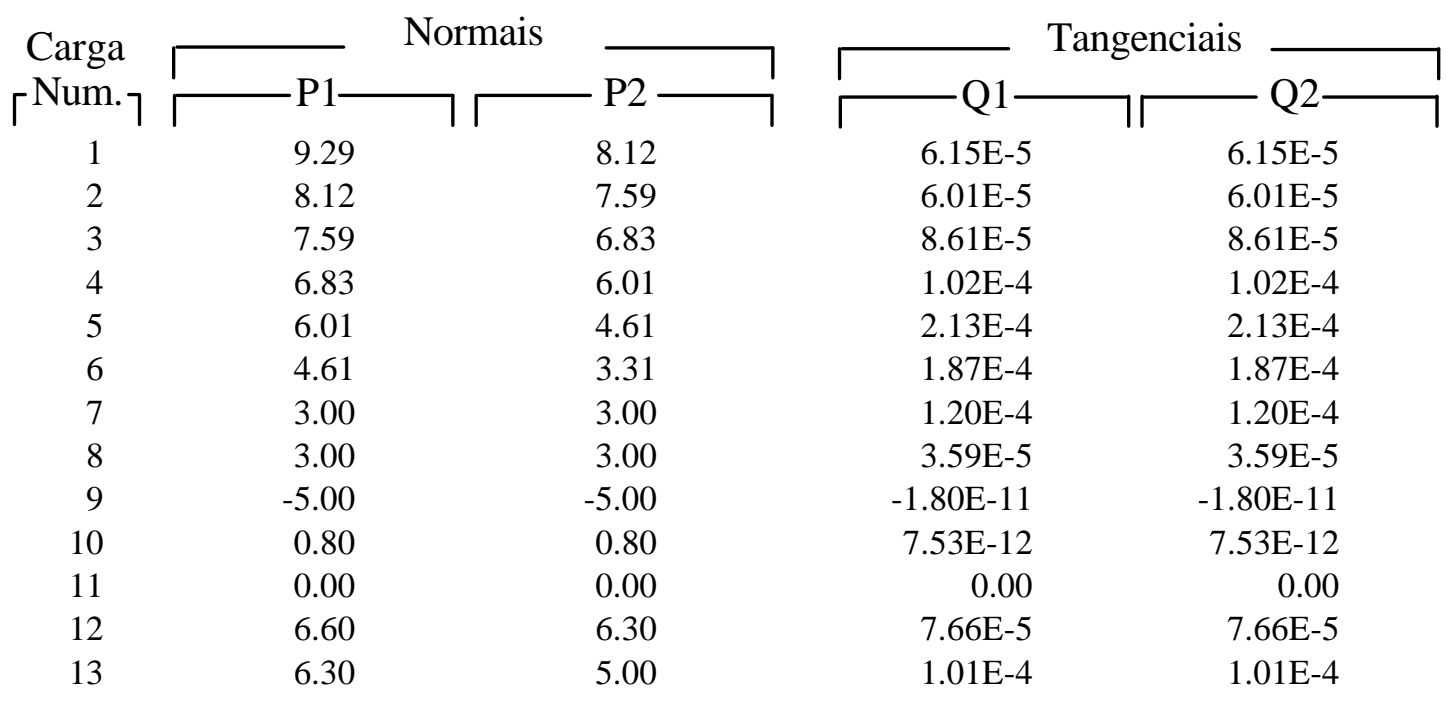


Tab.B.12 - Cav.17 - Incidência dos Elementos.

\begin{tabular}{|llll|}
\hline T R A N S E C & Sábado & $08 / 10 / 1994$ & $11: 11$ \\
\hline
\end{tabular}

Projeto da Caverna 17 - Navio Patrulha

\section{INCIDÊNCIA DOS ELEMENTOS}

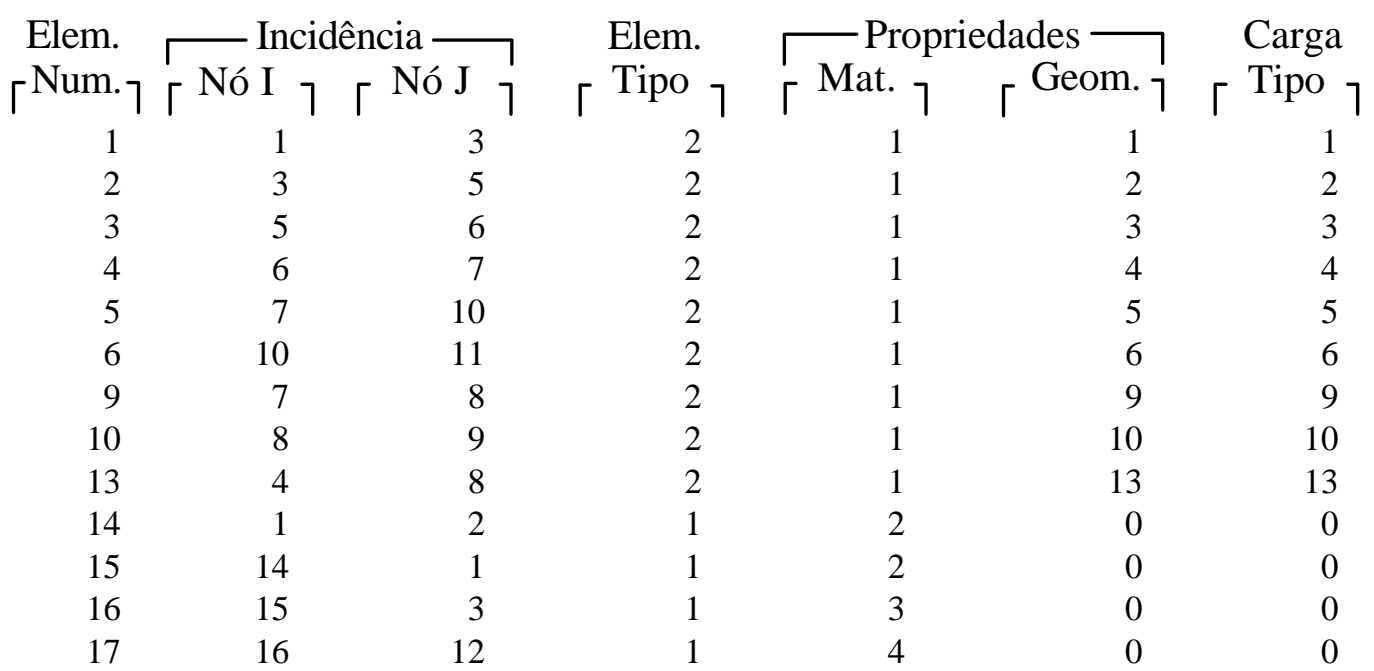

Observações:

Elemento Tipo 1: Mola ou Treliça.

Elemento Tipo 2: Viga. 
Tab.B.13- Cav.17- Multiplicadores de Cargas.

\begin{tabular}{|llll|}
\hline T R A N S E C & Sábado & $08 / 10 / 1994$ & $11: 11$ \\
\hline
\end{tabular}

Projeto da Caverna 17 - Navio Patrulha

FATORES DE CARGA

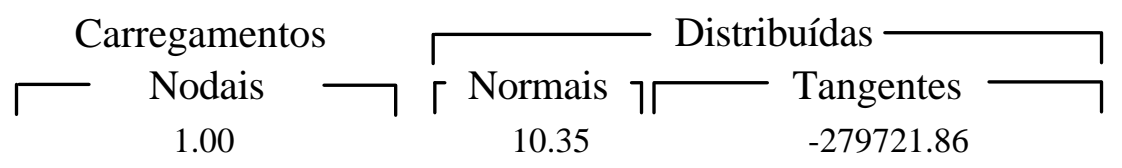


Tab. B.14 - Cav.17 - Perfis Disponíveis para Síntese.

\begin{tabular}{|llll|}
\hline T R A N S E C & Sábado & $08 / 10 / 1994$ & $11: 11$ \\
\hline
\end{tabular}

Projeto da Caverna 17 - Navio Patrulha

\section{BANCO DE DADOS DE PERFIS}

\begin{tabular}{|c|c|c|c|c|}
\hline Perfil & $\Gamma$ & $\square$ & $-F$ & e \\
\hline$\left.\Gamma^{\mathrm{Num}} \cdot\right\rceil$ & $\Gamma^{\text {larg. }}$. & spess. 7 & 厂 larg. & espess. \\
\hline 1 & 100.0 & 6.30 & 70.00 & 12.50 \\
\hline 2 & 110.0 & 6.30 & 70.00 & 12.50 \\
\hline 3 & 120.0 & 6.30 & 70.00 & 12.50 \\
\hline 4 & 130.0 & 6.30 & 70.00 & 12.50 \\
\hline 5 & 140.0 & 6.30 & 70.00 & 12.50 \\
\hline 6 & 150.0 & 6.30 & 70.00 & 12.50 \\
\hline 7 & 160.0 & 6.30 & 70.00 & 12.50 \\
\hline 8 & 170.0 & 6.30 & 70.00 & 12.50 \\
\hline 9 & 180.0 & 6.30 & 70.00 & 12.50 \\
\hline 10 & 190.0 & 6.30 & 70.00 & 12.50 \\
\hline 11 & 200.0 & 6.30 & 70.00 & 12.50 \\
\hline 12 & 210.0 & 6.30 & 70.00 & 12.50 \\
\hline 13 & 220.0 & 6.30 & 70.00 & 12.50 \\
\hline 14 & 230.0 & 6.30 & 70.00 & 12.50 \\
\hline 15 & 240.0 & 6.30 & 70.00 & 12.50 \\
\hline 16 & 250.0 & 6.30 & 70.00 & 12.50 \\
\hline 17 & 260.0 & 6.30 & 70.00 & 12.50 \\
\hline 18 & 270.0 & 6.30 & 70.00 & 12.50 \\
\hline 19 & 280.0 & 6.30 & 70.00 & 12.50 \\
\hline 20 & 290.0 & 6.30 & 70.00 & 12.50 \\
\hline 21 & 300.0 & 6.30 & 70.00 & 12.50 \\
\hline 22 & 310.0 & 6.30 & 70.00 & 12.50 \\
\hline 23 & 320.0 & 6.30 & 70.00 & 12.50 \\
\hline 24 & 330.0 & 6.30 & 70.00 & 12.50 \\
\hline 25 & 340.0 & 6.30 & 70.00 & 12.50 \\
\hline 26 & 350.0 & 6.30 & 70.00 & 12.50 \\
\hline
\end{tabular}


Tab.B.15 - Cav.17 - Chapa Colaborante para a Síntese dos Elementos.

$\begin{array}{lll}\text { T R A N S E C } \quad \text { Sábado } & \text { 08/10/1994 }\end{array}$

Projeto da Caverna 17 - Navio Patrulha

DADOS PARA A SÍNTESE DE ELEMENTOS

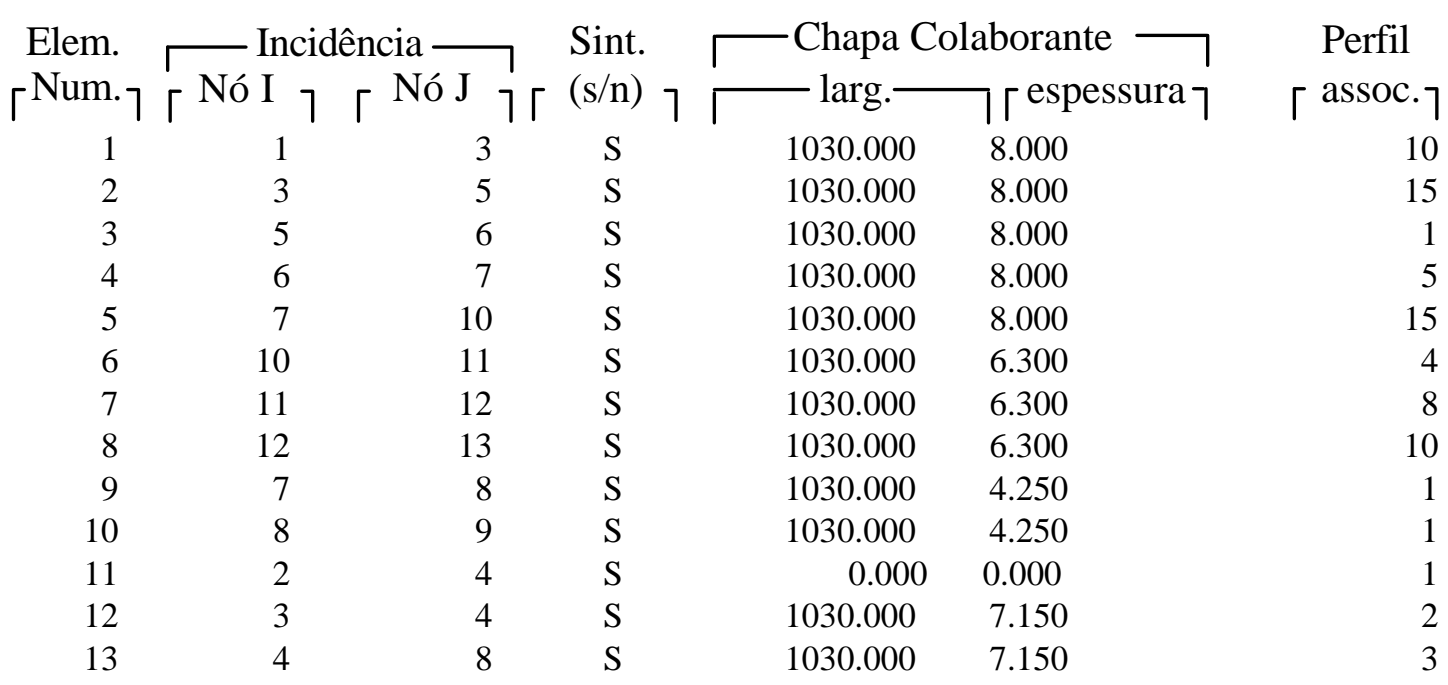


Tab.B.16-Cav.17- Perfis Sintetizados.

\begin{tabular}{|c|c|c|}
\hline T R A N S E C & Domingo & 09/10/1994 \\
\hline
\end{tabular}

Projeto de Caverna 17 - Navio Patrulha

\section{ESCANTILHÕES DOS PERFIS SINTETIZADOS}

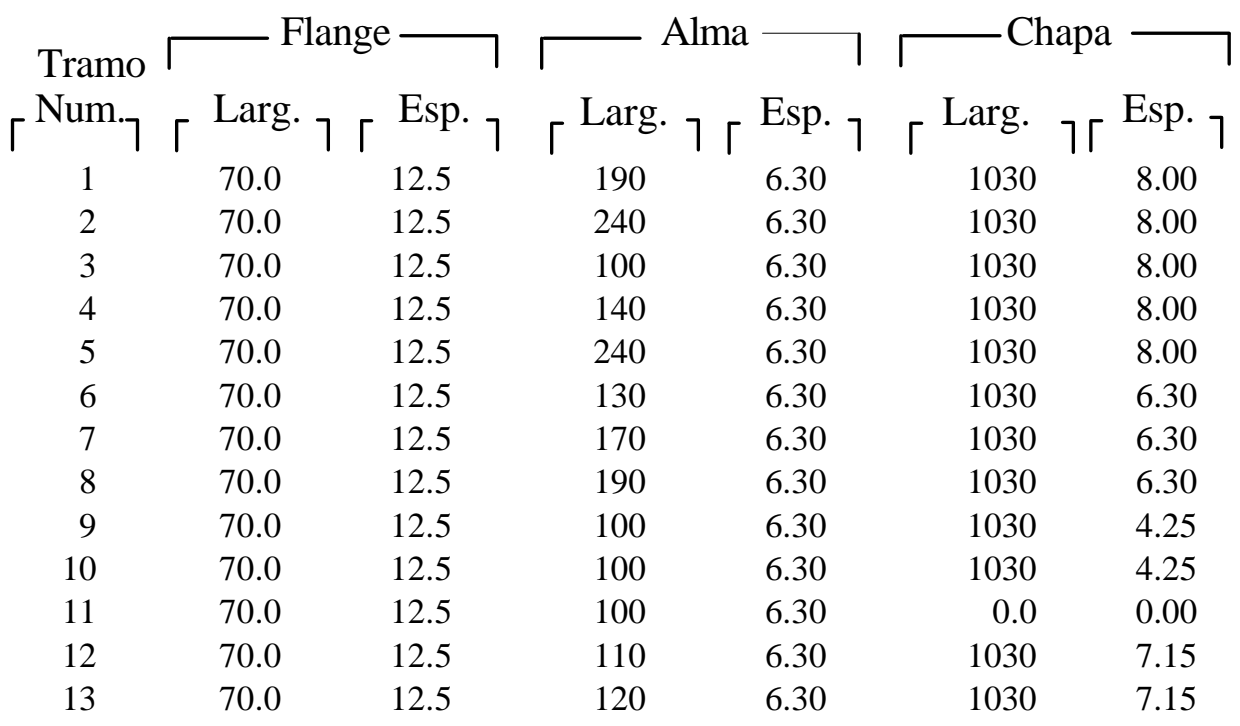


Tab.B.17 - Cav.17 - Propriedades Geométricas dos Perfis Sintetizados.

\begin{tabular}{|llll|}
\hline T R A N S E C & Sábado & $08 / 10 / 1994$ & $11: 11$ \\
\hline
\end{tabular}

Projeto da Caverna 17 - Navio Patrulha

\section{PROPRIEDADES GEOMÉTRICAS DOS PERFIS SINTETIZADOS}

\begin{tabular}{|c|c|c|c|c|c|}
\hline PG. & \multicolumn{3}{|c|}{ Propriedades de Rigidez } & $\neg\ulcorner$ Extrem & os Rígidos \\
\hline$\left.\left.\Gamma^{\mathrm{Num}}\right\rceil\right\rceil$ & $\lceil$ Área $\rceil$ & Inércia & \rceil$\Gamma$ Acis & \rceil$\left.\Gamma^{\mathrm{NoI}}\right\rceil$ & $\lceil\mathrm{NoJ} \neg$ \\
\hline 1 & 10312.00 & 42109446.00 & 1197.00 & 300.00 & 800.00 \\
\hline 2 & 10627.00 & 69812405.30 & 1512.00 & 200.00 & 0.00 \\
\hline 3 & 9745.00 & 11305812.40 & 630.00 & 0.00 & 0.00 \\
\hline 4 & 9997.00 & 22207255.20 & 882.00 & 0.00 & 180.00 \\
\hline 5 & 10627.00 & 69812405.30 & 1512.00 & 0.00 & 0.00 \\
\hline 6 & 8183.00 & 18130585.20 & 819.00 & 0.00 & 180.00 \\
\hline 7 & 8435.00 & 31603769.90 & 1071.00 & 200.00 & 0.00 \\
\hline 8 & 8561.00 & 39998459.10 & 1197.00 & 0.00 & 0.00 \\
\hline 9 & 5882.50 & 9760968.17 & 630.00 & 200.00 & 150.00 \\
\hline 10 & 5882.50 & 9760968.17 & 630.00 & 0.00 & 0.00 \\
\hline 11 & 1505.00 & 1695323.10 & 630.00 & 300.00 & 800.00 \\
\hline 12 & 8932.50 & 13314473.80 & 693.00 & 390.00 & 0.00 \\
\hline 13 & 8995.50 & 15848057.80 & 756.00 & 0.00 & 180.00 \\
\hline
\end{tabular}


Tab.B.18 - Cav.17 - Deslocamentos Nodais da Estrutura.

\begin{tabular}{|llll|}
\hline T R A N S E C & Sábado & $08 / 10 / 1994$ & $11: 11$ \\
\hline
\end{tabular}

Projeto da Caverna 17 - Navio Patrulha

\section{DESLOCAMENTOS NODAIS}

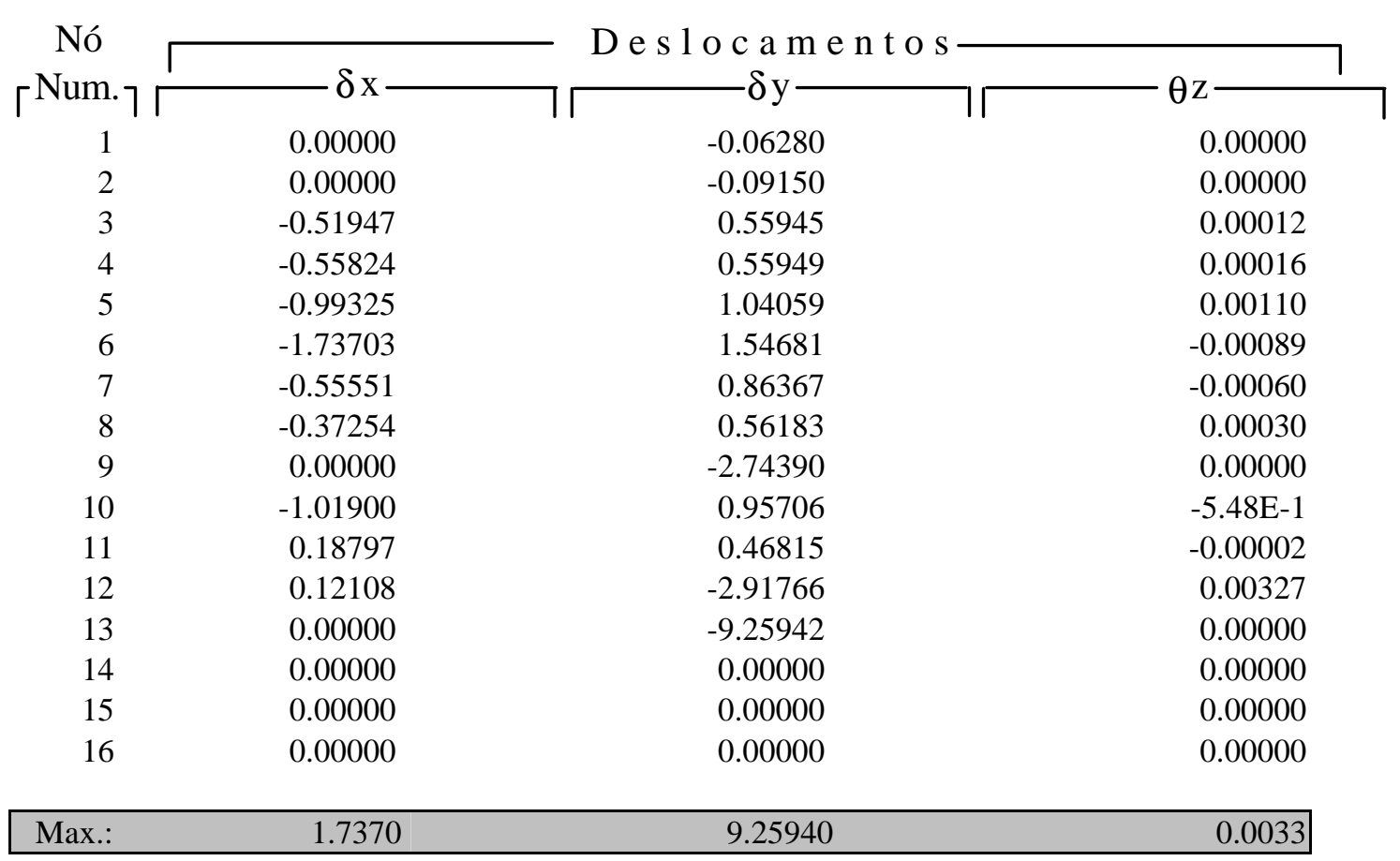


Tab.B.19 - Cav.17 - Reações Nodais.

\begin{tabular}{|llll|}
\hline T R A N S E C & Sábado & $08 / 10 / 1994$ & $11: 11$ \\
\hline
\end{tabular}

Projeto da Caverna 17 - Navio Patrulha

\section{REAÇÕES NODAIS}

\begin{tabular}{|c|c|c|c|}
\hline $\begin{array}{c}\text { Nó } \\
\text { [Num.ך}\end{array}$ & $-\mathrm{Rx}$ & - R e a ç õ e s & $-\mathrm{Mz}-$ \\
\hline 1 & 273872.35824 & $2.38 \mathrm{E}-02$ & -54469081.03 \\
\hline 2 & 110711.07960 & $-8.94 \mathrm{E}-03$ & -1932901.18 \\
\hline 3 & $-7.27 \mathrm{E}-01$ & -0.00004 & 0.00185 \\
\hline 4 & $7.75 \mathrm{E}-01$ & 0.00014 & -0.00038 \\
\hline 5 & $-7.15 \mathrm{E}-02$ & $5.84 \mathrm{E}-01$ & 0.00017 \\
\hline 6 & $3.40 \mathrm{E}-01$ & $7.15 \mathrm{E}-02$ & -0.00002 \\
\hline 7 & $-9.54 \mathrm{E}-02$ & $1.19 \mathrm{E}-02$ & 0.00011 \\
\hline 8 & $-6.56 \mathrm{E}-02$ & $-1.25 \mathrm{E}-01$ & 0.00000 \\
\hline 9 & 225504.40898 & 0.00000 & -5823709.82 \\
\hline 10 & $-1.73 \mathrm{E}-01$ & $5.96 \mathrm{E}-02$ & -0.00005 \\
\hline 11 & $-3.58 \mathrm{E}-02$ & $-2.32 \mathrm{E}-01$ & 0.00003 \\
\hline 12 & $1.79 \mathrm{E}-02$ & $1.19 \mathrm{E}-02$ & 0.00006 \\
\hline 13 & -66424.26872 & $-3.54 \mathrm{E}-03$ & -34737319.86 \\
\hline 14 & 0.00000 & 62799.06124 & 0.00000 \\
\hline 15 & 0.00000 & -167834.84612 & 0.00000 \\
\hline 16 & 0.00000 & 105035.89635 & 0.00000 \\
\hline
\end{tabular}


Tab.B.20 - Cav.17 - Ciclos da Síntese Estrutural.

$\begin{array}{lll}\text { T R A N S E C } \quad \text { Sábado } \quad 08 / 10 / 1994 & 11: 11\end{array}$

Projeto da Caverna 17 - Navio Patrulha

\section{CICLOS NA SÍNTESE DOS ELEMENTOS}

Elem. $\ulcorner$ Ciclo $1 \longrightarrow$ Ciclo $2 \longrightarrow \sqcap$ Ciclo $3 \longrightarrow$

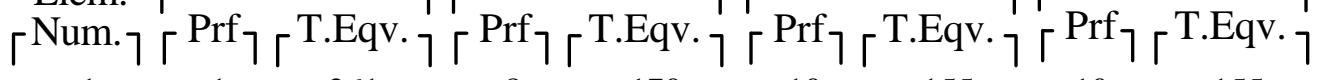

$\begin{array}{rrrrrrrrr}1 & 1 & 261 & 8 & 170 & 10 & 155 & 10 & 155 \\ 2 & 1 & 326 & 11 & 184 & 14 & 160 & 15 & 154 \\ 3 & 1 & 126 & 1 & 135 & 1 & 139 & 1 & 142 \\ 4 & 1 & 218 & 5 & 149 & 5 & 146 & 5 & 145 \\ 5 & 1 & 370 & 13 & 169 & 15 & 153 & 15 & 152 \\ 6 & 1 & 185 & 3 & 172 & 4 & 155 & 4 & 155 \\ 7 & 1 & 309 & 9 & 135 & 8 & 143 & 8 & 143 \\ 8 & 1 & 321 & 10 & 155 & 10 & 157 & 10 & 157 \\ 9 & 1 & 119 & 1 & 110 & 1 & 108 & 1 & 108 \\ 10 & 1 & 139 & 1 & 144 & 1 & 144 & 1 & 144 \\ 11 & 1 & 114 & 1 & 103 & 1 & 101 & 1 & 101 \\ 12 & 1 & 173 & 2 & 152 & 2 & 154 & 2 & 156 \\ 13 & 1 & 189 & 3 & 149 & 3 & 148 & 3 & 147\end{array}$


Tab.B.21- Cav.17- Esforços Solicitantes na Estrutura.

\begin{tabular}{llll}
\hline T R A N S E C & Domingo & $09 / 10 / 1994$ & $15: 32$
\end{tabular}

Projeto de Caverna 17 - Navio Patrulha

ESFORÇOS NOS ELEMENTOS DE VIGAS

Elem.

\begin{tabular}{|c|c|c|c|c|}
\hline Num. & ist. Nó I & _ Normal - & - Cortante- & Fletor \\
\hline 1 & 300.000 & -248735.74632 & -79582.21344 & -26314706.72700 \\
\hline & 1161.975 & -233907.27819 & -0.00000 & 7704890.33940 \\
\hline & 1513.562 & -227858.96788 & 31343.76356 & 2175907.18160 \\
\hline 2 & 200.000 & -144454.50069 & -77945.32229 & -41697478.05700 \\
\hline & 811.372 & -134176.54755 & -28654.54793 & -9240119.94380 \\
\hline 3 & 0.000 & -126245.85775 & -53725.34254 & -9240119.94370 \\
\hline & 710.103 & -109143.69691 & 0.00000 & 9591596.56060 \\
\hline & 963.714 & -103035.72794 & 18190.34305 & 7273870.40550 \\
\hline 4 & 0.000 & -104621.40965 & 1269.03711 & 7273870.40550 \\
\hline & 849.138 & -80394.11897 & 58321.94239 & -18447371.55700 \\
\hline 5 & 0.000 & -182500.85097 & -75782.93483 & -40163771.40800 \\
\hline & 1372.425 & -100730.73673 & -0.00000 & 9646585.26080 \\
\hline & 1423.464 & -97689.78441 & 2448.51606 & 9583987.36270 \\
\hline 6 & 0.000 & -97702.46464 & -1875.53017 & 9583987.36260 \\
\hline & 39.468 & -95637.98293 & -0.00000 & 9620948.79120 \\
\hline & 1195.772 & -35154.02975 & 48186.90164 & -19498418.29300 \\
\hline 7 & 200.000 & -36463.26623 & -35859.00003 & -20953260.53000 \\
\hline & 1354.879 & 2302.12966 & 0.00000 & -246853.39398 \\
\hline & 2705.408 & 47634.82971 & 41933.92728 & -28563347.07400 \\
\hline 8 & 0.000 & 46336.73577 & -62700.30921 & -28563347.07400 \\
\hline & 2000.081 & 66421.57870 & -597.79421 & 34737319.86300 \\
\hline 9 & 200.000 & -165300.32263 & 29886.10070 & 3182501.78110 \\
\hline & 777.509 & -165300.32554 & 0.00000 & -5447247.15590 \\
\hline & 1540.000 & -165300.32938 & -39458.89930 & 9596276.84490 \\
\hline 10 & 0.000 & -225504.41319 & -16560.00000 & -10736290.18300 \\
\hline & 2000.000 & -225504.40898 & 0.00000 & 5823709.81710 \\
\hline
\end{tabular}


$-114345.13102$

1277.732

$-114345.13102$

$-2375.94517$

$-2375.94517$

$-1220117.62860$

1102919.26970

12

390.000

8234.07515

400.000

8448.34209

$64886.26955 \quad-12000640.08900$

$65538.70767 \quad-12652765.62200$

13

0.000

$-20248.53866$

168.46824

$-45172.37194$

$-0.00000$

$-9649090.21830$

722.677

25576.05589

50768.12246

6438584.62550

1622.000 $-16842462.10800$ 
Tab.B.22 - Cav.17 - Módulos de Resistência e Fatores de Cisalhamento.

\begin{tabular}{|llll|}
\hline T R A N S E C & Domingo & $09 / 10 / 1994$ & $15: 32$ \\
\hline
\end{tabular}

Projeto de Caverna 17 - Navio Patrulha

MÓDULOS DE RESISTÊNCIA

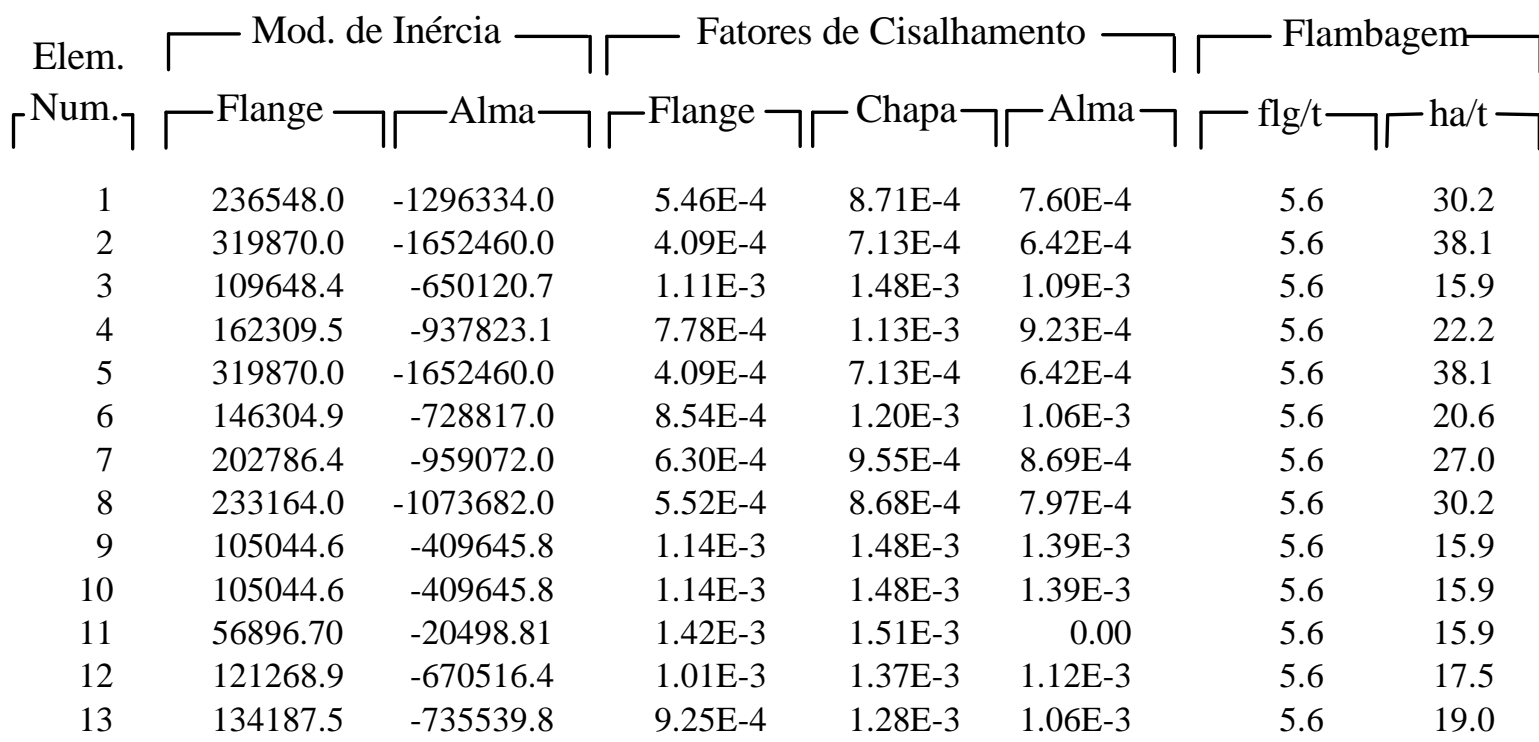




\section{B.3 CAVERNA 55.}

Tab.B.23 - Cav.55 - Coordenadas Nodais e Condições de Contorno.

\begin{tabular}{|llll|}
\hline T R A N S E C & Domingo & $09 / 10 / 1994$ & $15: 32$ \\
\hline
\end{tabular}

Projeto de Caverna Típica do Compartimento 50/60 - Navio Patrulha

$$
\text { COORDENADAS NODAIS }
$$

\begin{tabular}{|c|c|c|c|c|c|}
\hline \multirow{3}{*}{$\begin{array}{c}\text { Nó } \\
\left\lceil\begin{array}{c}\text { Num. } \\
1\end{array}\right.\end{array}$} & \multirow{2}{*}{\multicolumn{2}{|c|}{ - $\begin{array}{l}\text { Coordenadas } \\
-\mathrm{X} \rightarrow \Gamma \mathrm{Y}\end{array}$}} & \multicolumn{3}{|c|}{ ᄃ Cds.Contorno } \\
\hline & & & $\Gamma \delta x$ & $\delta y$ & $\theta \mathrm{z}$ \\
\hline & 0.00 & 0.00 & 1 & 0 & 1 \\
\hline 2 & 980.00 & 410.00 & 0 & 0 & 0 \\
\hline 3 & 1765.00 & 690.00 & 0 & 0 & 0 \\
\hline 4 & 2500.00 & 920.00 & 0 & 0 & 0 \\
\hline 5 & 3785.00 & 1465.00 & 0 & 0 & 0 \\
\hline 6 & 4540.00 & 2055.00 & 0 & 0 & 0 \\
\hline 7 & 4870.00 & 2840.00 & 0 & 0 & 0 \\
\hline 8 & 5200.00 & 5440.00 & 0 & 0 & 0 \\
\hline 9 & 3600.00 & 5570.00 & 0 & 0 & 0 \\
\hline 10 & 3600.00 & 8170.00 & 0 & 0 & 0 \\
\hline 11 & 2000.00 & 8240.00 & 0 & 0 & 0 \\
\hline 12 & 0.00 & 8270.00 & 1 & 0 & 1 \\
\hline 13 & 0.00 & 2840.00 & 1 & 0 & 1 \\
\hline 14 & 2000.00 & 2840.00 & 0 & 0 & 0 \\
\hline 15 & 2500.00 & 2840.00 & 0 & 0 & 0 \\
\hline 16 & 0.00 & 5670.00 & 1 & 0 & 1 \\
\hline 17 & 2000.00 & 5630.00 & 0 & 0 & 0 \\
\hline 18 & 980.00 & 2840.00 & 0 & 0 & 0 \\
\hline 19 & 5200.00 & 8050.00 & 0 & 0 & 0 \\
\hline 20 & 2000.00 & 7940.00 & 1 & 1 & 1 \\
\hline 21 & 2000.00 & 5330.00 & 1 & 1 & 1 \\
\hline 22 & 0.00 & 2540.00 & 1 & 1 & 1 \\
\hline 23 & 0.00 & -300.00 & 1 & 1 & 1 \\
\hline 24 & 2500.00 & 620.00 & 1 & 1 & 1 \\
\hline 25 & 5200.00 & 7750.00 & 1 & 1 & 1 \\
\hline 26 & 3600.00 & 5270.00 & 1 & 1 & 1 \\
\hline 27 & 5250.00 & 5833.90 & 1 & 1 & 1 \\
\hline
\end{tabular}


Tab.B.24 - Cav.55 - Propriedades dos Materiais Utilizados.

\begin{tabular}{|c|c|c|c|}
\hline T R A N SEC & Domingo & 09/10/1994 & $15: 32$ \\
\hline
\end{tabular}

Projeto de Caverna Típica do Compartimento 50/60 - Navio Patrulha

\begin{tabular}{|c|c|c|c|c|}
\hline \multicolumn{2}{|r|}{ MATERIAIS } & & \multirow[b]{2}{*}{ Coefic. } & \multirow[b]{2}{*}{ Tensão } \\
\hline Mat. & Módulo de & Módulo de & & \\
\hline$\lceil$ Num. $\rceil$ & $\lceil$ Young $(\mathrm{E})$ & Cis. (G) & $\lceil$ Poisson $(\mu$ & $\lceil$ Admissível $(\sigma)\rceil$ \\
\hline 1 & 205800.00 & 102900.00 & 0.30 & 157.00 \\
\hline 2 & 102466.00 & 51233.00 & 0.00 & 0.00 \\
\hline 3 & 36314.00 & 18157.00 & 0.00 & 0.00 \\
\hline 4 & 9600.00 & 4800.00 & 0.00 & 0.00 \\
\hline 5 & 387344.00 & 193672.00 & 0.00 & 0.00 \\
\hline 6 & 1000000.00 & 500000.00 & 0.00 & 0.00 \\
\hline 7 & 33780.00 & 16890.00 & 0.00 & 0.00 \\
\hline 8 & 10000000000 & 5000000000 & 0.00 & 0.00 \\
\hline
\end{tabular}


Tab.B.25 - Cav.55 - Cargas Distribuídas.

\begin{tabular}{|c|c|c|c|}
\hline T R A N S E C & Domingo & 09/10/1994 & $15: 32$ \\
\hline
\end{tabular}

Projeto de Caverna Típica do Compartimento 50/60 - Navio Patrulha

\section{CARGAS DISTRIBUÍDAS}

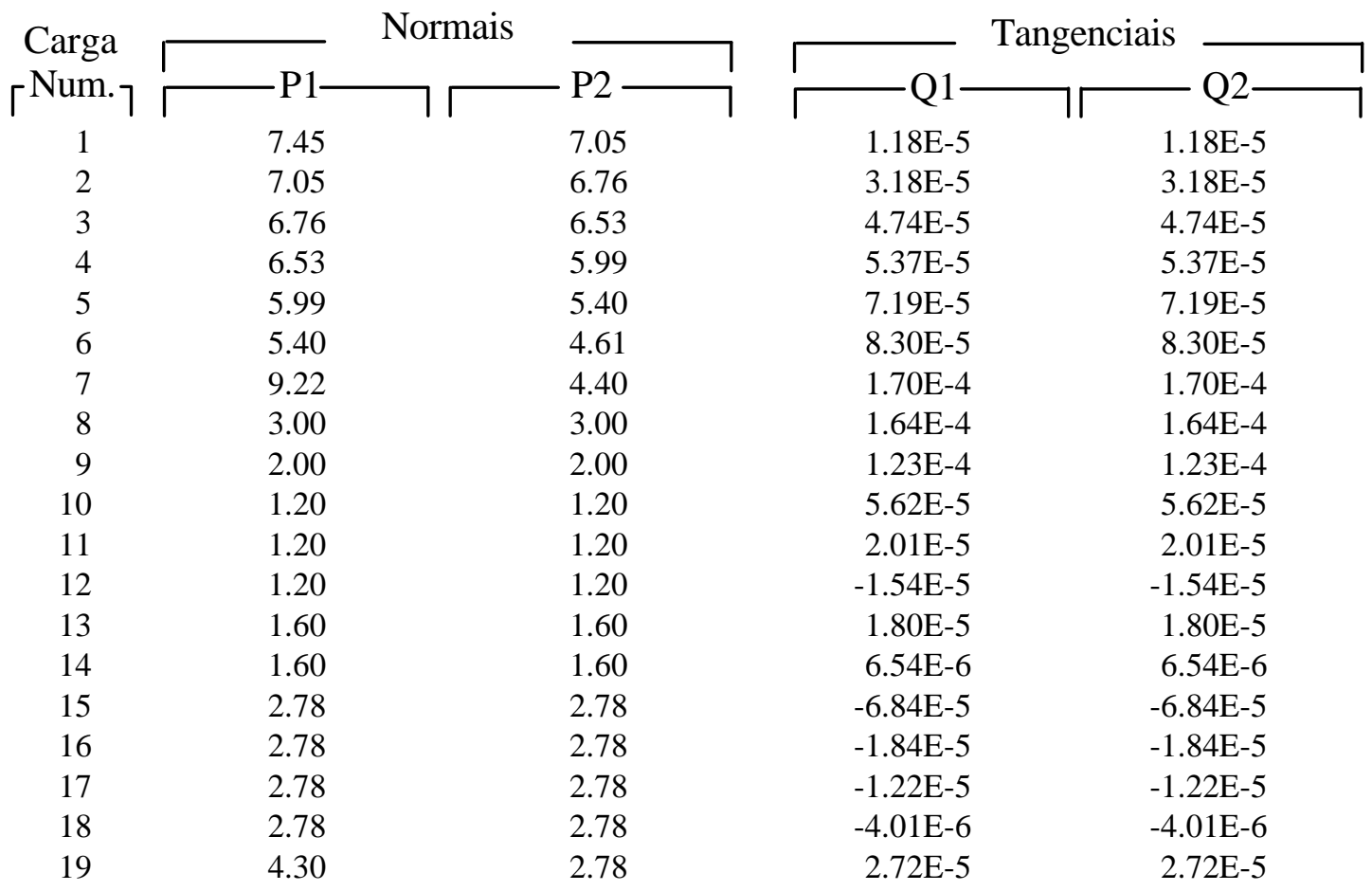


Tab.B.26 - Cav.55 - Incidência dos Elementos.

$\begin{array}{lll}\text { T R A N S E C } \quad \text { Domingo } & 09 / 10 / 1994\end{array}$

Projeto de Caverna Típica do Compartimento 50/60 - Navio Patrulha

INCIDÊNCIA DOS ELEMENTOS

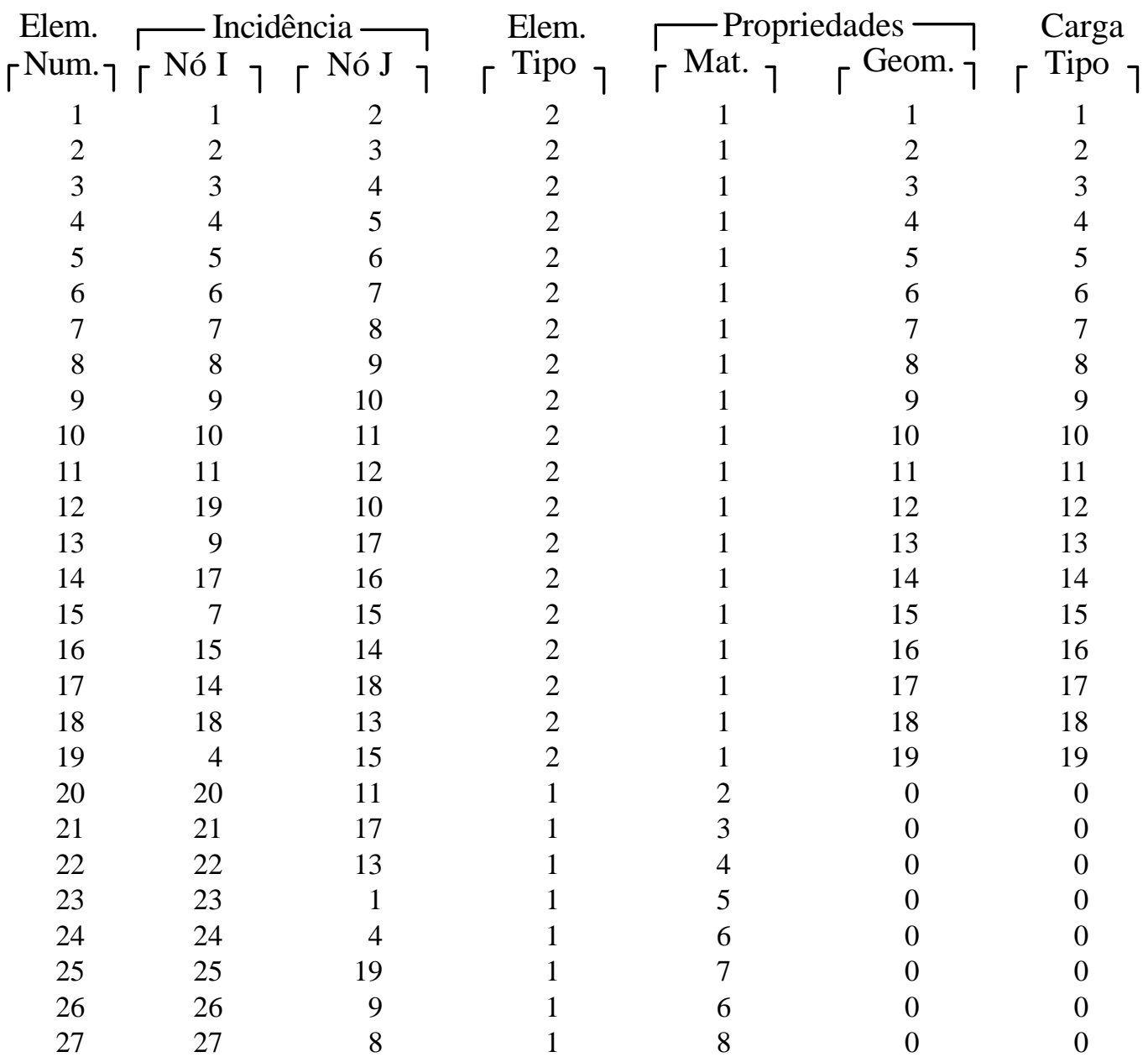

Observações:

Elemento Tipo 1: Mola ou Treliça.

Elemento Tipo 2: Viga. 
Tab.B.27 - Cav.55 - Multiplicadores de Cargas.

$\begin{array}{llll}\text { T R A N S E C } & \text { Domingo } & 09 / 10 / 1994 & 15: 32\end{array}$

Projeto de Caverna Típica do Compartimento 50/60 - Navio Patrulha

FATORES DE CARGA

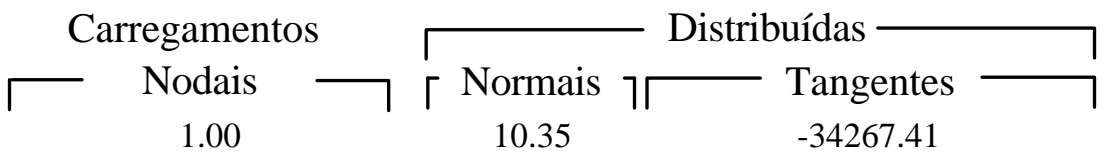


Tab.B.28 - Cav.55 - Perfis Disponiveis para Síntese.

\begin{tabular}{|c|c|c|c|}
\hline T R A N S E C & Domingo & 09/10/1994 & $15: 32$ \\
\hline
\end{tabular}

Projeto de Caverna Típica do Compartimento 50/60 - Navio Patrulha BANCO DE DADOS DE PERFIS

\begin{tabular}{|c|c|c|c|c|}
\hline Perfil & A & 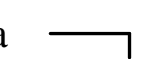 & $-F$ & 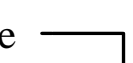 \\
\hline$\left\lceil^{\mathrm{Num}} \cdot\right\rceil$ & $\left\lceil^{\text {larg. }}\right\rceil$ & spess. 7 & 厂 larg. & pess. \\
\hline 1 & 100.0 & 6.30 & 70.00 & 12.50 \\
\hline 2 & 110.0 & 6.30 & 70.00 & 12.50 \\
\hline 3 & 120.0 & 6.30 & 70.00 & 12.50 \\
\hline 4 & 130.0 & 6.30 & 70.00 & 12.50 \\
\hline 5 & 140.0 & 6.30 & 70.00 & 12.50 \\
\hline 6 & 150.0 & 6.30 & 70.00 & 12.50 \\
\hline 7 & 160.0 & 6.30 & 70.00 & 12.50 \\
\hline 8 & 170.0 & 6.30 & 70.00 & 12.50 \\
\hline 9 & 180.0 & 6.30 & 70.00 & 12.50 \\
\hline 10 & 190.0 & 6.30 & 70.00 & 12.50 \\
\hline 11 & 200.0 & 6.30 & 70.00 & 12.50 \\
\hline 12 & 210.0 & 6.30 & 70.00 & 12.50 \\
\hline 13 & 220.0 & 6.30 & 70.00 & 12.50 \\
\hline 14 & 230.0 & 6.30 & 70.00 & 12.50 \\
\hline 15 & 240.0 & 6.30 & 70.00 & 12.50 \\
\hline 16 & 250.0 & 6.30 & 70.00 & 12.50 \\
\hline 17 & 260.0 & 6.30 & 70.00 & 12.50 \\
\hline 18 & 270.0 & 6.30 & 70.00 & 12.50 \\
\hline 19 & 280.0 & 6.30 & 70.00 & 12.50 \\
\hline 20 & 290.0 & 6.30 & 70.00 & 12.50 \\
\hline 21 & 300.0 & 6.30 & 70.00 & 12.50 \\
\hline 22 & 310.0 & 6.30 & 70.00 & 12.50 \\
\hline 23 & 320.0 & 6.30 & 70.00 & 12.50 \\
\hline 24 & 330.0 & 6.30 & 70.00 & 12.50 \\
\hline 25 & 340.0 & 6.30 & 70.00 & 12.50 \\
\hline 26 & 350.0 & 6.30 & 70.00 & 12.50 \\
\hline 27 & 400.0 & 8.00 & 70.00 & 12.50 \\
\hline 28 & 450.0 & 8.00 & 70.00 & 12.50 \\
\hline 29 & 500.0 & 9.00 & 70.00 & 12.50 \\
\hline 30 & 550.0 & 9.00 & 70.00 & 12.50 \\
\hline 31 & 600.0 & 9.00 & 70.00 & 12.50 \\
\hline 32 & 650.0 & 12.50 & 70.00 & 12.50 \\
\hline 33 & 700.0 & 12.50 & 70.00 & 12.50 \\
\hline
\end{tabular}


Tab.B.29 - Cav.55 - Chapa Colaborante para Síntese.

$\begin{array}{llll}\text { T R A N S E C } \quad \text { Domingo } & 09 / 10 / 1994 & 15: 32\end{array}$

Projeto de Caverna Típica do Compartimento 50/60 - Navio Patrulha

DADOS PARA A SÍNTESE DE ELEMENTOS

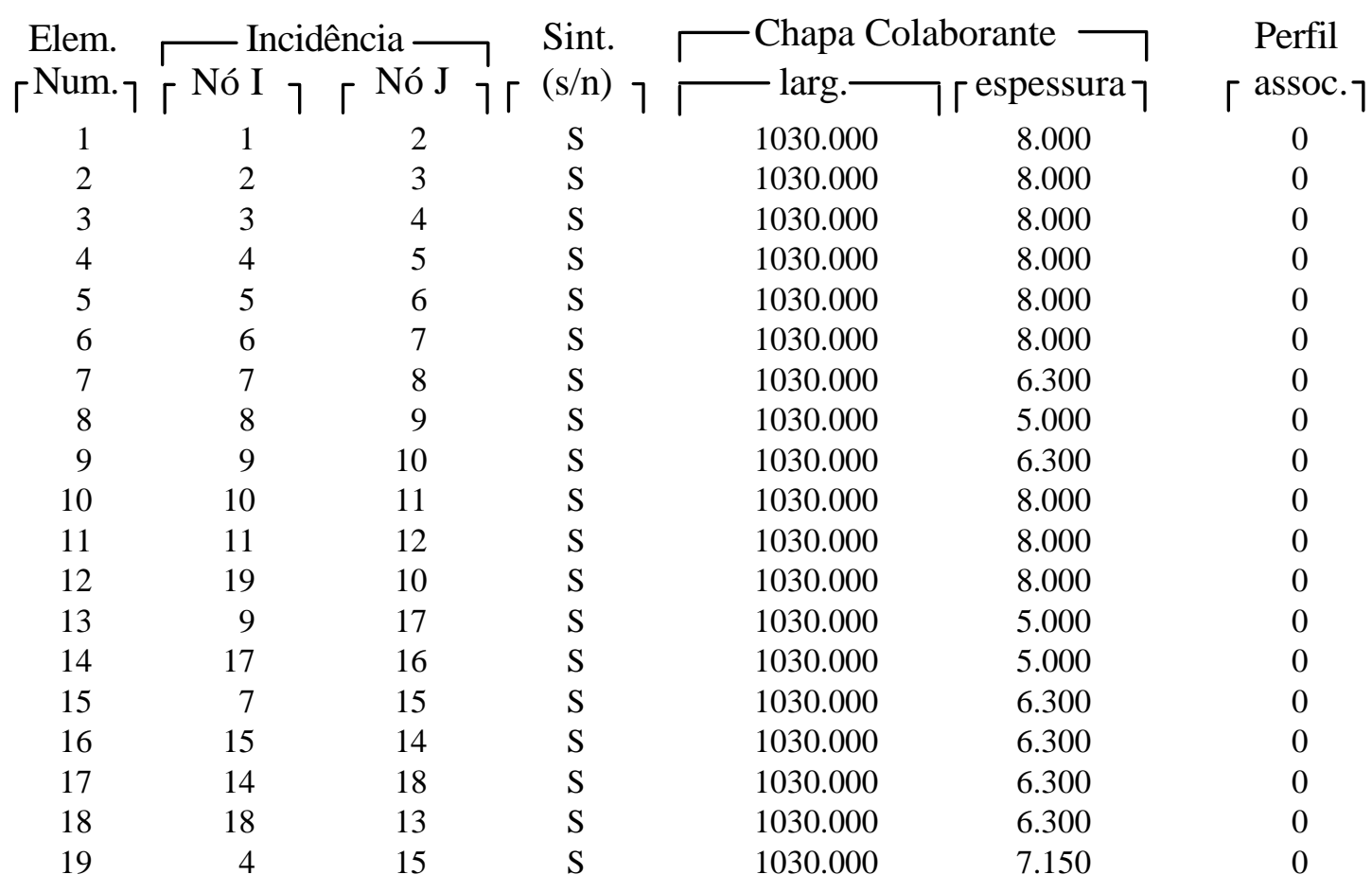


Tab.B.30 - Cav.55 - Perfis Sintetizados.

$\begin{array}{llll}\text { T R A N S E C } \quad \text { Domingo } & 09 / 10 / 1994\end{array}$

Projeto de Caverna Típica do Compartimento 50/60 - Navio Patrulha

ESCANTILHÕES DOS PERFIS SINTETIZADOS

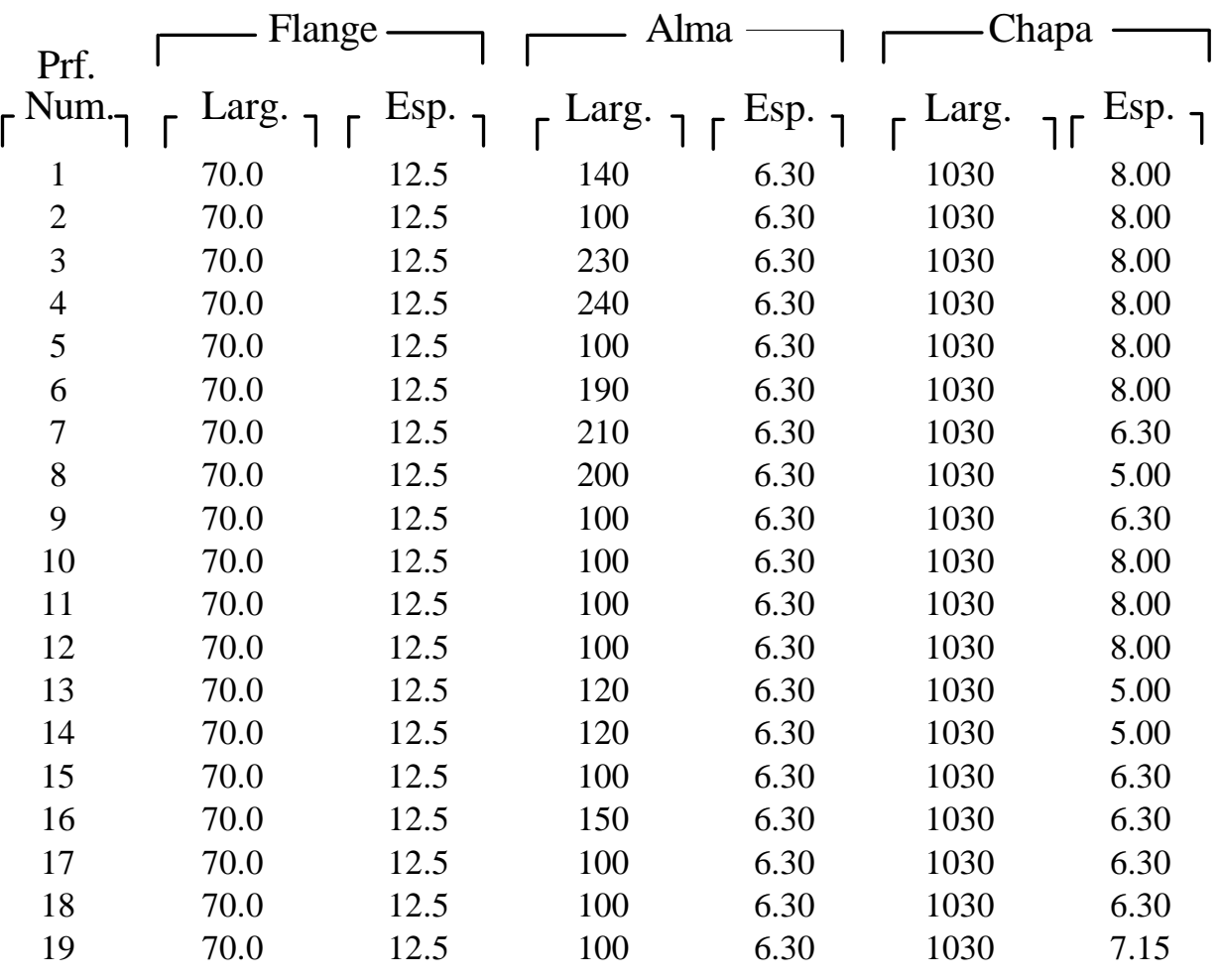


Tab.B.31 - Cav.55 - Propriedades Geométricas dos Perfis Sintetizados.
T R A N S E C
Domingo
09/10/1994
$15: 32$

Projeto de Caverna Típica do Compartimento 50/60 - Navio Patrulha

\section{PROPRIEDADES GEOMÉTRICAS DOS PERFIS SINTETIZADOS}

\begin{tabular}{|c|c|c|c|c|c|}
\hline PG. & & Propriedades de & igidez & $\neg\ulcorner$ Extr & s Rígidos \\
\hline$\left.\Gamma^{\mathrm{Num}} \cdot\right\rceil$ & Área & Inércia & $7\lceil$ Acis & NoI & $\lceil\mathrm{NoJ} \neg$ \\
\hline 1 & 10249.00 & 37532562.3 & 1134.00 & 700.00 & 0.00 \\
\hline 2 & 9745.00 & 11305812.4 & 630.00 & 0.00 & 0.00 \\
\hline 3 & 10312.00 & 42109446.0 & 1197.00 & 0.00 & 180.00 \\
\hline 4 & 10186.00 & 33260967.9 & 1071.00 & 0.00 & 0.00 \\
\hline 5 & 9871.00 & 16233257.3 & 756.00 & 0.00 & 0.00 \\
\hline 6 & 10123.00 & 29287645.0 & 1008.00 & 0.00 & 300.00 \\
\hline 7 & 10438.00 & 52206685.4 & 1323.00 & 0.00 & 180.00 \\
\hline 8 & 10123.00 & 29287645.0 & 1008.00 & 180.00 & 0.00 \\
\hline 9 & 9745.00 & 11305812.4 & 630.00 & 0.00 & 180.00 \\
\hline 10 & 9745.00 & 11305812.4 & 630.00 & 160.00 & 0.00 \\
\hline 11 & 9745.00 & 11305812.4 & 630.00 & 0.00 & 0.00 \\
\hline 12 & 9745.00 & 11305812.4 & 630.00 & 0.00 & 0.00 \\
\hline 13 & 9808.00 & 13642525.2 & 693.00 & 0.00 & 0.00 \\
\hline 14 & 9808.00 & 13642525.2 & 693.00 & 0.00 & 0.00 \\
\hline 15 & 9871.00 & 16233257.3 & 756.00 & 250.00 & 0.00 \\
\hline 16 & 10060.00 & 25605479.0 & 945.00 & 180.00 & 0.00 \\
\hline 17 & 9745.00 & 11305812.4 & 630.00 & 0.00 & 0.00 \\
\hline 18 & 9745.00 & 11305812.4 & 630.00 & 0.00 & 0.00 \\
\hline 19 & 9745.00 & 11305812.4 & 630.00 & 380.00 & 160.00 \\
\hline
\end{tabular}


Tab.B.32 - Cav.55 - Deslocamentos Nodais da Estrutura.
T R A N S E C
Domingo
$09 / 10 / 1994$
$15: 32$

Projeto de Caverna Típica do Compartimento 50/60 - Navio Patrulha

\section{DESLOCAMENTOS NODAIS}

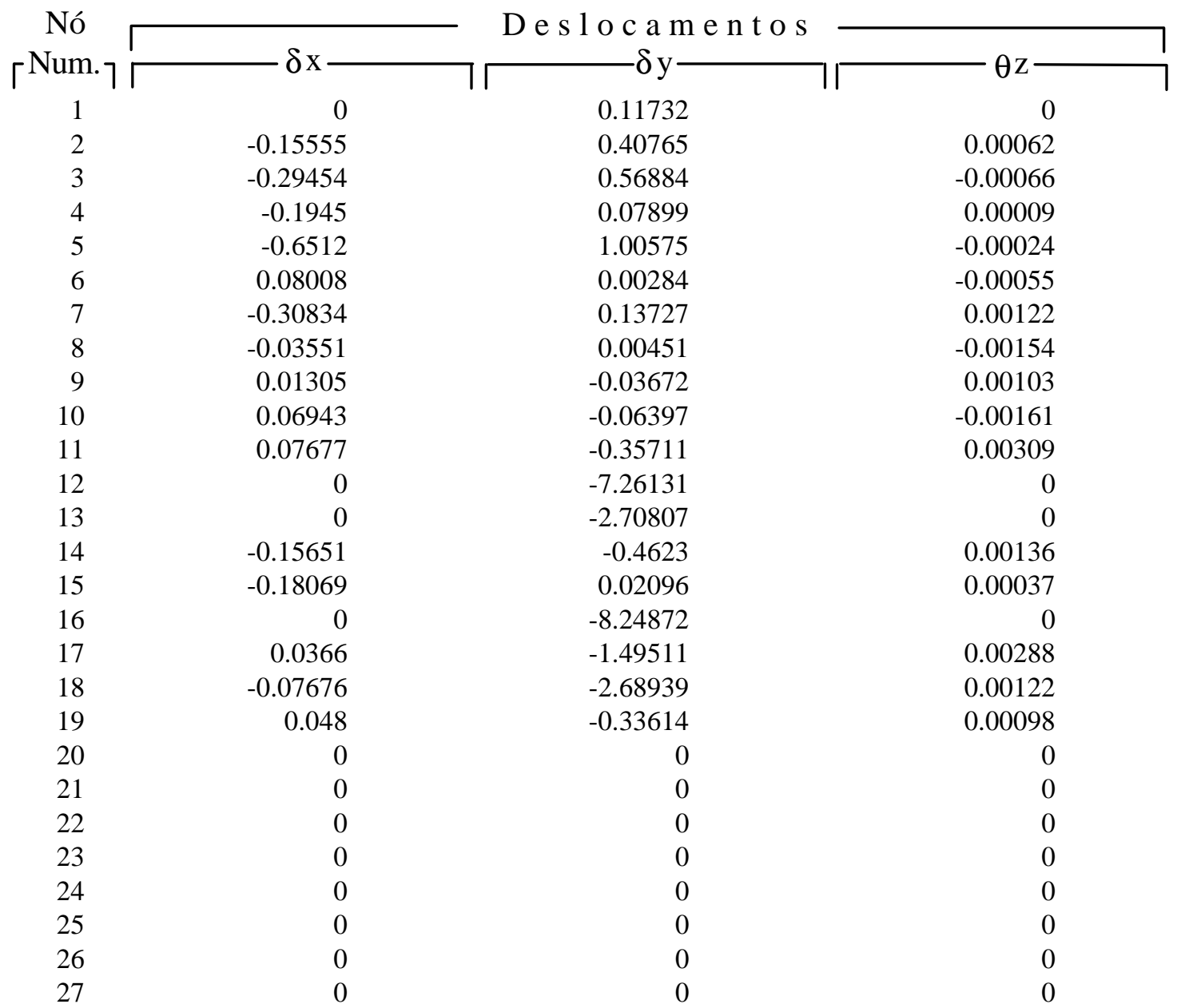


Tab.B.33 - Cav.55 - Reações Nodais.

\begin{tabular}{|llll|}
\hline T R A N S E C & Domingo & $09 / 10 / 1994$ & $15: 32$ \\
\hline
\end{tabular}

Projeto de Caverna Típica do Compartimento 50/60 - Navio Patrulha

$$
\text { REAÇÕES NODAIS }
$$

\begin{tabular}{|c|c|c|c|}
\hline $\begin{array}{c}\text { No } \\
\text { Num. }\end{array}$ & $-\mathrm{Rx}-$ & $\begin{array}{r}\mathrm{R} \text { e a ç ô } \\
\mathrm{Ry}-\end{array}$ & $-\mathrm{Mz}-$ \\
\hline 1 & 217794.22 & $-8.34 \mathrm{E}-07$ & -94339459 \\
\hline 2 & $1.19 \mathrm{E}-06$ & $1.01 \mathrm{E}-06$ & -0.00001 \\
\hline 3 & $9.54 \mathrm{E}-07$ & $-9.54 \mathrm{E}-07$ & $-7.63 \mathrm{E}-06$ \\
\hline 4 & $1.31 \mathrm{E}-06$ & $5.96 \mathrm{E}-07$ & 0.00006 \\
\hline 5 & $-1.19 \mathrm{E}-07$ & $-5.96 \mathrm{E}-08$ & 0 \\
\hline 6 & 4.77E-07 & 0 & -0.00002 \\
\hline 7 & $3.58 \mathrm{E}-07$ & 3.87E-07 & -0.00008 \\
\hline 8 & $-2.38 \mathrm{E}-06$ & 0.00003 & -0.00003 \\
\hline 9 & $-1.19 \mathrm{E}-07$ & 0 & 0.00005 \\
\hline 10 & $-7.53 \mathrm{E}-07$ & 4.47E-08 & 0.00005 \\
\hline 11 & $3.28 \mathrm{E}-07$ & 0 & -0.00005 \\
\hline 12 & 26173.59 & $6.52 \mathrm{E}-09$ & -11478269 \\
\hline 13 & 157149.2 & $-5.96 \mathrm{E}-08$ & 5227617.8 \\
\hline 14 & $-9.54 \mathrm{E}-07$ & 0 & 0.00003 \\
\hline 15 & $6.85 \mathrm{E}-07$ & $2.38 \mathrm{E}-07$ & -0.00003 \\
\hline 16 & 99143.207 & $-1.25 \mathrm{E}-07$ & -13102501 \\
\hline 17 & $-3.58 \mathrm{E}-07$ & $2.38 \mathrm{E}-07$ & 0 \\
\hline 18 & $7.15 \mathrm{E}-07$ & $1.64 \mathrm{E}-07$ & 0.00002 \\
\hline 19 & $8.29 \mathrm{E}-08$ & $2.98 \mathrm{E}-08$ & $3.81 \mathrm{E}-06$ \\
\hline 20 & 0 & 36591.387 & 0 \\
\hline 21 & 0 & 54293.268 & 0 \\
\hline 22 & 0 & 25997.499 & 0 \\
\hline 23 & 0 & -45441.796 & 0 \\
\hline 24 & 0 & -78991.36 & 0 \\
\hline 25 & 0 & 11354.744 & 0 \\
\hline 26 & 0 & 36717.696 & 0 \\
\hline 27 & -5143.6147 & -40521.397 & 0 \\
\hline
\end{tabular}


Tab.B.34 - Cav.55 - Evolução da Síntese dos Perfis.

\begin{tabular}{|llll|}
\hline T R A N S E C & Domingo & $09 / 10 / 1994$ & $15: 32$ \\
\hline
\end{tabular}

Projeto de Caverna Típica do Compartimento 50/60 - Navio Patrulha

\begin{tabular}{|c|c|c|c|c|c|c|}
\hline \multicolumn{5}{|c|}{ EVOLUÇÃO DA SÍNTESE } & \multirow{2}{*}{\multicolumn{2}{|c|}{ Ciclo }} \\
\hline & \multicolumn{2}{|c|}{ Ciclo } & \multicolumn{2}{|c|}{ Ciclo } & & \\
\hline $\begin{array}{l}\text { Elem. } \\
\text {-Num. }\end{array}$ & & Г.Eqv. & & $\overrightarrow{\text { T.Eqv. }}$ & & \\
\hline 1 & 1 & 253 & 7 & 169 & 9 & 150 \\
\hline 2 & 1 & 95 & 1 & 96 & 1 & 95 \\
\hline 3 & 1 & 273 & 8 & 168 & 10 & 151 \\
\hline 4 & 1 & 262 & 7 & 165 & 8 & 157 \\
\hline 5 & 1 & 187 & 3 & 151 & 3 & 149 \\
\hline 6 & 1 & 263 & 7 & 147 & 7 & 151 \\
\hline 7 & 1 & 388 & 13 & 135 & 12 & 146 \\
\hline 8 & 1 & 281 & 8 & 138 & 7 & 145 \\
\hline 9 & 1 & 83 & 1 & 106 & 1 & 104 \\
\hline 10 & 1 & 119 & 1 & 120 & 1 & 120 \\
\hline 11 & 1 & 126 & 1 & 127 & 1 & 127 \\
\hline 12 & 1 & 48 & 1 & 46 & 1 & 46 \\
\hline 13 & 1 & 169 & 2 & 148 & 2 & 148 \\
\hline 14 & 1 & 172 & 2 & 151 & 2 & 152 \\
\hline 15 & 1 & 185 & 3 & 148 & 3 & 151 \\
\hline 16 & 1 & 219 & 5 & 160 & 6 & 151 \\
\hline 17 & 1 & 118 & 1 & 126 & 1 & 129 \\
\hline 18 & 1 & 85 & 1 & 82 & 1 & 81 \\
\hline 19 & 1 & 86 & 1 & 100 & 1 & 100 \\
\hline
\end{tabular}


Tab.B.35 - Cav.55 - Esforços Solicitantes nos Elementos de Viga.
T R A N S E C
Domingo
$09 / 10 / 1994$
$15: 32$

Projeto de Caverna Típica do Compartimento 50/60 - Navio Patrulha

\section{ESFORÇOS NOS ELEMENTOS DE VIGAS}

Elem.

$\left.\Gamma^{\text {Num. }}\right\rceil$

$$
1
$$

Dist. Nó I

700

1062.309

2

$\begin{array}{rr}0 & -185168.02 \\ 505.073 & -184617.65 \\ 833.442 & -184259.83\end{array}$

3

$$
590.146
$$

4

1084.113

1395.797

5

$$
\begin{array}{r}
0 \\
58.666 \\
958.188
\end{array}
$$

6

551.543

7

1221.198

2440.859

8

$$
\begin{array}{r}
180 \\
1299.574 \\
1605.273
\end{array}
$$

9

$\begin{array}{rr}0 & -27688.622 \\ 1292.962 & -22238.981 \\ 2420 & -17488.686\end{array}$

10

160

562.284

1601.531

$-29415.937$

$-28641.214$

$-26639.825$

-89281.92
-87286.999

$-86713.455$

$-88808.899$

$-88664.358$

$-86448.113$

$-101246.63$

$-99677.954$

$-92782.69$

$-85668.72$

$-78563.708$

$-79634.306$

$-73342.522$

$-71624.56$

0

9491.926

$-5682451.514$

26764.319

$-26764.319$

23329.681

7662344.137

$-5484371.194$

$-4996.3719$

$-6880091.682$

12907.437

$-5875110.536$

$-12582112.73$ 
11 0
1968.618
2000.225

12

13

14

15

16

17

18

19

1604.494

0

100.118

1601.125

0
1880.686

2000.4

250

1062.76

2370

180

500

0

1020

0
76.462

980

380
$-27548.338$ $-26192.416$

$-26170.646$

$-849.22072$

$-1330.3208$

$-1695.9327$

957.82

1760
$-99054.016$

$-98992.262$

$-98066.43$

$-99571.688$

$-99150.213$

$-99123.385$

$-119826.21$

$-121731.21$

$-124795.21$

$-156386.35$

$-156588.11$

$-156588.11$

$-157014.53$

$-157014.53$

$-157025.04$

$-157149.2$

$-84983.588$

$-84445.022$
$-83697.339$

\begin{tabular}{|c|c|}
\hline-24450.235 & -12582112.73 \\
\hline 0 & 11484472.38 \\
\hline 392.5597 & 11478268.55 \\
\hline-11322.943 & 0 \\
\hline 0 & 5161394.452 \\
\hline 8604.8686 & 2180566.592 \\
\hline-1657.9529 & 2506999.825 \\
\hline 0 & 2589995.23 \\
\hline 24856.671 & -16065019 \\
\hline-31144.156 & -16065019 \\
\hline 0 & 13221165.51 \\
\hline 1982.4677 & 13102500.71 \\
\hline-23385.552 & -1895100.736 \\
\hline 0 & 7608323.494 \\
\hline 37613.208 & -16976415.72 \\
\hline-40755.861 & -22347317.2 \\
\hline-31548.501 & -10778619.35 \\
\hline-31548.501 & -10778619.35 \\
\hline-2200.0408 & 6433136.851 \\
\hline-2200.0408 & 6433136.851 \\
\hline 0 & 6517246.597 \\
\hline 25997.499 & -5227617.781 \\
\hline-22548.922 & -3804150.208 \\
\hline 0 & 2578732.462 \\
\hline 26769.086 & -8510543.62 \\
\hline
\end{tabular}


Tab.B.36 - Cav.55 - Módulos de Resistência e Fatores de Cisalhamento.

\begin{tabular}{|llll|}
\hline T R A N S E C & Domingo & $09 / 10 / 1994$ & $15: 32$ \\
\hline
\end{tabular}

Projeto de Caverna Típica do Compartimento 50/60 - Navio Patrulha

\section{MÓDULOS DE RESISTÊNCIA}

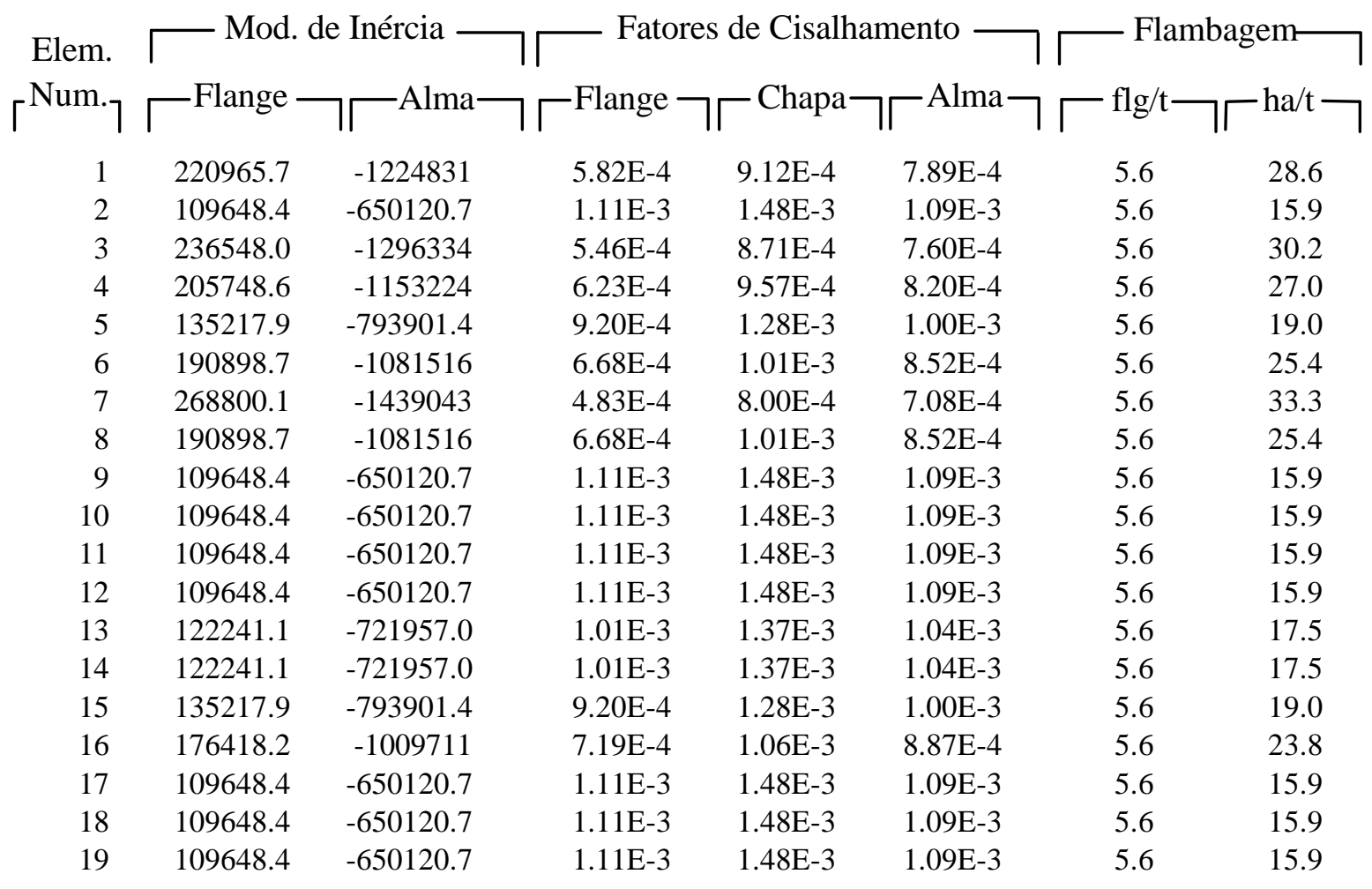

